Capa: Priscylla Moll.

Exemplares de Mesembrinella quadrilineata (Fabricius, 1805).

Fotos: Priscylla Moll. 


\section{Priscylla Moll}

\section{Análise Cladística e Biogeográfica de Mesembrinellidae (Diptera, Oestroidea)}

Dissertação apresentada ao Instituto de Biociências da Universidade de São Paulo, para a obtenção de Título de Mestre em Ciências Biológicas, na Área de Zoologia

Orientador(a): Prof. Dr. Carlos José Einicker Lamas

São Paulo 


\section{Ficha Catalográfica}

Moll, Priscylla

Análise Cladística e Biogeográfica de

Mesembrinellidae (Diptera, Oestroidea)

$214 \mathrm{p}$.

Dissertação (Mestrado) - Instituto de

Biociências da Universidade de São Paulo.

Departamento de Zoologia.

1. Diptera 2. Mesembrinellidae 3.

Sistemática. 4. Biogeografia. 5. Filogenia. I.

Universidade de São Paulo. Instituto de

Biociências. Departamento de Zoologia.

Comissão Julgadora:

$\operatorname{Prof}(a) \cdot \operatorname{Dr}(a)$

$\operatorname{Prof}(a) \cdot \operatorname{Dr}(a)$.

Prof(a). Dr.(a).

Orientador(a) 


\section{Agradecimentos/Acknowledgments}

Agradeço à minha família por todo o apoio durante minha vida e por terem me proporcionado o privilégio de ter o estudo como meu principal objetivo.

Ao meu companheiro de vida, Silvio Nihei, pela sua enorme paciência comigo, principalmente durante a fase final desse mestrado, pela sua compreensão com meus chiliques, pelo seu amor e seu apoio, sempre. Muito obrigada meu amor! Também agradeço ao Dr. Silvio Nihei, por ter me iniciado na Dipterologia, por ter me ensinado muita coisa desde os primórdios de 2008, quando entrei em seu laboratório, e também pela contribuição direta nessa dissertação.

À todos os meus amigos, em especial àqueles do Laboratório de Sistemática e Biogeografia de Diptera (ou Laboratório de Insetos) do Departamento de Zoologia do Instituto de Biociências da USP e àqueles do Laboratório de Diptera do Museu de Zoologia da USP, pela amizade e convivência, bem como ajuda psicológica, filosófica etc. Gostaria de destacar: Paula Rodrigues, pela amizade surpresa e muito agradável que surgiu na Argentina, pelo apoio tanto pessoal quanto profissional e pela revisão da dissertação; Daniel Máximo, também pela amizade e paciência em sempre me escutar reclamar de tudo; Rodrigo Dios e Filipe Gudin pela amizade e pelas discussões, especialmente na fase final; Rafaela Falaschi, pela amizade e pela disposição em sempre ajudar/escutar e Lívia Fusari pela amizade, desabafos e consolos. Também destaco João PPP (nunca sei o que significam os Pês) Barbosa (vulgo Mamilo) pela amizade e por me escutar incansavelmente, sempre que preciso.

Ao Carlos Lamas, pelo apoio e amizade, sempre presentes, mas que foram fundamentais, imprescindíveis, em alguns momentos específicos desse período, que nós sabemos muito bem quais são. Muito obrigada por ter aceitado me orientar de início, sem conhecer bem meu trabalho, e por ter me recebido no Museu de Zoologia, mesmo isso não tendo sido planejado. Além disso, claro, ao Dr. Carlos Lamas, pela orientação.

Ao Dr. Terry Whitworth por ter se dedicado a discutir meus resultados durante duas semanas inteiras em que estive na cidade de Tacoma, WA, EUA e por confiar no meu trabalho. Fico imensamente feliz pela parceria que estabelecemos. Além disso, agradeço por ter me recebido tão bem em sua casa, pela enorme hospitalidade, juntamente com sua esposa, Faye Whitworth, e as crianças, Gunny, Hunter e Zeb. To Dr. Terry Whitworth for having discussing my results during the period I spent in the city of 
Tacoma, WA, USA, and for having trusting my competence. I am extremely happy for the friendship we have stablished during this short period we have met. Besides that, I thank you and your wife, Faye Whitworth, as well as the kids Gunny, Hunter and Zeb, for all your hospitality during my stay. Thank you.

Ao Dr. Knut Rognes pela enorme disponibilidade dada a mim, durante o ICD8 e após ele. Muito obrigada pelas discussões morfológicas e cladísticas que tivemos pessoamente e por email, e pela paciência em analisar e estudar cada detalhe que te pedi antes de emitir uma opinião, sempre muito detalhada e bem humorada. I am cutting the Gordion knot!

Aos Drs. Torsten Dikow, Norman Woodley, Raymond Gagné e Lucrecia Rodriges, pela recepção na cidade de Washington, DC, EUA, e no museu de história natural. Tambem agradeço à Sheila Fernandes pela companhia nesse mesmo período.

Ao querido casal Henrike e Derick Nelson pela recepção maravilhosa e por terem me proporcionado uma estada tranquila, confortável, relaxante e amigável na cidade de Washington, DC, EUA, que me causou somente momentos e lembranças positivas dessa viagem. To the dear couple Henrike and Derick Nelson for the wonderful reception in your house, for making me feel confortable and relaxed during my stay in Washington, DC, USA, which has caused me only positive memories of that trip. Thank you.

Aos Professores Drs. Claudio Carvalho e Marcos Tavares, pelas discussões extremamente úteis para a composição final dessa dissertação.

Ao Dr. Sionei Bonatto, por toda a contribuição no estudo de Mesembrinelldae e por estar sempre disposto a conversar sobre o assunto. Espero que entenda meu posicionamento e as decisões tomadas aqui.

Ao Dr. Claudio Carvalho, pelo convite em apresentar os resultados de meu mestrado em seu simpósio (Advances in Neotropical Dipterology), realizado no ICD8 (International Congress of Dipterology) em Potsdam, Alemanha. Obrigada pela oportunidade.

Ao programa de pós-graduação em Ciências Biológicas (Zoologia) do Instituto de Biociências da Universidade São Paulo e, em especial, ao Prof. Dr. Marcelo Carvalho, coordenador, pela disposição em ajudar e pela paciência. 
Ao Instituto de Biociências da Universidade São Paulo e ao Museu de Zoologia da Universidade de São Paulo (MZUSP), assim como seus funcionários, por todo o apoio e estrutura fornecidos.

Ao National Museum of Natural History, Smithsonian Institution, Washington, DC, USA, pela oportunidade de realizar um estágio em sua Instituição e por toda a estrutura fornecida para tanto.

À Fundação de Amparo à Pesquisa do Estado de São Paulo (Fapesp), pela Bolsa Regular de Mestrado (Proc. No 2012/09256-5) usufruída durante o período de realização do projeto e pela Bolsa de Estágio de Pesquisa no Exterior (Proc. $\mathrm{N}^{\circ}$ 2013/16525-5) utilizada durante os três meses de permanência nos Estados Unidos para a visita ao National Museum of Natural History da cidade de Washington, DC.

Aos curadores que emprestaram material para estudo e/ou me receberam pessoalmente em suas coleções: Dr. Norman Woodley, Dr. Pablo Mulieri, Dr. Joachim Ziegler, Dra. Cátia Mello-Patiu e Dr. Cláudio de Carvalho.

À toda a equipe do SISBIOTA Diptera pelas coletas produtivas e extremamente agradáveis.

Finalmente, agradeço a todos que contribuíram direta ou indiretamente para a realização dessa dissertação. 
Aprender a ver - habituar os olhos à calma, à paciência, ao deixar que as coisas se aproximem de nós, aprender a adiar o juízo, a rodear e a abarcar o caso particular a partir de todos os lados. Este é o primeiro ensino preliminar para o espírito: não reagir imediatamente a um estímulo, mas sim controlar os instintos que põem obstáculos, que isolam. Aprender a ver, tal como eu entendo, é já quase o que o modo afilosófico de falar denomina vontade forte, o essencial nisto é, precisamente, o "poder" não querer, o poder diferir a decisão. Toda a não-espiritualidade, toda a vulgaridade descansa na incapacidade de opor resistência a um estímulo - "tem" que se reagir, seguem-se todos os impulsos. Em muitos casos esse "ter que" é já doença, decadência, sintonia de esgotamento, - quase tudo o que a rudeza afilosófica designa com o nome de "vício" é apenas essa incapacidade fisiológica de não reagir. - Uma aplicação prática do ter aprendido a ver: enquanto discente em geral, chegar-se-á ser lento, desconfiado, teimoso. Ao estranho, ao novo de qualquer espécie deixar-se-á a aproximar-se com uma tranquilidade hostil, - afasta-se dele a mão. $\mathrm{O}$ ter abertas todas as portas, o servil abrir a boca perante o facto pequeno, o estar sempre disposto a meter-se, a lancar-se de um salto para dentro de outros homens e outras coisas, em suma, a famosa objectividade moderna é mau gosto, é algo não-aristocrático par excellence.

Friedrich Nietzsche, in "Crepúsculo dos Ídolos"

(...) Há muitas pessoas de visão perfeita que nada vêem. "Não é bastante não ser cego para ver as árvores e as flores. Não basta abrir a janela para ver os campos e os rios", escreveu Alberto Caeiro, heterônimo de Fernando Pessoa. $\mathrm{O}$ ato de ver não é coisa natural. Precisa ser aprendido. Nietzsche sabia disso e afirmou que a primeira tarefa da educação é ensinar a ver. O zen-budismo concorda, e toda a sua espiritualidade é uma busca da experiência chamada "satori", a abertura do "terceiro olho". Não sei se Cummings se inspirava no zen-budismo, mas o fato é que escreveu: "Agora os ouvidos dos meus ouvidos acordaram e agora os olhos dos meus olhos se abriram". (...) 


\section{Índice}

Lista de Tabelas

Lista de Figuras

Lista de Apêndices

Lista de Anexos

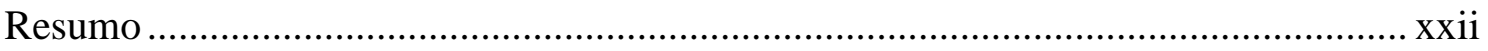

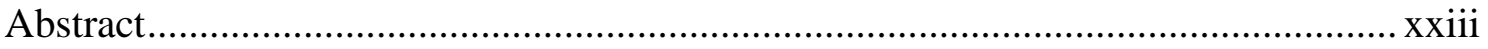

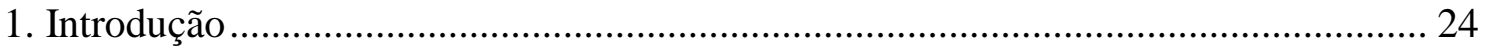

1.1. Histórico sistemático de Mesembrinellidae....................................................... 31

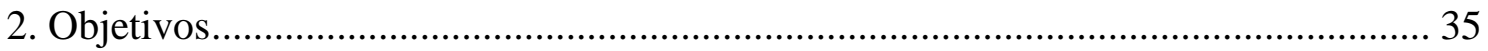

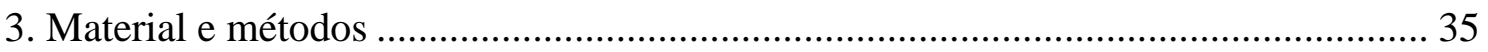

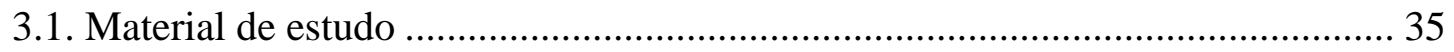

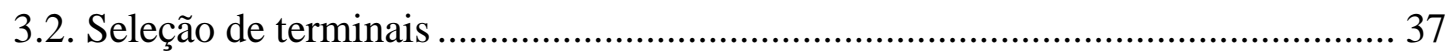

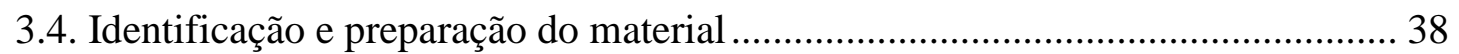

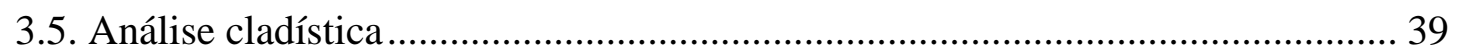

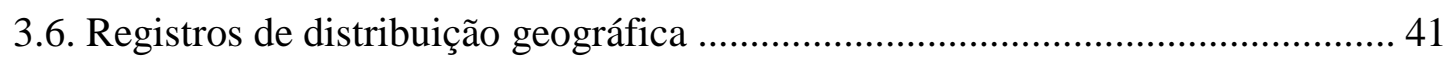

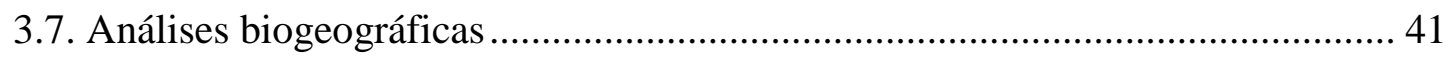

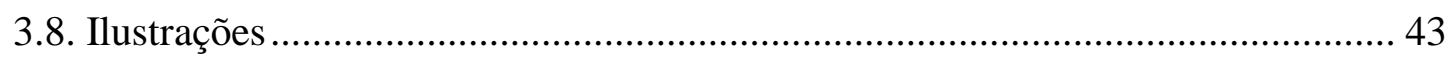

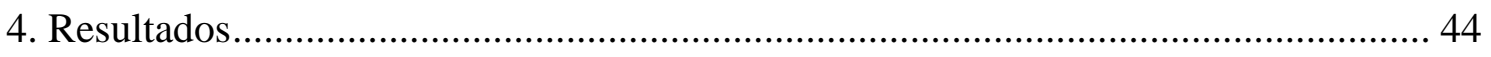

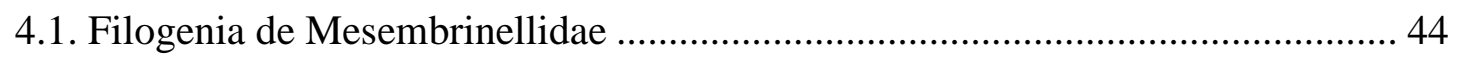

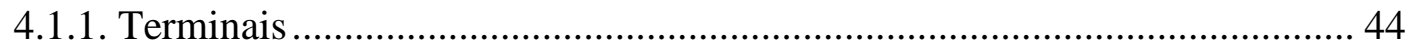

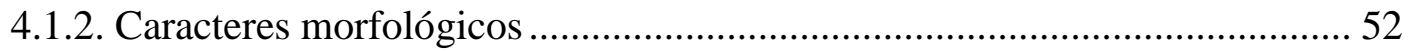

4.1.3. Análise cladística..................................................................................... 113

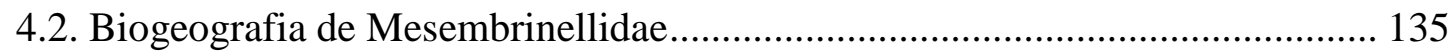

4.2.1. Distribuição geográfica das espécies ..................................................... 135

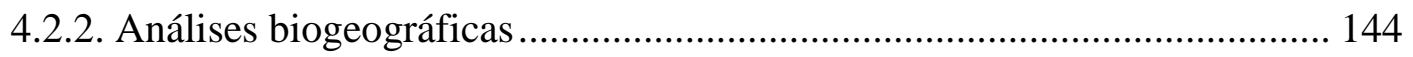

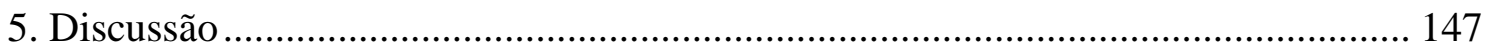


5.1. Breves considerações sobre posicionamento de Mesembrinellidae e relacionamentos no grupo externo

5.2. O relacionamento de Mesembrinellidae com as subfamílias Phumosiinae, Auchmeromyinae e Bengaliinae

5.3. Monofilia de Mesembrinellidae 150

5.4. Relações internas de Mesembrinellidae 152

5.5. Cenários biogeogáficos em Mesembrinellidae.

5.6. O que é um gênero e como estabelecer sua validade? Implicações na taxonomia de Mesembrinellidae

6. Conclusões 164

7. Referências bibliográficas 166

APÊNDICES 176

ANEXOS 192 


\section{Lista de Tabelas}

Tabela 1. Terminais utilizados na análise cladística do presente trabalho, com sua respectiva classificação e distribuição geográfica. Para os Mesembrinellidae são apresentados entre colchetes, e sempre que pertinente, os gêneros da combinação original.

comb. n. combinação nova .44

Tabela 2. Lista das espécies de Mesembrinellidae, com um histórico de nomenclatura dos principais autores que estudaram o grupo, com o respectivo status considerado por cada um deles e nomes válidos. Entre colchetes encontram-se, sempre que pertinente, os gêneros da combinação original. Espaços com “_“ representam a falta de informação sobre a espécie naquele trabalho, ou pela omissão do autor por motivo desconhecido ou porque a espécie ainda não havia sido descrita....

Tabela 3. Valores de $k$ utilizados na análise de parcimônia com pesagem implícita, com seu respectivo número de passos, valor do fit e número de árvores encontradas. 124 


\section{Lista de Figuras}

Figura. 1. Cladograma adaptado demostrando o resultado da análise cladística de Oestroidea, com base em caracteres morfológicos, implementada por Pape (1992).........26

Figura 2. Cladograma retirado de Rognes (1997) representando os resultados da análise cladística de Calliphoridae, com base em caracteres morfológicos. As barras e flechas indicam Calliphoridae sensu lato.

Figura 3. Parte do cladograma obtido de Kutty et al. (2010), representando os resultados de análise cladística com base em dados moleculares. Em rosa, a família Calliphoridae e em vermelho, Tachinidae. A flecha indica o posicionamento de Mesembrinellidae .28

Figura 4. Parte do cladograma retirado de Marinho et al. (2012), obtido por análise cladística baseada em dados moleculares. A flecha indica o posicionamento de Mesembrinellidae. .29

Figura 5. Cladograma retirado de Singh \& Wells (2013), obtido por meio de análise cladística com base em dados moleculares. A flecha indica o posicionamento de Mesembrinellidae. 30

Figuras 6-11. Caracteres de cabeça. 6. Mesembrinella batesi Aldrich, 1922 §. 7. Mesembrinella benoisti comb. n. (Séguy, 1925) $\lesssim$. 8. Mesembrinella latifrons comb. $\mathbf{n}$.

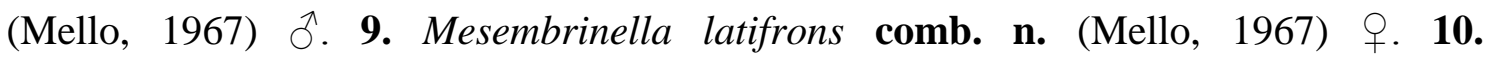
Mesembrinella quadrilineata (Fabricius, 1905) సึ. 11. Mesembrinella quadrilineata (Fabricius, 1905) ․ O número do caráter e seu respectivo estado entre parênteses são apontados nas figuras. Barras vermelhas indicam o comprimento da estrutura apontada.

Figuras 12-17. Caracteres de cabeça. 12. Amenia leonina Fabricius, 1775 $\widehat{~} 13$. Mesembrinella currani Guimarães, 1977 + . 14. Prophorostoma pulchra Townsend, 1927 §. 15. Prophorostoma pulchra Townsend, 1927 ふ઼. 16. Mesembrinella flavicrura Aldrich, 1925 đ. 17. Mesembrinella decrepita (Sèguy, 1925) đ̂. O número do caráter e 
seu respectivo estado entre parênteses são apontados nas figuras. Barras vermelhas e pretas indicam o comprimento da estrutura apontada

Figuras 18-23. Caracteres de tórax. 18. Mesembrinella bicolor Fabricius, 1805 (detalhe do subescutelo). 19. Mesembrinella decrepita (Sèguy, 1925) đ̂. 20. Adejeania townsendi Curran, 1947 †. 21. Mesembrinella bicolor Fabricius, 1805 q. 22. Mesembrinella bicolor Fabricius, 1805 ๆ. 23. Mesembrinella quadrilineata (Fabricius, 1905) P. O número do caráter e seu respectivo estado entre parênteses são apontados nas figuras. .94

Figuras 24-29. Caracteres de tórax. 24. Mesembrinella aeneiventris (Wiedemann, 1830) †. 25. Mesembrinella nigripes comb. n. (Guimarães, 1977) §. 26. Mesembrinella bellardiana Aldrich, 1922 ふ. 27. Mesembrinella quadrilineata (Fabricius, 1905) ๆ. 28. Mesembrinella anomala comb. n. HT (Guimarães, 1977) $\lesssim$. 29. Prophorostoma pulchra Townsend, 1927 $\widehat{~}$. O número do caráter e seu respectivo estado entre parênteses são apontados nas figuras .95

Figuras 30-35. Caracteres de tórax. 30. Prophorostoma pulchra Townsend, $1927 \precsim$ (detalhe do prosterno). 31. Mesembrinella bellardiana Aldrich, 1922 q. 32. Sarconesia chlorogaster (Wiedemann, 1830) ઈิ. 33. Adejeania townsendi Curran, 1947 .34. Mesembrinella aeneiventris (Wiedemann, 1830) §. 35. Mesembrinella bicolor (Fabricius, 1805) †. O número do caráter e seu respectivo estado entre parênteses são apontados nas figuras .96

Figuras 36-41. Caracteres de tórax. 36. Cynomya cadaverina Robineau-Desvoidy, 1830

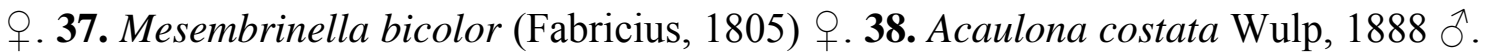
39. Mesembrinella currani Guimarães, 1977 ․ 40. Mesembrinella facialis (Aldrich, 1922) Ô. 41. Amenia imperialis Robineau-Desvoidy, 1830 ๆ. O número do caráter e seu respectivo estado entre parênteses são apontados nas figuras.

Figuras 42-47. Caracteres de tórax. 42. Fannia heydenii (Wiedemann, 1830) Mesembrinella facialis (Aldrich, 1922) ঐ. 44. Peckia intermutans (Walker, 1861) §. 45. Mesembrinella bicolor (Fabricius, 1805) ๆ. 46. Fannia heydenii (Wiedemann, 1830) $\widehat{\jmath}$. 
47. Prophorostoma pulchra Townsend, 1927 đ. O número do caráter e seu respectivo estado entre parênteses são apontados nas figuras.

Figuras 48-53. Caracteres de perna. 48. Mesembrinella nigripes comb. n. (Guimarães, 1977) $\curvearrowright$. 49. Mesembrinella bicolor (Fabricius, 1805) ${ }^{\circ}$. 50. Mesembrinella bicolor (Fabricius, 1805) ๆ. 51. Mesembrinella aeneiventris (Wiedemann, 1830) §. 52. Mesembrinella benoisti comb. n. (Séguy, 1925) $\curvearrowright$. 53. Mesembrinella aeneiventris (Wiedemann, 1830) $\widehat{~}$. O número do caráter e seu respectivo estado entre parênteses são apontados nas figuras .99

Figuras 54-59. Caracteres de perna. 54. Mesembrinella bicolor (Fabricius, 1805) $\uparrow .55$. Mesembrinella aeneiventris (Wiedemann, 1830) $\curvearrowright$. 56. Mesembrinella xanthorrhina (Bigot, 1887) ๆ. 57. Mesembrinella aeneiventris (Wiedemann, 1830) §ิ. 58. Mesembrinella nigripes comb. n. (Guimarães, 1977) §ิ. 59. Mesembrinella spicata (Aldrich, 1922) $\widehat{~}$. O número do caráter e seu respectivo estado entre parênteses são apontados nas figuras 100

Figuras 60-64. Caracteres de asa. 60. Mesembrinella bellardiana Aldrich, 1922 q. 61. Mesembrinella bellardiana Aldrich, 1922 9. 62. Mesembrinella benoisti comb. n. (Séguy, 1925) స. 63. Calliphora vomitoria (Linnaeus, 1758) స. 64. Mesembrinella decrepita (Séguy, 1925) đ̊. O número do caráter e seu respectivo estado entre parênteses são apontados nas figuras. 101

Figuras 65-67. Caracteres de asa. 65. Mesembrinella semiflava (Aldrich, 1925) ${ }_{\text {. }} 66$. Mesembrinella uniseta (Aldrich, 1925) ڤึ. 67. Mesembrinella pictipennis Aldrich, 1922 †. O número do caráter e seu respectivo estado entre parênteses são apontados nas figuras. 102

Figuras 68-70. Caracteres de asa. 68. Polietina flavithorax (Stein, 1904) ․ 69. Neta chilensis (Walker, 1836) §. 70. Phasia hemiptera (Fabricius, 1794) §. O número do caráter e seu respectivo estado entre parênteses são apontados nas figuras 103

Figuras 71-76. Caracteres de asa. 71. Mesembrinella bellardiana Aldrich, 1922 q. 72. Prophorostoma pulchra Townsend, 1927 ふ. 73. 74. Mesembrinella xanthorrhina (Bigot, 
1887) ๆ. 75. Mesembrinella benoisti comb. n. (Séguy, 1925) §. 76. Mesembrinella xanthorrhina (Bigot, 1887) q O número do caráter e seu respectivo estado entre parênteses são apontados nas figuras 104

Figuras 77-82. Caracteres de abdômen. 77. Mesembrinella aeneiventris (Wiedemann, 1830) §. 78. Mesembrinella quadrilineata (Fabricius, 1805) ๆ. 79. Mesembrinella aeneiventris (Wiedemann, 1830) つ̂. 80. Mesembrinella benoisti comb. n. (Séguy, 1925) đ. 81. Mesembrinella xanthorrhina (Bigot, 1887) ${ }_{+}$. 82. Mesembrinella anomala comb. n. PT Guimarães, 1977 ๆ. O número do caráter e seu respectivo estado entre parênteses são apontados nas figuras. 105

Figuras 83-86. Caracteres de terminália feminina. 83. Mesembrinella bicolor Aldrich, 1922 q. 84. Mesembrinella xanthorrhina (Bigot, 1887) 9. 85. Mesembrinella umbrosa (Wiedemann, 1830) §̂. 86. Mesembrinella purpurata (Aldrich, 1922) ๆ. O número do caráter e seu respectivo estado entre parênteses são apontados nas figuras 106

Figuras 87-89. Caracteres de terminália feminina. 87. Adejeania townsendi Curran, 1947 ․ 88. Peckia intermutans (Walker, 1861) q. 89. Mesembrinella nigripes comb. $\mathbf{n}$. (Guimarães, 1977) ․ O O número do caráter e seu respectivo estado entre parênteses são apontados nas figuras 107

Figuras 90-91. Caracteres de terminália feminina. 90. Mesembrinella facialis (Aldrich, 1922) ․ 91. Mesembrinella umbrosa (Wiedemann, 1830) ๆ. O número do caráter e seu respectivo estado entre parênteses são apontados nas figuras. 108

Figuras 92-97. Caracteres de terminália masculina. 92. Mesembrinella nigripes com. $\mathbf{n}$.

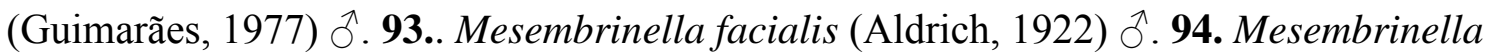
umbrosa Aldrich, $1922 ~ \curvearrowright$ 95. Mesembrinella xanthorrhina (Bigot, 1887) $ぇ$. 96. Polenia rudis (Fabricius, 1794) §ิ. 97. Mesembrinella semyhialina Mello, 1967 đ̊. O número do caráter e seu respectivo estado entre parênteses são apontados nas figuras. 109

Figuras 98-103. Caracteres de terminália masculina. 98. Phasia hemiptera (Fabricius,

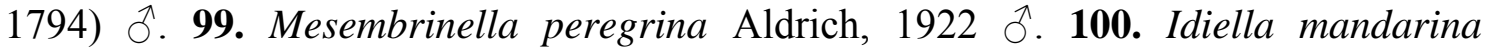

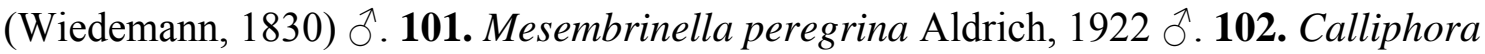


vomitória $\widehat{\jmath}$. 103. Mesembrinella peregrina Aldrich, 1922 đ. O número do caráter e seu respectivo estado entre parênteses são apontados nas figuras

Figuras 104-109. Caracteres de terminália masculina.104. Mesembrinella umbrosa Aldrich, 1922 ๙ิ. 105. Mesembrinella batesi Aldrich, 1922 ઈ. 106. Acaulona costata Wulp 1888 ふૈ. 107. Mesembrinella semyhialina Mello, 1967 $\curvearrowright$. 108. Mesembrinella

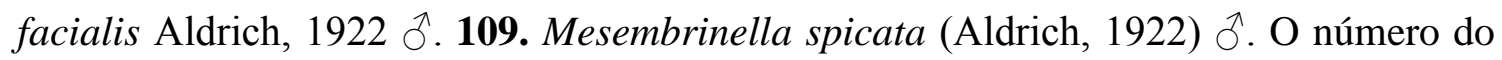
caráter e seu respectivo estado entre parênteses são apontados nas figuras 111

Figuras 110-115. Caracteres de terminália masculina. 110. Mesembrinella anomala HT (Guimarães, 1977) $\widehat{\jmath}$ 111. Mesembrinella anomala HT (Guimarães, 1977) $\widehat{\jmath} .112$. Mesembrinella anomala HT (Guimarães, 1977) $\widehat{~}$. 113. Mesembrinella flavicrura Aldrich, 1925 ふૈ. 114. Mesembrinella benoisti comb. n. Séguy, 1925 đิ. 115. Mesembrinella umbrosa Aldrich, 1922 $\widehat{~}$. O número do caráter e seu respectivo estado entre parênteses são apontados nas figuras 112

Figura 116. Árvore de consenso estrito dos 392 cladogramas igualmente parcimoniosos ( $L=671 ; \mathrm{IC}=21 ; \mathrm{RI}=67$ ) encontrados na análise de parcimônia sob pesagem igual dos caracteres. Os números acima dos nós, dentro de retângulos, indicam os valores do Índice de decaimento de Bremer (1994). Os números abaixo dos nós, dentro de círculos, são uma codificação arbitrária dos nós, utilizada para referência ao longo do texto. 115

Figura 117. Parte 1 da árvore de consenso estrito dos 392 cladogramas igualmente parcimoniosos ( $\mathrm{L}=671 ; \mathrm{IC}=21 ; \mathrm{RI}=67)$ encontrados na análise de parcimônia sob pesagem igual dos caracteres. Os números acima dos nós, dentro de retângulos, indicam os valores do Índice de decaimento de Bremer (1994). Os números abaixo dos nós, dentro de círculos, são uma codificação arbitrária dos nós, utilizada para referência ao longo do texto. 116

Figura 118. Parte 2 da árvore de consenso estrito dos 392 cladogramas igualmente parcimoniosos $(\mathrm{L}=671 ; \mathrm{CI}=21 ; \mathrm{RI}=67)$ encontrados na análise de parcimônia sob pesagem igual dos caracteres. Os números acima dos nós, dentro de retângulos, indicam os valores do Índice de decaimento de Bremer (1994). Os números abaixo dos nós, dentro 
de círculos, são uma codificação arbitrária dos nós, utilizada para referência ao longo do texto.

Figura 119. Cladograma obtido na análise sob pesagem implícita dos caracteres ( $L=679$; $\mathrm{CI}=21 ; \mathrm{RI}=67 ; k=9,6875)$. Os números acima dos nós, dentro de retângulos, indicam os valores do Índice de decaimento de Bremer (1994). Os números abaixo dos nós, dentro de círculos, são uma codificação arbitrária dos nós, utilizada para referência ao longo do texto. Nos ramos, os círculos pretos representam sinapomorfias e os brancos, homoplasias. Otimização ACCTRAN. 118

Figura 120. Parte 1 do cladograma obtido na análise sob pesagem implícita dos caracteres ( $\mathrm{L}=679 ; \mathrm{CI}=21 ; \mathrm{RI}=67 ; k=9,6875)$. Os números acima dos nós, dentro de retângulos, indicam os valores do Índice de decaimento de Bremer (1994). Os números abaixo dos nós, dentro de círculos, são uma codificação arbitrária dos nós, utilizada para referência ao longo do texto. Nos ramos, os círculos pretos representam sinapomorfias e os brancos, homoplasias. Otimização ACCTRAN. 119

Figura 121. Parte 2 do cladograma obtido na análise sob pesagem implícita dos caracteres ( $\mathrm{L}=679 ; \mathrm{CI}=21 ; \mathrm{RI}=67 ; k=9,6875)$. Os números acima dos nós, dentro de retângulos, indicam os valores do Índice de decaimento de Bremer (1994). Os números abaixo dos nós, dentro de círculos, são uma codificação arbitrária dos nós, utilizada para referência ao longo do texto. Nos ramos, os círculos pretos representam sinapomorfias e os brancos, homoplasias. Otimização ACCTRAN. 120

Figura 122. Parte 3 do cladograma obtido na análise sob pesagem implícita dos caracteres ( $\mathrm{L}=679 ; \mathrm{CI}=21 ; \mathrm{RI}=67 ; k=9,6875)$. Os números acima dos nós, dentro de retângulos, indicam os valores do Índice de decaimento de Bremer (1994). Os números abaixo dos nós, dentro de círculos, são uma codificação arbitrária dos nós, utilizada para referência ao longo do texto. Nos ramos, os círculos pretos representam sinapomorfias e os brancos, homoplasias. Otimização ACCTRAN.

Figura 123. Parte 4 do cladograma obtido na análise sob pesagem implícita dos caracteres ( $\mathrm{L}=679 ; \mathrm{CI}=21 ; \mathrm{RI}=67 ; k=9,6875)$. Os números acima dos nós, dentro de retângulos, indicam os valores do Índice de decaimento de Bremer (1994). Os números abaixo dos 
nós, dentro de círculos, são uma codificação arbitrária dos nós, utilizada para referência ao longo do texto. Nos ramos, os círculos pretos representam sinapomorfias e os brancos, homoplasias. Otimização ACCTRAN.

Figura 124. Parte 5 do cladograma obtido na análise sob pesagem implícita dos caracteres ( $\mathrm{L}=679 ; \mathrm{CI}=21 ; \mathrm{RI}=67 ; k=9,6875)$. Os números acima dos nós, dentro de retângulos, indicam os valores do Índice de decaimento de Bremer (1994). Os números abaixo dos nós, dentro de círculos, são uma codificação arbitrária dos nós, utilizada para referência ao longo do texto. Nos ramos, os círculos pretos representam sinapomorfias e os brancos, homoplasias. Otimização ACCTRAN.

Figura 125. Cladograma mais parcimonioso resultante da análise sob pesagem implícita dos caracteres $(\mathrm{L}=708 ; \mathrm{CI}=20 ; \mathrm{RI}=65 ; k=1)$

Figura 126. Cladograma de consenso estrito resultante das duas árvores igualmente parcimoniosas encontradas na análise sob pesagem implícita dos caracteres $(\mathrm{L}=695$; $\mathrm{CI}=20 ; \mathrm{RI}=66 ; k=3)$

Figura 127. Cladograma mais parcimonioso resultante da análise sob pesagem implícita dos caracteres $(\mathrm{L}=686 ; \mathrm{CI}=21 ; \mathrm{RI}=67 ; k=5)$ 128

Figura 128. Cladograma mais parcimonioso resultante da análise sob pesagem implícita dos caracteres $(\mathrm{L}=684 ; \mathrm{CI}=21 ; \mathrm{RI}=67 ; k=7)$.

Figura 129. Cladograma mais parcimonioso resultante da análise sob pesagem implícita dos caracteres $(\mathrm{L}=679 ; \mathrm{CI}=20 ; \mathrm{RI}=67 ; k=11)$ 130

Figura 130. Cladograma mais parcimonioso resultante da análise sob pesagem implícita dos caracteres $(\mathrm{L}=674 ; \mathrm{CI}=21 ; \mathrm{RI}=67 ; k=13)$

Figura 131. Cladograma mais parcimonioso resultante da análise sob pesagem implícita dos caracteres $(\mathrm{L}=674 ; \mathrm{CI}=20 ; \mathrm{RI}=67 ; k=15)$ 
Figura 132. Cladograma mais parcimonioso resultante da análise sob pesagem implícita dos caracteres $(\mathrm{L}=671 ; \mathrm{CI}=21 ; \mathrm{RI}=68 ; k=30)$.

Figura 133. Cladograma mais parcimonioso resultante da análise sob pesagem implícita dos caracteres $(\mathrm{L}=671 ; \mathrm{CI}=21 ; \mathrm{RI}=68 ; k=40)$

Figuras 134-137. Distribuição geográfica das espécies de Mesembrinellidae. 134. Mesembrinella benoisti comb. n. (Séguy, 1925). 135. Mesembrinella cyaneicincta (Surcouf, 1919). 136. Mesembrinella randa (Walker, 1849). 137. Mesembrinella quadrilineata (Fabricius, 1805). 135

Figuras 138-141. Distribuição geográfica das espécies de Mesembrinellidae. 138. Giovanella bolivar Bonatto \& Marinoni, 2005. 139. Mesembrinella carvalhoi comb. $\mathbf{n}$. (Wolff, 2013). 140. Mesembrinella nigripes comb. n. (Guimarães, 1977). 141. Mesembrinella perisi (Mariluis, 1987). .136

Figuras 142-145. Distribuição geográfica das espécies de Mesembrinellidae. 142. Mesembrinella aeneiventris (Wiedemann, 1830). 143. Mesembrinella decrepita (Séguy, 1925). 144. Mesembrinella flavicrura Aldrich, 1925. 145. Mesembrinella lara comb. $\mathbf{n}$. (Bonatto \& Marinoni, 2005). 137

Figuras 146-149. Distribuição geográfica das espécies de Mesembrinellidae. 146. Huscaromusca purpurata (Aldrich, 1922). 147. Mesembrinella semiflava (Aldrich, 1925). 148. Mesembrinella spicata (Aldrich, 1922). 149. Mesembrinella uniseta (Aldrich, 1925) 138

Figuras 150-153. Distribuição geográfica das espécies de Mesembrinellidae. 150. Mesembrinella vogelsangi comb. n. (Mello, 1967). 151. Mesembrinella xanthorrhina (Bigot, 1887). 152. Mesembrinella facialis (Aldrich, 1922). 153. Mesembrinella anomala comb. n. (Guimarães, 1977). 139

Figuras 154-157. Distribuição geográfica das espécies de Mesembrinellidae. 154. Mesembrinella latifrons comb. n. (Mello, 1967). 155. Mesembrinella abaca (Hall, 1948). 
156. Mesembrinella apollinaris Séguy, 1925. 157. Mesembrinella batesi Aldrich, 1922 140

Figuras 158-161. Distribuição geográfica das espécies de Mesembrinellidae. 158. Mesembrinella bellardiana Aldrich, 1922. 159. Mesembrinella bicolor (Fabricius, 1805). 160. Mesembrinella brunnipes Surcouf, 1919. 161. Mesembrinella currani Guimarães, 1977

Figuras 162-165. Distribuição geográfica das espécies de Mesembrinellidae. 162. Mesembrinella patriciae Wolff, 2013. 163. Mesembrinella peregrina Aldrich, 1922. 164. Mesembrinella pictipennis Aldrich, 1922. 165. Mesembrinella semyhialina Mello, 1867 142

Figuras 166-167. Distribuição geográfica das espécies de Mesembrinellidae. 166. Mesembrinella townsendi Guimarães, 1977. 167. Mesembrinella umbrosa Aldrich, 1922 143

Figura. 168. Domínios delimitados para a Região Neotropical por Morrone (2014), utilizados para as análises biogeográficas do presente estudo. 144

Figura 169. Cladograma resultante da análise implícita dos caracteres com todas as possibilidades de áreas ancestrais encontrada com a Análise de Dispersão Vicariância. Para a codificação das áreas, ver Fig. 168. As letras dentro de retângulos representam as áreas de ocorrência dos terminais. Números dentro de círculos são uma codificação arbitrária dos nós, utilizada ao longo do texto 146

Figura 170. Cladograma obtido pela Análise de Parcimônia de Brooks ( $L=99, C I=69$, $\mathrm{RI}=55)$ 146 


\section{Lista de Apêndices}

APÊNDICE 1. Matriz de caracteres morfológicos

APÊNDICE 2. Espécimenes utilizados durante o presente estudo. A tabela apresenta os dados dos exemplares do material examinado no estudo morfológico, bem como provenientes de banco de dados de coleções científicas e da literatura, conforme especificado na coluna "Fonte da informação". nt=não-tipo; HT=holótipo; PT=parátipo; LT=lectótipo; PLT=paralectótipo 186

APÊNDICE 3. Script construído para a Análise de Dispersão e Vicariância (DIVA) 187

APÊNDICE 4. Cladograma mais parcimonioso obtido por análise com pesagem implícita com os terminais e nós numerados para a construção da matriz binária da Análise de Parcimônia de Brooks 190

APÊNDICE 5. Matriz binária Táxon x Área utilizada para a Análise de Parcimônia de Brooks (BPA) .191

\section{Lista de Anexos}

ANEXO 1. Script utilizado para busca de valor de k, na análise de parcimônia com pesagem implícita dos caracteres.

ANEXO 2. Script utilizado para cálculo do índice de Bremer, utilizado como suporte de ramos nas análises de parcimônias. 196 


\section{Resumo}

Mesembrinellidae é um grupo de dípteros de distribuição exclusivamente Neotropical, habitantes de florestas úmidas do Sul do México ao Norte da Argentina. Atualmente são conhecidas 36 espécies e seu posicionamento dentro da superfamília Oestroidea, bem como sua classificação interna, vem gerando frequentes discussões na literatura, com propostas bastante divergentes. Tradicionalmente, Mesembrinellidae é considerado uma subfamília de Calliphoridae s.l. No entanto, devido a características morfológicas e biológicas peculiares desse grupo, diversos autores propuseram a elevação para o status de família, como considerado no presente trabalho. Os objetivos desse trabalho eram: testar a monofilia de Mesembrinellidae; testar a monofilia dos gêneros subordinados; encontrar uma hipótese de agrupamento entre as espécies do grupo e realizar um estudo biogeográfico de Mesembrinellidae, a partir da filogenia gerada. Para tanto, foram construídos 120 caracteres morfológicos e foram realizadas análises cladísticas, sob pesagem igual e implícita dos caracteres. Para a análise de pesagem igual foram obtidas 392 árvores igualmente parcimoniosas ( $\mathrm{L}=671 ; \mathrm{IC}=21 ; \mathrm{RI}=67)$, porém o consenso estrito mostrou diversas politomias. A análise de pesagem implícita resultou em uma árvore mais parcimoniosa ( $\mathrm{L}=679 ; \mathrm{CI}=21 ; \mathrm{RI}=67 ; k=9,6875)$, muito mais resolvida que a análise anterior. A maioria dos gêneros foram recuperados como monfiléticos, no entanto foram mal suportados, tanto pela ausência de sinapomorfias, na maioria deles, quanto pelo baixo suporte de ramos. As análises biogeográficas mostraram que Mesembrinellidae tem uma origem mais ao sul da região Neotropical, tendo sua distribuição expandida para Norte. Além disso, a área de interseção das Américas do Sul e Central parece ter papel fundamental na evolução biogeográfica do grupo, sendo área ancestral de dois grandes clados. O relacionamento entre as áreas mostrou que o norte da Amazônia é mais proximamente relacionado ao Chaco do que as demais regiões neotropicais florestadas, o que refuta a hipótese de que a diagonal seca do continente sul americano teria uma história isolada das regiões florestadas. De acordo com os resultados obtidos no presente estudo e pelos gêneros de Mesembrinellidae serem pouco suportados pelos nossos dados, nós concluímos que todos os gêneros sejam sinonimizados a Mesembrinella.

PALAVRAS-CHAVE: Diptera, Mesembrinellidae, Sistemática, Biogeografia, Filogenia. 


\begin{abstract}
Mesembrinellidae is an exclusive Neotropical group of Diptera, which includes 36 described species. Members of this group are restricted to tropical rainforests and found from Southern Mexico to Northern Argentina. The placement of this family within Oestroidea has generated frequent discussions in the literature. Traditionally, the group has been placed within the Calliphoridae s.l., but some authors have suggested the subfamily merits full species status. In addition, the interspecific relationships of this group remained unclear and some genera appeared not to be monophyletic. In this study, the main goals were: to test Mesembrinellidae monophyly; to test genera monophyly; to infer the relationships of Mesembrinellidae species and to perform a biogeographic analysis, based on the phylogenetic hypothesis. One hundred twenty (120) characters were constructed and cladistics analyses were performed, under equal and implied weighting schemes. Under the equal weighting analysis, 392 equally parsimonious trees were obtained $(\mathrm{L}=671 ; \mathrm{IC}=21$; $\mathrm{RI}=67)$, with the strict consensus showing many polytomies in the cladogram. On the other hand, the implied weighting analysis resulted in only one most parsimonious tree $(\mathrm{L}=679 ; \mathrm{CI}=21 ; \mathrm{RI}=67 ; k=9,6875)$, much more structured and with few politomies, in comparison to the previous analysis. The results indicated most of genera were recovered as monophyletic. However, they were poorly supported, because of the absence of synapomorphies and a low branch support. The biogeographic analyses showed Mesembrinellidae's origin was probably in South America and the southernmost part of Central America, having dispersed lateron to Central America. Moreover, the area (Pacific Dominion) that connects Central and South America seems to play an important role in Mesembrinellidae biogeographic evolution, being the ancestral area for two major clades inside the group, in different times. Furthermore, the area relationships indicated the northern part of the Amazon is more closely related to the dry central areas of South America than to jungle regions of this continent, which contradicts the theories about the dry areas being disconnected and having an isolated history in the Neotropical region. Given the results of this study of mesembrinellid genera, and the fact that the genera were weakly supported by our data, we conclude that for now, all species should be placed in a single genus, Mesembrinella.
\end{abstract}

KEY-WORDS: Diptera, Mesembrinellidae, Systematics, Biogeography, Phylogeny. 


\section{Introdução}

A família Mesembrinellidae pertencem ao grupo dos Schizophora, que compreende cerca de 75 famílias e abrange a maior diversidade de dípteros, cuja monofilia é bem suportada por caracerísticas relacionadas à emergência do adulto de seu pupário (Yeates \& Wiedemann, 1999). Tradicionalmente, eram reconhecidos dois grupos dentro de Schizophora, Acalyptratae e Calyptratae, pela presença ou não da caliptra inferior muito desenvolvida (Griffiths, 1972). Porém, trabalhos recentes apontam para a não monofilia dos acaliptrados, que não apresentam nenhuma característica sinapomórfica convincente (Yeates et al., 2007). Entretanto, os Calyptratae, são bem suportados em todas as filogenias propostas (e.g. Wiegmann, 2011).

Dentro do clado dos Calyptratae, são tradicionalmente reconhecidas três superfamílias, Hippoboscoidea, Muscoidea e Oestroidea (McAlpine, 1989). Hipposcoidea é composta pelas famílias Glossinidae, Streblidae e Hippoboscidae, parasitas de aves e mamíferos (Brown et al., 2009). Já Muscoidea inclui as famílias Fanniidae, Scatophagidae, Anthomyiidae e Muscidae. Entretanto, trabalhos recentes apontam para a parafilia dessa superfamília (e.g. Kutty et al., 2008; 2010). A superfamília Oestroidea é, tradicionalmente, composta pelas seguintes famílias: Sarcophagidae, Rhinophoridae, Tachinidae, Oestridae e Calliphoridae senso latu. O grupo é suportado pelas seguintes sinapomorfias: fileira de cerdas no méron; tufo de sétulas no anatergito; veia $\mathrm{M}$ curvada anteriormente e falo com dentículos (Griffiths 1982, McAlpine 1981, Pape 1992; Yeates \& Wiegmann, 1999). Contudo, sua classificação interna é bastante controversa na literatura (e.g. Rognes, 1997; Yeates \& Wiegmann, 1999; Yeates et al., 2007; Kutty et al., 2010; Wiegmann, 2011), principalmente quanto à monofilia de Calliphoridae, e trabalhos mais recentes apontam para a elevação do status de família de alguns grupos controversos, como Mesembrinellidae e Rhiniidae (e.g. Rognes, 1997, Kutty, 2010, Marinho et al., 2012).

Calliphoridae é uma família de Diptera, de coloração metálica em todo ou em parte do corpo, em sua maioria, podendo variar entre 4 e $16 \mathrm{~mm}$ de comprimento 
(Shewell, 1981; Vargas \& Wood, 2009). Assemelham-se aos Sarcophagidae e Tachinidae pela presença de cerdas no méron e da curvatura da veia $\mathrm{M}$ em direção à margem anterior da asa. São considerados o grupo de moscas de maior importância forense (e g. Pohjoismäki et al., 2010) e médico-veterinária (e g. Guimarães et al., 1983; Nascimento et al., 2005; Stevens et al., 2006) pelo hábito saprófago das larvas de diversas espécies, que podem causar doenças e transtornos aos homens e aos animais, como por exemplo miíases (Guimarães et al., 1983). Os califorídeos estão distribuídos em todas as regiões biogeográficas do mundo, exceto Antártica. Possuem cerca de 100 gêneros e mais de 1500 espécies (Pape \& Thompson, 2010), sendo que destas, 130 são conhecidas da região Neotropical (Amorim et al., 2002).

Rognes, $(1986,1991)$ afirma que Calliphoridae é provavelmente um grupo natural pelas seguintes características: presença de cerdas no pró-externo, pró-pleura e parede pós-alar; machos com a região distal dos processos laterais muito esclerosados, livre da parede do distifalo por uma distância considerável e no formato de um longo e estreito processo, gancho ou uma placa nua ou denticulada; e coloração metálica do tórax e abdômen. Dentro da família, esse autor reconhece as subfamílias: Calliphorinae, Chrysomyinae, Helicoboscinae, Luciliinae, Melanomyinae, Poleniinae e Rhiniinae. Cabe destacar que as classificações propostas nesses trabalhos não foram embasadas em uma análise cladística.

Pape (1992; Fig. 1), por sua vez, realiza a primeira análise filogenética importante para Oestroidea e recupera Calliphoridae como grupo monofilético, suportado pelas seguintes sinapomorfias: falos com pontas livres do processo dorsolateral e barras parastomais presentes. Segundo Pape, os califorídeos seriam grupo irmão de Oestridae e as famílias Sarcophagidae e Tachinidae seriam proximamente relacionadas. Contudo, o relacionamento entre as subfamílias de Calliphoridae é bastante inconclusivo, apresentando como resultado uma politomia entre a maioria delas. 


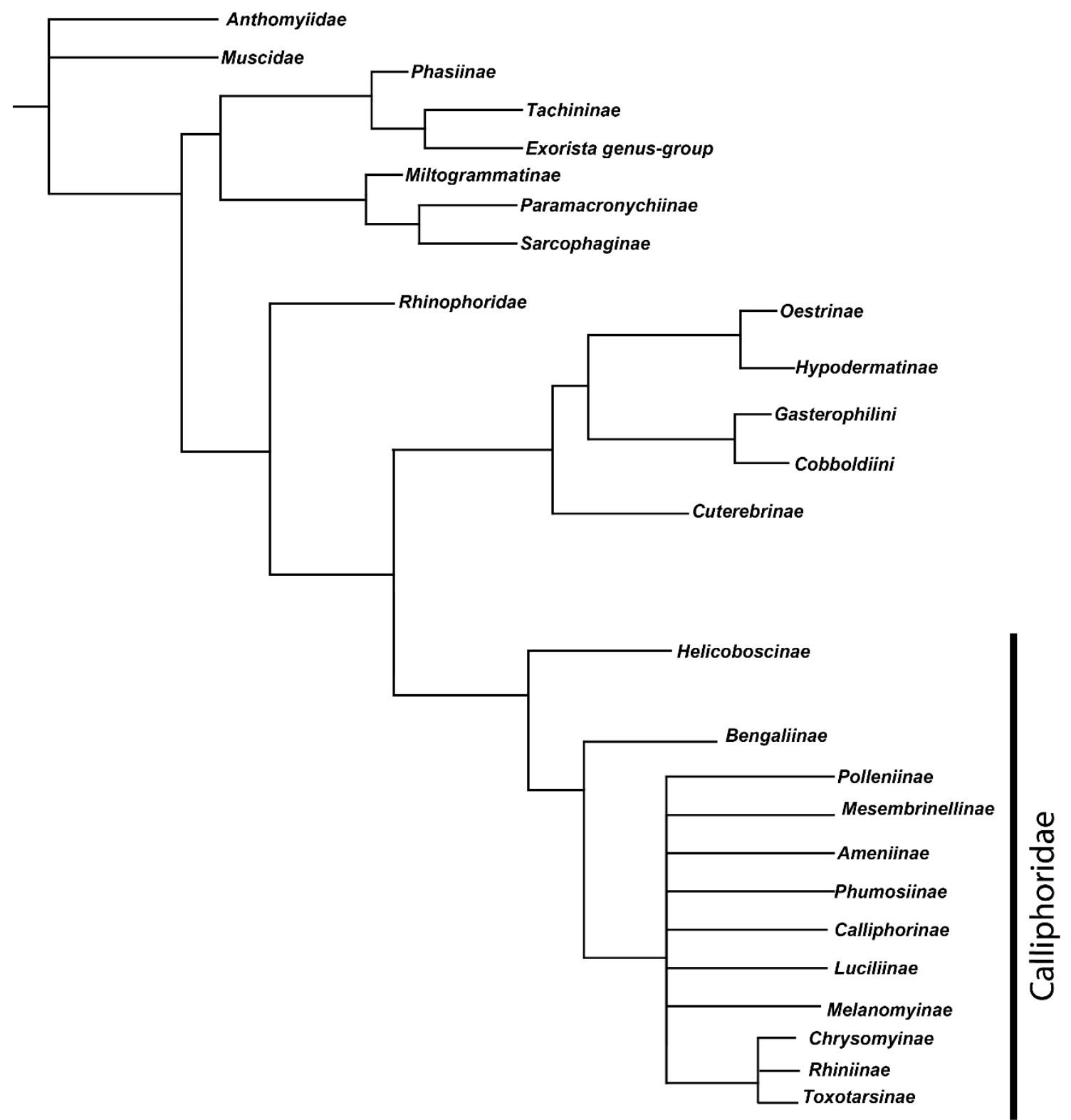

Figura. 1. Cladograma adaptado do resultado da análise cladística de Oestroidea, com base em caracteres morfológicos, implementada por Pape (1992).

Posteriormente, Rognes (1997) realiza um estudo filogenético de Calliphoridae, utilizando caracteres morfológicos. Seus resultados corroboram a hipótese levantada por Hennig (1973) sobre a polifilia dessa família. Essa polifilia se dá pela presença da família Oestridae dentro de Calliphoridae e a então subfamília Rhiniinae fora dela. Mesembrinellidae, por sua vez, aparece dentro do clado dos califorídeos, sendo grupo irmão de um clado formado por Phumosiinae, Euphumosia, Ameniini, Parameniini e Catapicephala (Fig. 2). 


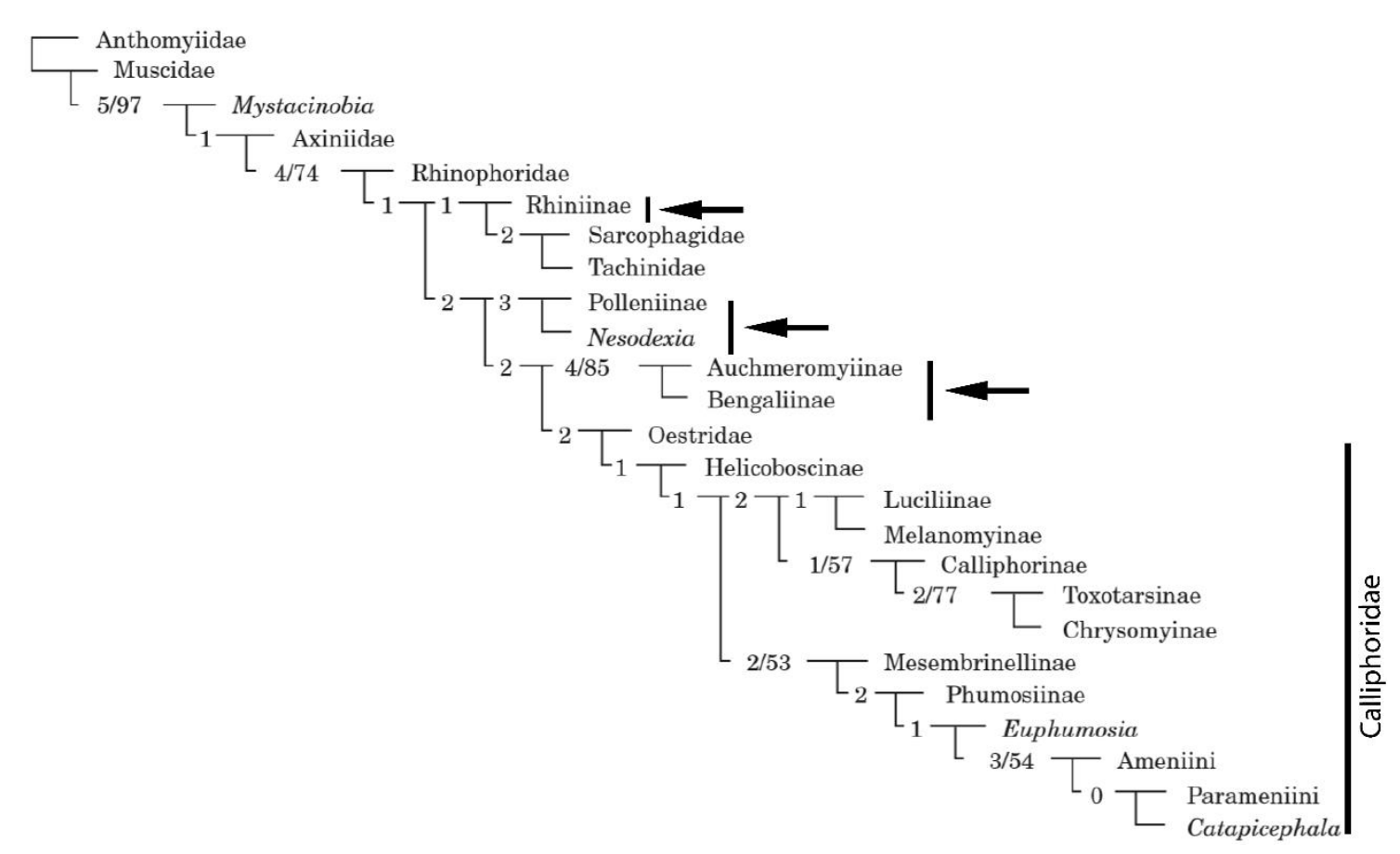

Figura 2. Cladograma retirado de Rognes (1997) representando os resultados da análise cladística de Calliphoridae, com base em caracteres morfológicos. As barras e flechas indicam Calliphoridae sensu lato.

Mais adiante, Kutty et al. (2010) inferem uma filogenia molecular dos Calyptratae (Fig. 3) e constatam o posicionamento dos mesembrinelídeos dentro da família Tachinidae, grupo irmão de uma das espécies representantes da subfamília Phasiinae, que também se mostra polifilética. Além do posicionamento de Mesembrinellidae, a polifilia de Calliphoridae se deu pelas ausências de Poleniinae e Helicoboscinae dentro do clado dos Calliphoridae. Nesse trabalho, Rhiniidae já era tratado como família pelos autores, por indicação da análise feita por Rognes (1977), que encontrou essa família fora do clado dos Calliphoridae. Nos últimos anos, dois trabalhos de filogenias moleculares confirmam o posicionamento de Mesembrinellidae, conferindo status de família ao clado, fora de Calliphoridae. Em Marinho et al. (2012), Mesembrinellidae é grupo irmão de Tachinidae e em Sigh \& Wells (2013), um clado separado dentro de Oestroidea, o que corrobora a hipótese do status de família proposto por Guimarães (1977). Tais resultados corroboram a hipótese intuitiva de Guimarães (1977), que já havia proposto que o grupo deveria receber status de família. 


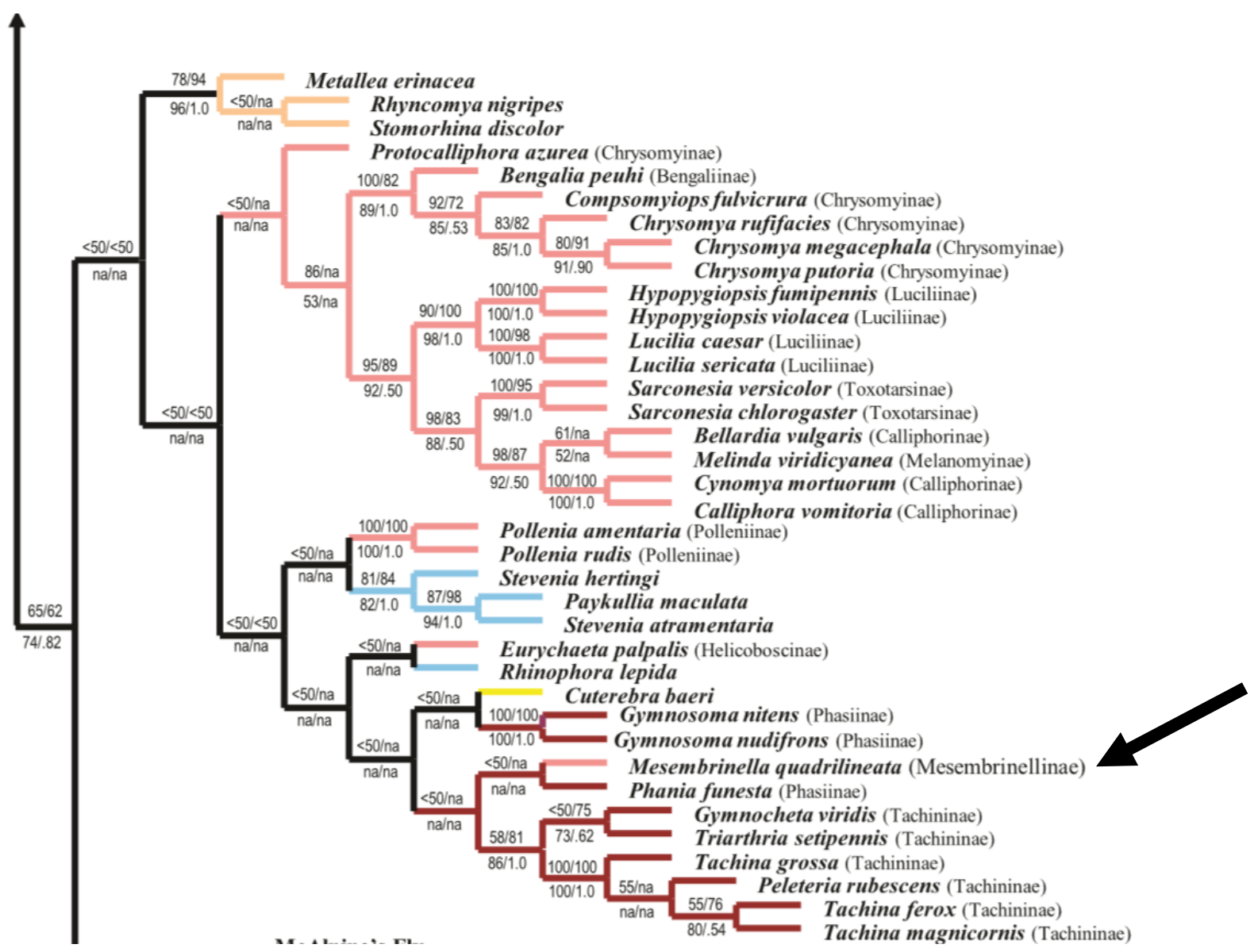

Figura 3. Parte do cladograma obtido de Kutty et al. (2010) representando os resultados de análise cladística com base em dados moleculares. Em rosa, a família Calliphoridae e em vermelho, Tachinidae. A flecha indica o posicionamento de Mesembrinellidae. 


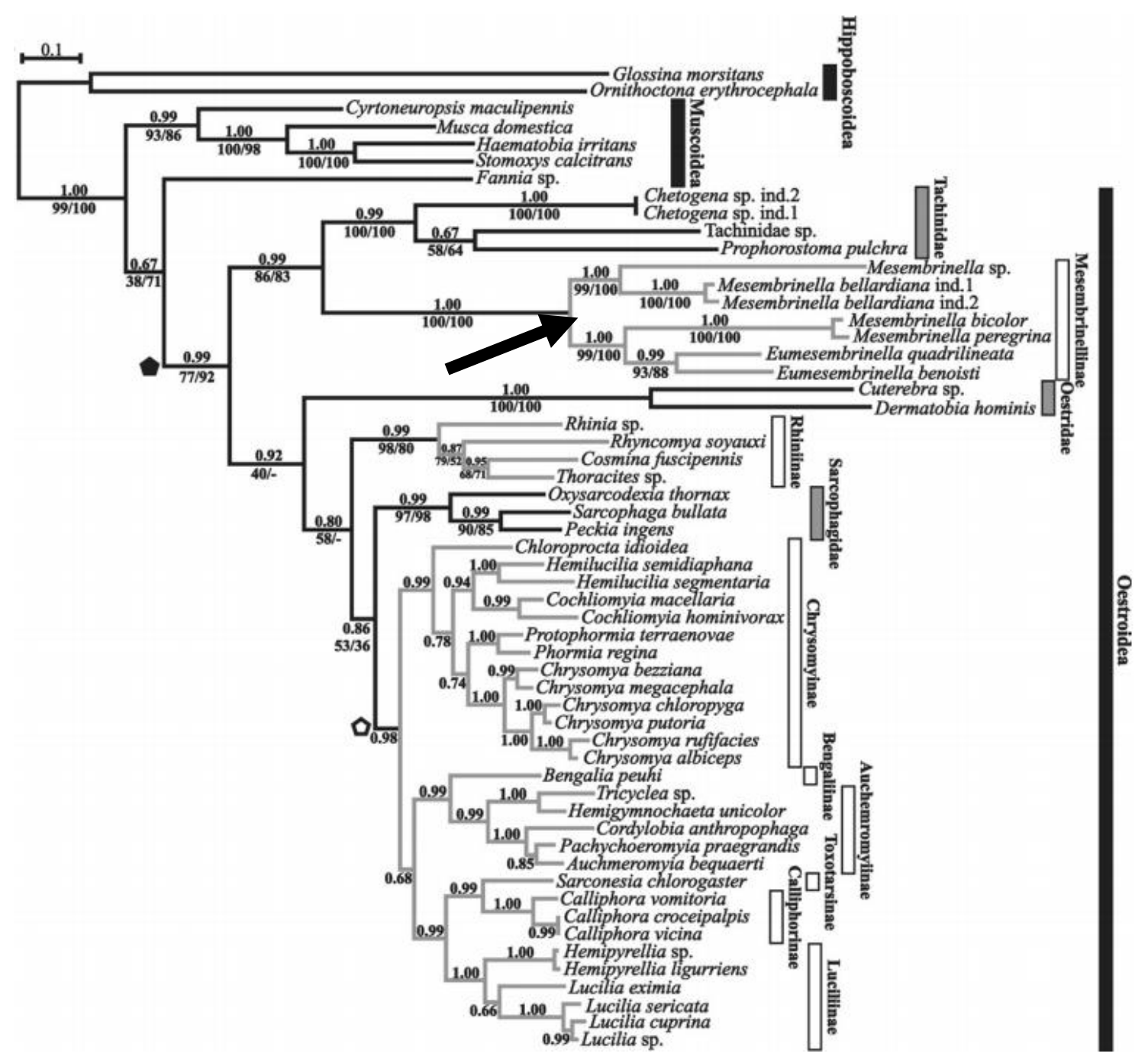

Figura 4. Parte do cladograma retirado de Marinho et al. (2012), obtido por análise cladística baseada em dados moleculares. A flecha indica o posicionamento de Mesembrinellidae. 


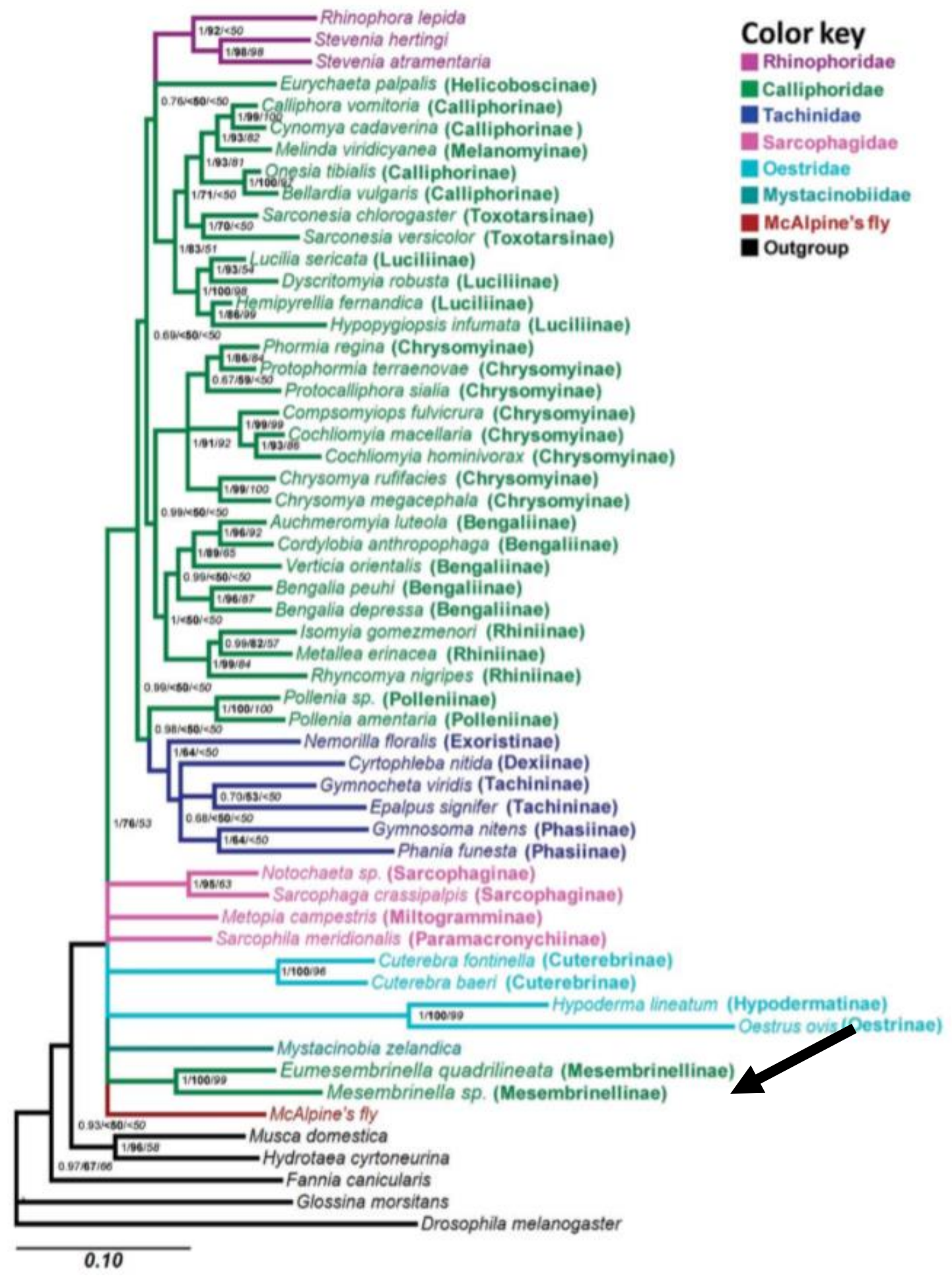

Figura 5. Cladograma retirado de Singh \& Wells (2013), obtido por meio de análise cladística com base em dados moleculares. A flecha indica o posicionamento de Mesembrinellidae. 


\subsection{Histórico sistemático de Mesembrinellidae}

Mesembrinellidae é um grupo de moscas exclusivamente Neotropicais (Bonatto \& Marinoni, 2005), encontrados em florestas tropicais úmidas (Guimarães, 1977) desde o sul do México até o norte da Argentina (Peris \& Mariluis, 1984). Sâo bastante restritas quanto ao seu habitat, Devido à especificidade do ambiente que ocupam, os mesembrinelideos foram classificados como assinantrópicos, por não serem capazes de conviver no mesmo ambiente que a espécie humana (Mello et al., 2007; Ferrera, 1978). Por isso, podem ser utilizados como bioindicadores de áreas preservadas (Gadelha et al., 2009). Previamente ao presente trabalho, eram reconhecidas 36 espécies distribuídas em nove gêneros (Mello, 1967; Guimarães, 1977; Toma \& Carvalho, 1995; Bonatto, 2001; Bonatto \& Marinoni, 2005; Wolff, 2013; Wolff et al. 2013a; Wolff et al., 2013b).

O gênero Mesembrinella foi descrito por Giglio-Tos (1893), para abrigar as espécies Musca quadrilineata Fabricius, 1805 e Musca bicolor Fabricius, 1805. Então, Brauer (1895) alocou o gênero dentro de Muscidae Testaceae, grupo inicialmente criado por Robineau-Desvoidy (1830) para abrigar Bengalia, Phumosia, Ormia e Palpostoma, que sofreu algumas modificações feitas por autores subsequentes (e.g. Villeneuve, 1920). Dentre essas, destaca-se a revisão do grupo Muscidae Testaceae, que terminou com 29 espécies (Surcouf, 1919).

Townsend (1918) descreveu o gênero Huascaromusca (espécie tipo $H$. cruciata Townsend, 1918) com base na presença de cerdas discais no quinto tergito abdominal, característica exclusiva desse grupo. Aldrich (1922), em seu trabalho sobre o gênero Mesembrinella e outras moscas do grupo Muscidae Testaceae, redescreveu as espécies conhecidas de Mesembrinella e descreveu novas espécies, além de sinonimizar o gênero Huascaromusca à Mesembrinella. Nesse trabalho, o autor não fez nenhuma modificação sobre o posicionamento do grupo, mantendo-o em Muscidae Testaceae.

Shannon (1923), por sua vez, foi o primeiro autor a comentar sobre as afinidades de Mesembrinella com a família Calliphoridae, considerando a presença de cerdas no prosterno o caráter unificador. 
No entanto, Townsend (1931) descreveu o gênero Eumesembrinella (espécie tipo Musca quadrilineata Fabricius, 1805) e, em seu trabalho posterior (Townsend, 1935) realocou os gêneros Mesembrinella e Eumesembrinella para a tribo Mesembrinellini dentro da família Rhiniidae, que também incluía as tribos Rhiniini, Bengaliini e Poleniini.

Hall (1948) reconheceu a existência de cinco subfamílias dentro de Calliphoridae, inclusive Mesembrinellinae. Entretanto, apesar de manter Mesembrinellinae em Calliphoridae, o autor lista diversas características divergentes entre esses dois grupos, sugerindo a existência de uma linhagem distinta daquela dos verdadeiros Calliphoridae. Dentre essas características, uma das mais marcantes é a viviparidade adenotrófica, em que as larvas se desenvolvem dentro do oviduto materno e são liberadas para o meio externo somente no último instar, quando imediatamente empupam (Guimarães, 1977). Essa característica biológica faz com que as larvas de Mesembrinellidae não sejam capazes de colonizar matéria orgânica em decomposição, pois a fêmea não efetua a postura de ovos no ambiente. Isso diferencia essas espécies das demais espécies de califorídeos.

A despeito da sugestão de Hall (1948), Roback (1951), em sua classificação dos muscóideos caliptrados, manteve o posicionamento de Mesembrinellinae dentro de Calliphoridae. Já Crosskey (1965), em sua revisão da subfamília Ameniinae, comentou sobre os grupos anômalos dentro de Calliphoridae, sendo um deles Mesembrinellidae, e sugeriu que esses fossem elevados ao status de família. Autores subsequentes (Mello, 1967; James, 1970) não seguiram a proposta de Crosskey (1965).

Mello (1967) fez uma segunda revisão do grupo, após Aldrich (1922), e descreveu os novos gêneros Laneella (espécie tipo Mesembrinella brunnipes Surcouf, 1919) e Albuquerquea (espécie tipo A. latifrons Mello, 1967), além de descrever algumas espécies novas em gêneros existentes. James (1970), em seu catálogo da família Calliphoridae, incluiu a subfamília Mesembrinellinae, com 17 espécies em quatro gêneros.

Uma terceira revisão abrangente de Mesembrinellidae foi feita por Guimarães (1977) que, influenciado pelas ideias de Crosskey (1965), reafirmou que 
Mesembrinellinae é um grupo anômalo, designando, pela primeira vez, a família Mesembrinellidae. Nesse trabalho, o autor descreveu os gêneros Thompsoniella (espécie tipo T. anomala Guimarães, 1977) e Souzalopesiella (espécie tipo Mesembrinella facialis Aldrich, 1922), além de descrever várias espécies novas e fazer inúmeras contribuições para o estudo biológico e morfológico desse grupo. Certamente, como apontou Hall (1948) e sumarizou Guimarães (1977), os mesembrinelíneos são muito distintos do restante dos grupos que compõem a família Calliphoridae, principalmente no que diz respeito à biologia reprodutiva, à morfologia da genitália e à anatomia externa.

Quase 20 anos mais tarde, Toma \& Carvalho (1995) realizaram o primeiro estudo de Mesembrinellinae após o advento da sistemática filogenética de Hennig (1966). Os autores utilizam o status de subfamília para o grupo (Mesembrinellinae), não seguindo a proposta de Guimarães (1977). Nesse trabalho, os autores investigaram o relacionamento entre as espécies e gêneros de Mesembrinellidae, com ênfase no gênero Eumesembrinella e postularam que o provável grupo irmão de Mesembrinellidae seria a subfamília Ameniinae, pela presença do subescutelo desenvolvido e, ainda, pela ausência de um ovopositor telescopado, característico dos demais califorídeos. Além disso, levantaram diversos caracteres importantes à morfologia de Mesembrinellidae, tais como aqueles que compõem as sinapomorfias que sustentam a monofilia do grupo: espiráculo metatorácico único, reniforme, com abertura dorsal; espermateca alongada e esclerosada; asa com mácula na porção médio-apical, próximo às veias $\mathrm{R}_{1}$ e $\mathrm{R}_{2+3}$; estemito 8 ausente na fêmea e afilamento da porção apical da espermateca.

Bonatto (2001), em sua tese de doutorado, realizou uma revisão bastante detalhada de todas as espécies de Mesembrinellidae, além de descrever gêneros e espécies novas (Bonatto \& Marinoni, 2005). Também apresentou uma análise cladística contendo todas as espécies do grupo, em que forneceu diversos caracteres importantes para uma melhor compreensão morfológica dessas espécies, bem como relacionamento entre elas. Este trabalho foi extremamente importante para a taxonomia e morfologia de Mesembrinellidae.

Como pôde ser compreendido no histórico apresentada acima, Mesembrinellidae é, certamente, um grupo extremamente complexo e há pouco 
consenso sobre diversos aspectos da sua classificação, além de seu posicionamento dentro de Oestroidea, e todos os esforços em tentar elucidar esses aspectos ainda não foram suficientes. Dessa forma, acredita-se que esse grupo ainda necessita de estudos mais aprofundados, envolvendo aspectos dos seus relacionamentos internos, posicionamento dentro de Oestroidea, biologia, bioeografia etc.

O presente trabalho é o primeiro a realizar uma análise cladística muito abrangente do grupo, envolvendo um número bastante extenso de terminais do grupo externo, contendo espécies de todas as famílias de Oestroidea (Calliphoridae, Tachinidae, Sarcophagidae, Rhinophoridae e Rhiniidae). Além disso, é o primeiro a fornecer mapas de distribuição com uma quantidade bastante elevada de localidades geográficas e a realizar análises biogeográficas de acordo com os paradigmas da biogeografia moderna, com análises formais. Previamente ao presente estudo, as únicas iniciativas biogeográficas existentes para o grupo foram apresentadas por meio de mapas de distribuição, fornecidos por Guimarães (1977), porém com uma quantidade bastante limitada de localidades geográficas. 


\section{Objetivos}

- Testar a monofilia da família Mesembrinellidae;

- Testar a monofilia dos gêneros incluídos em Mesembrinellidae;

- Inferir as relações de parentesco entre as espécies de Mesembrinellidae;

- Realizar um estudo biogeográfico de Mesembrinellidae a partir da hipótese filogenética gerada.

\section{Material e métodos}

\subsection{Material de estudo}

Abaixo são listadas todas as Instituições depositárias de Mesembrinellidae, citadas ao longo do trabalho.

AMNH - American Museum of Natural History, Nova Iorque, Estados Unidos da América.

BMNH - Natural History Museum, Londres, Reino Unido.

CAS - California Academy of Sciences, Califórnia, Estados Unidos da América.

CEUA - Laboratorio Colecciones Entomológicas, Universidad de Antioquia, Antioquia, Colombia.

DZUP - Coleção de Entomologia Pe. Jesus Santiago Moure, Curitiba, Brasil.

IAVH - Instituto de Investigación de Recursos Biológicos Alexander von Humboldt, Bogotá, Venezuela.

INBIO - Instituto Nacional de Biodiversidad, San José, Costa Rica.

INPA - Instituto Nacional de Pesquisas da Amazônia, Manaus, Brasil.

MNHN - Muséum National d'Histoire Naturelle, Paris, França.

MNRJ - Museu Nacional da Universidade Federal do Rio de Janeiro, Rio de Janeiro, Brasil.

MZUSP - Museu de Zoologia da Universidade de São Paulo, São Paulo, Brasil. 
USNM - National Museum of Natural History, Washington DC, Estados Unidos da América.

ZMHB - Berlin Museum für Naturkunde der Humboldt-Universität, Berlim, Alemanha.

Grande parte do material examinado é proveniente da MZUSP, local onde foi realizado este estudo. Além desse, foi obtido empréstimo de material das seguintes Instituições, nacionais e internacionais: DZUP, MNRJ, ZMHB.

No Brasil, foram realizadas visitais às coleções das Instituições citadas anteriormente, DZUP e MNRJ. Na coleção do MNRJ, destaca-se a descoberta do holótipo de Huascaromusca vogelsangi, cujo local de depósito não foi citado por Mello (1967) e foi considerado desconhecido por Guimarães (1977). Já no exterior, foram visitadas as coleções do USNM, para exame de diversas espécies não disponíveis para estudo no Brasil, durante estágio de pesquisa no exterior, e a coleção do MACN.

Por último, foi utilizado material proveniente de novas coletas. Os locais de realização de coletas desse projeto se concentraram na Região Centro-Oeste do Brasil, nos Estados de Mato Grosso, Mato Grosso do Sul e Rondônia. Para a coleta de Mesembrinellidae, foi utilizada a armadilha Van-Sommeren-Rydon, inicialmente desenvolvida para a captura de lepidópteros (Shuey, 1997). A armadilha consiste em um cilindro feito de tela, com uma isca em decomposição na parte inferior. Os insetos são atraídos pelo odor da isca e ficam retidos no cilindro, sendo capturados, posteriormente, com a ajuda de um pote de coleta contendo atmosfera de acetato de etila, substância tóxica. Os espécimes foram, então, montados em alfinete entomológico. Após a expedição de coleta, os mesembrinelídeos foram depositados no MZUSP e identificados até o nível de espécie.

Além das Instituições citadas acima, outras coleções foram citadas em momento durante o texto, bem como no Apêndice 2, que contêm inúmeras informações, tanto de material examinado quanto provenientes de bases de dados online. 


\subsection{Seleção de terminais}

O grupo interno foi composto por 35 espécies de Mesembrinellidae (Tabela 1). Duas delas, Giovanella carvalhoi e Mesembrinella patriciae, foram descritas recentemente e não havia material disponível para estudo. Por esse motivo, foram utilizadas as descrições originais (Wolff et al., 2013b e Wolff, 2013, respectivamente) para a codificação dos caracteres.

Como mencionado no capítulo introdutório, Mesembrinellidae é um grupo controverso na literatura quanto ao seu posicionamento dentro de Oestroidea. Por esse motivo, não foi possível uma escolha restrita e objetiva para a composição do grupo externo. Em uma análise cladística, o grupo externo é de extrema importância e é definido por um conjunto de terminais que possuam sinapomorfias mais inclusivas compartilhadas com o grupo interno (Nixon \& Carpenter, 1993). Entretanto, não se sabe quais grupos são mais proximamente relacionados à Mesembrinellidae e, portanto, compartilhariam sinapomorfias mais exclusivas com esse grupo. Como apontado por Barriel \& Tassy (1998), a escolha de um grupo externo grande minimiza o erro de uma escolha errada, o que é ainda mais relevante nesse estudo em que um grande erro poderia ocorrer se somente terminais de califorídeos fossem utilizados. Além disso, um grupo externo extenso traz, empiricamente, melhores resultados para uma análise desse tipo (Nixon \& Carpenter, 1999). Sendo assim, foram selecionados terminais de todas as famílias de Oestroidea (Oestridae, Rhiniidae, Rhinophoridae, Sarcophagidae, Tachinidae e Calliphoridae), de acordo com o apresentado na Tabela 1.

Diversas mudanças taxonômicas foram feitas no presente trabalho, após o resultado das análises cladísticas. Sendo assim, a Tabela 1 será apresentada no iníco da seção "4. Resultados" e contém a lista de todas as espécies utilizadas na análise, com o status taxonômico proposto aqui e sua distribuição geográfica. Nomes entre colchetes representam as combinações originais. A justificativa para tais mudanças taxonômicas encontra-se na seção "5. Discussão". 


\subsection{Terminologia}

Foram estudados indivíduos adultos das espécies de Mesembrinellidae e dos terminais do grupo externo seguindo, predominantemente, a terminologia de McAlpine (1981). No entanto, para quetotaxia do tórax e da cabeça foi utilizada a nomenclatura de Rognes (1991).

\subsection{Identificação e preparação do material}

A identificação das espécies foi feita utilizando a chave dicotômica de Guimarães (1977) e Bonatto (2001), com posterior confirmação, quando necessário, por meio redescrições ou descrições originais. As espécies do grupo externo foram identificadas por meio dos trabalhos pertinentes a cada grupo, assim como pelo auxílio de especialistas nessas famílias. Estágios imaturos não foram considerados, por indisponibilidade de material.

Os indivíduos secos em alfinete foram examinados com auxílio de estereomicroscópio Zeiss Stemi Dv4 e Stereo Discovery V8.

Para o estudo das terminálias masculinas e femininas, foram utilizados dois protocolos diferentes, sendo que um deles (Protocolo 2) foi considerado mais adequado por manter todo abdômen preservado. No protocolo número 1, primeiramente o espécime é armazenado em câmara úmida por cerca de $24 \mathrm{~h}$ ou até que seu tecido abdominal esteja amolecido. É, então, feita a dissecção da terminália a partir do tergito 4 para fêmeas e 5 para machos, seguida de clareamento em solução de 50\% de água e 50\% de água oxigenada 10vol., com adição de hidróxido de potássio $(\mathrm{KOH})$, obtendo-se uma solução final com $\mathrm{KOH}$ a $10 \%$. Após esse procedimento, a terminália é desidratada em álcool $70 \%$ e transferida para lâmina temporária com glicerina, para estudo. No protocolo número 2 (Whitworth, 2010), o abdômen é totalmente destacado do corpo do inseto, quando ainda seco, e, em seguida, clareado na mesma solução de $\mathrm{KOH} 10 \%$ citada no protocolo número 1. Quando amolecido, o abdômen é dissecado para que sejam destacados todos os esternitos e a terminália, restando os tergitos. Os tergitos, então, são secos em papel filme e colados em um pequeno pedaço de papel, alfinetado ao espécime dissecado. A partir desse ponto, o procedimento com a terminália é igual ao protocolo 
número 1 em que, após clareada, é hidratada em álcool 70\% e transferida para lâmina com glicerina. Para ambos os protocolos, após serem estudadas e ilustradas, as terminálias são armazenadas em pequenos tubos plásticos com glicerina, fixados ao alfinete do espécime dissecado.

\subsection{Análise cladística}

O estudo das relações de parentesco entre as espécies de Mesembrinellidae foi feito por meio do método de análise cladística (Kitching et al., 1988; Wiley \& Lieberman, 2011). Os caracteres foram construídos a partir do estudo da morfologia externa de exemplares adultos dos terminais selecionados, seguindo a proposta de Sereno (2007). Quando cabível, foi utilizada a codificação contingenciada, em que informações independentes de uma mesma estrutura são codificadas como caracteres separados, como presença/ausência e variações de cor, no caso da presença. Esse tipo de codificação é vantajoso porque se acredita que a evolução da cor, no exemplo citado, é independente da presença e ausência de determinada estrutura, sendo fontes de homologia distintas e que devem ser tratadas como tal (Pleijeil, 1995; Forey \& Kitching, 2000; Hawkins, 1997; Wiley \& Lieberman, 2011).

Adicionalmente, foram utilizados caracteres previamente construídos por outros autores (Pape, 1992; Rognes, 1997; Toma \& Carvalho, 1995; Bonatto, 2001). Esses caracteres estão devidamente indicados, com as citações das quais foram retirados entre parênteses, na lista de caracteres da seção 4.2. Todos os caracteres foram considerados não aditivos e os polimorfismos tratados como tal (Wiens, 1998). Após a descrição do caráter, foram adicionados comentários, quando pertinente.

A matriz de caracteres foi confeccionada no software Mesquite 2.75 (Madison \& Madison, 2011). Já as análises de parcimônia foram feitas no programa TNT 1.1 (Goloboff et al., 2008), com pesagem igual e implícita dos caracteres. Para a análise de pesagem igual dos caracteres, foram realizadas análises por meio dos quatro algoritmos (Ratchet, Drift, Tree Fusion e Sectorial Searches) das novas tecnologias implementadas no TNT (New Technologies searches), sob os seguintes parâmetros: random seed=1; número de réplicas $=10.000$ e número de árvores salvas por replicação=10). Esses 
algoritimos são capazes de perturbar os dados de diferentes maneiras, a fim de encontrar melhores árvores, de forma muito mais rápida e eficiente (Goloboff et al., 2008).

A pesagem igual dos caracteres supõe que todos têm o mesmo valor para a análise e, então, obtém-se o cladograma com o menor número de custos para o conjunto dos dados (Goloboff, 1993). No entanto, tradicionalmente considera-se que os caracteres homoplásticos são menos confiáveis e, por isso, deveriam ter menor peso na análise (Goloboff, 1993, 2008). A pesagem sucessiva (Farris, 1969) foi a primeira abordagem de pesagem a posteriori a ser amplamente utilizada na literatura. Nesta abordagem, os caracteres são pesados em função dos índices de consistência das árvores mais parcimoniosas obtidas em análise prévia com pesagem igual. São feitas, então, reanálises dos dados continuamente, até que se encontre uma solução estável. No entanto, como apontado por Goloboff (1993), o grande problema da pesagem sucessiva é seu pressuposto inicial baseado na pesagem igual dos caracteres. Para solucionar esse problema, Goloboff (1993) propõe um novo método, a pesagem implícita dos caracteres, que trabalha visando não necessariamente árvores mais curtas, mas sim as de maior fitness, que é o ajuste da topologia aos seus caracteres. O método utiliza-se de uma constante de concavidade $k$, que representa a força da pesagem que é aplicada aos caracteres, ou seja, quanto menor o $k$ mais peso é colocado nos caracteres menos homoplásticos e vice-versa. Dessa forma, quanto maior o $k$, mais se aproxima da pesagem igual dos caracteres (Goloboff, 1993). Para a escolha do valor de $k$, foi utilizado o script propk.run (ANEXO 1) desenvolvido por Salvador Arias (CONICET, Argentina), que se baseia na proporção da máxima homoplasia observada em uma árvore de Wagner com a total falta de homoplasia nessa mesma árvore. Para efeito de comparação, foram feitas análises com diferentes valores de $k$, além daquele indicado pela análise com o uso do script mencionado.

A otimização dos caracteres nas topologias foi realizada no programa Asado 1.89. Foi utilizada a otimização ACCTRAN (accelerated transformation) por preservar as homologias primárias e as informações dos terminais, em detrimento da DELTRAN (delayed transformation) que enfatiza as informações dos nós e, consequentemente da raíz, região de muita incerteza. A edição de árvores foi feita nos softwares Asado 1.89 e Adobe Ilustrator CS6. Já o suporte dos ramos foi verificado pelo índice de decaimento (usualmente conhecido como Índice de Bremer, Bremer, 1994), com uso do script Bremer.run (ANEXO 2). Esse índice é quantificado como o custo extra 
necessário para a perda de um ramo no consenso estrito das árvores mais parcimoniosas, de modo que ramos bem suportados necessitariam de muitos passos extras para sua perda. Ramos pouco suportados podem ser facilmente colapsados no consenso estrito dos cladogramas obtidos e, portanto, têm índice de Bremer baixos (Bremer, 1994). Por fim, o desempenho dos caracteres foi verificado pelos índices de consistência (CI) (Kluge \& Farris, 1969) e de retenção (RI) (Farris, 1989).

\subsection{Registros de distribuição geográfica}

Os dados de distribuição geográfica das espécies de Mesembrinellidae foram obtidos, majoritariamente, por meio dos dados da etiqueta dos espécimes examinados. Adicionalmente, foram utilizados dados de literatura (Bonatto, 2001; Bonatto \& Marinoni, 2005; Guimarães, 1977; Wolff, 2013; Wolff et al., 2013a; Wolff et $a l ., 2013 b)$ e da base de dados da coleção científica da Costa Rica, disponível online (Atta INBIO). De maneira geral, as localidades foram georreferenciadas por meio da base de dados geográficos online Global Gazeteer (www.fallingrain.com) e do software Google Earth. Em alguns poucos casos particulares, em que a localidade não foi encontrada dessa maneira, utilizaram-se páginas específicas da internet, todas citadas no APÊNDICE 2.

Os mapas foram confeccionados com auxílio do programa Quantum GIS 2.2, com a camada de divisões políticas do Continente Americano. A espécie Huascaromusca bequaerti não foi incluída nos mapas porque em suas etiquetas consta apenas "Peru", impossibilitando sua localização mais precisa nesse país.

\subsection{Análises biogeográficas}

As análises biogeográficas foram embasadas nos princípios da Biogeografia Cladística, construída sob os pilares da Sistemática Filogenética de Hennig, da Teoria da Deriva Continental de Wegener e das ideias de vicariância de Croizat (Nihei, 2011). A partir das informações sobre o relacionamento filogenético dos táxons, sua distribuição geográfica no espaço e a ideia de que a Terra está em constante movimento, podem ser feitas análises com o objetivo de se estudar a história espacial desses organismos (Crisci et al., 2003). Previamente às análises, é necessário, para a grande 
maioria dos métodos cladísticos biogeográficos, a delimitação de áreas que serão as unidades básicas das análises. Essas áreas podem ser estabelecidas de diversas maneiras pelo próprio autor do trabalho ou obtidas de trabalhos prévios. No presente estudo, serão utilizadas as áreas delimitadas para a região Neotropical por Morrone (2014), de acordo com a Figura 168. A figura é apresentada somente nos resultados para facilitar a compreensão do leitor. O mapa foi construído por meio do arquivo shapefile de Löwenberg \& Neto, 2014, no software Quantum GIS 2.2.

Foram realizados dois métodos biogeográficos cladísticos: Análise de Dispersão-Vicariância (DIVA) e Análise de Parcimônia de Brooks (BPA). Foi escolhida a utilização de dois métodos distintos, pois cada um deles responde a diferentes questões biogeográficas, que serão abordadas na discussão.

A Análise de Dispersão e Vicariância é um método inserido no conjunto de métodos biogeográficos que utilizam um modelo de evolução a priori à análise, em que são atribuídos custos para a ocorrência de tais eventos (Almeida \& Santos, 2011), sendo os maiores custos atribuídos a eventos menos prováveis, como dispersão e, menores custos, à vicariância, considerada mais provável (Ronquist, 1997). Dessa maneira, procura-se inferir as distribuições dos nós ancestrais, de modo a minimizar os custos de ocorrência dos eventos (Crisci et al., 2003). A análise DIVA foi executada no programa DIVA 1.2. (Ronquist, 1996). Para tanto foi construído um script (APÊNDICE 3) que apresenta a ocorrência de cada táxon nas áreas delimitadas e a filogenia do grupo. Não foi determinado o número máximo de áreas para cada nó.

A Análise de Parcimônia de Brooks (BPA) é um método proposto inicialmente por Brooks (1981) para estudar a relação entre parasitas e hospedeiros, que foi utilizado posteriormente por Willey (1988) no estudo da biogeografia. O método consiste em encontrar relacionamento entre áreas, por meio da aplicação da sistemática filogenética, em que táxons são tratados como se fossem caracteres evoluindo dentro das áreas (Brooks et al., 2001). Para tanto, é necessária a construção de uma matriz binária taxón x área, em que as presenças de cada táxon ou nó são codificadas como 1 e, as ausências, 0 (Nihei, 2011). Os terminais da matriz são todas as áreas utilizadas na análise (Fig. 168) e os táxons ("caracteres") são todos os táxons terminais do cladograma dos táxons mais todos os nós, para que a informação filogenética, ou seja, todos os agrupamentos do cladograma, sejam mantidos e levados em consideração durante a análise. Para facilitar a codificação, os terminais e nós foram numerados e essa 
codificação pode ser consultada no APÊNDICE 4. A matriz foi então construída no software Mesquite 2.75 (Madison \& Madison, 2011) (APÊNDICE 5) e analisada por parcimônia no programa TNT 1.1 (Goloboff et al., 2003), com 100 replicações e 10 árvores retidas.

\subsection{Ilustrações}

Foram confeccionadas fotografias dos caracteres construídos no estudo, para facilitar a compreensão do leitor quanto às estruturas analisadas. Por se tratarem de animais tão pequenos, é impossível obter uma única fotografia totalmente focada. Foi feita, então, uma tomada de imagens que se inicia do foco mais próximo da câmera até o mais distante. Para isso, foi utilizada a câmera digital Zeiss AxioCam MRc5 acoplada ao estereomicroscópio Zeiss Discovery V21 e ao microscópio óptico Zeiss Axioskop 40, por meio do software Zen 1.0. Após esse procedimento, as diversas fotografias foram combinadas em uma única com a utilização do mesmo software citado anteriormente. Além disso, foram confeccionados desenhos de estruturas cujas fotografias obtidas não ficaram satisfatórias para uma boa visualização das estruturas apresentadas. Para a confecção dos desenhos, foi utilizado o estereomicroscópio Discovery $V 8$, com câmara clara acoplada. Os desenhos a lápis, então, foram editados no software Adobe Illustrator CS6. Para a edição tanto das fotografias, assim como confecção de pranchas de ilustrações, foi utilizado o software Adobe Photoshop CS6. 


\section{Resultados}

\subsection{Filogenia de Mesembrinellidae}

\subsubsection{Terminais}

Na tabela 1 são apresentados todos os terminais utilizados na análise cladística, com sua respectiva classificação e distribuição geográfica. Os nomes apresentados nessa tabela já se encontram alterados, após terem sido feitas mudanças taxonômicas pertinentes e justificadas na seção “5. Discussão”. A tabela 2, por sua vez, apresenta uma lista completa de todas as espécies de Mesembrinellidae, com todas as suas sinonímias, de acordo com os principais autores que estudaram esse grupo.

Tabela 1. Terminais utilizados na análise cladística do presente trabalho, com sua respectiva classificação e distribuição geográfica. Para os Mesembrinellidae são apresentados entre colchetes, e sempre que pertinente, os gêneros da combinação original. comb. n.: combinação nova.

\begin{tabular}{|c|c|c|c|c|c|c|c|c|}
\hline & Superfamília & Família & Subfamília & Gênero & $\begin{array}{l}\text { Epíteto } \\
\text { específico }\end{array}$ & Status & Autor/ano & Distribuição geográfica \\
\hline \multirow{15}{*}{ 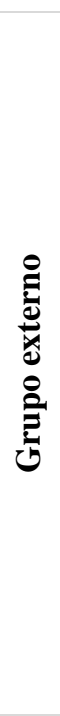 } & \multirow{3}{*}{ Muscoidea } & Fannidae & & Fannia & heydenii & & (Wiedemann, 1830) & Neotropical \\
\hline & & \multirow{2}{*}{ Muscidae } & Muscinae & Polietina & flavithorax & & (Stein, 1904) & Neotropical \\
\hline & & & Phaoninae & Phaonia & advena & & Snyder, 1957 & Neotropical \\
\hline & \multirow{12}{*}{ 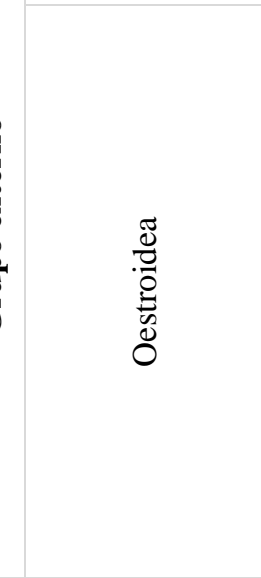 } & Oestridae & Cuterebrinae & Cuterebra & apicais & & Gerin-Meneville, 1835 & Neotropical \\
\hline & & \multirow{2}{*}{ Rhiniidae } & & Idiella & mandarina & & (Wiedemann, 1830) & Oriental \\
\hline & & & & Strongyloneura & nebulosa & & Townsend, 1917 & Oriental \\
\hline & & Rhinophoridae & & Shannoniella & cuspidata & & Townsend, 1939 & Neotropical \\
\hline & & \multirow{2}{*}{ Sarcophagidae } & Miltogramiinae & Amobia & floridens & & (Townsend, 1892) & Neártica \\
\hline & & & Sarcophaginae & Peckia & intermutans & & (Walker, 1861) & Neotropical \\
\hline & & \multirow{6}{*}{ Tachinidae } & Dexiinae & Prophorostoma & pulchra & & Townsend, 1927 & Neotropical \\
\hline & & & Exoristinae & Winthemia & analis & & (Macquart, 1846) & Neotropical \\
\hline & & & \multirow{4}{*}{ Phasiinae } & Acaulona & costata & & Wulp, 1888 & Neotropical \\
\hline & & & & Ectophasia & crassipenis & & (Fabricius, 1794) & Paleártica \\
\hline & & & & Gymnosoma & rotundatum & & (Linnaeus, 1758) & Paleártica \\
\hline & & & & Phasia & hemiptera & & (Fabricius, 1794) & Paleártica \\
\hline
\end{tabular}




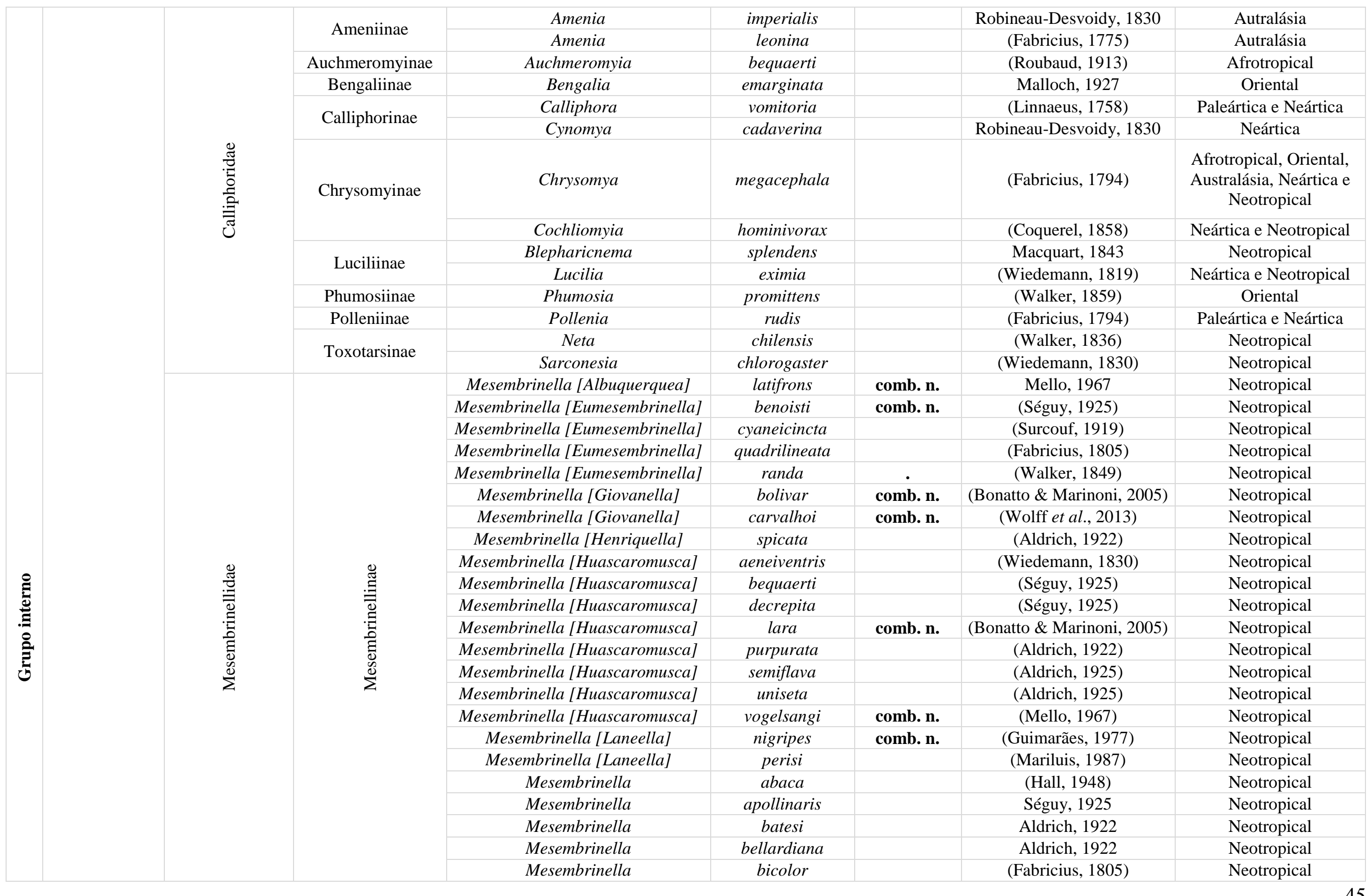




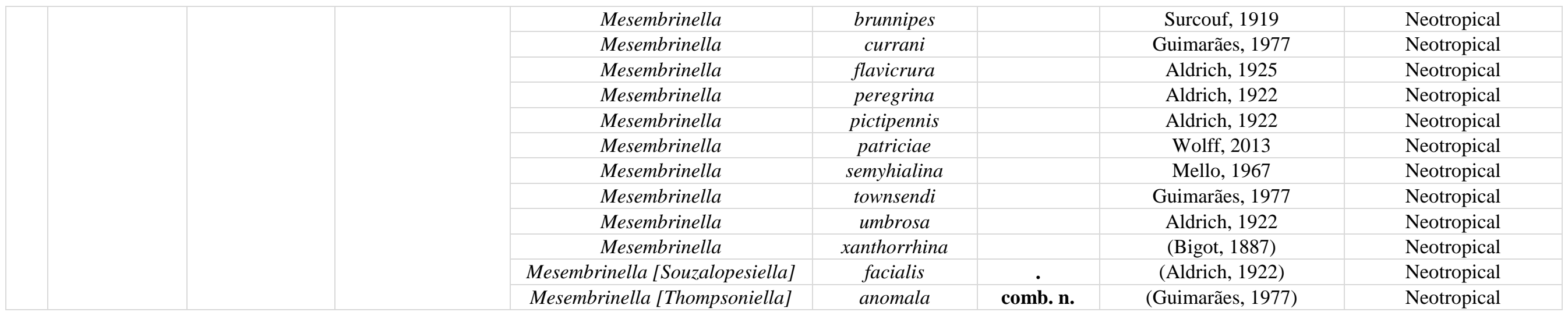


Tabela 2. Lista das espécies de Mesembrinellidae, com um histórico de nomenclatura dos principais autores que estudaram o grupo, com o respectivo status considerado por cada um deles e nomes válidos. Entre colchetes encontram-se, sempre que pertinente, os gêneros da combinação original. Espaços com “_“"representam a falta de informação sobre a espécie naquele trabalho, ou pela omissão do autor por motivo desconhecido ou porque a espécie ainda não havia sido descrita.

\begin{tabular}{|c|c|c|c|c|c|c|c|}
\hline Autores & Hall, 1948 & Mello, 1967 & James, 1970 & Guimarães, 1977 & $\begin{array}{c}\text { Toma \& Carvalho, } \\
1995\end{array}$ & Bonatto, 2001 & Presente estudo \\
\hline $\begin{array}{l}\text { Status do } \\
\text { grupo }\end{array}$ & $\begin{array}{c}\text { Subfamília } \\
\text { Mesembrinellinae }\end{array}$ & $\begin{array}{c}\text { Subfamília } \\
\text { Mesembrinellinae }\end{array}$ & $\begin{array}{c}\text { Subfamília } \\
\text { Mesembrinellinae }\end{array}$ & $\begin{array}{c}\text { Família } \\
\text { Mesembrinellidae }\end{array}$ & $\begin{array}{c}\text { Subfamília } \\
\text { Mesembrinellinae }\end{array}$ & $\begin{array}{c}\text { Família } \\
\text { Mesembrinellidae }\end{array}$ & $\begin{array}{c}\text { Família } \\
\text { Mesembrinellidae }\end{array}$ \\
\hline \multirow[t]{4}{*}{ Espécies } & - & $\begin{array}{c}\text { Albuquerquea } \\
\text { latifrons Mello, } \\
1967\end{array}$ & - & $\begin{array}{c}\text { Albuquerquea } \\
\text { latifrons Mello, } \\
1967\end{array}$ & $\begin{array}{c}\text { Albuquerquea } \\
\text { latifrons Mello, } \\
1967\end{array}$ & $\begin{array}{c}\text { Albuquerquea } \\
\text { latifrons Mello, } \\
1967\end{array}$ & $\begin{array}{l}\text { Mesembrinella } \\
\text { latifrons comb. n. } \\
\text { [Albuquerquea] } \\
\text { (Mello, 1967) }\end{array}$ \\
\hline & - & $\begin{array}{c}\text { Eumesembrinella } \\
\text { lanei (Séguy, 1925) }\end{array}$ & $\begin{array}{c}\text { Eumesembrinella } \\
\text { incompleta (Séguy, } \\
1925)\end{array}$ & $\begin{array}{c}\text { Eumesembrinella } \\
\text { benoisti } \\
\text { [Ochromyia] } \\
\text { (Séguy, 1925) }\end{array}$ & $\begin{array}{c}\text { Eumesembrinella } \\
\text { benoisti } \\
{[\text { Ochromyia }]} \\
\text { (Séguy, 1925) }\end{array}$ & $\begin{array}{c}\text { Eumesembrinella } \\
\text { benoisti } \\
\text { [Ochromyia }] \\
\text { (Séguy, 1925) }\end{array}$ & $\begin{array}{c}\text { Mesembrinella } \\
\text { benoisti comb. n. } \\
\text { [Ochromyia] } \\
\text { (Séguy, 1925) }\end{array}$ \\
\hline & - & $\begin{array}{c}\text { Eumesembrinella } \\
\text { pauciseta (Surcouf, } \\
1919)\end{array}$ & - & $\begin{array}{c}\text { Eumesembrinella } \\
\text { cyaneicincta } \\
\text { [Ochromyia] } \\
\text { (Surcouf, 1919) }\end{array}$ & $\begin{array}{c}\text { Eumesembrinella } \\
\text { cyaneicincta } \\
\text { [Ochromyia] } \\
\text { (Surcouf, 1919) }\end{array}$ & $\begin{array}{c}\text { Eumesembrinella } \\
\text { cyaneicincta } \\
\text { [Ochromyia] } \\
\text { (Surcouf, 1919) }\end{array}$ & $\begin{array}{c}\text { Mesembrinella } \\
\text { cyaneicincta } \\
{[\text { Ochromyia }]} \\
\text { (Surcouf, 1919) }\end{array}$ \\
\hline & - & $\begin{array}{c}\text { Eumesembrinella } \\
\text { quadrilineata } \\
\text { [Musca] (Fabricius, } \\
\text { 1805) }\end{array}$ & $\begin{array}{c}\text { Eumesembrinella } \\
\text { quadrilineata } \\
\text { [Musca] (Fabricius, } \\
\text { 1805) }\end{array}$ & $\begin{array}{c}\text { Eumesembrinella } \\
\text { quadrilineata } \\
\text { [Musca] (Fabricius, } \\
\text { 1805) }\end{array}$ & $\begin{array}{c}\text { Eumesembrinella } \\
\text { quadrilineata } \\
\text { [Musca] (Fabricius, } \\
\text { 1805) }\end{array}$ & $\begin{array}{c}\text { Eumesembrinella } \\
\text { quadrilineata } \\
\text { [Musca] (Fabricius, } \\
\text { 1805) }\end{array}$ & $\begin{array}{c}\text { Mesembrinella } \\
\text { quadrilineata } \\
\text { [Musca] (Fabricius, } \\
\text { 1805) }\end{array}$ \\
\hline
\end{tabular}




\begin{tabular}{|c|c|c|c|c|c|c|}
\hline- & $\begin{array}{l}\text { Eumesembrinella } \\
\text { randa [Dexia] } \\
\text { (Walker, 1849) }\end{array}$ & $\begin{array}{l}\text { Eumesembrinella } \\
\text { randa [Dexia] } \\
\text { (Walker, 1849) }\end{array}$ & $\begin{array}{l}\text { Eumesembrinella } \\
\text { randa [Dexia] } \\
\text { (Walker, 1849) }\end{array}$ & $\begin{array}{l}\text { Eumesembrinella } \\
\text { randa [Dexia] } \\
\text { (Walker, 1849) }\end{array}$ & $\begin{array}{l}\text { Eumesembrinella } \\
\text { randa [Dexia] } \\
\text { (Walker, 1849) }\end{array}$ & $\begin{array}{l}\text { Mesembrinella } \\
\text { randa }[\text { Dexia }] \\
(\text { Walker, } 1849)\end{array}$ \\
\hline- & - & - & - & - & - & $\begin{array}{c}\text { Mesembrinella } \\
\text { bolivar comb. } \mathbf{n} . \\
\text { [Giovanella] } \\
\text { (Bonatto \& } \\
\text { Marinoni, 2005) }\end{array}$ \\
\hline- & - & - & - & - & - & $\begin{array}{l}\text { Mesembrinella } \\
\text { carvalhoi comb. n. } \\
\text { [Giovanella] (Wolff } \\
\text { et al., 2013) }\end{array}$ \\
\hline $\begin{array}{c}\text { Huascaromusca } \\
\text { spicata (Aldrich, } \\
\text { 1922) }\end{array}$ & - & - & $\begin{array}{c}\text { Mesembrinella } \\
\text { spicata (Aldrich, } \\
1922 \text { ) }\end{array}$ & - & $\begin{array}{c}\text { Henriquella spicata } \\
\text { [Mesembrinella] } \\
\text { (Aldrich, 1922) }\end{array}$ & $\begin{array}{c}\text { Mesembrinella } \\
\text { spicata (Aldrich, } \\
\text { 1922) }\end{array}$ \\
\hline- & $\begin{array}{c}\text { Huascaromusca } \\
\text { aeneiventris } \\
{[\text { Dexia }]} \\
\text { (Wiedemann, 1830) }\end{array}$ & $\begin{array}{c}\text { Huascaromusca } \\
\text { aeneiventris } \\
{[\text { Dexia }]} \\
\text { (Wiedemann, 1830) }\end{array}$ & $\begin{array}{c}\text { Huascaromusca } \\
\text { aeneiventris [Dexia] } \\
\text { (Wiedemann, 1830) }\end{array}$ & $\begin{array}{c}\text { Huascaromusca } \\
\text { aeneiventris }[\text { Dexia] } \\
\text { (Wiedemann, 1830) }\end{array}$ & $\begin{array}{c}\text { Huascaromusca } \\
\text { aeneiventris }[\text { Dexia] } \\
\text { (Wiedemann, 1830) }\end{array}$ & $\begin{array}{c}\text { Mesembrinella } \\
\text { aeneiventris [Dexia] } \\
\text { (Wiedemann, 1830) }\end{array}$ \\
\hline- & - & - & $\begin{array}{c}\text { Huascaromusca } \\
\text { bequaerti } \\
{[\text { Mesembrinella }]} \\
\text { (Séguy, 1925) }\end{array}$ & $\begin{array}{l}\text { Huascaromusca } \\
\text { bequaerti } \\
\text { [Mesembrinella] } \\
\text { (Séguy, 1925) }\end{array}$ & $\begin{array}{l}\text { Huascaromusca } \\
\text { bequaerti } \\
\text { [Mesembrinella] } \\
\text { (Séguy, 1925) }\end{array}$ & $\begin{array}{c}\text { Mesembrinella } \\
\text { bequaerti (Séguy, } \\
1925)\end{array}$ \\
\hline- & - & - & $\begin{array}{c}\text { Huascaromusca } \\
\text { decrepita } \\
{[\text { Mesembrinella }]} \\
\text { (Séguy, 1925) }\end{array}$ & $\begin{array}{l}\text { Huascaromusca } \\
\text { decrepita } \\
{[\text { Mesembrinella }]} \\
\text { (Séguy, 1925) }\end{array}$ & $\begin{array}{l}\text { Huascaromusca } \\
\text { decrepita } \\
{[\text { Mesembrinella }]} \\
\text { (Séguy, 1925) }\end{array}$ & $\begin{array}{c}\text { Mesembrinella } \\
\text { decrepita Séguy, } \\
1925\end{array}$ \\
\hline
\end{tabular}




\begin{tabular}{|c|c|c|c|c|c|c|}
\hline- & - & - & - & - & - & $\begin{array}{c}\text { Mesembrinella lara } \\
\text { comb. n. } \\
{[\text { Huascaromusca] }} \\
\text { (Bonatto \& } \\
\text { Marinoni, 2005) }\end{array}$ \\
\hline- & $\begin{array}{c}\text { Huascaromusca } \\
\text { nigrifrons } \\
\text { [Mesembrinella] } \\
\text { (Aldrich, 1922) }\end{array}$ & - & $\begin{array}{c}\text { Huascaromusca } \\
\text { purpurata } \\
{[\text { Mesembrinella] }} \\
\text { (Aldrich, 1922) }\end{array}$ & $\begin{array}{c}\text { Huascaromusca } \\
\text { purpurata } \\
{[\text { Mesembrinella }]} \\
\text { (Aldrich, 1922) }\end{array}$ & $\begin{array}{c}\text { Huascaromusca } \\
\text { purpurata } \\
\text { [Mesembrinella] } \\
\text { (Aldrich, 1922) }\end{array}$ & $\begin{array}{c}\text { Mesembrinella } \\
\text { purpurata Aldrich, } \\
1922\end{array}$ \\
\hline $\begin{array}{c}\text { Promesembrinella } \\
\text { semiflava } \\
{[\text { Mesembrinella }]} \\
\text { (Aldrich, 1925) }\end{array}$ & $\begin{array}{c}\text { Huascaromusca } \\
\text { semiflava } \\
{[\text { Mesembrinella }]} \\
\text { (Aldrich, 1925) }\end{array}$ & $\begin{array}{c}\text { Huascaromusca } \\
\text { semiflava } \\
{[\text { Mesembrinella }]} \\
\text { (Aldrich, 1925) }\end{array}$ & $\begin{array}{c}\text { Huascaromusca } \\
\text { semiflava } \\
{[\text { Mesembrinella }]} \\
\text { (Aldrich, 1925) }\end{array}$ & $\begin{array}{c}\text { Huascaromusca } \\
\text { semiflava } \\
{[\text { Mesembrinella }]} \\
\text { (Aldrich, 1925) }\end{array}$ & $\begin{array}{c}\text { Huascaromusca } \\
\text { semiflava } \\
{[\text { Mesembrinella }]} \\
\text { (Aldrich, 1925) }\end{array}$ & $\begin{array}{c}\text { Mesembrinella } \\
\text { semiflava (Aldrich, } \\
\text { 1925) }\end{array}$ \\
\hline $\begin{array}{c}\text { Huascaromusca } \\
\text { uniseta } \\
{[\text { Mesembrinella }]} \\
\text { (Aldrich, 1925) }\end{array}$ & $\begin{array}{c}\text { Huascaromusca } \\
\text { uniseta } \\
{[\text { Mesembrinella }]} \\
\text { (Aldrich, 1925) }\end{array}$ & $\begin{array}{c}\text { Huascaromusca } \\
\text { uniseta } \\
{[\text { Mesembrinella }]} \\
\text { (Aldrich, 1925) }\end{array}$ & $\begin{array}{c}\text { Huascaromusca } \\
\text { uniseta } \\
{[\text { Mesembrinella }]} \\
\text { (Aldrich, 1925) }\end{array}$ & $\begin{array}{c}\text { Huascaromusca } \\
\text { uniseta } \\
{[\text { Mesembrinella }]} \\
\text { (Aldrich, 1925) }\end{array}$ & $\begin{array}{c}\text { Huascaromusca } \\
\text { uniseta } \\
{[\text { Mesembrinella }]} \\
\text { (Aldrich, 1925) }\end{array}$ & $\begin{array}{l}\text { Mesembrinella } \\
\text { uniseta Aldrich, } \\
1925\end{array}$ \\
\hline - & $\begin{array}{c}\text { Huascaromusca } \\
\text { vogelsangi Mello, } \\
1967\end{array}$ & $\begin{array}{c}\text { Huascaromusca } \\
\text { vogelsangi Mello, } \\
1967\end{array}$ & $\begin{array}{c}\text { Huascaromusca } \\
\text { vogelsangi Mello, } \\
1967\end{array}$ & $\begin{array}{c}\text { Huascaromusca } \\
\text { vogelsangi Mello, } \\
1967\end{array}$ & $\begin{array}{c}\text { Huascaromusca } \\
\text { vogelsangi Mello, } \\
1967\end{array}$ & $\begin{array}{c}\text { Mesembrinella } \\
\text { vogelsangi comb. } \\
\text { n. } \\
{[\text { Huascaromusca }]} \\
\text { (Mello, 1967) }\end{array}$ \\
\hline- & - & - & $\begin{array}{l}\text { Laneella nigripes } \\
\text { Guimarães, } 1977\end{array}$ & $\begin{array}{l}\text { Laneella nigripes } \\
\text { Guimarães, } 1977\end{array}$ & $\begin{array}{l}\text { Laneella nigripes } \\
\text { Guimarães, } 1977\end{array}$ & $\begin{array}{c}\text { Mesembrinella } \\
\text { nigripes comb. n. } \\
{[\text { Laneella }]} \\
\text { (Guimarães, 1977) }\end{array}$ \\
\hline - & - & - & - & $\begin{array}{c}\text { Mesembrinella } \\
\text { perisi Mariluis, } \\
1987\end{array}$ & $\begin{array}{l}\text { Laneella perisi } \\
\text { comb. n. } \\
\text { [Mesembrinella] } \\
\text { (Mariluis, 1987) }\end{array}$ & $\begin{array}{c}\text { Mesembrinella } \\
\text { perisi Mariluis, } \\
1987\end{array}$ \\
\hline
\end{tabular}




\begin{tabular}{|c|c|c|c|c|c|c|}
\hline $\begin{array}{l}\text { Huascaromusca } \\
\text { abaca Hall, } 1948\end{array}$ & $\begin{array}{c}\text { Mesembrinella } \\
\text { abaca } \\
\text { [Huascaromusca }] \\
\text { (Hall, 1948) }\end{array}$ & $\begin{array}{c}\text { Mesembrinella } \\
\text { abaca } \\
\text { [Huascaromusca }] \\
\text { (Hall, 1948) }\end{array}$ & $\begin{array}{c}\text { Mesembrinella } \\
\text { abaca } \\
{[\text { Huascaromusca }]} \\
\text { (Hall, 1948) }\end{array}$ & $\begin{array}{c}\text { Mesembrinella } \\
\text { abaca } \\
\text { [Huascaromusca }] \\
\text { (Hall, 1948) }\end{array}$ & $\begin{array}{c}\text { Mesembrinella } \\
\text { abaca } \\
\text { [Huascaromusca }] \\
\text { (Hall, 1948) }\end{array}$ & $\begin{array}{c}\text { Mesembrinella } \\
\text { abaca } \\
{[\text { Huascaromusca }]} \\
\text { (Hall, 1948) }\end{array}$ \\
\hline - & $\begin{array}{c}\text { Mesembrinella } \\
\text { apollinaris Séguy, } \\
1925\end{array}$ & $\begin{array}{c}\text { Mesembrinella } \\
\text { apollinaris Séguy, } \\
1925\end{array}$ & $\begin{array}{c}\text { Mesembrinella } \\
\text { apollinaris Séguy, } \\
1925\end{array}$ & $\begin{array}{c}\text { Mesembrinella } \\
\text { apollinaris Séguy, } \\
1925\end{array}$ & $\begin{array}{c}\text { Mesembrinella } \\
\text { apollinaris Séguy, } \\
1925\end{array}$ & $\begin{array}{c}\text { Mesembrinella } \\
\text { apollinaris Séguy, } \\
1925\end{array}$ \\
\hline $\begin{array}{l}\text { Mesembrinella } \\
\text { batesi Aldrich, } \\
1922\end{array}$ & $\begin{array}{l}\text { Mesembrinella } \\
\text { batesi Aldrich, } \\
1922\end{array}$ & $\begin{array}{c}\text { Mesembrinella } \\
\text { batesi Aldrich, } \\
1922\end{array}$ & $\begin{array}{c}\text { Mesembrinella } \\
\text { batesi Aldrich, } 1922\end{array}$ & $\begin{array}{c}\text { Mesembrinella } \\
\text { batesi Aldrich, } 1922\end{array}$ & $\begin{array}{c}\text { Mesembrinella } \\
\text { batesi Aldrich, } 1922\end{array}$ & $\begin{array}{c}\text { Mesembrinella } \\
\text { batesi Aldrich, } 1922\end{array}$ \\
\hline $\begin{array}{l}\text { Mesembrinella } \\
\text { bellardiana } \\
\text { Aldrich, } 1922\end{array}$ & $\begin{array}{l}\text { Mesembrinella } \\
\text { bellardiana } \\
\text { Aldrich, } 1922\end{array}$ & $\begin{array}{l}\text { Mesembrinella } \\
\text { bellardiana } \\
\text { Aldrich, } 1922\end{array}$ & $\begin{array}{c}\text { Mesembrinella } \\
\text { bellardiana Aldrich, } \\
1922\end{array}$ & $\begin{array}{c}\text { Mesembrinella } \\
\text { bellardiana Aldrich, } \\
1922\end{array}$ & $\begin{array}{c}\text { Mesembrinella } \\
\text { bellardiana Aldrich, } \\
1922\end{array}$ & $\begin{array}{l}\text { Mesembrinella } \\
\text { bellardiana } \\
\text { Aldrich, } 1922\end{array}$ \\
\hline $\begin{array}{l}\text { Huascaromusca } \\
\text { bicolor }[\text { Musca] } \\
\text { (Fabricius, 1805) }\end{array}$ & $\begin{array}{l}\text { Mesembrinella } \\
\text { bicolor }[\text { Musca }] \\
\text { (Fabricius, 1805) }\end{array}$ & $\begin{array}{l}\text { Mesembrinella } \\
\text { bicolor }[\text { Musca] } \\
\text { (Fabricius, 1805) }\end{array}$ & $\begin{array}{l}\text { Mesembrinella } \\
\text { bicolor }[\text { Musca] } \\
\text { (Fabricius, 1805) }\end{array}$ & $\begin{array}{l}\text { Mesembrinella } \\
\text { bicolor }[\text { Musca] } \\
\text { (Fabricius, 1805) }\end{array}$ & $\begin{array}{l}\text { Mesembrinella } \\
\text { bicolor }[\text { Musca] } \\
\text { (Fabricius, 1805) }\end{array}$ & $\begin{array}{l}\text { Mesembrinella } \\
\text { bicolor }[\text { Musca }] \\
\text { (Fabricius, 1805) }\end{array}$ \\
\hline - & $\begin{array}{c}\text { Laneella } \\
\text { brunnipesSurcouf, } \\
1919\end{array}$ & $\begin{array}{c}\text { Mesembrinella } \\
\text { brunnipes Surcouf, } \\
1919\end{array}$ & $\begin{array}{c}\text { Mesembrinella } \\
\text { brunnipes Surcouf, } \\
1919\end{array}$ & $\begin{array}{c}\text { Mesembrinella } \\
\text { brunnipes Surcouf, } \\
1919\end{array}$ & $\begin{array}{c}\text { Mesembrinella } \\
\text { brunnipes Surcouf, } \\
1919\end{array}$ & $\begin{array}{c}\text { Mesembrinella } \\
\text { brunnipes } \text { Surcouf, } \\
1919\end{array}$ \\
\hline- & - & - & $\begin{array}{c}\text { Mesembrinella } \\
\text { currani Guimarães, } \\
1977\end{array}$ & $\begin{array}{c}\text { Mesembrinella } \\
\text { currani Guimarães, } \\
1977\end{array}$ & $\begin{array}{c}\text { Mesembrinella } \\
\text { currani Guimarães, } \\
1977\end{array}$ & $\begin{array}{c}\text { Mesembrinella } \\
\text { currani Guimarães, } \\
1977\end{array}$ \\
\hline - & - & $\begin{array}{c}\text { Mesembrinella } \\
\text { flavicrura Aldrich, } \\
1925\end{array}$ & $\begin{array}{c}\text { Mesembrinella } \\
\text { flavicrura Aldrich, } \\
1925\end{array}$ & - & $\begin{array}{c}\text { Huascaromusca } \\
\text { flavicrura } \\
\text { [Mesembrinella] } \\
\text { (Aldrich, 1925) }\end{array}$ & $\begin{array}{c}\text { Mesembrinella } \\
\text { flavicrura Aldrich, } \\
1925\end{array}$ \\
\hline $\begin{array}{c}\text { Mesembrinella } \\
\text { peregrina Aldrich, } \\
1922\end{array}$ & $\begin{array}{c}\text { Mesembrinella } \\
\text { peregrina Aldrich, } \\
1922\end{array}$ & $\begin{array}{c}\text { Mesembrinella } \\
\text { peregrina Aldrich, } \\
1922\end{array}$ & $\begin{array}{c}\text { Mesembrinella } \\
\text { peregrina Aldrich, } \\
1922\end{array}$ & $\begin{array}{c}\text { Mesembrinella } \\
\text { peregrina Aldrich, } \\
1922\end{array}$ & $\begin{array}{c}\text { Mesembrinella } \\
\text { peregrina Aldrich, } \\
1922\end{array}$ & $\begin{array}{c}\text { Mesembrinella } \\
\text { peregrina Aldrich, } \\
1922\end{array}$ \\
\hline $\begin{array}{c}\text { Mesembrinella } \\
\text { pictipennis Aldrich, } \\
1922\end{array}$ & $\begin{array}{c}\text { Mesembrinella } \\
\text { pictipennis Aldrich, } \\
1922\end{array}$ & $\begin{array}{c}\text { Mesembrinella } \\
\text { pictipennis Aldrich, } \\
1922\end{array}$ & $\begin{array}{c}\text { Mesembrinella } \\
\text { pictipennis Aldrich, } \\
1922\end{array}$ & $\begin{array}{c}\text { Mesembrinella } \\
\text { pictipennis Aldrich, } \\
1922\end{array}$ & $\begin{array}{c}\text { Mesembrinella } \\
\text { pictipennis Aldrich, } \\
1922\end{array}$ & $\begin{array}{c}\text { Mesembrinella } \\
\text { pictipennis Aldrich, } \\
1922\end{array}$ \\
\hline
\end{tabular}




\begin{tabular}{|c|c|c|c|c|c|c|}
\hline & & & & & & $\begin{array}{l}\text { Mesembrinella } \\
\text { patriciae Wolff, } \\
2013\end{array}$ \\
\hline- & $\begin{array}{c}\text { Mesembrinella } \\
\text { semyhialina Mello, } \\
1967\end{array}$ & $\begin{array}{c}\text { Mesembrinella } \\
\text { semyhialina Mello, } \\
1967\end{array}$ & $\begin{array}{c}\text { Mesembrinella } \\
\text { semyhialina Mello, } \\
1967\end{array}$ & $\begin{array}{c}\text { Mesembrinella } \\
\text { semyhialina Mello, } \\
1967\end{array}$ & $\begin{array}{c}\text { Mesembrinella } \\
\text { abaca } \\
{[\text { Huascaromusca }]} \\
\text { (Hall, 1948) }\end{array}$ & $\begin{array}{c}\text { Mesembrinella } \\
\text { semyhialina Mello, } \\
1967\end{array}$ \\
\hline- & - & - & $\begin{array}{c}\text { Mesembrinella } \\
\text { townsendi } \\
\text { Guimarães, } 1977\end{array}$ & $\begin{array}{c}\text { Mesembrinella } \\
\text { townsendi } \\
\text { Guimarães, } 1977\end{array}$ & $\begin{array}{c}\text { Mesembrinella } \\
\text { townsendi } \\
\text { Guimarães, } 1977\end{array}$ & $\begin{array}{c}\text { Mesembrinella } \\
\text { townsendi } \\
\text { Guimarães, } 1977\end{array}$ \\
\hline $\begin{array}{c}\text { Huascaromusca } \\
\text { umbrosa } \\
\text { [Mesembrinella] } \\
\text { (Aldrich, 1922) }\end{array}$ & $\begin{array}{l}\text { Mesembrinella } \\
\text { umbrosa Aldrich, } \\
1922\end{array}$ & $\begin{array}{c}\text { Mesembrinella } \\
\text { umbrosa Aldrich, } \\
1922\end{array}$ & $\begin{array}{c}\text { Mesembrinella } \\
\text { umbrosa Aldrich, } \\
1922\end{array}$ & $\begin{array}{c}\text { Mesembrinella } \\
\text { umbrosa Aldrich, } \\
1922\end{array}$ & $\begin{array}{c}\text { Mesembrinella } \\
\text { umbrosa Aldrich, } \\
1922\end{array}$ & $\begin{array}{c}\text { Mesembrinella } \\
\text { umbrosa Aldrich, } \\
1922\end{array}$ \\
\hline- & - & - & $\begin{array}{c}\text { Mesembrinella } \\
\text { xanthorrhina } \\
\text { [Calliphora] (Bigot, } \\
\text { 1887) }\end{array}$ & $\begin{array}{c}\text { Mesembrinella } \\
\text { xanthorrhina } \\
\text { [Calliphora] (Bigot, } \\
\text { 1887) }\end{array}$ & $\begin{array}{c}\text { Huascaromusca } \\
\text { xanthorrhina } \\
\text { [Calliphora] (Bigot, } \\
\text { 1887) }\end{array}$ & $\begin{array}{c}\text { Mesembrinella } \\
\text { xanthorrhina } \\
\text { [Calliphora] (Bigot, } \\
\text { 1887) }\end{array}$ \\
\hline $\begin{array}{l}\text { Huascaromusca } \\
\text { facialis Aldrich, } \\
1922\end{array}$ & $\begin{array}{c}\text { Mesembrinella } \\
\text { facialis Aldrich, } \\
1922\end{array}$ & $\begin{array}{c}\text { Mesembrinella } \\
\text { facialis Aldrich, } \\
1922\end{array}$ & $\begin{array}{l}\text { Souzalopesiella } \\
\text { facialis } \\
{[\text { Mesembrinella] }} \\
\text { (Aldrich, 1922) }\end{array}$ & $\begin{array}{l}\text { Souzalopesiella } \\
\text { facialis } \\
\text { [Mesembrinella] } \\
\text { (Aldrich, 1922) }\end{array}$ & $\begin{array}{l}\text { Souzalopesiella } \\
\text { facialis } \\
\text { [Mesembrinella] } \\
\text { (Aldrich, 1922) }\end{array}$ & $\begin{array}{c}\text { Mesembrinella } \\
\text { facialis Aldrich, } \\
1922\end{array}$ \\
\hline- & - & - & $\begin{array}{c}\text { Thompsoniella } \\
\text { anomala } \\
\text { Guimarães, } 1977\end{array}$ & $\begin{array}{c}\text { Thompsoniella } \\
\text { anomala } \\
\text { Guimarães, } 1977\end{array}$ & $\begin{array}{c}\text { Thompsoniella } \\
\text { anomala } \\
\text { Guimarães, } 1977\end{array}$ & $\begin{array}{c}\text { Mesembrinella } \\
\text { anomala comb. n. } \\
\text { [Thompsoniella] } \\
\text { (Guimarães, 1977) }\end{array}$ \\
\hline
\end{tabular}




\subsubsection{Caracteres morfológicos}

Foram construídos 120 caracteres morfológicos, listados e comentados abaixo. Os 6 caracteres autapomórficos e, portanto, não-informativos $(95,97,105,106$, 118 e 119) foram mantidos somente como um registro das características exclusivas dos terminais que os possuem, não tendo agregado valor filogenético à análise.

\section{Cabeca}

1. Macho, vita frontal, condição (Toma \& Carvalho, 1995; Bonatto, 2001) (L=13; CI=7; $\mathrm{RI}=55)$.

0 - Obliterada (Fig. 6)

1 - Não obliterada (Figs. 8 e 10)

A maioria das espécies de Calliphoridae apresentam a vita frontal parcial ou totalmente obliterada (Brown et al., 2009). Mesembrinellidae, em sua maioria, também têm essa condição, com exceção de Mesembrinella latifrons comb. n., Mesembrinella quadrilineata, Mesembrinella spicata, Mesembrinella aeneiventris, Mesembrinella bequaerti comb. n., Mesembrinella decrepita, Mesembrinella uniseta , Mesembrinella xanthorrhina e Mesembrinella anomala comb. $\boldsymbol{n}$.

2. Macho, distância entre os olhos na porção mais estreita em relação à largura do ocelo anterior, se vita frontal obliterada $(\mathrm{L}=4 ; \mathrm{CI}=25 ; \mathrm{R}=57)$.

0 - Menor ou igual (Fig. 6)

1 - No mínimo o dobro (Fig. 7)

Foi observada uma variação grande na distância entre os olhos do macho, quando a vita frontal está obliterada. Em algumas espécies, os olhos estão muito próximos, quase se tocando, de modo que a fonte também está quase totalmente obliterada, enquanto em outras a fronte é bastante larga. Para se ter um parâmetro de 
comparação, foi utilizado o tamanho do ocelo em relação à distância entre os olhos. Para os terminais cuja vita frontal não é obliterada, esse caráter foi considerado inaplicável.

\section{Macho, distância entre os olhos na porção mais estreita em relação à distância entre os olhos da fêmea, se vita frontal não obliterada ( $L=4$; $\mathrm{CI}=25 ; \mathrm{RI}=70)$.}

0 - Menor (Fig. 10)

1 - Aproximadamente igual (Fig. 8)

Quando o macho não possui a vita frontal obliterada, foi constatado que em algumas espécies a distância entre os outros é menor que a da fêmea, sendo possível a diferenciação entre os sexos com bastante facilidade. Esse estado foi observado em algumas espécies de Mesembrinellidae e de alguns terminais do grupo externo, porém se mostrou homoplástico na análise final. No estado 1, por sua vez, a distância entre os olhos do macho é praticamente igual à das fêmeas, sendo difícil diferenciar os dois sexos, sem utilizar a terminália como fonte de comparação. Em Mesembrinellidae, somente Mesembrinella latifrons comb. n. possui essa condição. Essa espécie era considerada um gênero monotípico (Albuquerquea latifrons sensu Mello, 1967), cuja monofilia foi postulado por Toma \& Carvalho (1995) pela condição dicóptica e a presença de cerdas interfrontais, no macho (Caráter 6). Para os terminais cuja vita frontal é obliterada, esse caráter foi considerado inaplicável.

4. Macho, cerdas ocelares, grau de desenvolvimento ( $\mathrm{L}=13 ; \mathrm{CI}=7 ; \mathrm{RI}=25)$.

0 - Reduzidas, finas e fracas

1 - Desenvolvidas, fortes

A maioria dos terminais utilizados nessa análise possuem as cerdas ocelares fortes. No entanto, em algumas espécies de Mesembrinellidae, bem como terminais do grupo externo, essas cerdas são bastante reduzidas e em alguns casos, praticamente vestigiais. 
5. Macho, cerdas ocelares, tamanho em relação ao triângulo ocelar, se desenvolvidas $(\mathrm{L}=2 ; \mathrm{CI}=50 ; \mathrm{RI}=83)$.

0 - Curtas, não mais que o dobro

1 - Muito longas, mais que o triplo (Fig. 17)

Nas espécies Mesembrinella latifrons comb. n., Mesembrinella uniseta, Mesembrinella decrepita, Mesembrinella aeneiventris, Mesembrinella spicata e Mesembrinella flavicrura, as cerdas ocelares são bastante mais longas do que nas demais espécies, em que essas cerdas são também desenvolvidas. Para os terminais cujas cerdas ocelares são reduzidas, esse caráter foi considerado inaplicável.

6. Macho, cerdas interfrontais cruzadas (Toma \& Carvalho, 1995; Bonatto, 2001) ( $\mathrm{L}=2 ; \mathrm{CI}=0 ; \mathrm{RI}=50)$.

0 - Ausentes

1 - Presentes (Fig. 8)

Somente o macho das espécies Mesembrinella latifrons comb. n. e Peckia intermutans possuem cerdas interfrontais cruzadas.

7. Fêmea, cerdas interfrontais cruzadas (Rognes, 1991) (L=2; CI=50; RI=96).

0 - Ausentes

1 - Presentes (Fig. 9)

Rognes (1997) comenta que a presença de cerdas interfrontais cruzadas na fêmea é uma possível sinapomorfia de Mesembrinellinae, condição também encontrada no plano basal de Anthomyiidae e Muscidae. De fato, todas as espécies de Mesembrinellidae na presente análise foram codificadas com o estado 1. Porém, somente 
a espécie de Muscidae Polietina flavithorax possui esse estado, sendo o estado 0 encontrado para Phaonia advena.

8. Fêmea, cerdas orbitais proclinadas (Bonatto, 2001) ( $\mathrm{L}=9 ; \mathrm{CI}=11 ; \mathrm{RI}=50)$.

0 - Ausentes

1 - Presentes (Fig. 11)

A presença de cerdas orbitais proclinadas nas fêmeas é maioria dentre os terminais analisado no presente estudo. Algumas espécies de Mesembrinellidae, além dos terminais de Muscidae, alguns Tachinidae e alguns Calliphoridae, possuem o estado 0.

9. Fêmea, cerdas orbitais proclinadas, número, se presentes (L=3; CI=33; RI=33).

0 - Duas

1 - Uma (Fig. 11)

Dentre os terminais cuja fêmea possui cerdas orbitais proclinadas, a maioria deles apresenta duas dessas cerdas, sendo que somente Mesembrinella lara comb. n., M.. uniseta, M. semiflava e Auchmeromyia bequaerti possuem apenas uma orbital proclinada.

10. Parafaciália, sétulas (Rognes, 1997) (L=9; CI=11; RI=38).

0 - Ausentes

1 - Presentes (Fig. 14)

Em Mesembrinellidae, a parafaciália não possui sétulas. O estado 1 foi codificado para alguns terminais do grupo externo. Rognes (1991) cita esse caráter como um dos definidores da subfamília de Luciliinae, mas que em Calliphorinae ao menos a porção superior é setosa. Ambas subfamílias aqui foram codificadas com o estado 1. 
11. Carena facial (Rognes, 1997; Bonatto, 2001) ( $\mathrm{L}=4$; $\mathrm{CI}=50 ; \mathrm{RI}=33)$.

0 - Fraca ou ausente (Fig. 10)

1 - Moderada

2 - Forte e proeminente (Fig. 12)

A maioria das espécies foram codificadas com o estado 0 , sendo que somente para Pollenia rudis e Idiella mandarina foi considerada a condição moderada da carena facial, e em Prophorostoma pulchra e as duas espécies de Amenia foi codificado o estado 2.

12. Vibrissa $(\mathrm{L}=2 ; \mathrm{CI}=50 ; \mathrm{RI}=66)$.

0 - Ausente

1 - Presente (Fig. 8)

Somente as espécies de Phasiinae Ectophasia crassipenis, Gymnosoma rotundatum e Phasia hemiptera, além de Cuterebra apicalis, não possuem vibrissa.

13. Subvibrissa quase tão longa e robusta quanto a vibrissa $(L=5 ; C I=20 ; R I=84)$.

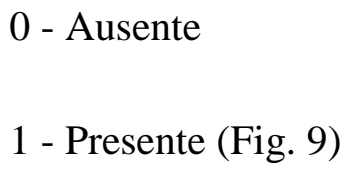

A maioria das espécies de Mesembrinellidae possuem uma única subvibrissa quase tão longa e robusta quanto à vibrissa, além de outras subvibrissas menores. As espécies codificadas com o estado 0 possuem subvibrissas, mas menos desenvolvidas que a vibrissa, sem que nenhuma delas se destaque das demais. 
14. Antena, posição relativa à altura do olho, vista lateral $(L=5 ; C I=20 ; R I=80)$.

0 - Abaixo da metade (Fig. 15)

1 - Acima da metade (Fig. 17)

15. Antena, flagelômero, tamanho (L=7; $\mathrm{CI}=14 ; \mathrm{RI} ; 77)$.

0 - Curto, no máximo três vezes mais longo que largo (Fig. 13)

1 - Longo, mais de quatro vezes mais longo que largo (Fig. 7)

16. Pedicelo, comprimento em relação ao primeiro flagelômero ( $\mathrm{L}=7$; $\mathrm{CI} 14$; $\mathrm{RI}=68)$.

0 - Menos da metade (Fig. 8)

1 - Mais da metade (Fig. 13)

17. Gena, tamanho relativo ao olho, vista lateral $(\mathrm{L}=5 ; \mathrm{CI}=20 ; \mathrm{RI}=66)$.

0 - Menor que um terço (Fig. 16)

1 - Maior que um terço (Fig. 15)

O estado 0 foi codificado para todos os mesembrinelideos, Phumosia promittens, Auchmeromyia bequaerti, Bengalia emarginata, taquinídeos exceto Prophorostoma pulchra, sarcofagídeos, mucídios e Fannia heydenii. Os demais terminais apresentes uma gena bastante grande, sendo maior que um terço do tamanho do olho.

18. Parafaciália, espessura em relação à crista facial na porção mais larga $(L=6$; $\mathrm{CI}=16 ; \mathrm{RI}=84)$.

0 - Maior (Fig. 11) 
1 - Menor (Fig. 9)

Foi observado que o tamanho da parafaciália variava bastante entre diversas espécies do grupo interno e externo. Como uma medida de comparação, foi utilizada a espessura da crista facial, que pode ser menor ou do mesmo tamanho da parafaciália. Esse caráter se mostrou bastante homoplástico. O estado 0 foi codificado para a maioria dos terminais, enquanto o estado 1 esteve presente em algumas espécies de Mesembrinellidae, e em algumas espécies de maneira espalhada no grupo externo.

19. Crista facial, cerdas, cor $(\mathrm{L}=3 ; \mathrm{CI}=66 ; \mathrm{RI}=75)$.

0 - Castanho-escuras (Fig. 8)

1 - Amarelo a douradas (Fig. 11)

2 - Avermelhadas (Fig. 13)

Na maioria das espécies, as cerdas da crista facial são castanho escuras. Entretando, somente em Mesembrinella latifrons comb. n. e Cuterebra apicalis essas cerdas são amareladas e no grupo formado por Mesembrinella umbrosa, M. pictipennis, M. apollinaris e $M$. currani essas cerdas são avermelhadas.

20. Palpo, cor $(\mathrm{L}=7 ; \mathrm{CI}=14 ; \mathrm{RI}=25)$.

0 - Amarelo a laranja (Fig. 9)

1 - Castanho médio a escuro (Fig. 14)

A maioria das espécies têm os palpos amarelados a alaranjados (estado 0). O estado 1 foi codificado para Mesembrinella nigripes comb. n. e Mesembrinella apollinaris, além de alguns poucos terminais do grupo externo.

21. Antena, $\operatorname{cor}(\mathrm{L}=10 ; \mathrm{CI}=10 ; \mathrm{RI}=57)$. 
0 - Amarelo a laranja (Fig. 6)

1 - Castanho médio a escuro (Fig. 14)

Assim como no caráter anterior, a coloração da antena é amarela a alaranjada na maioria dos terminais da presente análise. Dentro do grupo interno, somente Mesembrinella nigripes comb. n. e Mesembrinella apollinaris possuem antena de coloração mais escura, porém essas espécies não estão relacionadas, o que sugere uma aparição independente da coloração dos palpos (Caráter 20) e da antena mais escurecidos na evolução de Mesembrinellidae.

\section{Tórax}

22. Escutelo, porção inferior, sétulas eretas ( $L=4 ; \mathrm{CI}=35 ; \mathrm{RI}=76)$.

0 - Ausentes

1 - Presentes (Fig. 18)

Brown et al. (2009) citam esse caráter como uma característica da então família Mesembrinellidae. No entanto, outras espécies de califorídeos também apresentam sétulas eretas na região inferior do escutelo, mas em uma conformação diferente (Caráter 23).

23. Escutelo, porção inferior, sétulas eretas, disposição, se presentes ( $L=1 ; C I=100$; $\mathrm{RI}=100)$.

0 - Concentradas nas laterais

1 - Homogeneamente distribuídas (Fig. 18)

Todas Mesembrinellidae foram codificadas com o estado 1 e as demais espécies cujas sétulas eretas na porção inferior do escutelo estão presentes, com o estado 0. A única exceção a essa codificação é Strongyloneura nebulosa, que assim como as espécies de Mesembrinellidae, também apresentam essas sétulas por toda a porção 
inferior do escutelo. Para as demais espécies, cujas sétulas estão ausentes, esse caráter foi considerado inaplicável.

24. Cerdas humerais, número (Rognes, 1997; Bonatto, 2001) (L=15; CI=13; RI=51).

0 - Duas

1 - Três (Fig. 19)

2 - De três a cinco

Guimarães (1977) divide Mesembrinellidae em diferentes subfamílias, tribos e subtribos. O gênero Mesembrinella, exclusivo da tribo Mesembrinellini, é caracterizado da seguinte maneira: "Calo humeral [úmero] com três cerdas distinguíveis, 2 ou 3 esternopleurais [catepisternais], Remígio [veia tronco] nu ou com cerdas”. A tribo Eumesembrinellini, composta pelos gêneros Albuquerquea, Thompsoniella, Huascaromusca e Eumesembrinella, eram caracterizados pela presença de duas cerdas humerais. No entanto, essa caracterização não está correta, pois o número de cerdas humerais varia entre as espécies de Mesembrinellidae não formando nenhum agrupamento. $\mathrm{O}$ estado 2 foi criado para alguns terminais do grupo externo que possuem uma condição bastante variável de cerdas humerais.

25. Cerdas pós-humerais $(\mathrm{L}=3 ; \mathrm{CI}=33 ; \mathrm{RI}=33)$.

\author{
0 - Ausentes \\ 1 - Presentes (Fig. 19)
}

As cerdas pós-humerais são formadas pela primeira cerda pré-sutural supralar e as duas primeiras cerdas pré-sututais intralares na terminologia de Mcalpine (1981). Estão presentes para quase todos os terminais da presente análise, exceto em Phasiinae e Cuterebra apicalis. 
26. Cerdas pós-humerais, número, se presentes ( $\mathrm{L}=18 ; \mathrm{CI}=11 ; \mathrm{RI}=54)$.

0 - Uma

1 - Duas

2 - Três (Fig. 19)

O número de cerdas pós-humerais se mostrou bastante homoplástico ao longo do cladograma obtido na presente análise.

27. Cerda pós-humeral externa, disposição em relação à pré-sutural, se presente (Pape, 1992; Rognes, 1997) (L=4; CI=25; RI=62).

0 - Em linha ou mais internamente posicionada (Fig. 20)

1 - Mais externamente posicionada (Fig. 19)

Rognes (1991) é o primeiro a citar a importância desse caráter, afirmando que em um primeiro momento o estado 1 poderia ser uma condição exclusiva de Calliphoridae. No entanto, ao analisá-lo melhor, o autor constatou que não é uma condição homogênea dentro da família. Para todas as espécies de Mesembrinellidae e a maioria dos califorídeos utilizados como grupo externo nessa análise, a pós-humeral externa está mais externamente posicionada. Os demais terminais possuem o estado 0 . Para os terminais que não possuem cerdas pós-humerais ou que a cerda humeral externa está ausente, esse caráter foi considerado inaplicável.

28. Cerdas acrosticais pós-suturais (Toma \& Carvalho, 1995; Bonatto, 2001) (L=5; $\mathrm{CI}=20 ; \mathrm{RI}=33$ ).

0 - Ausentes

1 - Presentes (Fig. 21) 
A condição ausente das cerdas acrosticais pós-suturais é encontrada somente nas espécies Mesembrinella bolivar comb. n., Mesembrinella carvalhoi comb.n., Cuterebra apicalis e Sarconesia chlorogaster.

29. Cerdas acrosticais pós-suturais, número, se presentes (Toma \& Carvalho, 1995; Bonatto, 2001) ( $\mathrm{L}=18 ; \mathrm{CI}=16 ; \mathrm{RI}=34)$.

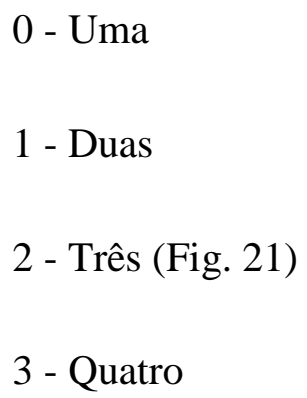

Guimarães (1977) e Toma \& Carvalho (1995) afirmam que o número típico de cerdas acrosticais para a então família Mesembrinellidae é 2:3, mas que nos antigos gêneros Eumesembrinella, Huascaromusca e Thompsoniella é 0:1. No entanto, isso não se confirma nessa análise, pois esse caráter varia bastante dentro de Mesembrinellidae.

30. Cerda intralar pré-sutural $(\mathrm{L}=7 ; \mathrm{CI}=14 ; \mathrm{RI}=77)$.

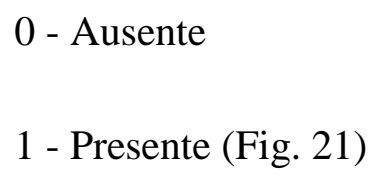

A cerda intralar pré-sutural está presente em diversas espécies do grupo externo. Dentro de Mesembrinellidae esse caráter é importante pois a ausência dessa cerda aparece como uma reversão dentro do grupo, formando o clado 13.

31. Cerdas intralares pós-suturais, número ( $\mathrm{L}=6 ; \mathrm{CI}=33 ; \mathrm{RI}=60)$.

$$
0 \text { - Uma }
$$


1 - Duas (Fig. 21)

2 - Três

32. Cerdas catepisternais, número, se presentes (Rognes, 1997) $(\mathrm{L}=14 ; \mathrm{CI}=28 ; \mathrm{RI}=64)$.

$$
\begin{aligned}
& 0-1+1 \text { (Fig. 22) } \\
& 1-2+1 \\
& 2-2+0 \\
& 3-1+0 \\
& 4-1+2 \\
& 5-0+1
\end{aligned}
$$

As cerdas catepisternais são amplamente utilizadas na literatura em trabalhos taxonômicos. No entanto, sua codificação se mostrou bastante homoplástica nessa análise, sem informação filogenética relevante.

33. Cerdas pós-alares, número $(\mathrm{L}=12 ; \mathrm{CI}=16 ; \mathrm{RI}=68)$.

$$
\begin{aligned}
& 0 \text { - Uma } \\
& 1 \text { - Duas } \\
& 2 \text { - Três (Fig. 23) }
\end{aligned}
$$

34. Cerda escutelar subapical $(\mathrm{L}=1 ; \mathrm{CI}=100 ; \mathrm{RI}=100)$.

$$
\begin{aligned}
& 0 \text { - Ausente } \\
& 1 \text { - Presente (Fig. 24) }
\end{aligned}
$$


35. Cerdas escutelares apicais, posição relativa $(\mathrm{L}=8 ; \mathrm{CI}=12 ; \mathrm{RI}=41)$.

0 - Paralelas (Fig. 24)

1 - Convergentes (Fig. 25)

36. Cerdas no méron (Pape, 1992; Rognes, 1997) ( $\mathrm{L}=1 ; \mathrm{CI}=100 ; \mathrm{RI}=100)$.

0 - Ausentes

1 - Presentes (Figs. 26-29)

A presença de cerdas no méron é a principal característica que define a superfamília Oestroidea, diferenciando-a de Muscoidea (Brown et al., 2009; McAlpine, 1981). Tanto Pape (1992) quanto Rognes (1997) utilizaram esse caráter em suas análises filogenéticas como sinapomorfia de Oestroidea.

37. Cerdas no méron, disposição, se presentes (Toma \& Carvalho, 1995; Rognes, 1997; Bonatto, 2001) ( $\mathrm{L}=10 ; \mathrm{CI}=30 ; \mathrm{RI}=68)$.

0 - Em uma linha que começa perpendicular ao eixo do corpo e se curva bruscamente ao eixo paralelo (Fig. 26)

1 - Em uma linha que começa perpendicular ao eixo do corpo e se curva suavemente ao eixo paralelo (Fig. 27)

2 - Em uma linha reta perpendicular ao eixo do corpo (Fig. 28)

3 - Em um tufo de cerdas desordenadas (Fig. 29)

Pape (1992) tem dois estados para a presença de cerdas no méron, uma linha vertical de cerdas ou um tufo. Porém, como afirmam Toma \& Carvalho (1995), a linha de cerdas no méron pode se apresentar com uma curva brusca ou suave, mudando do eixo perpendicular do corpo para o eixo paralelo. 
38. Prosterno, cerdas (Pape, 1992; Rognes, 1997) ( $\mathrm{L}=5 ; \mathrm{CI}=20 ; \mathrm{RI}=63)$.

\author{
0 - Ausentes \\ 1 - Presentes (Fig. 30)
}

A presença de cerdas no prosterno foi citado por Shannon (1923) para caracterizar os califorídeos, sendo o primeiro a relacionar Mesembrinellidae com Calliphoridae. Rognes (1997) também afirma que essa seria uma das autapomorfias de Calliphoridae. Entretanto, cerdas no prosterno estão amplamentes presentes em diversas espécies dentro de Oestroidea, que rejeita a hipótese de que seria uma autapomorfia de Calliphoridae.

39. Parede pós-alar, cerdas (Pape, 1992; Rognes, 1997) ( $\mathrm{L}=11 ; \mathrm{CI}=9 ; \mathrm{RI}=44$ ).

\author{
0 - Ausentes \\ 1 - Presentes (Fig. 31)
}

40. Depressão proepisternal (propleura), cerdas (Rognes, 1997) ( $\mathrm{L}=4 ; \mathrm{CI}=25 ; \mathrm{RI}=80$ ).

\author{
0 - Ausentes \\ 1 - Presentes (Fig. 32)
}

41. Anepímeron, metade anterior da porção inferior, cerdas (Rognes, 1997) (L=7; $\mathrm{CI}=14 ; \mathrm{RI}=72)$.
0 - Ausentes (Fig. 34)
1 - Presentes (Fig. 33) 
Caráter discutido por Rognes (1997). Em Mesembrinellidae ambos os estados ocorrem.

42. Anatergito, cerdas (Pape, 1992) $(\mathrm{L}=4 ; \mathrm{CI}=25 ; \mathrm{RI}=57)$.

0 - Ausentes

1 - Presentes (Fig. 35)

43. Úmero, cor (Bonatto, 2001) ( $\mathrm{L}=10 ; \mathrm{CI}=20 ; \mathrm{RI}=71)$.

0 - Claro (amarelo a laranja) (Fig. 21)

1 - Escuro (castanho escuro ou cinza) (Fig. 20)

2 - Metálico (Fig. 19)

Bonatto (2001) comenta que os califorídeos senso stricto geralmente apresentam o úmero e o tórax metálico. Já em Mesembrinellidae as espécies que apresentam o tórax amarelo ou alaranjado têm o úmero dessa mesma cor, enquanto as espécies que possuem o tórax metálico também apresentam o úmero metálico. Para esse autor, talvez esses caracteres fossem dependentes. No entanto, isso não se confirma em Mesembrinella semiflava e Mesembrinella flavicrura que, embora possuam o tórax metálico, apresentam o úmero com coloração amarela, descartando a hipótese de dependência desses dois caracteres.

44. Espiráculos, cor ( $\mathrm{L}=9 ; \mathrm{CI}=11 ; \mathrm{RI}=57)$.

0 - Claro (amarelo a laranja) (Fig. 37)

1 - Escuro (castanho-escuro) (Fig. 36) 
45. Espiráculo posterior, forma (Pape, 1992; Toma \& Carvalho, 1995; Rognes, 1997; Bonatto, 2001) ( $\mathrm{L}=4 ; \mathrm{CI}=50 ; \mathrm{RI}=92)$.

0 - Arredondado (Fig. 38)

1 - Ovalado (Fig. 36)

2 - Reniforme (Fig. 37)

A forma do espiráculo posterior reniforme foi citado primeiramente por Guimarães (1977) como uma das características que distinguiria Mesembrinellidae dos califorídeos, justificando o status de família proposto por ele para esse grupo. Toma \& Carvalho (1995) reiteram que esse caráter é uma sinapomorfia de Mesembrinellidae, juntamente com outros caracteres. Como comentado por Pape (1992) a presença de uma franja contínua, única e não operculada é uma característica exclusiva de Mesembrinellidae dentro de Oestroidea, mas semelhante a espécies de Muscidae. Essa afirmação é corroborada aqui, uma vez que a forma do espiráculo metatorácico em Polietina flavithorax é bastante semelhante à de Mesembrinellidae.

46. Espiráculo posterior, tamanho relativo à distância entre as catepisternais $(\mathrm{L}=4$. $\mathrm{CI}=25 ; \mathrm{RI}=76$ ).

0 - Menor (Fig. 42)

1 - Igual ou maior (Fig. 43)

Foi observada uma grande variação no tamanho dos espiráculos e, para efeito de comparação, foi utilizada a distância entre as catepisternais. As espécies que apresentam espiráculos grandes, com o tamanho igual ou maior que a distância entre as catepisternais são, com pequenas exceções, todos os terminais de Calliphoridae. O estado 0, por sua vez, está presente na maioria das espécies das demais famílias, com exceção de Peckia intermutans, que possui um espiráculo bastante semelhante ao dos califorídeos, e Polietina flavithorax cuja forma do espiráculo é muito parecida com a de Mesembrinellidae, como comentado no caráter 45. 
47. Espiráculo posterior, posição da abertura (Pape, 1992; Toma \& Carvalho, 1995; Bonatto, 2001) ( $\mathrm{L}=7 ; \mathrm{CI}=28 ; \mathrm{RI}=80)$.

0 - Central (Fig. 38)

1 - Posterior (Fig. 36)

2 - Dorsal (Fig. 37)

A abertura dorsal do espiráculo posterior está presente nos Mesembrinellidae, devido à sua forma reniforme exclusiva. No entanto, em Polietina flavithorax, embora o espiráculo não seja reniforme, é bastante semelhante ao de Mesembrinellidae, também com uma abertura dorsal. Nos Calliphoridae senso stricto, geralmente os espiráculos possuem uma abertura posterior, por meio de uma membrana operculada. Nas demais famílias, há maior variação da posição da abertura e forma das membranas.

48. Espiráculo posterior, membranas, tamanho ( $\mathrm{L}=7 ; \mathrm{CI}=28 ; \mathrm{RI}=66)$.

0 - Membrana anterior maior que a posterior (Fig. 36)

1 - Duas membranas do mesmo tamanho (Fig. 38)

2 - Membrana posterior maior que anterior

A presença de duas membranas no espiráculo posterior é exclusiva de terminais do grupo externo dessa análise, sendo, portanto, inaplicável para todos os Mesembrinellidae. A maioria das espécies do grupo externo possuem a membrana posterior maior que a anterior, condição presente em todos os califorídeos senso stricto.

49. Espiráculo posterior, membranas, movimentação ( $L=5 ; C I=20 ; R I=20)$.

0 - Duas membranas operculadas

1 - Membrana posterior operculada (Fig. 36) 
50. Espiráculo posterior, cerdas (Bonatto, 2001) $(\mathrm{L}=4 ; \mathrm{CI}=25 ; \mathrm{RI}=87)$.

\author{
0 - Ausentes \\ 1 - Presentes (Fig. 37)
}

51. Espiráculo posterior, cerdas, composição, se presentes (Bonatto, 2001) (L=4; $\mathrm{CI}=75 ; \mathrm{RI}=83$ ).

0 - Recobrindo todo o espiráculo (Fig. 39)

1 - Na margem ventral a partir dos $2 / 3$ posteriores (Fig. 37)

2 - Concentradas na porção anterior (Fig. 41)

3 - Concentradas na porção posterior (Fig. 40)

Em Mesembrinellidae, há grande variação da composição de cerdas no espiráculo posterior, quando presentes, o que dificultou imensamente a construção dos estados desse caráter e sua codificação. O estado 1 possivelmente englobe outras condições, como "a partir da metade posterior". Porém, para não criar muito ruído à análise, foi considerado somente o estado 1. Os outros estados são mais facilmente distinguíveis.

52. Espiráculo anterior, forma da abertura (Bonatto, 2001) $(\mathrm{L}=3 ; \mathrm{CI}=33 ; \mathrm{R}=93)$.

0 - Em fenda (Fig. 44)

1 - Com uma abertura dorsal arredondada (Fig. 45)

Todos os terminais do grupo externo possuem uma abertura do espiráculo anterior em fenda. Em Mesembrinellidae, surgiu uma abertura dorsal arredondada, o que se assemelha com uma gota. Entretanto, nas espécies Mesembrinella bolívar comb. n. e 
Mesembrinella carvalhoi comb. n. houve reversão desse caráter para o estado 0 , em fenda.

53. Subscutelo (Pape, 1992; Rognes, 1997) ( $L=6 ; C I=16 ; R I=66)$.

0 - Achatado (Fig. 46)

1 - Proeminente (Fig. 47)

A presença de subscutelo proeminente é, tradicionalmente, considerada sinapomorfia para a família Tachinidae. Entretanto, outras espécies de outras famílias também possuem essa característica. Na presente análise, o subscutelo foi considerado proeminente em Mesembrinellidae, bem como em diversas espécies de Calliphoridae.

54. Subscutelo, grau de desenvolvimento, se proeminente $(\mathrm{L}=1 ; \mathrm{CI}=100 ; \mathrm{RI}=100)$.

0 - Discreto (Fig. 18)

1 - Conspícuo (Fig. 47)

Apesar da presença do subescutelo em diversos terminais dessa análise, foi constatado que somente em Tachinidae o subescutelo é bastante desenvolvido, enquanto nas outras espécies é bem mais discreto.

55. Mesonoto, reflexão metálica $(\mathrm{L}=7 ; \mathrm{CI}=14 ; \mathrm{RI}=62)$.

0 - Ausente

1 - Presente (Fig. 19)

56. Mesonoto, polinosidade formando faixas longitudinais (Bonatto, 2001) ( $\mathrm{L}=8$; $\mathrm{CI}=12 ; \mathrm{RI}=58)$. 


$$
\begin{aligned}
& 0 \text { - Ausentes } \\
& 1 \text { - Presentes }
\end{aligned}
$$

\section{$\underline{\text { Perna }}$}

57. Coxa posterior, superfície posterior, cerdas (Rognes, 1997) (L=7; CI=14; RI=71).

$$
0 \text { - Ausentes }
$$

1 - Presentes (Fig. 48)

$$
\text { Como comentado por Rognes (1997), essas cerdas podem estar }
$$

distribuídas de forma diferente, por toda a estrutura, na parte central ou lateral. Poderiam ser considerados diferentes estados, mas considerou-se somente a presença relevante para a presente análise, assim como na análise desse autor.

58. Fêmur mediano, cerdas posterodorsais apicais, número ( $\mathrm{L}=15 ; \mathrm{CI}=13 ; \mathrm{RI}=27)$.

$$
\begin{aligned}
& 0 \text { - Duas } \\
& 1 \text { - Três (Fig. 49) } \\
& 2 \text { - Quatro }
\end{aligned}
$$

A maioria das espécies utilizadas nessa análise apresentam três cerdas posterodorsais apicais no fêmur mediano. Entretanto, em alguns terminais houve aumento ou diminuição dessas cerdas.

59. Fêmur posterior, face dorsal, fileira de cerdas robustas $(\mathrm{L}=4 ; \mathrm{CI}=25 ; \mathrm{RI}=0)$.

0 - Ausentes

1 - Presentes (Fig. 50) 
60. Fêmur posterior, cerdas posterodorsais apicais ( $L=6 ; \mathrm{CI}=16 ; \mathrm{RI}=66)$.

\author{
0 - Ausentes \\ 1 - Presentes (Fig. 51)
}

As cerdas posterodorsais apicais estão presentes na maioria dos Calliphoridae s.l., incluindo Mesembrinellidae, e ausente na maioria dos terminais mais próximos à raíz.

61. Macho, fêmur mediano, face posterodorsal, porção mediana distal, fileira de cerdas $(\mathrm{L}=1 ; \mathrm{CI}=100 ; \mathrm{RI}=100)$.

0 - Ausente

1 - Presente (Fig. 52)

Foi encontrada uma fileira de cerdas na porção mediana distal da face posterodorsal do fêmur mediano somente em machos das espécies Mesembrinella randa, M. benoisti comb. n. e M. quadrilineata.

62. Tíbia, banda de cerdas alaranjadas ( $\mathrm{L}=4 ; \mathrm{CI}=25 ; \mathrm{RI}=85)$.

\author{
0 - Ausentes \\ 1 - Presentes (Fig. 53)
}

63. Fêmures, cor (Bonatto, 2001) ( $\mathrm{L}=6 ; \mathrm{CI}=16 ; \mathrm{RI}=81)$.

0 - Amarelo a alaranajdo (Fig. 54)

1 - Castanho médio a escuro (Fig. 56) 
64. Fêmures, porção apical, mácula escura (Toma \& Carvalho, 1995; Bonatto, 2001) $(\mathrm{L}=8 ; \mathrm{CI}=12 ; \mathrm{RI}=61)$.

0 - Ausente

1 - Presente (Fig. 55)

65. Garras tarsais, metade basal, cor (Toma \& Carvalho, 1995; Bonatto, 2001) (L=10; $\mathrm{CI}=20 ; \mathrm{RI}=57)$.

0 - Amarelada (Fig. 57)

1 - Branca (Fig. 58)

2 - Castanha-escura (Fig. 59)

A presença de garras tarsais brancas é tradicionalmente considerada a única característica exclusiva do agrupamento das espécies Mesembrinella nigripes comb. n. e Mesembrinella perisi (Guimarães, 1977; Toma \& Carvalho, 1995; Bonatto, 2001; Wolff et al., 2013). Na presente análise, o estado 1 foi codificado para a espécie Auchmeromyia bequaerti, que também possui essa coloração da metade basal das garras tarsais.

$\underline{\text { Asa }}$

66. Veia tronco, superfície dorsal, cerdas (Pape, 1992; Rognes, 1997; Bonatto, 2001) ( $\mathrm{L}=7 ; \mathrm{CI}=14 ; \mathrm{RI}=33)$.

0 - Ausentes

1 - Presentes (Fig. 60)

A presença ou ausência de cerdas na superfície dorsal da veia tronco foi utilizada primeiramente por Aldrich (1922) para separar os subgêneros Mesembrinella e 
Mesembolia, sendo este último composto pelas espécies Mesembrinella (Mesembolia) bellardiana, Mesembrinella (Mesembolia) fulvipes e Mesembrinella (Mesembolia) peregrina. Posteriormente, Guimarães (1977) também utilizou esse caráter em seu estudo taxonômico, porém esse autor comenta que é um caráter bastante variável, de “importância secundária para suporte em nível genérico, mas útil em nível específico". Esse caráter se mostrou bastante homoplástico aqui.

67. Esclerito subcostal, cerdas (Rognes, 1997; Bonatto, 2001) (L=5; CI=20; RI=71).

0 - Ausentes

1 - Presentes (Fig. 61)

Assim como a presença de cerdas na veia tronco, esse caráter foi bastante utilizado na taxonomia de Mesembrinellidae, mas provavelmente teve vários surgimentos independentes, sendo bastante homoplástico.

68. Ponte supra-esquamal, cerdas (Pape, 1992; Rognes, 1997) (L=9; CI=11; RI=33).

$$
\begin{aligned}
& 0 \text { - Ausentes } \\
& 1 \text { - Presentes }
\end{aligned}
$$

69. Veia R4+5, nó basal, ventralmente, cerdas (Pape, 1992) ( $\mathrm{L}=4$; $\mathrm{CI}=25 ; \mathrm{RI}=57)$.

\author{
0 - Ausentes \\ 1 - Presentes (Fig. 62)
}

Caráter bastante discutido por Pape (1992). Como comentado por esse autor e confirmado aqui, a maioria das espécies de Oestroidea apresentam alguma cerda no nó basal da R4+5, com poucas exceções. Na presente análise, somente as espécies Fannia heydenii, Phaonia advena, Shannoniela cuspidata, Cuterebra apicalis, Idiela mandarina e o gênero Amenia foram codificados com o estado 0. 
70. Caliptra inferior, superfície dorsal, sétulas (L=1; CI=100; RI=100).

\author{
0 - Ausentes \\ 1 - Presentes (Fig. 63)
}

O estado 1 é sinapomórfico da subfamília Calliphorinae (Rognes, 1991).

71. Veia costal, macula bem definida (Toma \& Carvalho, 1995) $(\mathrm{L}=14 ; \mathrm{CI}=7 ; \mathrm{RI}=23)$.

\author{
0 - Ausente \\ 1 - Presente (Fig. 64)
}

A presença de uma mácula bem definida na veia costal foi apontado por Toma \& Carvalho (1995) como uma sinapomorfia de Mesembrinellidae. No entanto, diversas espécies, que não foram examinadas pelos autores, possuem asas totalmente hialinas e, portanto, esse caráter é homoplástico.

72. Infuscação ao longo de todas as principais veias ( $\mathrm{L}=4 ; \mathrm{CI}=25 ; \mathrm{RI}=62)$.

$$
\begin{aligned}
& 0 \text { - Ausente } \\
& 1 \text { - Presente (Fig. 67) }
\end{aligned}
$$

Algumas espécies de Mesembrinellidae possuem uma infuscação de cor marron acinzentado ao longo de todas as veias da asa.

73. Calipra inferior, forma (Pape, 1992; Rognes, 1997) ( $\mathrm{L}=4 ; \mathrm{CI}=25 ; \mathrm{RI}=86$ ).

0 - Glossiforme (Fig. 71)

1 - Alargada na porção interior (Fig. 72) 
Pape (1992) possui quatro estados para esse caráter: (0) estreita, (1) oval, (2) alargada e (3) glossiforme. De acordo com esse autor, a condição estreita se restringe aos Anthomyiidae, pois a caliptra superior é maior que a inferior. Já o formato glossiforme encontra-se em Rhinophoridae e em alguns Calliphoridae e o estado 2 está presente na maioria das espécies de Oestroidea. Devido aos terminais utilizados aqui, foram utilizados somente os estados glossiforme e alargada na porção interior. Todas Mesembrinellidae e apenas alguns terminais do grupo externo possuem a condição glossiforme, enquanto nas demais espécies a caliptra é alargada na porção interior, corroborando Pape (1992).

74. Veia M, forma (Rognes, 1997) ( $\mathrm{L}=1 ; \mathrm{CI}=100 ; \mathrm{RI}=100)$.

0 - Curvada anteriormente em direção à R4+5 (Fig. 65)

1 - Reta em direção ao ápice da asa (Fig. 68)

O estado 1 é sinapormorfia do clado composto por todos os Oestroidea exceto a espécie Shannoniela cuspidata (Rhinophoridae).

75. Veia $M$, grau de curvatura, se curvada anteriormente $(L=4 ; C I=25 ; R I=86)$.

0 - Curva suave (Fig. 65)

1 - Curva brusca (Fig. 69)

$\mathrm{Na}$ grande maioria dos Oestroidea, a curvatura da veia $\mathrm{M}$ em direção anterior ao corpo é brusca, formando um cotovelo na porção mais posterior, antes de virar-se na direção anterior. No entanto, em Mesembrinellidae, e em algumas poucas espécies do grupo externo, não há formação desse cotovelo e a curvatura da veia M é bastante suave.

76. Veias $M$ e $\mathbf{R} 4+5$, posição relativa, se $M$ curvada anteriormente ( $L=1 ; C I=100$. $\mathrm{RI}=100)$. 
0 - Separadas até encontrarem a margem da asa (Fig. 65)

1 - Unindo-se antes da argem da asa, formando um pecíolo (Fig. 70)

Somente duas espécies de Phasiinae (Tachinidae), Gymnosoma rotundatum e Phasia hemiptera, possuem a fusão das veias M e R4+5, formando um pecíolo que atinge a margem da asa.

77. Veias $M$ e $R 4+5$, ápice, distância relativa entre o ápice da $R 4+5$ e $R 2+3$, se separadas na margem da asa e veia M curvada (Bonatto, 2001) ( $\mathrm{L}=1 ; \mathrm{CI}=100$. $\mathrm{RI}=100)$.

0 - Menor (Fig. 65)

1 - Igual (Fig. 67)

Estado (1) sinapomórfico para o clado composto pelas espécies Mesembrinella pictipennis, M. currani, M. umbrosa e M. apollinaris, como previamente discutido em Bonatto (2001).

78. Veias $M$ e $\mathbf{R 4 + 5}$, margem da asa, distância relativa ao tamanho da veia transversal $\mathbf{r}-\mathbf{m}$, se separadas na margem da asa e veia $M$ curvada $(L=2 ; C I=50$; $\mathrm{RI}=75)$.

0 - Menor ou igual (Fig. 66)

1 - O dobro ou maior (Fig. 67)

Geralmente, o tamanho da veia r-m é menor ou, no máximo, igual à distância entre as veias M e R4+5. Porém, em algumas espécies, a veia r-m é menor que essa distância.

79. Veia M, porção apical, forma em relação à margem posterior da asa, se curvada anteriormente $(\mathrm{L}=10 ; \mathrm{CI}=10 ; \mathrm{RI}=60)$. 
0 - Paralela (Fig. 66)

1 - Sinuosa (Fig. 65)

80. Veia transversal dm-cu, forma $(\mathrm{L}=11 ; \mathrm{CI}=9 ; \mathrm{RI}=54)$.

0 - Reta ou quase reta (Fig. 67)

1 - Sinuosa (Fig. 66)

81. Caliptras, $\operatorname{cor}(\mathrm{L}=16 ; \mathrm{CI}=12 ; \mathrm{RI}=30)$.

0 - Hialinas (Fig. 71)

1 - Esbranquiçadas (Fig. 73)

2 - Enegrecidas (Fig. 74)

82. Basicosta, cor ( $\mathrm{L}=9 ; \mathrm{CI}=11 ; \mathrm{RI}=73)$.

0 - Amarelo a laranja (Fig. 75)

1 - Castanho médio a escuro (Fig. 75)

\section{Abdômen}

83. Tergito $1+2$, cerda marginal lateral $(L=10 ; C I=10 ; R I=62)$.

0 - Ausente

1 - Presente (Fig. 79) 
84. Tergito 1+2, linha de cerdas dorsolaterais (Bonatto, 2001) ( $\mathrm{L}=2 ; \mathrm{CI}=50 ; \mathrm{RI}=94)$.

\author{
0 - Ausente \\ 1 - Presente (Fig. 77)
}

85. Tergito $1+2$, linha de cerdas dorsolaterais, orientação, se presentes (Bonatto, 2001) (L=1; CI=100; RI=100).

0 - Paralela à margem do tergito (Fig. 77)

1 - Oblíqua à margem do tergito (Fig. 78)

86. Tergito 3, cerda marginal lateral única e muito forte ( $\mathrm{L}=10 ; \mathrm{CI}=10 ; \mathrm{RI}=67)$.

$$
\begin{aligned}
& 0 \text { - Ausente } \\
& 1 \text { - Presente (Fig. 79) }
\end{aligned}
$$

87. Tergito 4, fileira completa de cerdas marginais (Toma \& Carvalho, 1995; Bonatto, 2001) ( $\mathrm{L}=13 ; \mathrm{CI}=7 ; \mathrm{RI}=14)$.

$$
\begin{aligned}
& 0 \text { - Ausente } \\
& 1 \text { - Presente (Fig. 79) }
\end{aligned}
$$

88. Tergito 5, cerdas discais em machos e fêmeas (Toma \& Carvalho, 1995; Bonatto, 2001) ( $\mathrm{L}=7 ; \mathrm{CI}=14 ; \mathrm{RI}=60)$. 
0 - Ausentes

1 - Presentes (Fig. 79)

A presença de cerdas discais no tergito 5 é tradicionalmente considerada sinapomorfia do antigo gênero Huascaromusca, como apontado primeiramente por Guimarães (1977). As espécies Mesembrinella flavicrura e M. xanthorrhina, foram incluídas no gênero Huascaromusca por Bonatto (2001) por também possuírem essas cerdas, além de outras características. Dentro de Mesembrinellidae foi confirmada essa característica exclusiva do agrupamento 22. Porém alguns terminais do grupo externo também possuem essas cerdas e por esse motivo, o caráter é homoplástico na análise.

89. Tergito 5, cerdas discais, organização, se presentes $(\mathrm{L}=2 ; \mathrm{CI}=50 ; \mathrm{RI}=85)$.

0 - Em uma linha central bem definida (Fig. 79)

1 - Desorganizadas

Observou-se que, para as espécies de Mesembrinellidae que possuíram cerdas discais no tergito 5, na maioria delas havia a formação de uma linha central bem definida de cerdas muito robustas. Já em algumas espécies essas cerdas estavam desorganizadas no centro do tergito e eram muito mais fracas.

90. Tergito 5, cerdas discais somente na fêmea ( $L=1 ; C I=100 ; R I=100)$.

0 - Ausentes

1 - Presentes

O estado 1 é sinapomórfico para os terminais da subfamília Toxotarsinae, Sarconesia chlorogaster e Neta chilensis.

91. Abdômen, reflexão metálica ( $\mathrm{L}=8 ; \mathrm{CI}=12 ; \mathrm{RI}=68)$. 
0 - Ausente

1 - Presente (Fig. 81)

92. Tergito 1+2, metade basal, cor (Bonatto, 2001) ( $\mathrm{L}=7 ; \mathrm{CI}=14 ; \mathrm{RI}=77)$.

0 - Escura (Castanho médio a escuro ou metálico) (Fig. 81)

1 - Clara (Amarelo a castanho claro) (Fig. 80)

Em Mesembrinellidae o abdômen é metálico na grande maioria das espécies, porém a metade basal do tergito 1+2 é amarelada. Entretanto, algumas espécies apresentam essa região escurecida, de coloração idêntica aos demais tergitos.

\section{Tergito 3, coloração amarela em pelo menos metade do tergito exclusivamente} nos machos (Toma \& Carvalho, 1995; Bonatto, 2001) (L=1; CI=100; RI=100).

0 - Ausente

1 - Presente (Fig. 80)

Toma \& Carvalho (1995) e Bonatto (2001) mencionaram esse caráter como "dimorfismo sexual no padrão de coloração do abdômen". Entretanto, o título desse caráter era adequado, pois poderia englobar qualquer diferença na coloração do abdômen de machos e fêmea. Na verdade, o que esses autores queriam mostrar era a coloração amarela em pelo menos na metade basal do tergito 3 do macho que, em Mesembrinellidae, é geralmente metálica, em machos e fêmeas, mas no agrupamento 17, é amarela somente nos machos.

94. Tergitos abdominais, margem posterior, bandas transversais violetas (Toma \& Carvalho, 1995; Bonatto, 2001) ( $\mathrm{L}=2 ; \mathrm{CI}=50 ; \mathrm{RI}=75)$.

0 - Ausente 
1 - Presente (Fig. 79)

Dentro de Mesembrinellidae, a presença de bandas na margem posterior dos tergitos abdominais é homoplástica e compartilhada pelo clado formado pelas espécies Mesembrinella purpurata, M. aeneiventris e M. bequaerti comb. n. e pela espécie Mesembrinella cyaneicincta.

95. Tergito 5, tamanho em relação ao tergito 4 (Toma \& Carvalho, 1995; Bonatto, 2001) (L=1; não-informativo)

0 - Aproximadamente do mesmo tamanho (Fig. 81)

1 - Pelo menos 1,5 vezes maior (Fig. 82)

O estado 1 é autapomórfico da espécie Mesembrinella anomala comb. $\mathbf{n}$.

\section{$\underline{\text { Terminália feminina }}$}

96. Fêmea, tergito 6, forma (Bonatto, 2001) $(\mathrm{L}=3 ; \mathrm{CI}=33$; $\mathrm{RI}=60)$.

0 - Inteiro (Fig. 83)

1 - Dividido (Fig. 84)

A maioria das espécies de Mesembrinellidae possuem o tergito 6 inteiro, sem nenhuma divisão. No entanto, como apontado por Bonatto (2001), três espécies (Mesembrinella xanthorrhina, M. lara comb. n. e M. decrepita) possuem uma sutura visível, dividindo o tergito ao meio.

97. Fêmea, tergito 8 ( $\mathrm{L}=1$; não-informativo).

0 - Ausente

1 - Presente (Fig. 85) 
O tergito 8 está presente em todas as espécies analisadas aqui, com exceção somente de Mesembrinella anomala comb.n. Como afirmaram Toma \& Carvalho (1995), uma das possibilidades dessa perda do tergito 8 é que, em realidade, houve uma migração do esternito 8 para a posição que seria ocupada pelo terigo 8 , já que todas Mesembrinellidae não possuem o esternito 8 , condição sinapomórfica.

98. Fêmea, tergito 8, forma, se presente (Bonatto, 2001) ( $\mathrm{L}=4 ; \mathrm{CI}=25 ; \mathrm{RI}=76)$.

0 - Posicionado lateralmente (Fig. 85)

1 - Projetado dorsalmente (Fig. 86)

O estado 1 foi apontado por Bonatto (2001) para o agrupamento Giovanella+. A condição exclusiva desse estado de caráter foi confirmada para o grupo interno. Entretanto, no grupo externo, há espécies com as duas condições, não formando nenhum agrupamento.

99. Fêmea, tergito 8, cerdas marginais, se presente (Bonatto, 2001) ( $\mathrm{L}=5 ; \mathrm{CI}=20$; $\mathrm{RI}=85)$.

$$
\begin{aligned}
& 0 \text { - Ausentes } \\
& 1 \text { - Presentes }
\end{aligned}
$$

100. Fêmea, esternito 8 (Toma \& Carvalho, 1995; Rognes, 1997; Bonatto, 2001) (L=2; $\mathrm{CI}=50 ; \mathrm{RI}=96)$.

0 - Ausente ou muito reduzido (Fig. 85)

1 - Presente e desenvolvido

O estado 0 é sinapomórfico de Mesembrinellidae. Para todos os terminais do grupo externo analisados e Mesembrinella anomala comb. n., o esternito 8 era presente. Os demais terminais foram codificados com o estado 0. 
101. Fêmea, espermateca, forma (Toma \& Carvalho, 1995; Bonatto, 2001) (L=6; $\mathrm{CI}=33 ; \mathrm{RI}=77$ ).

0 - Esférica ou ovalada

1 - Pouco alongada, cilíndrica

2 - Muito alongada, afilada (Figs. 89-91)

A maioria das espécies de Oestroidea possuem a espermateca esférica ou pouco alongada. A condição muito alongada foi atribuída como caráter exclusivo de Mesembrinellidae (e.g. Guimarães, 1977). No entanto, após o estudo das diversas espécies utilizadas como grupo externo da presente análise, foi encontrada forma semelhante em Phumosia promittens e Auchmeromyia bequaerti.

102. Fêmea, espermateca, forma, se muito alongada (Toma \& Carvalho, 1995; Bonatto, 2001) ( $\mathrm{L}=2 ; \mathrm{CI}=100 ; \mathrm{RI}=100)$.

0 - Tuberiforme (Fig. 89)

1 - Bulbosa (Fig. 90)

2 - Filiforme (Fig. 91)

Guimarães (1977) didiviu Mesembrinellidae em três subfamilias, de acordo com o formato da espermateca. O grupo A, possuía a espermateca em forma de tubo e era composto pela espécie Mesembrinella nigripes comb. n.. O grupo B, composto pela espécie Mesembrinella facialis possuía a espermateca bulbosa. Finalmente o grupo C, com a espermateca filiforme, era composto por todas as demais espécies de Mesembrinellidae. De fato, esse caráter se mostrou extremamemente importante na presente análise, sendo a condição filiforme (2) sinapomórfica para o clado 12.

103. Fêmea, ovopositor (Pape, 1992; Rognes, 1997) ( $\mathrm{L}=4 ; \mathrm{CI}=25 ; \mathrm{RI}=76)$. 
0 - Longo, telescopado

1 - Curto, não-telescopado (Fig. 85)

A maioria das espécies de Oestroidea apresentam o ovopositor telescopado e um tipo de reprodução ovípara, em que os ovos são liberados para o meio externo onde se desenvolvem. Entretanto, alguns terminais do grupo externo, bem como em Mesembrinellidae, possuem um ovopositor curto, relacionado com o tipo de reprodução vivípara, em que o ovo se desenvolve dentro do útero materno e é liberado para o meio externo já sob forma de larva. Esse caráter foi previamente discutido em Pape (1992) e Rognes (1997), e as subfamílias de Calliphoridae Ameniinae, Bengaliinae e Mesembrinellinae foram codificadas como contendo o ovopositor curto por estes autores.

\section{$\underline{\text { Terminália masculina }}$}

104. Macho, tergito 6 e sintergito 7+8, grau de fusão (Pape, 1992; Toma \& Carvalho, 1995; Bonatto, 2001) ( $\mathrm{L}=2 ; \mathrm{CI}=50 ; \mathrm{RI}=96)$.

0 - Não-fundidos e separados por membrana (Fig. 92)

1 - Parcial ou totalmente fundidos (Fig. 94)

A maioria das espécies de Mesembrinellidae possuem o tergito 6 e o sintergito 7+8 parcial ou totalmente fundidos ao epândrio. Somente em Mesembrinella nigripes comb. n., M. perisi e M. facialis, as duas estruturas estão claramente separados por uma membrana visível.

105. Macho, tergito 6 e sintergito $7+8$, esclerotização da membrana, se separados por membrana (Bonatto, 2001) ( $\mathrm{L}=1$; não-informativo).

0 - Não esclerosada (Fig. 92)

1 - Esclerosada (Fig. 93) 
Embora nas espécies Mesembrinella nigripes comb. n., $M$. perisi e $M$. facialis o tergito 6 e sintergito $7+8$ totalmente separados por membrana, essa membrana encontra-se de duas maneiras distintas. Em Mesembrinella nigripes comb. n. e M. perisi, há uma membrana fina, não esclerosada e em M. facialis a membrana é esclerosada.

106. Macho, tergito 6 e sintergito $7+8$, sutura, se parcial ou totalmente fundidos (Bonatto, 2001) (L=1; não-informativo).

0 - Presente (Fig. 94-95)

1 - Ausente

Das espécies de Mesembrinellidae que apresentam o tergito 6 e sintergito $7+8$ ao menos parcialmente fusionados, na maioria deles é possível ver claramente uma sutura entre as duas estruturas. No entanto, em Mesembrinella anomala comb. n., há fusão total dos tergitos, formando uma peça única.

107. Macho, surstilos, grau de movimentação (Bonatto, 2001) $(\mathrm{L}=2 ; \mathrm{CI}=50 ; \mathrm{RI}=96)$.

0 - Livres e móveis (Fig. 96)

1 - Fundidos ao epândrio (Fig. 97)

A condição dos surstilos fundidos ao epândrio é sinapomórfica para Mesembrinellidae. Dentro dessa família, contudo, há uma reversão para o estado de caráter 0, na espécie espécies Mesembrinella uniseta.

108. Macho, parafalo, forma (Pape, 1992; Rognes, 1997) ( $\mathrm{L}=4$; $\mathrm{CI}=50 ; \mathrm{RI}=84$ ).

0 - Confluente com a parede do edeago (Fig. 98)

1 - Separado da parede do edeago, com pontas livres (Fig. 99) 
2 - Separado da parede do edeago, porém com as pontas fundidas no distifalo (Fig. 100)

Esse caráter é extensamente discutido por Pape (1992) e por Rognes (1997). De acordo com esses autores, a maioria dos Oestroidea apresentam o parafalo confluente com a parede do edeago, com exceção dos Calliphoridae e de algumas espécies de Oestridae. No presente trabalho, concordando com a proposta de Rognes (1997) foi considerado o estado 2 sinapomórfico de Rhiniidae por acreditar que o parafalo possui pontas livres, porém estas são fundidas no distifalo em uma conformação semelhante a uma armadura.

109. Macho, parafalo, porção apical, dentículos, se possuir pontas livres (Pape, 1992; Bonatto, 2001) ( $\mathrm{L}=14 ; \mathrm{CI}=7 ; \mathrm{RI}=18)$.

0 - Ausentes

1 - Presentes (Fig. 99)

Esse caráter, como apontado por Bonatto (2001) apresentou-se extremamente homoplástico e presente em diversas espécies de Calliphoridae, sem formar nenhum agrupamento. Esse autor afirma que, provavelmente haja alguma informação filogenética importante nesse caráter, mas que talvez não seja possível observar somente com auxílio de uma lupa. Técnicas de microscopia podem ser muito úteis para auxiliar no estudo mais detalhado e aprofundado do edeago de Mesembrinellidae.

110. Macho, parafalo, localização no início da separação entre as duas porções, se possuir pontas livres (Pape, 1992; Rognes, 1997) ( $\mathrm{L}=3$; $\mathrm{CI}=33$; $\mathrm{RI}=77$ ).

0 - Antes da metade do comprimento do edeago (Fig. 101)

1 - A partir de pelo menos a metade do comprimento do edeago (Fig. 102) 
Nas espécies que possuem o parafalo com pontas livres, é possível observar que a divisão do parafalo geralmente se inicia bem próximo à base do edeago, antes de metade dessa estrutura. No entanto, em Mesembrinellidae e alguns outros teminais do grupo externo dessa análise, o parafalo se mantém unido até quase atingir a ponta do edeago, se separado, portanto, próximo à face distal.

111. Macho, lobo hipofálico, espinhos $(\mathrm{L}=4 ; \mathrm{CI}=25 ; \mathrm{RI}=50)$.

\author{
0 - Ausentes \\ 1 - Presentes (Fig. 99)
}

112. Macho, cercos, grau de fusão $(\mathrm{L}=6 ; \mathrm{CI}=16 ; \mathrm{R}=16)$.

0 - Separados (Fig. 104)

1 - Parcial ou totalmente unidos (Fig. 105)

A maiora das espécies estudadas aqui apresenta alguma fusão dos cercos na porção medial. Somente em algumas espécies é possível ver a separação total dos cercos em duas peças.

113. Macho, cercos, grau de fusão, se parcial ou totalmente unidos ( $L=1 ; C I=100$; $\mathrm{RI}=100)$.

0 - Unidos somente na porção mediana, apresentando extremidades livres (Fig. 105)

1 - Totalmente unidos, formando uma placa cercal cuja divisão é indiferenciável (Fig. 106)

O estado 1 é sinapomórfico formado pelo agrupamento das subfamílias Phasiinae e Tachininae, Tachinidae. $\mathrm{O}$ estado 0 está presente na maioria das demais espécies. 
114. Macho, cercos, porção apical, gancho $(\mathrm{L}=14 ; \mathrm{CI}=7 ; \mathrm{RI}=55)$.

0 - Ausente

1 - Presente (Fig. 97)

Na maiora das espécies analisadas, a ponta dos cercos é romba e voltada para baixo. No entanto, em algumas espécies, essa ponta é afilada e curvada anteriormente, formando uma estrutura chamada aqui de gancho. Porém, esse caráter se mostrou bastante homoplástico, não formando nenhum agrupamento.

115. Macho, cercos, vista lateral, forma $(L=1 ; C I=100 ; R I=100)$.

0 - Aproximadamente perpendiculares ao epândrio (Fig. 107)

1 - Fortemente arqueados (Fig. 108)

A condição fortemente arqueada dos cercos está presente no clado formado pelas espécies Mesembrinella nigripes comb. n., M. perisi e M. facialis .

116. Macho, escleritos baciliformes, grau de desenvolvimento (Pape, 1992) ( $\mathrm{L}=1$; $\mathrm{CI}=100 ; \mathrm{RI}=100)$.

0 - Reduzidos

1 - Desenvolvidos (Fig. 108)

De acordo com Pape (1992), todos os membros de Oestroidea e Muscoidea analisados por ele possuem os escleritos baciliformes desenvolvidos. A condição reduzida fica restrita aos Sarcophagidae. Essa afirmação é corroborada na presente análise, pois o estado 0 foi encontrado somente nos terminais de sarcofagídeos utilizados. 
117. Macho, apódema basal do gonóstilo/"Gelenkfortsatz" (Pape, 1992; Rognes, 1997) ( $\mathrm{L}=1 ; \mathrm{CI}=100 ; \mathrm{RI}=100)$.

0 - Ausente

1 - Presente (Fig. 103)

Como apontado por Pape (1992), esse caráter foi primeiramente destacado por Tschornig (1985) como tendo importante valor filogenético. Para o último autor, todos os membros de Tachinidae, Sarcophagidae, Rhinophoridae e Calliphoridae possuem esse apódema, enquanto nem todos os membros de Oestridae o possuem, bem como famílias fora dos Oestroidea. Esse caráter é de difícil visualização e interpretação, pois muitas vezes o formato do gonóstilo apresenta uma ponta que pode ser confundida com o apódema. Na presente análise, todos os membros de Mesembrinellidae e a grande maioria dos terminais do grupo externos foram codificados como 1. Porém, em alguns exemplares não foi possível a visualização do apódema, seja pela falta do macho (caráter inaplicável) seja pela dificuldade de visualização. No último caso, quando havia muita dúvida quanto à presença ou não do apódema, foram considerados dados faltantes e codificados com “?”. Os representantes dos “Muscoidea”, por sua vez, foram codificados como 0 .

118. Macho, esternito 5, face anterior, projeções ( $\mathrm{L}=1$; não-informativo).

0 - Ausentes

1 - Presentes (Fig. 109)

O estado 1 é autapormófico da espécie Mesembrinella spicata.

119. Macho, epândrio, cercos e surstilos fortemente alargados ( $\mathrm{L}=1$; nãoinformativo).

0 - Ausente

1 - Presente (Figs. 110-112) 
O estado 1 é autapomórfico da espécie Mesembrinella anomala comb. $\mathbf{n}$.

\section{Tamanho}

120. Comprimento total $(\mathrm{L}=7 ; \mathrm{CI}=14 ; \mathrm{RI}=33)$.

0 - Pequenas a médias (máximo 10mm) (Fig. 113, 114)

1 - Grandes (acima de 13mm) (Fig. 115)

Dentro de Mesembrinellidae é muito clara a diferença de comprimento de algumas espécies, enquanto outras se mostram medianas em relação aos extremos. As maiores espécies são: Mesembrinella facialis, Mesembrinella pictipennis, M. umbrosa, M. currani e M. apollinaris, com mais de $13 \mathrm{~mm}$ (1) de comprimento, enquanto que algumas das menores são Mesembrinella latifrons comb. n. e Mesembrinella nigripes comb. n., entre outras, que não ultrapassam os $10 \mathrm{~mm}(0)$. 

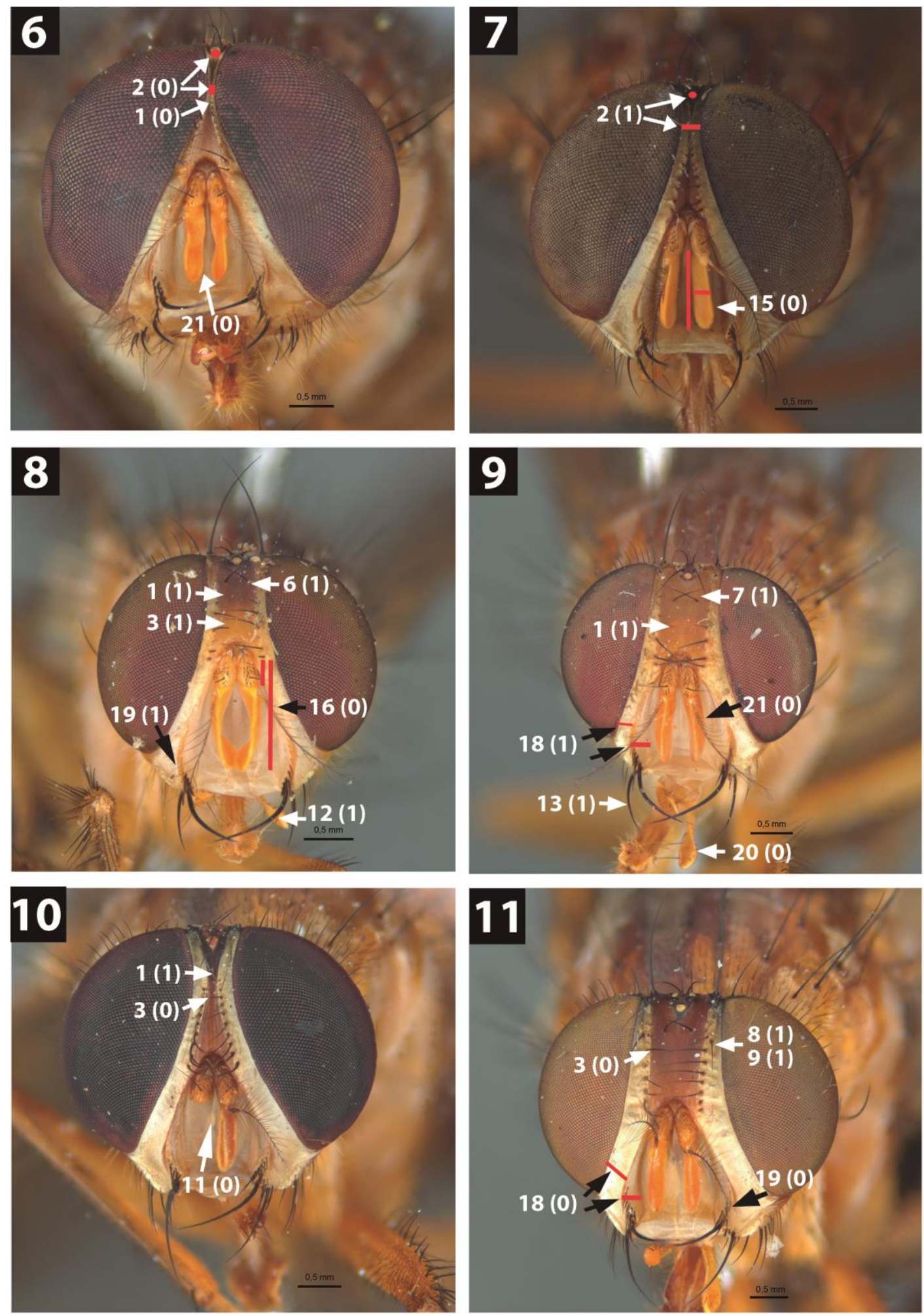

Figuras 6-11. Caracteres de cabeça. 6. Mesembrinella batesi Aldrich, $1922 \curvearrowright$. 7. Mesembrinella benoisti comb. n. (Séguy, 1925) §. 8. Mesembrinella latifrons comb. n. (Mello, 1967) đ.. 9. Mesembrinella latifrons comb. n. (Mello, 1967) ๆ. 10. Mesembrinella quadrilineata (Fabricius, 1905) §ิ. 11. Mesembrinella quadrilineata (Fabricius, 1905) q. O número do caráter e seu respectivo estado entre parênteses são apontados nas figuras. Barras vermelhas indicam o comprimento da estrutura apontada. 

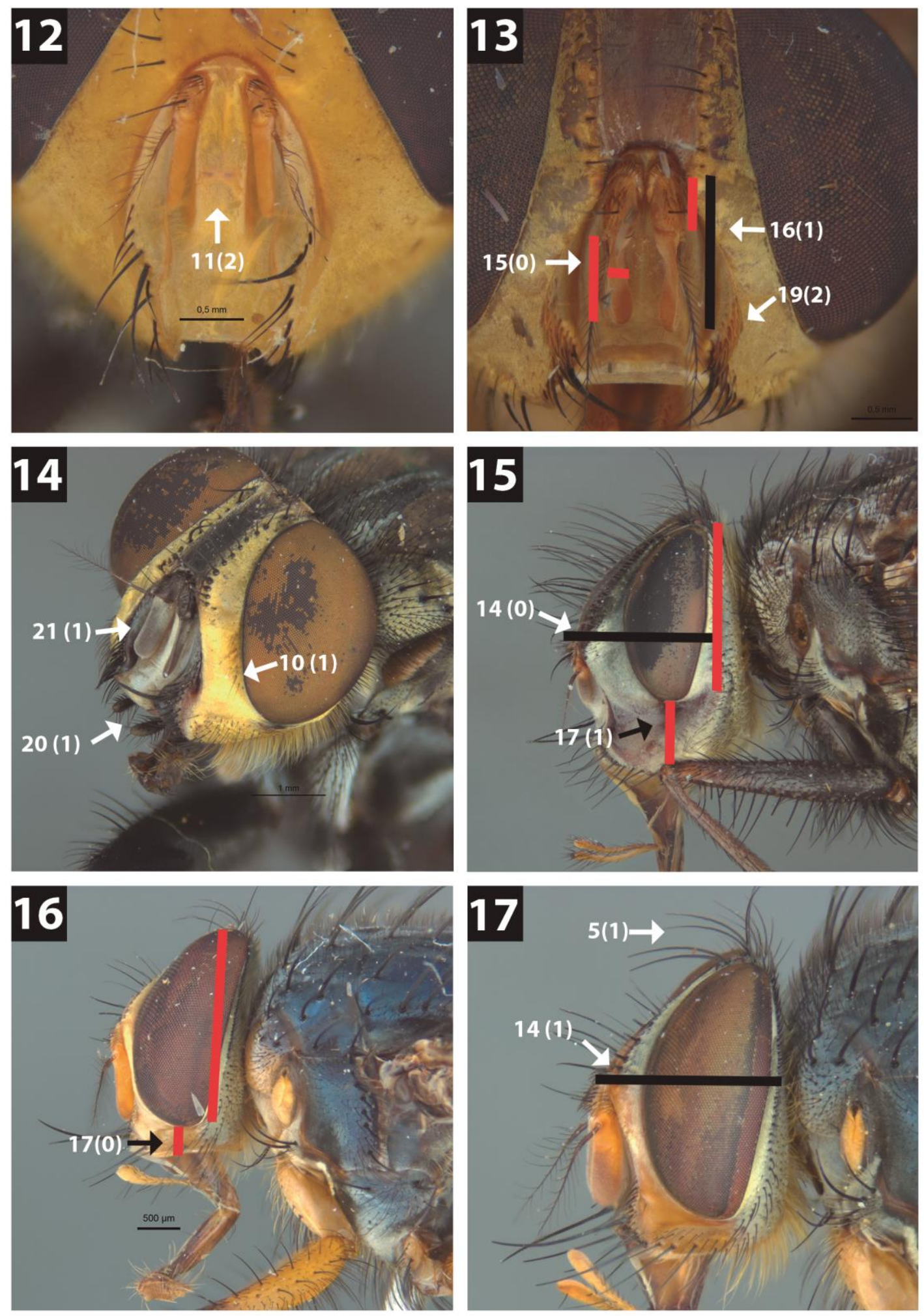

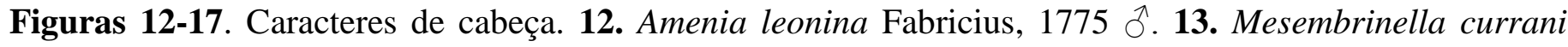
Guimarães, 1977 †. 14. Prophorostoma pulchra Townsend, 1927 Ð๋. 15. Prophorostoma pulchra Townsend, 1927 đ. 16. Mesembrinella flavicrura Aldrich, 1925 đ. 17. Mesembrinella decrepita (Sèguy, 1925) đ. O número do caráter e seu respectivo estado entre parênteses são apontados nas figuras. Barras vermelhas e pretas indicam o comprimento da estrutura apontada. 

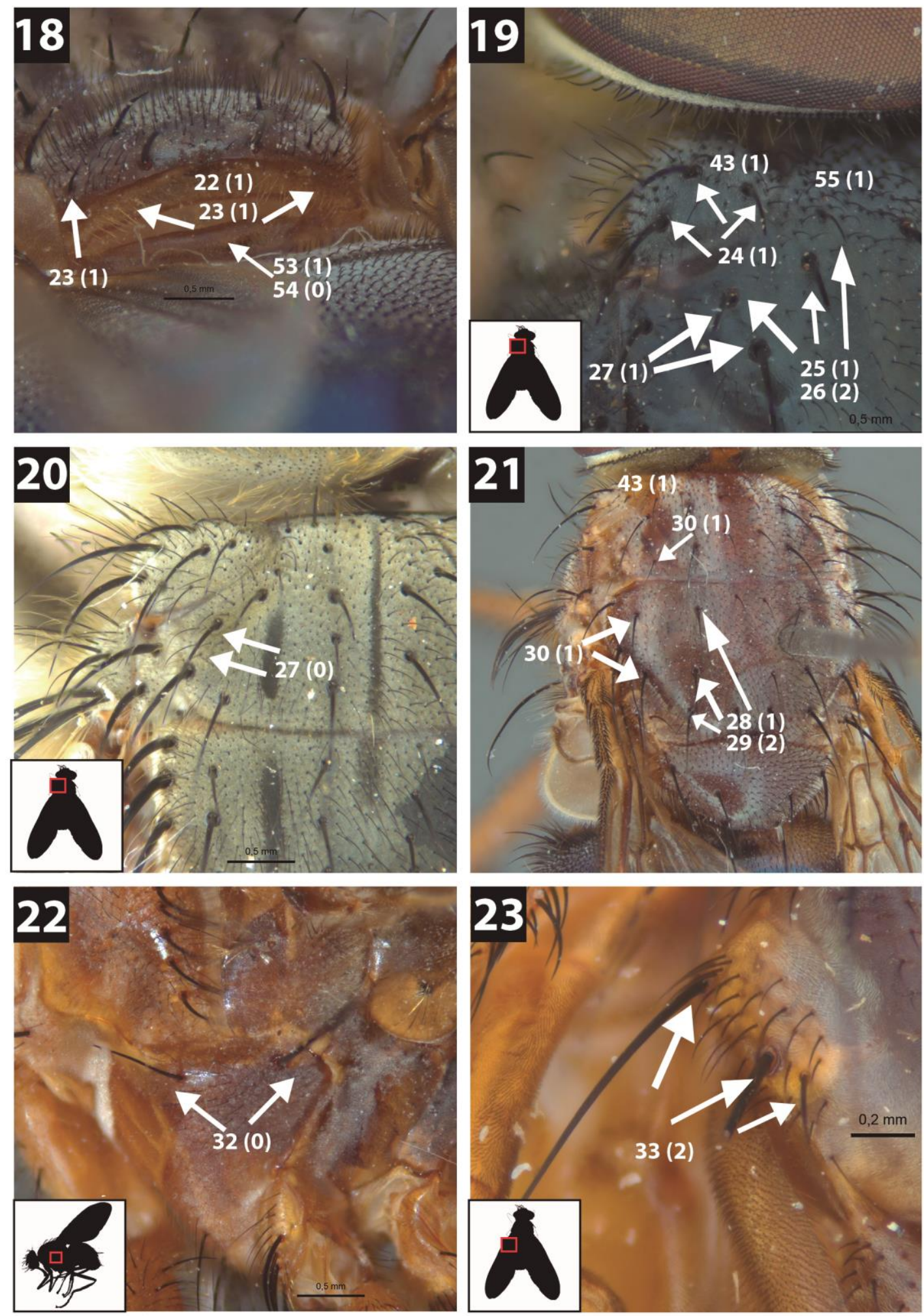

Figuras 18-23. Caracteres de tórax. 18. Mesembrinella bicolor Fabricius, $1805 q$ (detalhe do subescutelo). 19. Mesembrinella decrepita (Sèguy, 1925) §. 20. Adejeania townsendi Curran, 1947 ๆ. 21. Mesembrinella bicolor Fabricius, 1805 ․ 22. Mesembrinella bicolor Fabricius, 1805 ․ 23. Mesembrinella quadrilineata (Fabricius, 1905) q. O número do caráter e seu respectivo estado entre parênteses são apontados nas figuras. 

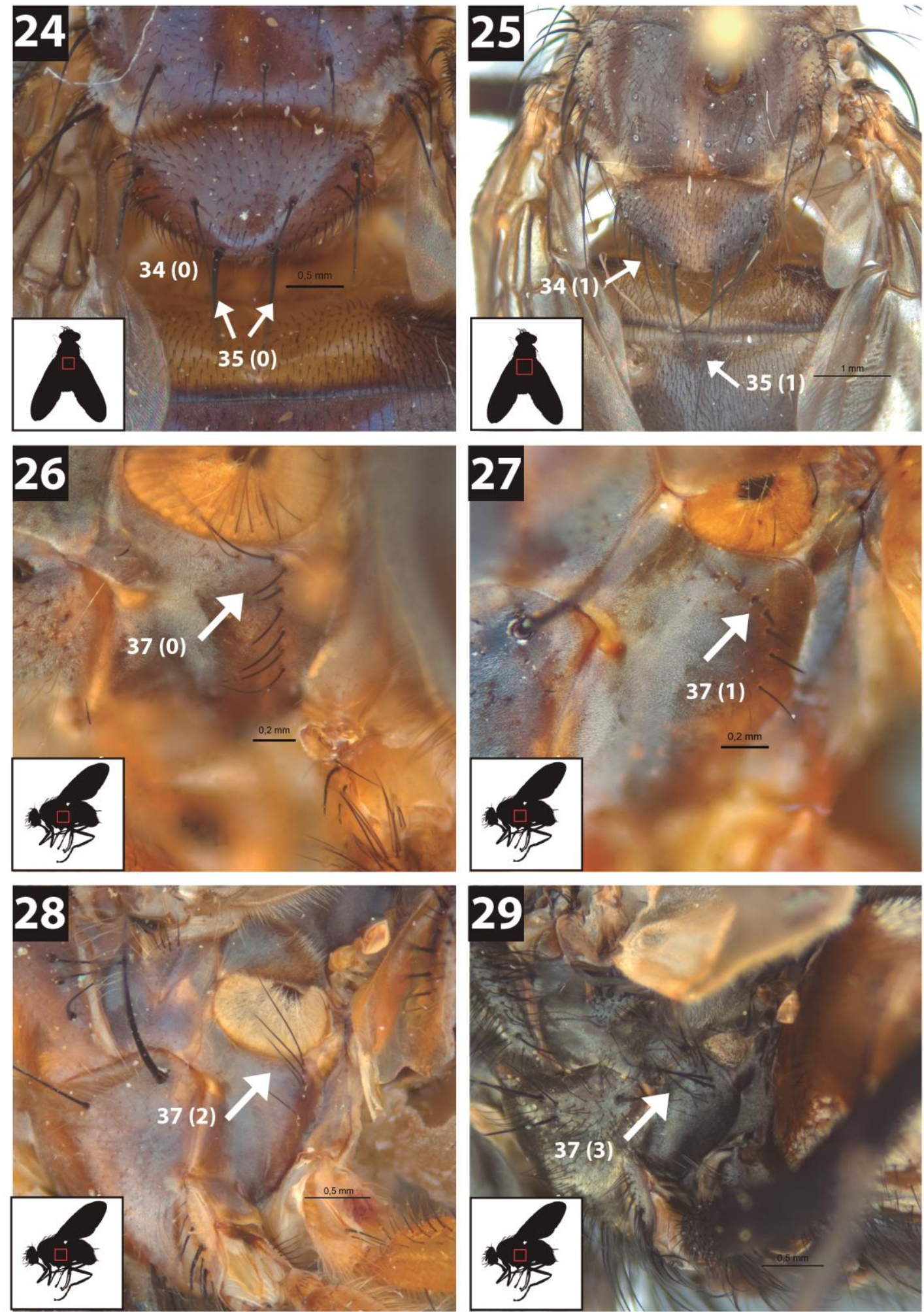

Figuras 24-29. Caracteres de tórax. 24. Mesembrinella aeneiventris (Wiedemann, 1830) q. 25.

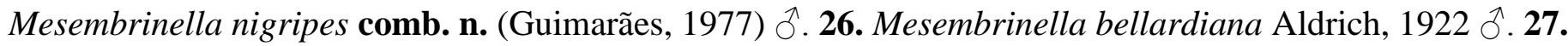
Mesembrinella quadrilineata (Fabricius, 1905) q. 28. Mesembrinella anomala comb. n. HT (Guimarães, 1977) §ิ. 29. Prophorostoma pulchra Townsend, 1927 ઈ. O número do caráter e seu respectivo estado entre parênteses são apontados nas figuras. 

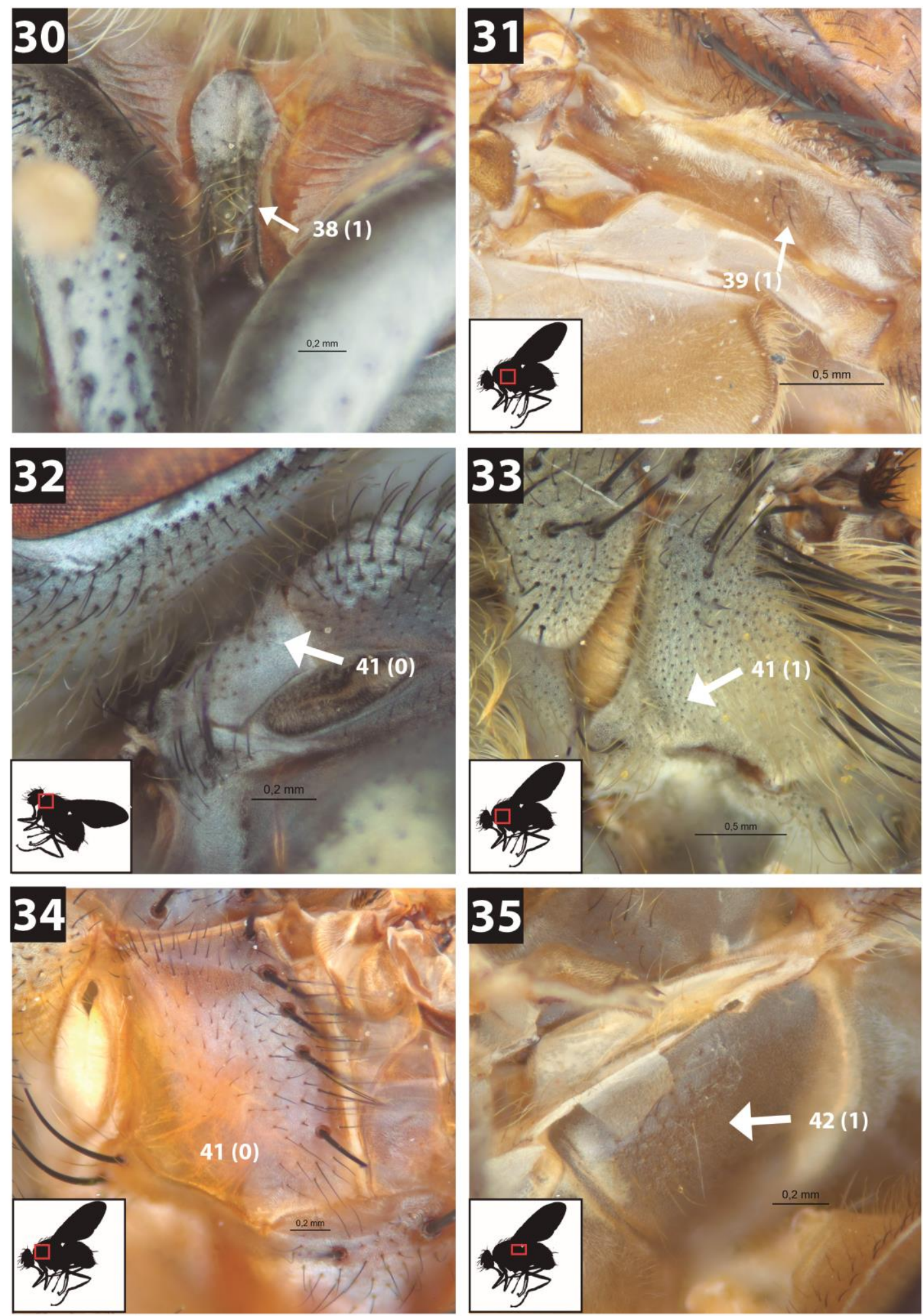

Figuras 30-35. Caracteres de tórax. 30. Prophorostoma pulchra Townsend, $1927 \precsim$ (detalhe do prosterno). 31. Mesembrinella bellardiana Aldrich, 1922 ๆ. 32. Sarconesia chlorogaster (Wiedemann, 1830) $\overbrace{}^{\lambda} .33$.

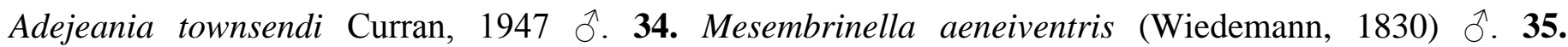
Mesembrinella bicolor (Fabricius, 1805) ๆ. O número do caráter e seu respectivo estado entre parênteses são apontados nas figuras. 

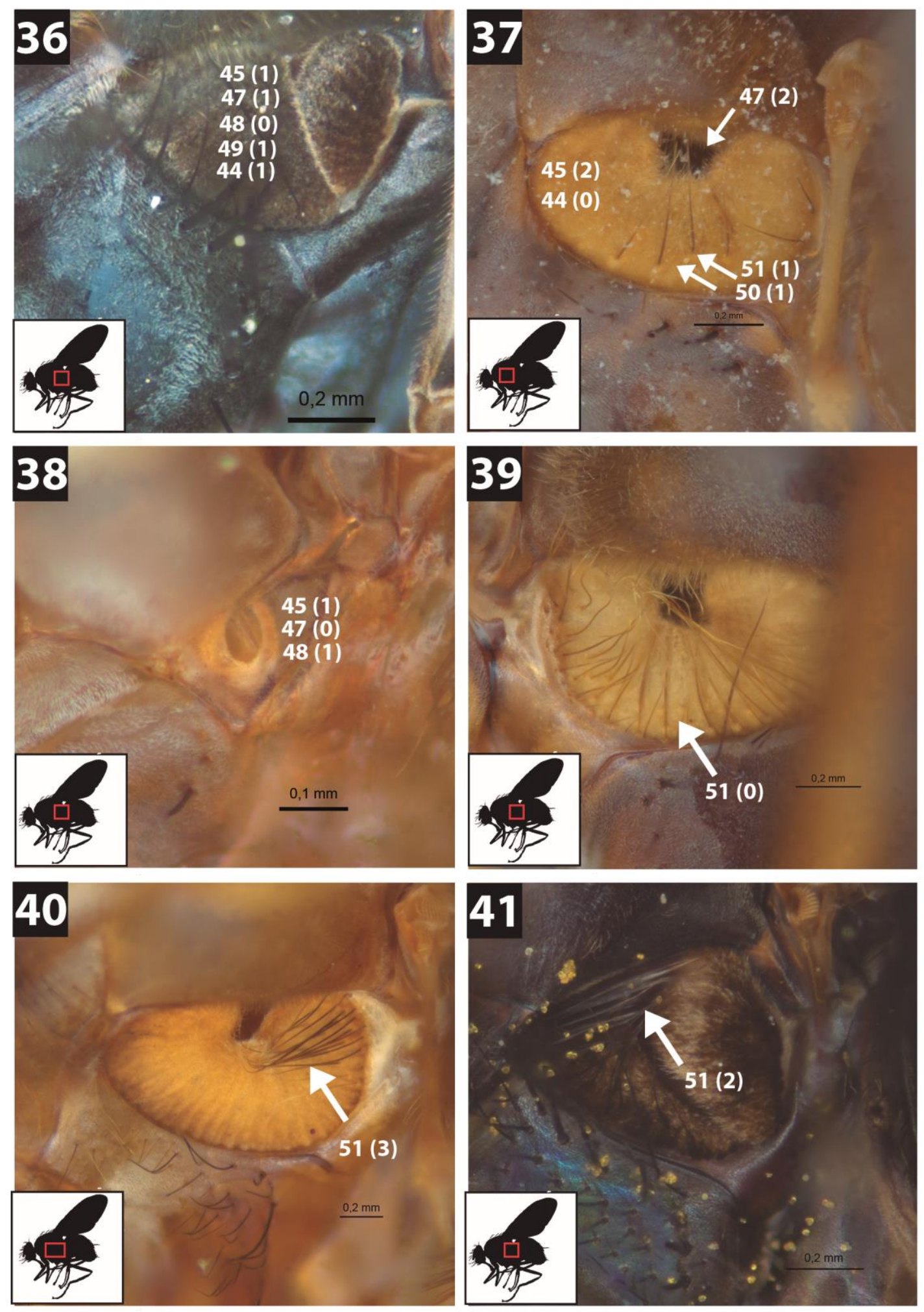

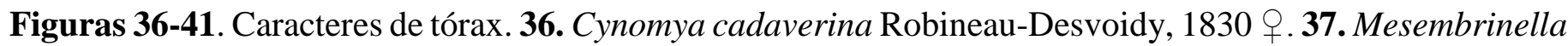
bicolor (Fabricius, 1805) ․ 38. Acaulona costata Wulp, 1888 §̂. 39. Mesembrinella currani Guimarães, 1977 ๆ. 40. Mesembrinella facialis (Aldrich, 1922) Ô. 41. Amenia imperialis Robineau-Desvoidy, 1830 ๆ. $\mathrm{O}$ número do caráter e seu respectivo estado entre parênteses são apontados nas figuras. 

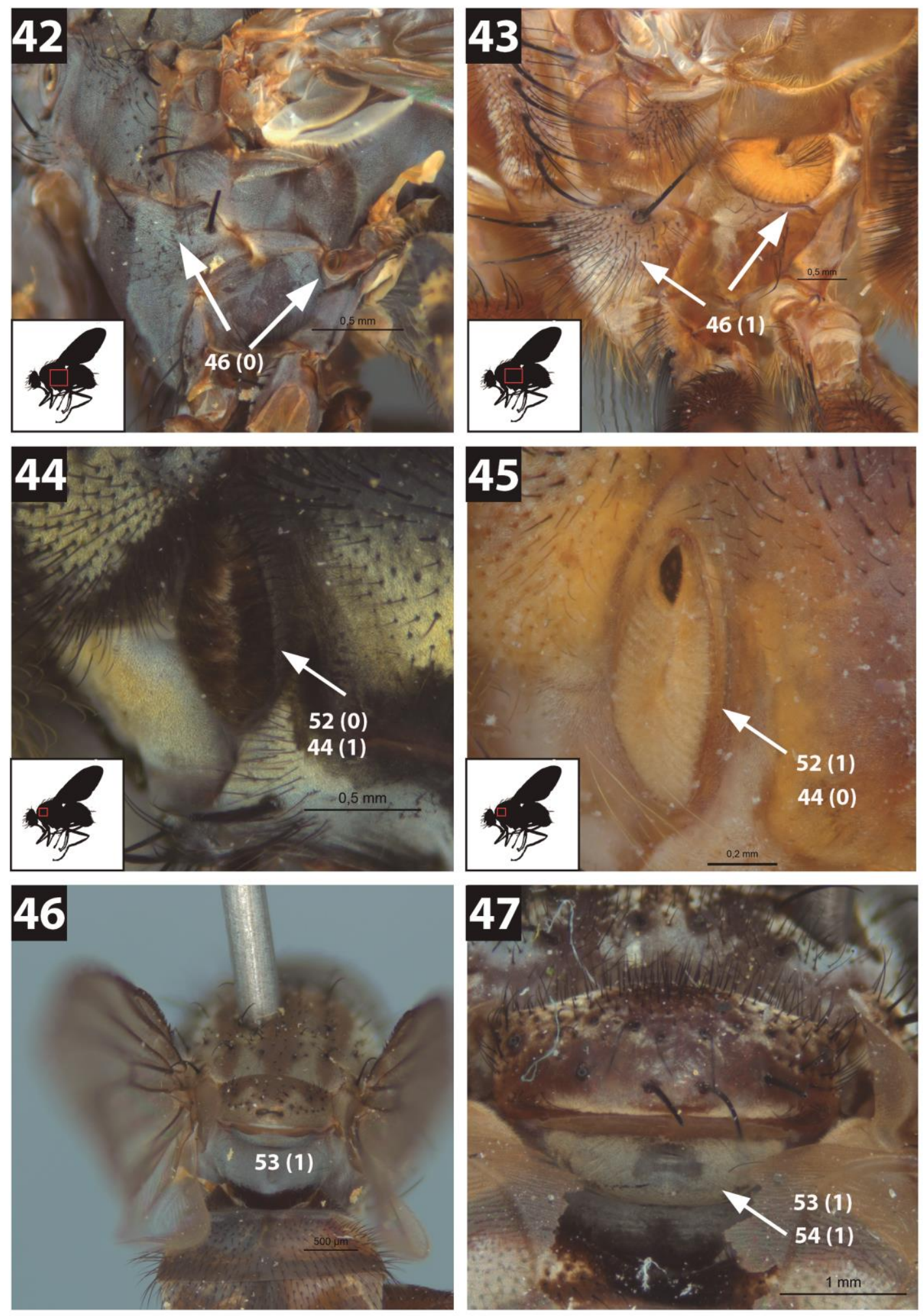

Figuras 42-47. Caracteres de tórax. 42. Fannia heydenii (Wiedemann, 1830) §. 43. Mesembrinella facialis

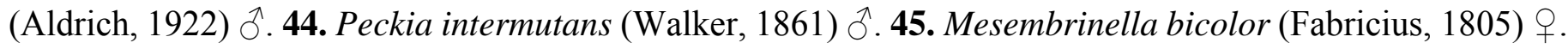

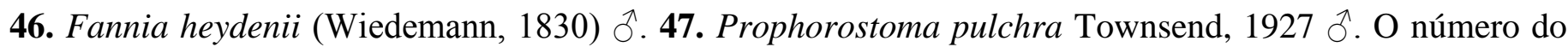
caráter e seu respectivo estado entre parênteses são apontados nas figuras. 

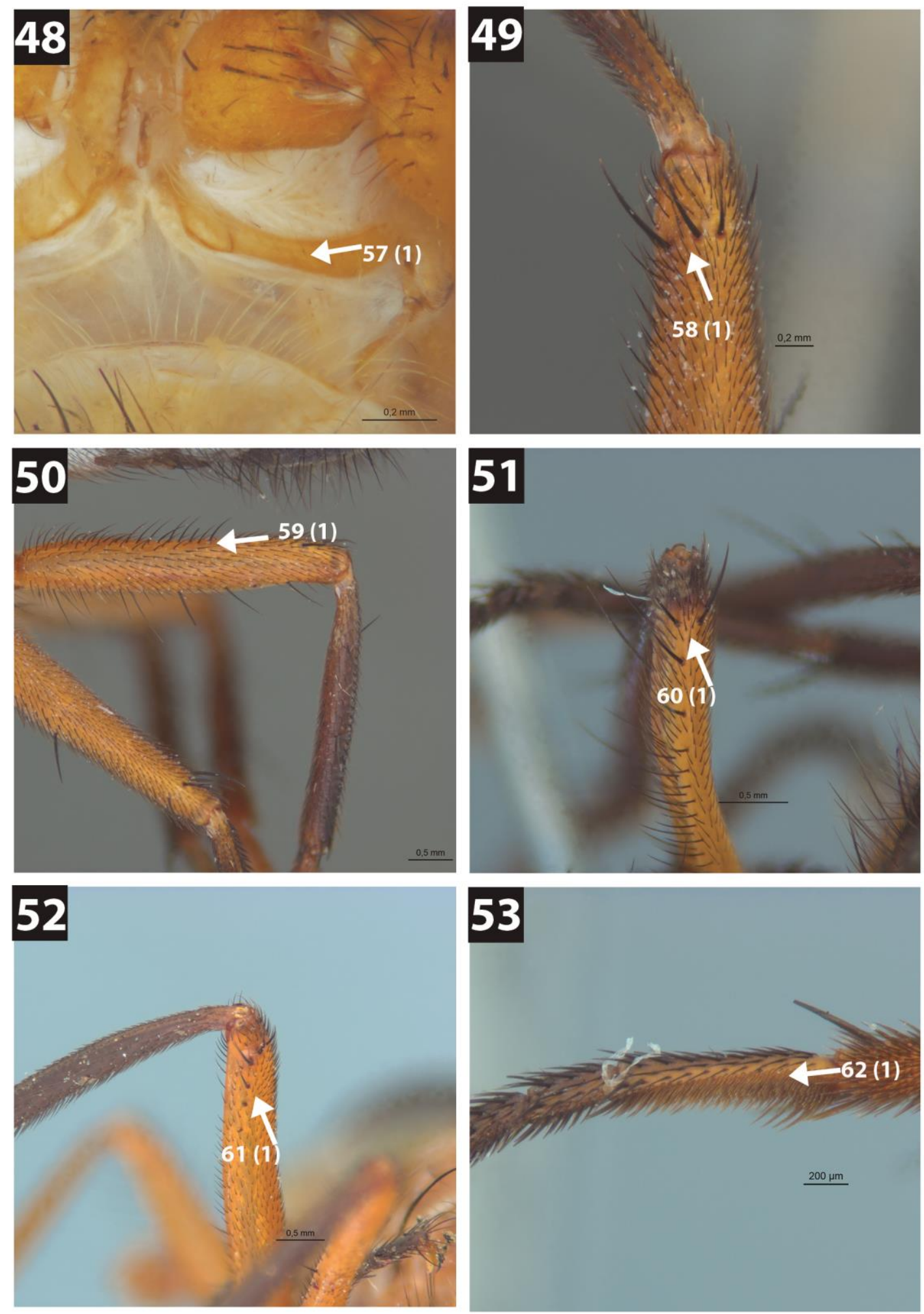

Figuras 48-53. Caracteres de perna. 48. Mesembrinella nigripes comb. n. (Guimarães, 1977) $\overbrace{}^{\Uparrow}$. Mesembrinella bicolor (Fabricius, 1805) ․ 50. Mesembrinella bicolor (Fabricius, 1805) +. 51.

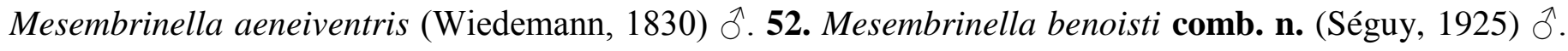
53. Mesembrinella aeneiventris (Wiedemann, 1830) đ̂. O número do caráter e seu respectivo estado entre parênteses são apontados nas figuras. 

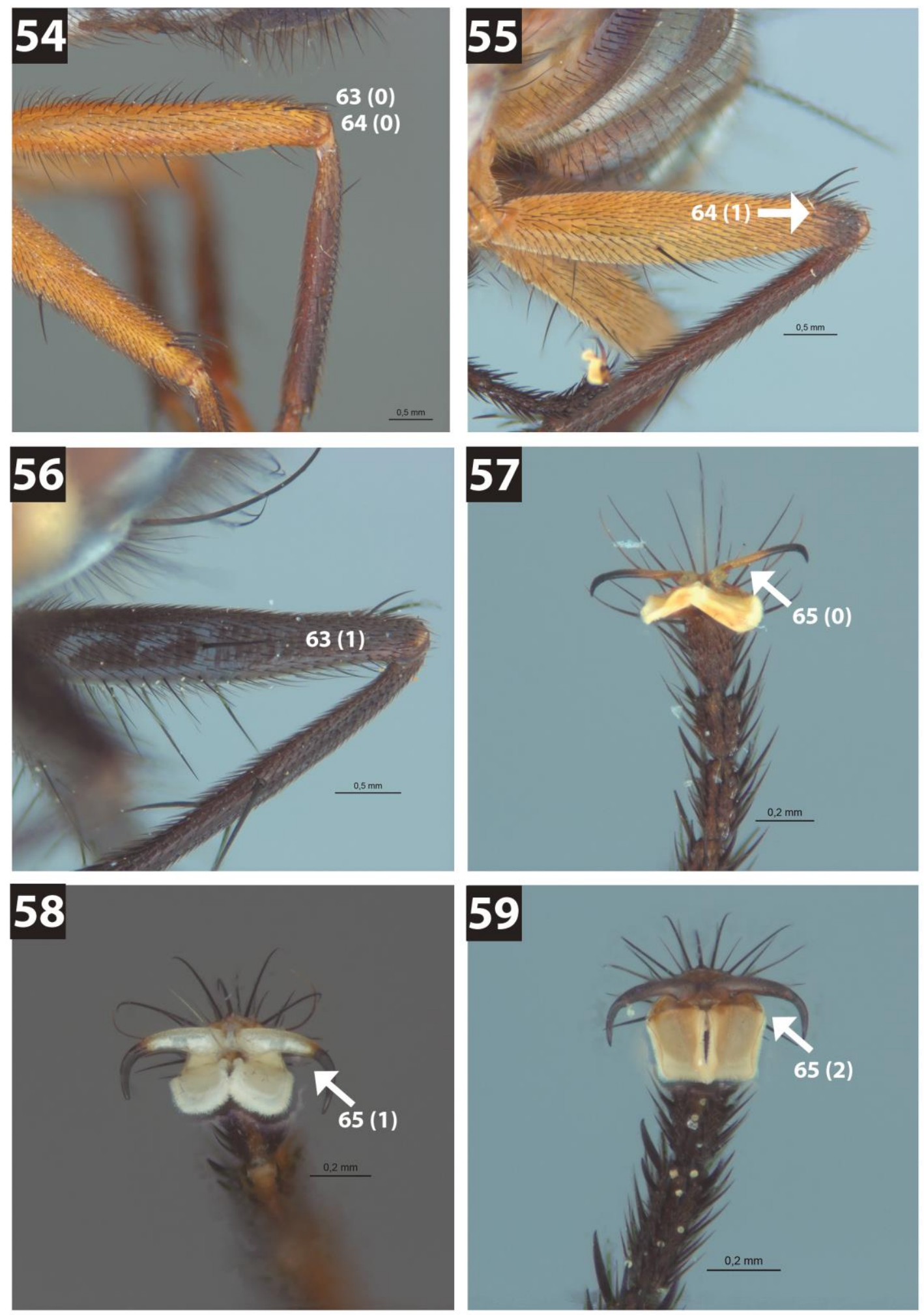

Figuras 54-59. Caracteres de perna. 54. Mesembrinella bicolor (Fabricius, 1805) ․ 55. Mesembrinella aeneiventris (Wiedemann, 1830) § . 56. Mesembrinella xanthorrhina (Bigot, 1887) ๆ. 57. Mesembrinella aeneiventris (Wiedemann, 1830) $\widehat{\jmath}$. 58. Mesembrinella nigripes comb. n. (Guimarães, 1977) $\widehat{\jmath} .59$. Mesembrinella spicata (Aldrich, 1922) đ̃. O número do caráter e seu respectivo estado entre parênteses são apontados nas figuras. 

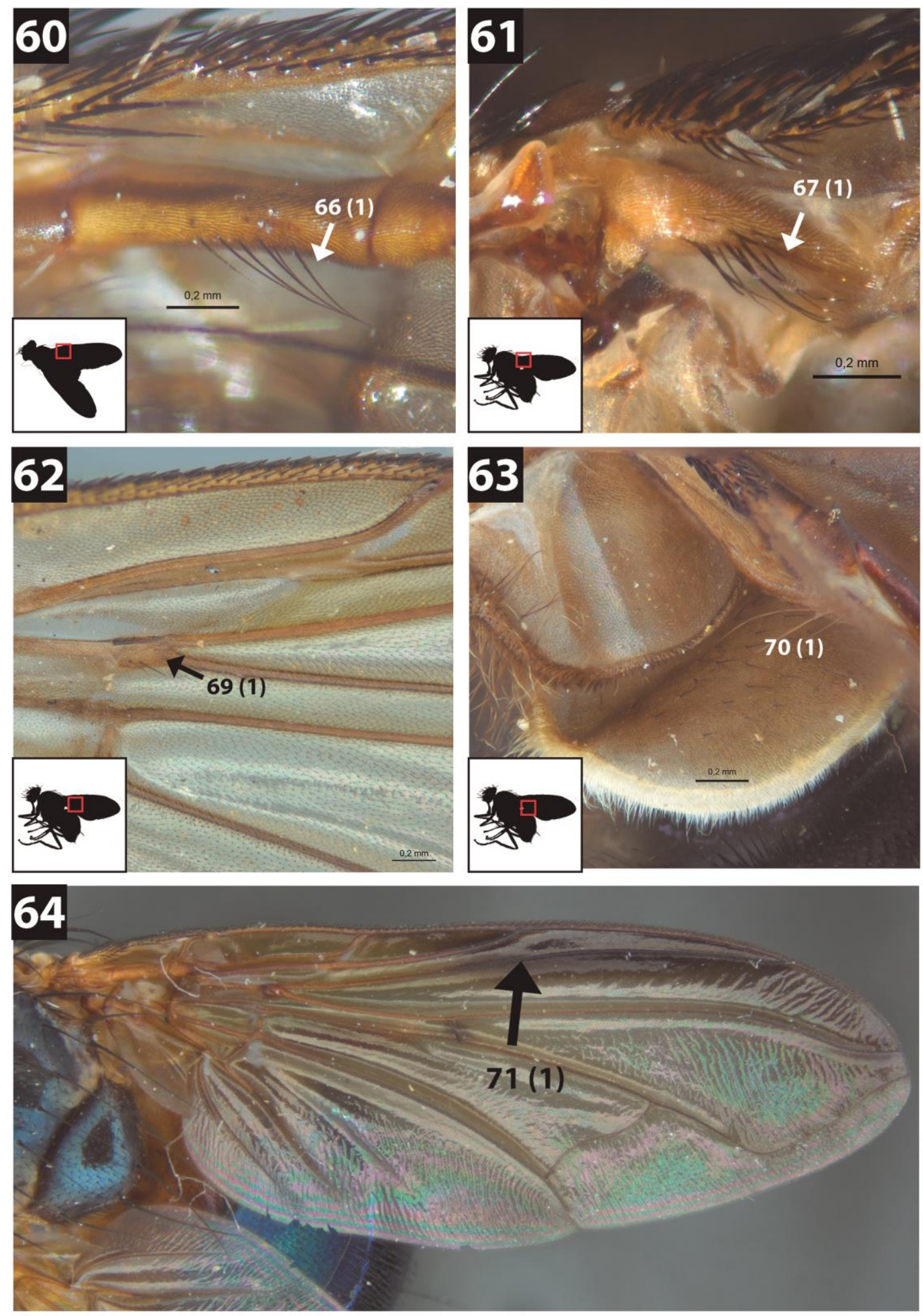

Figuras 60-64. Caracteres de asa. 60. Mesembrinella bellardiana Aldrich, 1922 +. 61. Mesembrinella bellardiana Aldrich, 1922 †. 62. Mesembrinella benoisti comb. n. (Séguy, 1925) §̊. 63. Calliphora vomitoria (Linnaeus, 1758) $\widehat{\partial}$. 64. Mesembrinella decrepita (Séguy, 1925) $\widehat{\jmath}$. O número do caráter e seu respectivo estado entre parênteses são apontados nas figuras. 

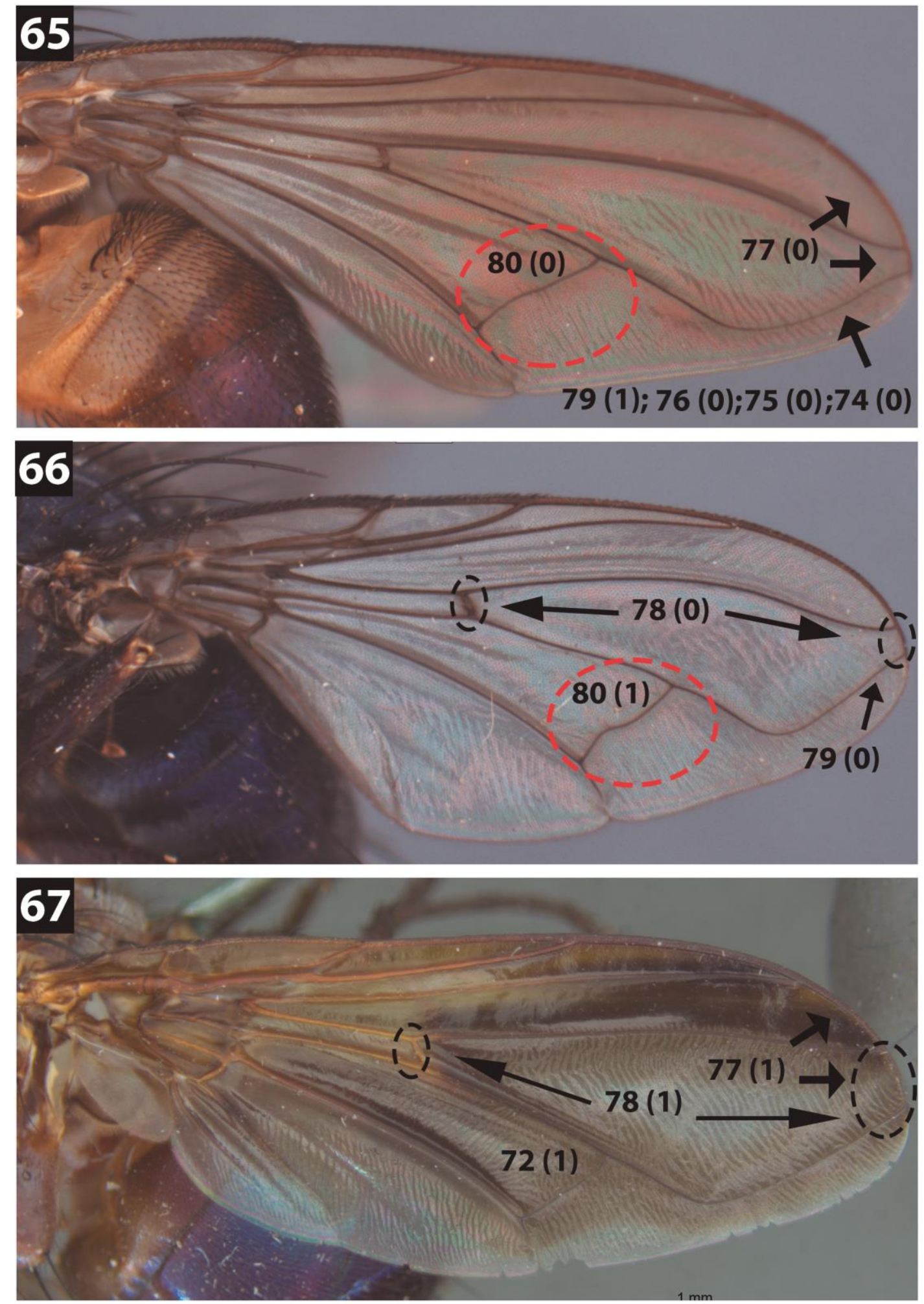

Figuras 65-67. Caracteres de asa. 65. Mesembrinella semiflava (Aldrich, 1925) ㅇ. 66. Mesembrinella uniseta (Aldrich, 1925) đ. 67. Mesembrinella pictipennis Aldrich, 1922 ๆ. O número do caráter e seu respectivo estado entre parênteses são apontados nas figuras. 

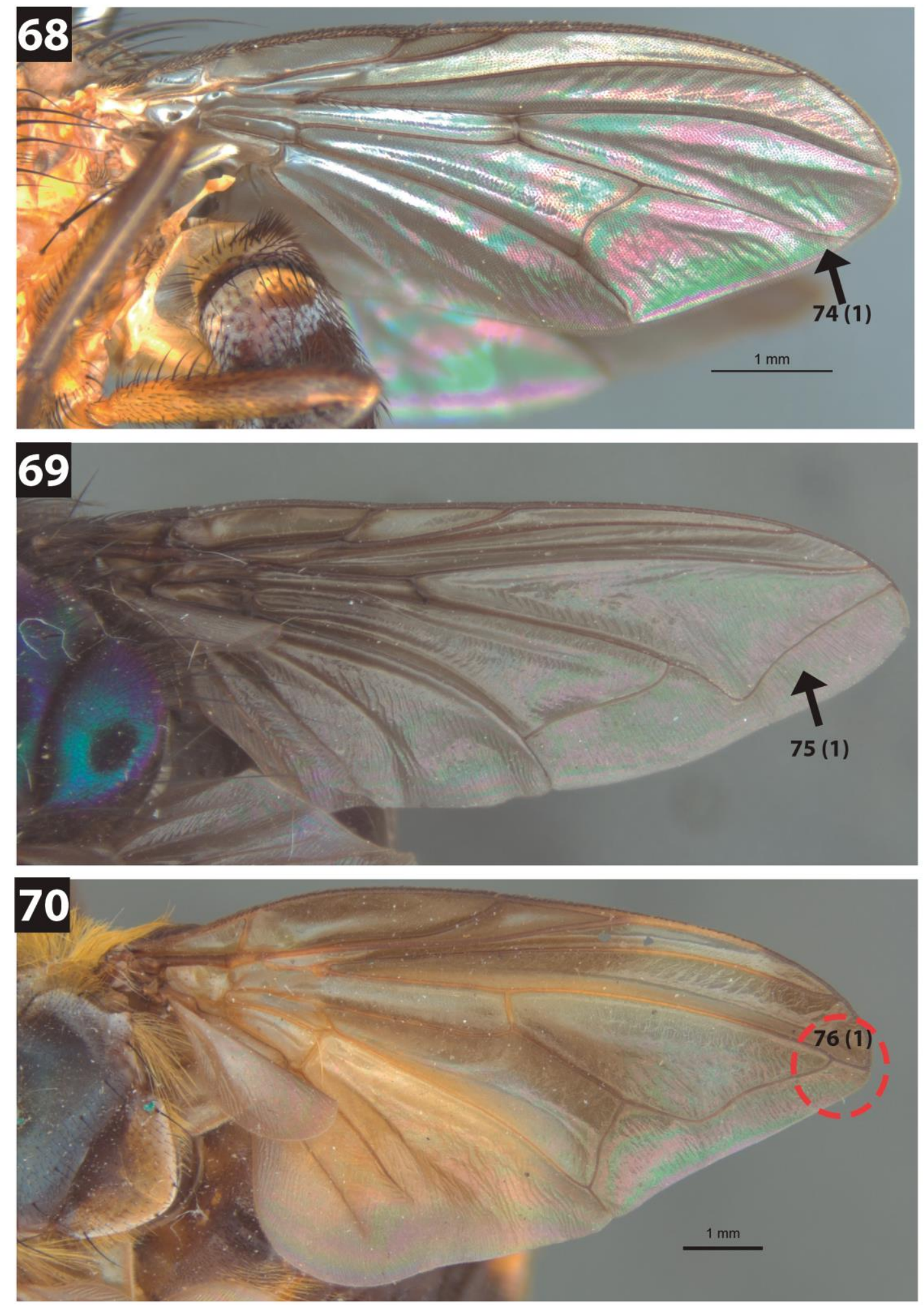

Figuras 68-70. Caracteres de asa. 68. Polietina flavithorax (Stein, 1904) ${ }_{+}$. 69. Neta chilensis (Walker, 1836)

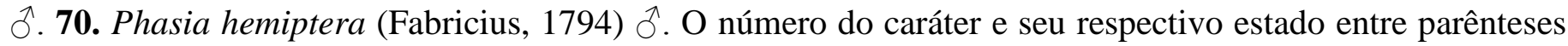
são apontados nas figuras. 

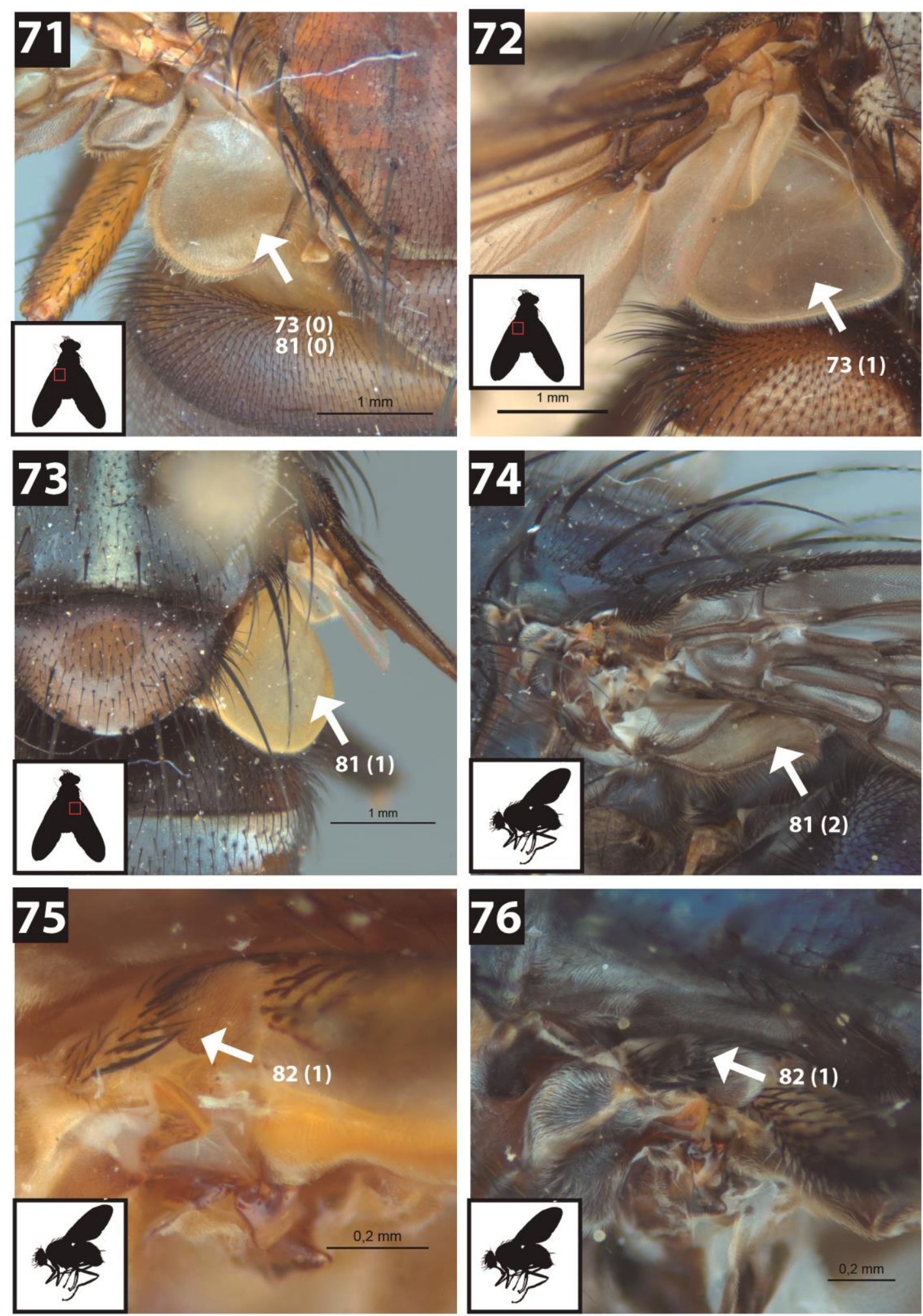

Figuras 71-76. Caracteres de asa. 71. Mesembrinella bellardiana Aldrich, 1922 q. 72. Prophorostoma

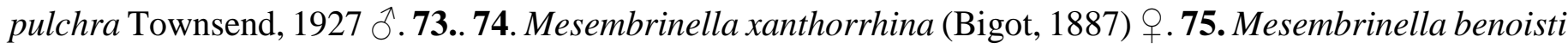
comb. n. (Séguy, 1925) §ึ. 76. Mesembrinella xanthorrhina (Bigot, 1887) † O número do caráter e seu respectivo estado entre parênteses são apontados nas figuras. 

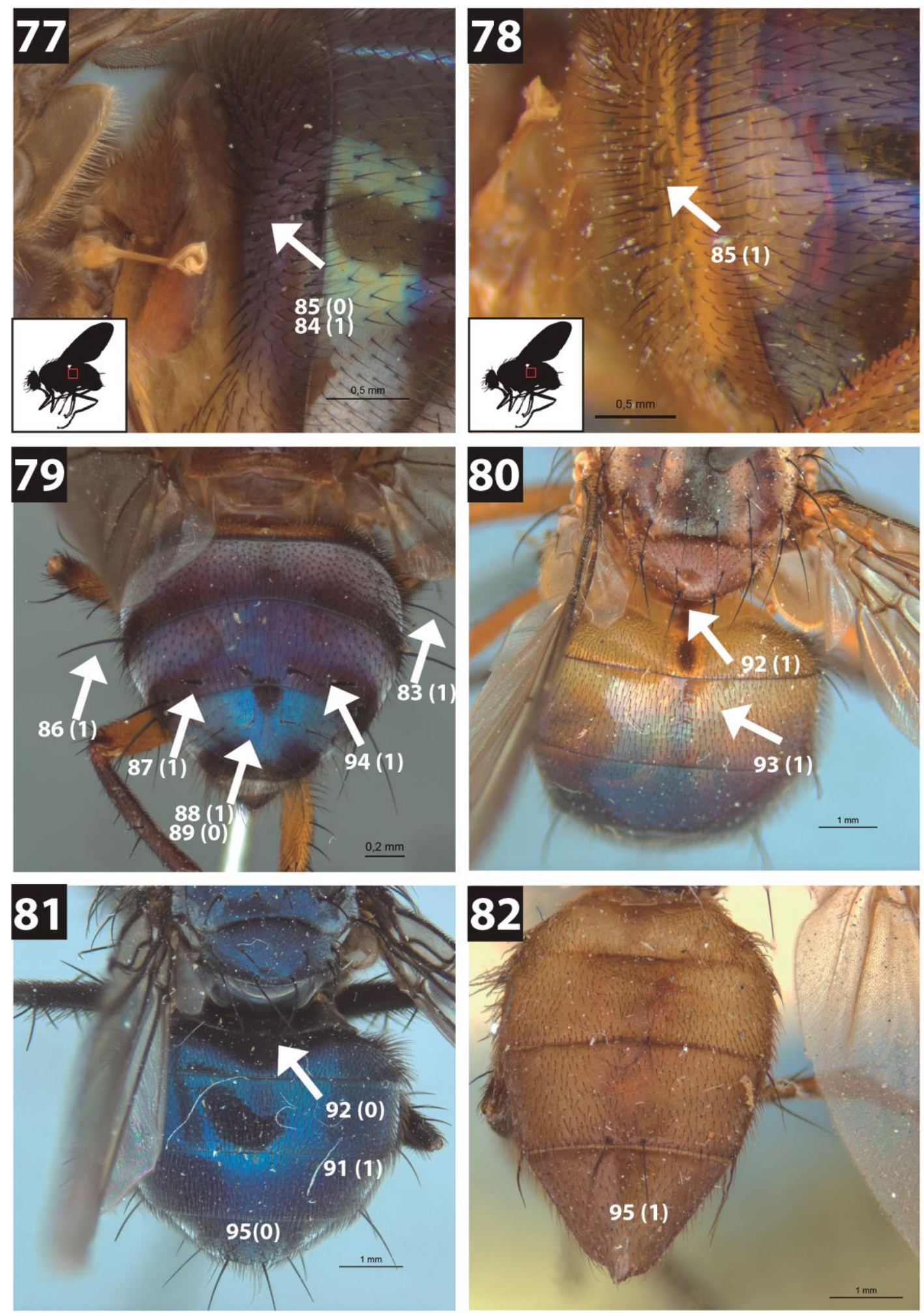

Figuras 77-82. Caracteres de abdômen. 77. Mesembrinella aeneiventris (Wiedemann, 1830) $\overbrace{}^{\lambda} .78$. Mesembrinella quadrilineata (Fabricius, 1805) ․ 79. Mesembrinella aeneiventris (Wiedemann, 1830) $\widehat{\partial}$. 80. Mesembrinella benoisti comb. n. (Séguy, 1925) Mesembrinella anomala comb. n. PT Guimarães, 1977 \&. O número do caráter e seu respectivo estado entre parênteses são apontados nas figuras. 

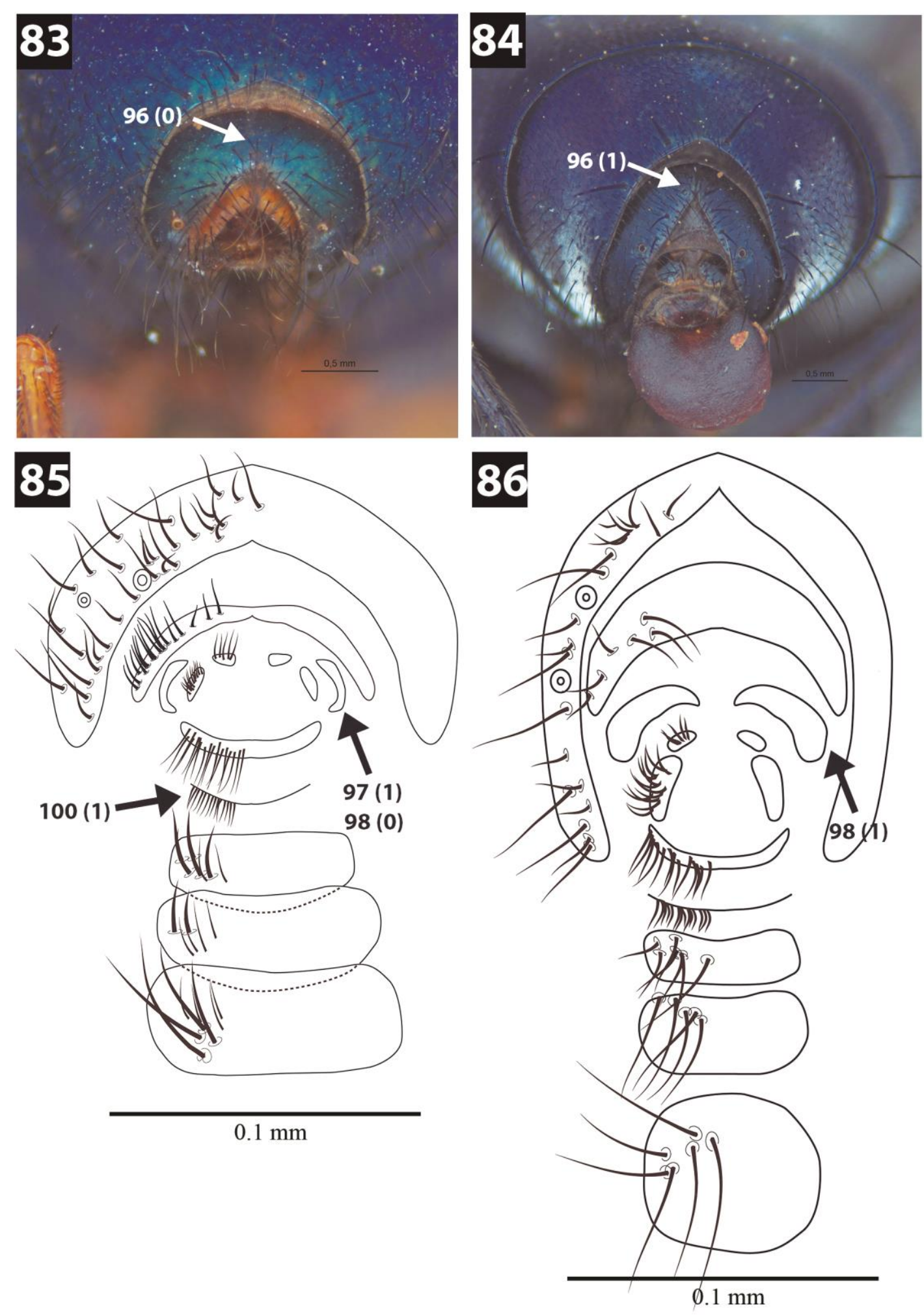

Figuras 83-86. Caracteres de terminália feminina. 83. Mesembrinella bicolor Aldrich, 1922 q. 84. Mesembrinella xanthorrhina (Bigot, 1887) ․ 85. Mesembrinella umbrosa (Wiedemann, 1830) $\widehat{\jmath} .86$. Mesembrinella purpurata (Aldrich, 1922) 9 . O número do caráter e seu respectivo estado entre parênteses são apontados nas figuras. 

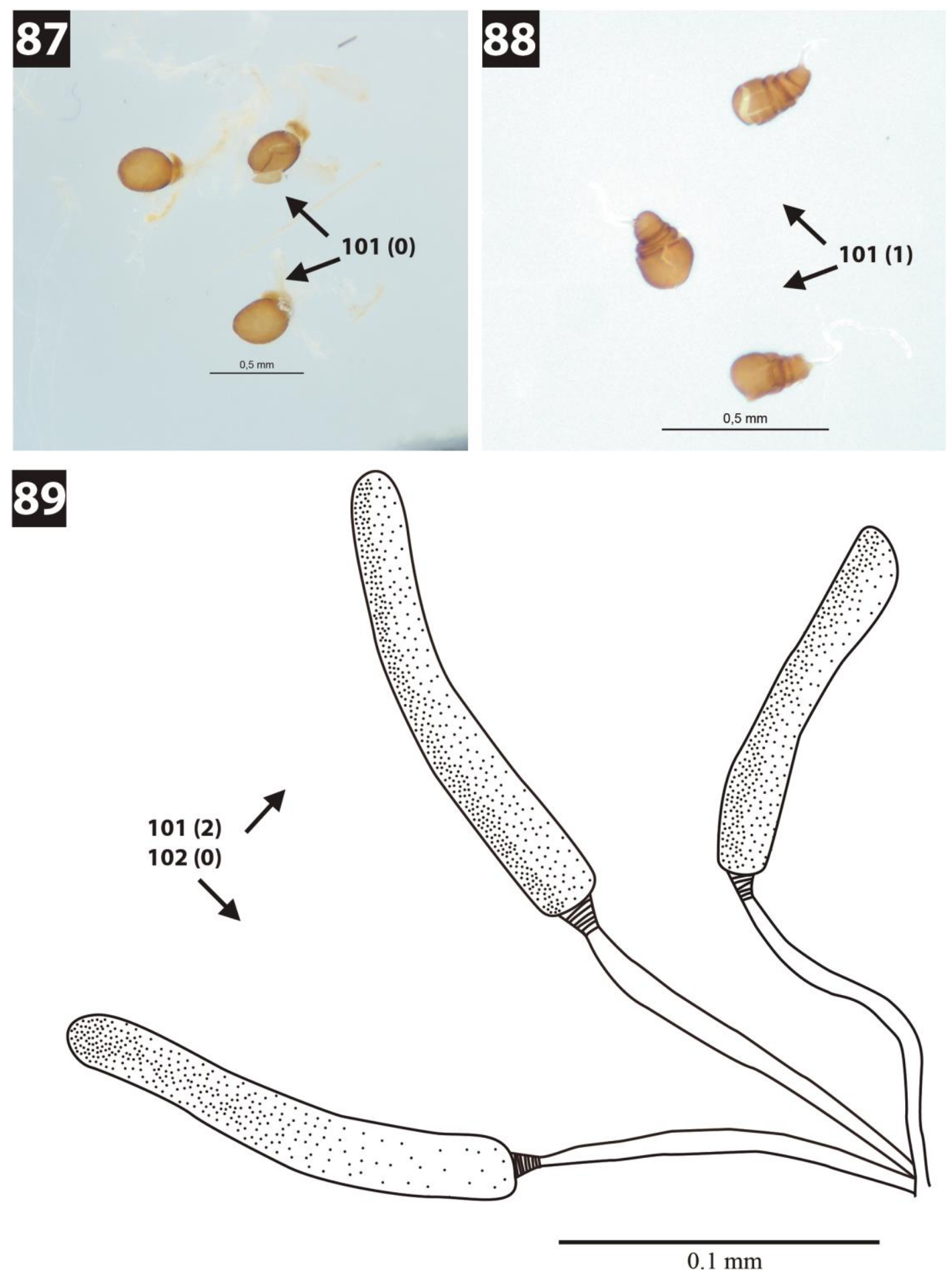

Figuras 87-89. Caracteres de terminália feminina. 87. Adejeania townsendi Curran, 1947 q. 88. Peckia intermutans (Walker, 1861) ․ 89. Mesembrinella nigripes comb. n. (Guimarães, 1977) †. O número do caráter e seu respectivo estado entre parênteses são apontados nas figuras. 

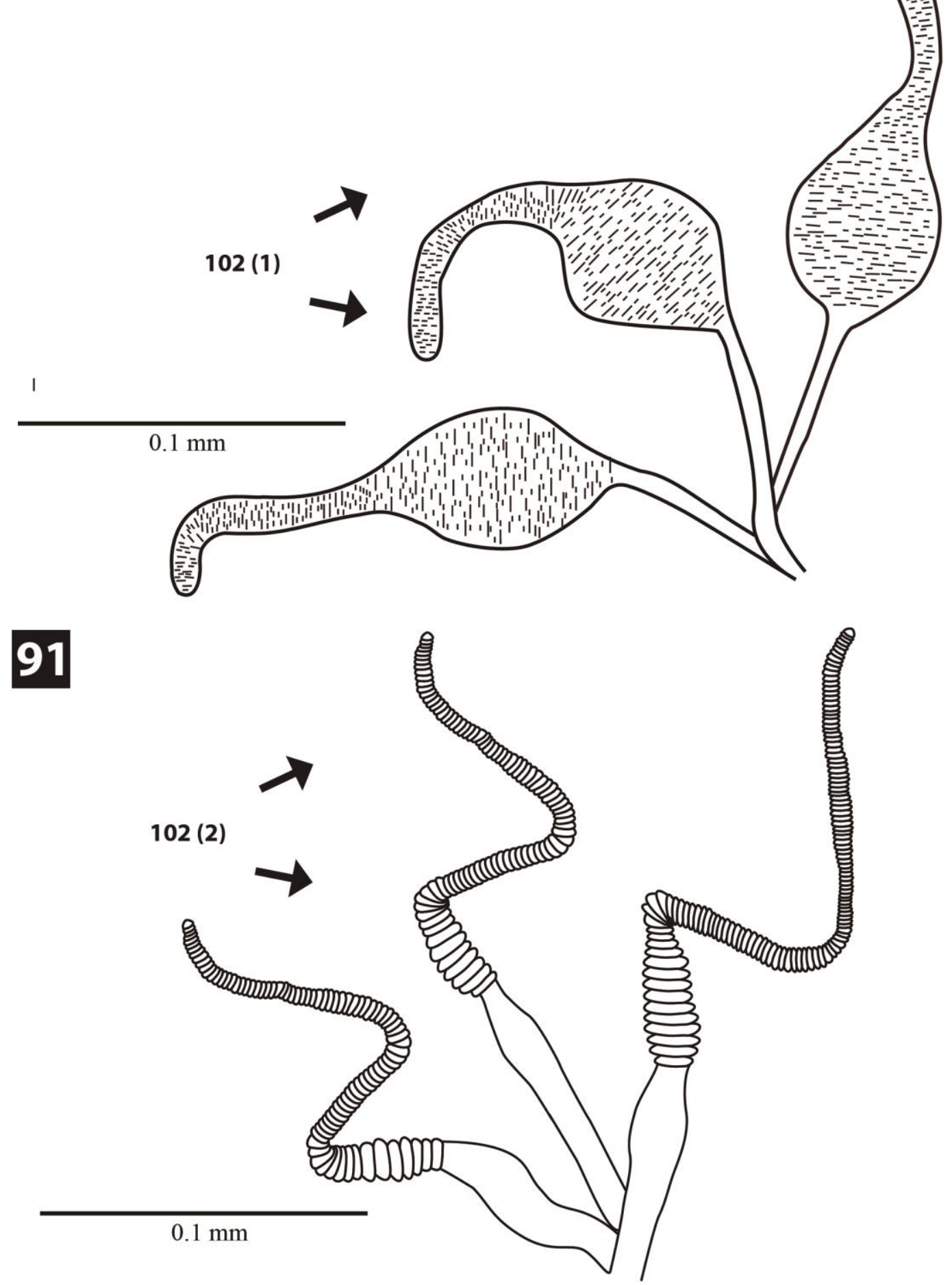

Figuras 90-91. Caracteres de terminália feminina. 90. Mesembrinella facialis (Aldrich, 1922) $q .91$. Mesembrinella umbrosa (Wiedemann, 1830) ․ O número do caráter e seu respectivo estado entre parênteses são apontados nas figuras. 

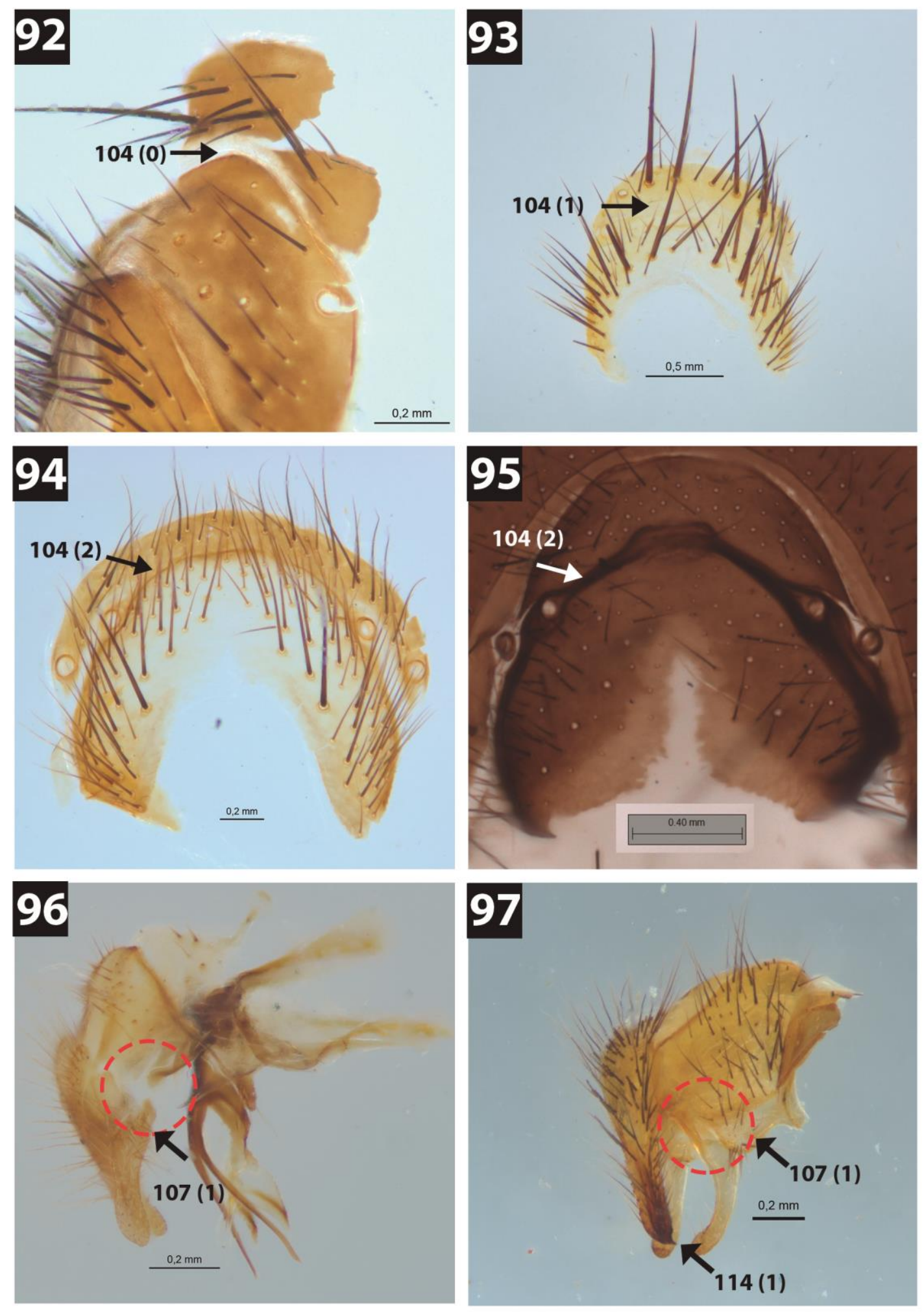

Figuras 92-97. Caracteres de terminália masculina. 92. Mesembrinella nigripes com. n. (Guimarães, 1977)

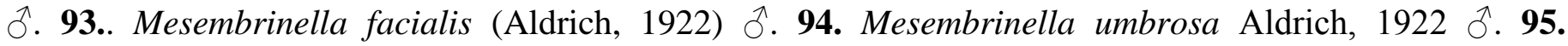
Mesembrinella xanthorrhina (Bigot, 1887) §ิ. 96. Polenia rudis (Fabricius, 1794) §ิ. 97. Mesembrinella semyhialina Mello, 1967 đ. O número do caráter e seu respectivo estado entre parênteses são apontados nas figuras. 


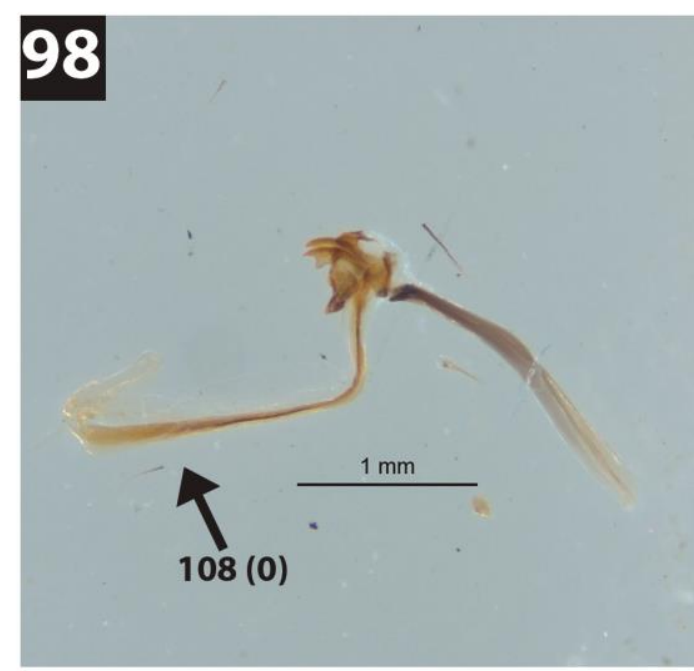

\section{9}

\section{0}

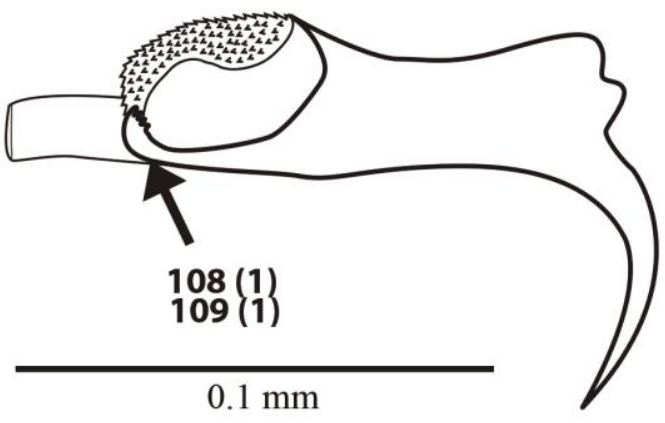

101
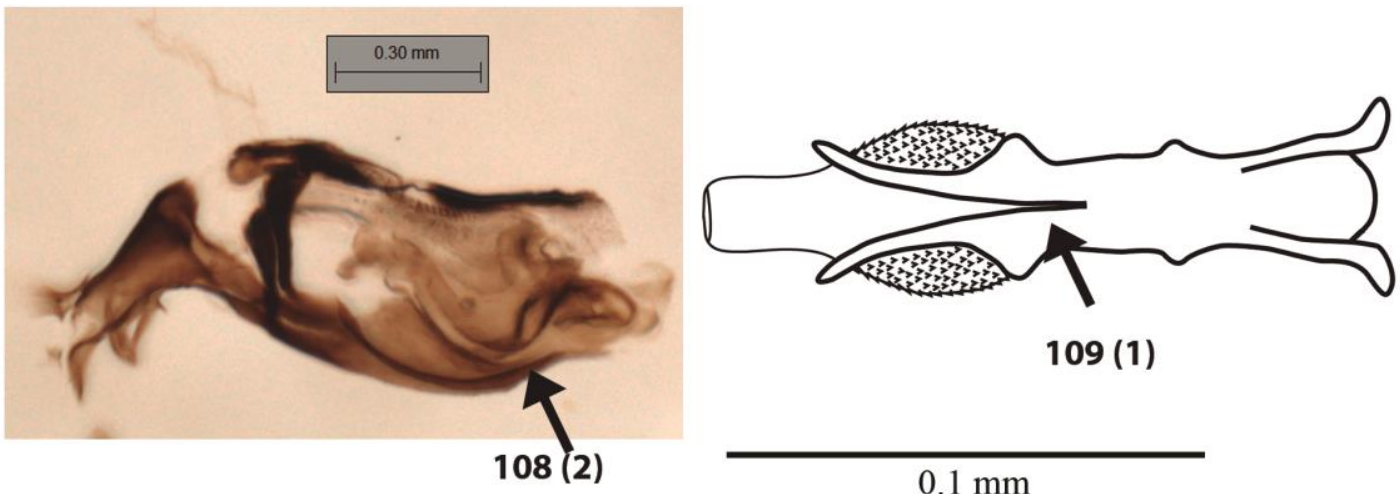

102

\section{3}
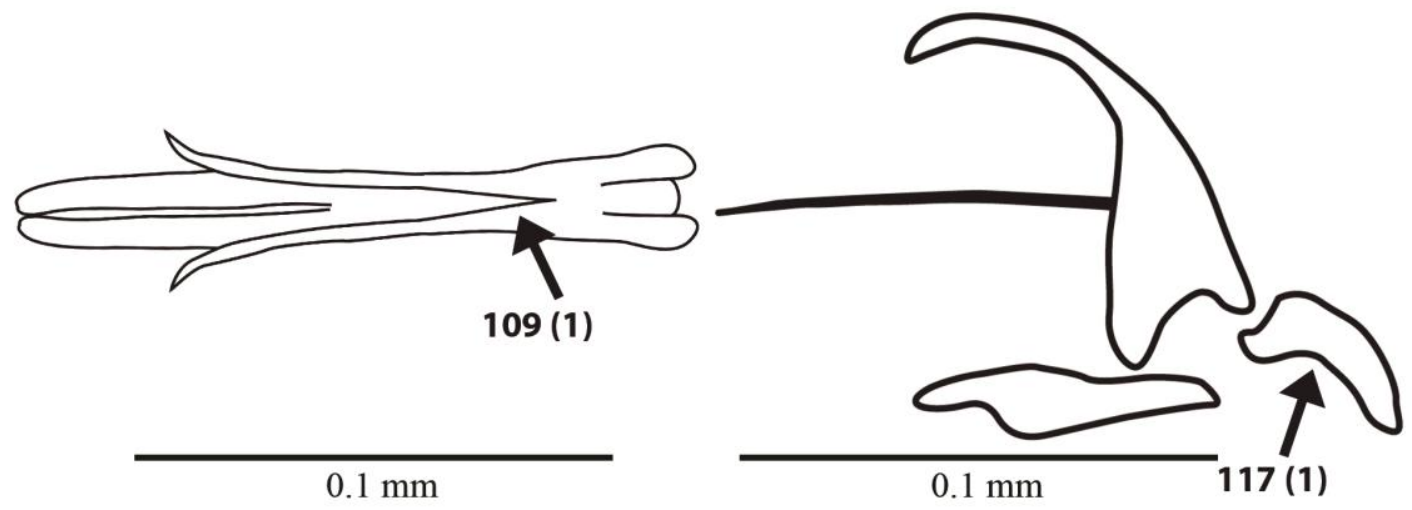

Figuras 98-103. Caracteres de terminália masculina. 98. Phasia hemiptera (Fabricius, 1794) $\overbrace{}^{\Uparrow} .99$. Mesembrinella peregrina Aldrich, 1922 $\curvearrowright$. 100. Idiella mandarina (Wiedemann, 1830) $\widehat{\jmath} 101$. Mesembrinella peregrina Aldrich, $1922 \hat{\jmath}$. 102. Calliphora vomitória $\widehat{\jmath}$. 103. Mesembrinella peregrina Aldrich, 1922 đ. O número do caráter e seu respectivo estado entre parênteses são apontados nas figuras. 

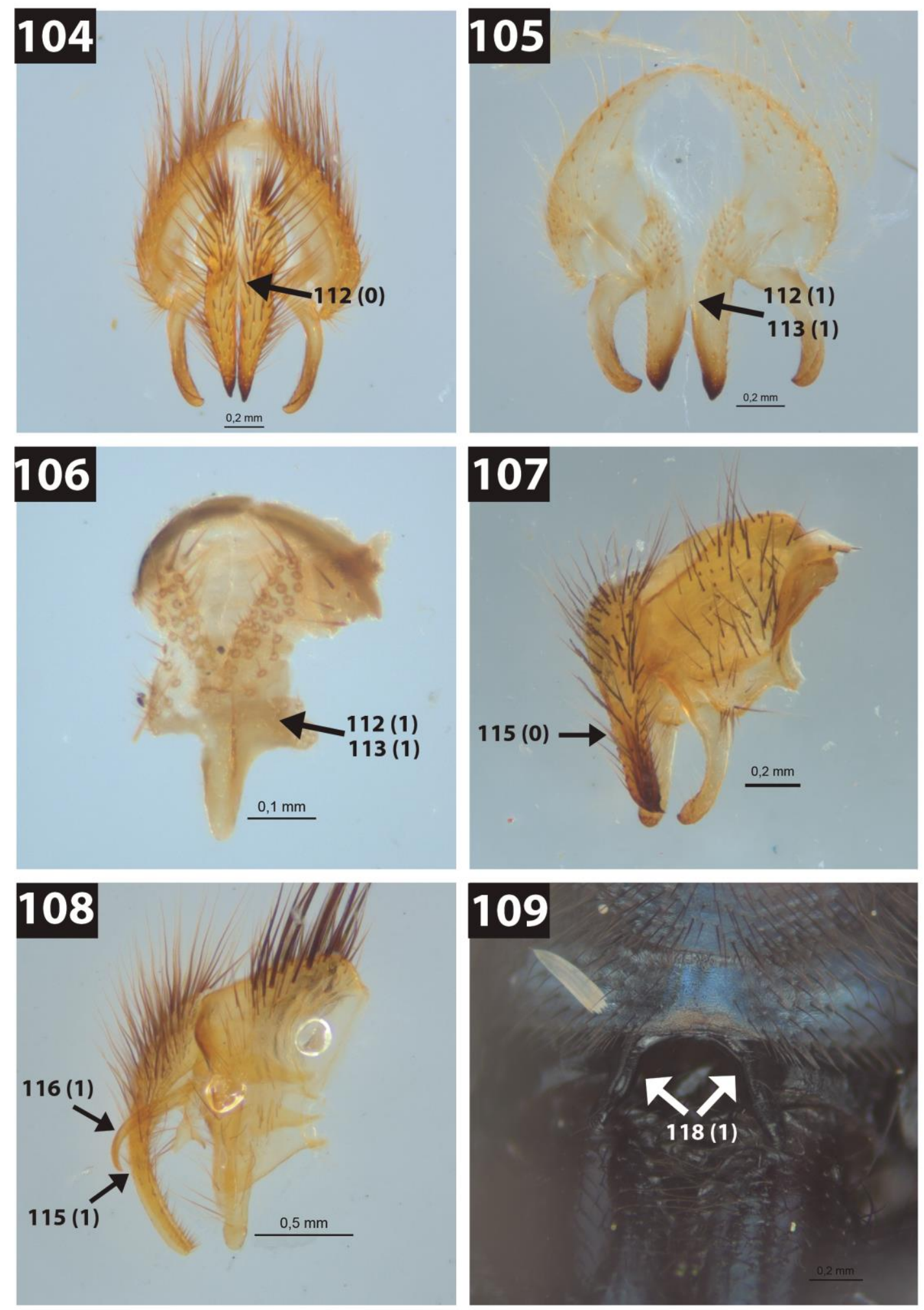

Figuras 104-109. Caracteres de terminália masculina.104. Mesembrinella umbrosa Aldrich, 1922 ${ }^{\Uparrow}$. Mesembrinella batesi Aldrich, $1922 \precsim$

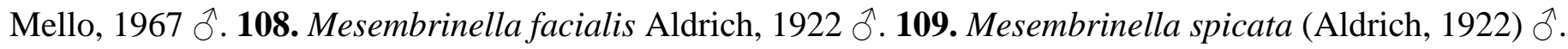
O número do caráter e seu respectivo estado entre parênteses são apontados nas figuras. 

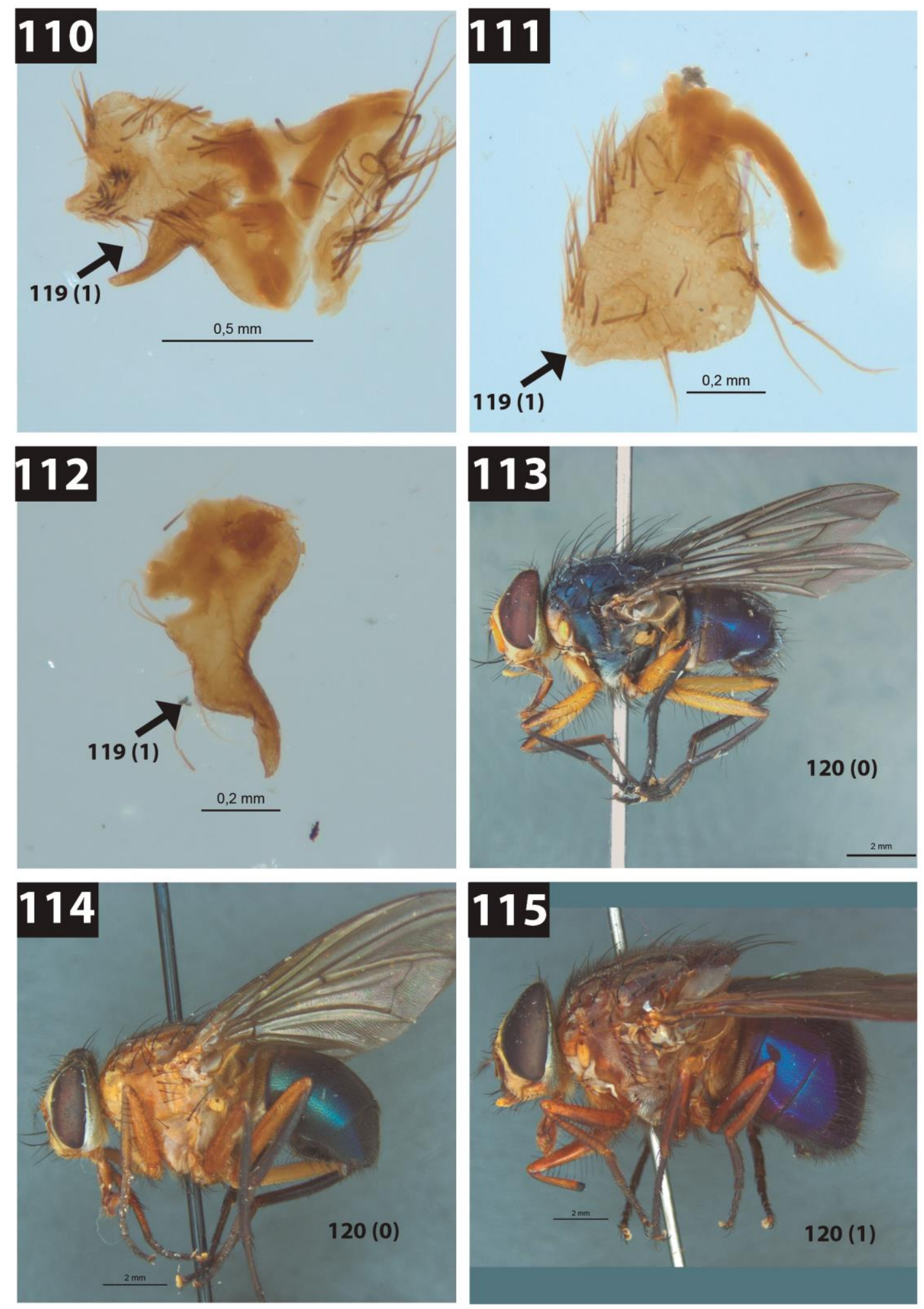

Figuras 110-115. Caracteres de terminália masculina. 110. Mesembrinella anomala HT (Guimarães, 1977) $\overbrace{}^{\lambda}$ 111. Mesembrinella anomala HT (Guimarães, 1977) $\lesssim$. 112. Mesembrinella anomala HT (Guimarães, 1977)

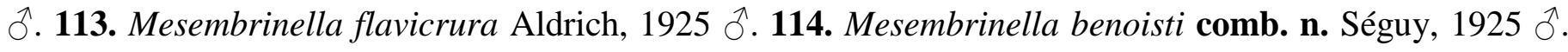
115. Mesembrinella umbrosa Aldrich, 1922 đ̃. O número do caráter e seu respectivo estado entre parênteses são apontados nas figuras. 


\subsubsection{Análise cladística}

As análises de parcimônia com pesagem igual dos caracteres resultaram em 392 cladogramas igualmente parcimoniosos ( $\mathrm{L}=671 ; \mathrm{IC}=21 ; \mathrm{RI}=67)$. A árvore de consenso estrito é mostrada nas Figuras 116-118. Mesembrinellidae (clado 9) é um grupo monofilético, com bom suporte (Índice de Bremer=7). Seu grupo irmão está representado por uma politomia entre a espécie de Phumosiinae, Phumosia promittens, e o clado composto pelas espécies Auchmeromyia bequaerti e Bengalia emarginata. Dentro de Mesembrinellidae, é possível observar a formação de dois grandes grupos, clado 13 e clado 16.

Três dos antigos gêneros de Mesembrinellidae foram recuperados como monofiléticos: Laneella (clado 11), Eumesembrinella (clado 17) e Giovanella (clado 20), com índices de Bremer 3, 4 e 2, respectivamente. Por sua vez, o antigo gênero Mesembrinella senso stricto foi encontrado como polifilético, estando representado por um clado maior (clado 13), composto de 12 espécies, por M. patriciae de posição incerta, e por $M$. flavicrura e $M$. xanthorrhina relacionadas com o clado 22. O antigo gênero Huascaromusca é polifilético pela inclusão de Mesembrinella flavicrura, $M$. xanthorrhina e M. spicata (clado 22). Além disso, as relações internas desse clado são bastante inconclusivas com base nessa análise, tendo sido obtida uma grande politomia que inclui quase todas as espécies, sendo mantido somente o clado $M$. bequaerti comb. n. + M. purpurata. Por último, os antigos gêneros monotípicos Souzalopesiella, Albuquerquea e Thompsoniella foram recuperados como espécies irmãs de outros clados maiores. O clado 25 está destacado de cor diferente na Fig. 118 por ser o único agrupamento encontrado na análise com pesagem igual e não encontrado na análise de pesagem implícita.

$\mathrm{Na}$ análise de parcimônia com pesagem implícita dos caracteres foi encontrada somente uma árvore ( $\mathrm{L}=679 ; \mathrm{CI}=21 ; \mathrm{RI}=67 ; k=9875 ;$ Figs. 119-124), Mesembrinellidae (clado 9) também é um grupo monofilético, com suporte de Bremer=0,48 e seu grupo irmão é o clado composto pelas espécies Auchmeromyia bequaerti e Bengalia emarginata. As relações internas de Mesembrinellidae são, de uma maneira geral, semelhantes às da análise com pesagem igual dos caracteres. A diferença mais significativa é a presença do clado 10, formado por Mesembrinella facialis, Mesembrinella nigripes comb. n. e Mesembirnella perisi, como grupo irmão de um clado 
maior (clado 12), composto por todas as demais espécies. $\mathrm{Na}$ análise de pesagem implícita, portanto, há três grandes grupos dentro de Mesembrinellidae, enquanto que na análise anterior havia dois grandes grupos com algumas espécies de posição incerta.

O clado 12 possui bom suporte (Índice de Bremer=0.12) e é composto por dois clados maiores (13 e 15). O clado 13, assim como na análise de pesagem igual dos caracteres, é formado pela maioria das espécies do antigo gênero Mesembrinella senso stricto, com exceção de Mesembrinella patriciae, M. flavicrura e M. xanthorrhina. O clado 15, por sua vez, é formado pelos antigos gêneros: Eumesembrinella, Albuquerquea, Giovanella, Thompsoniella e Huascaromusca, além de três espécies de Mesembrinella mencionadas acima. A espécie Mesembrinella patriciae aparece como o primeiro ramo a divergir desse clado, sendo grupo irmão das demais espécies (clado 16). Essa espécie, entretanto, foi descrita recentemente (Wolff, 2013) e não foi possível seu estudo até a conclusão desta dissertação. Toda a codificação dos seus estados de caráter foi baseada na descrição original, impossibilitando a observação de alguns dos caracteres e, consequentemente, gerando algumas entradas em branco na matriz e, imponderavelmente, possibilitando a existência de erros de codificação para alguns caracteres. O posicionamento dessa espécie ainda é duvidoso e precisa ser melhor estudado. Dentro do clado 16, o clado 17 possui um bom suporte de ramos (Índice de Bremer=0,23). Mesembrinella anomala comb. n. é grupo irmão do clado 22, que era considerado Huascaromusca senso lato, com a inclusão de Mesembrinella flavicrura, $M$. xanthorrhina e M. spicata. Por sua vez, o clado 20, antigo gênero Giovanella, é monofilético com Índice de Bremer=0.16. 


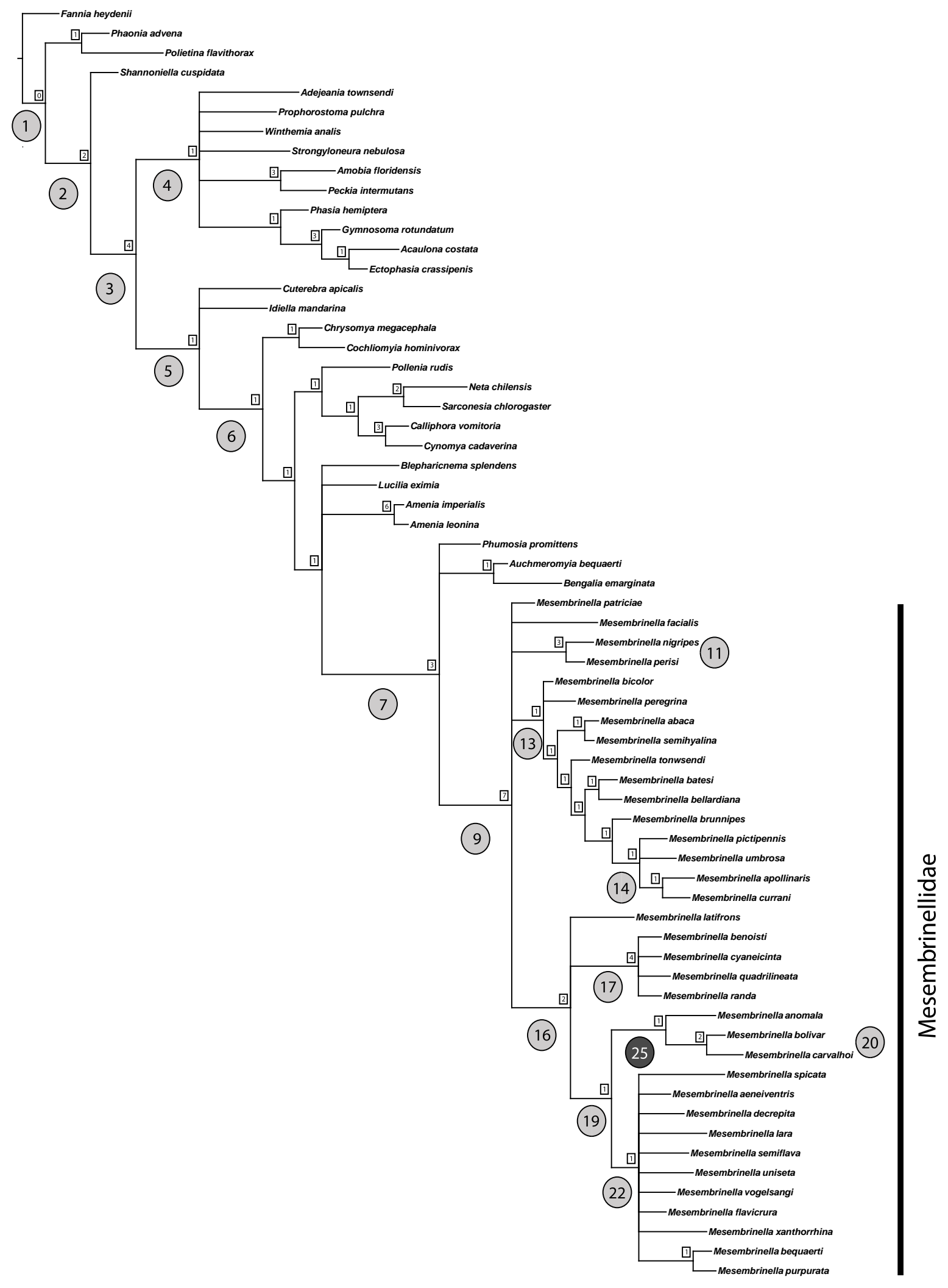

Figura 116. Árvore de consenso estrito dos 392 cladogramas igualmente parcimoniosos ( $\mathrm{L}=671$; IC=21; $\mathrm{RI}=67$ ) encontrados na análise de parcimônia sob pesagem igual dos caracteres. Os números acima dos nós, dentro de retângulos, indicam os valores do Índice de decaimento de Bremer (1994). Os números abaixo dos nós, dentro de círculos, são uma codificação arbitrária dos nós, utilizada para referência ao longo do texto. 


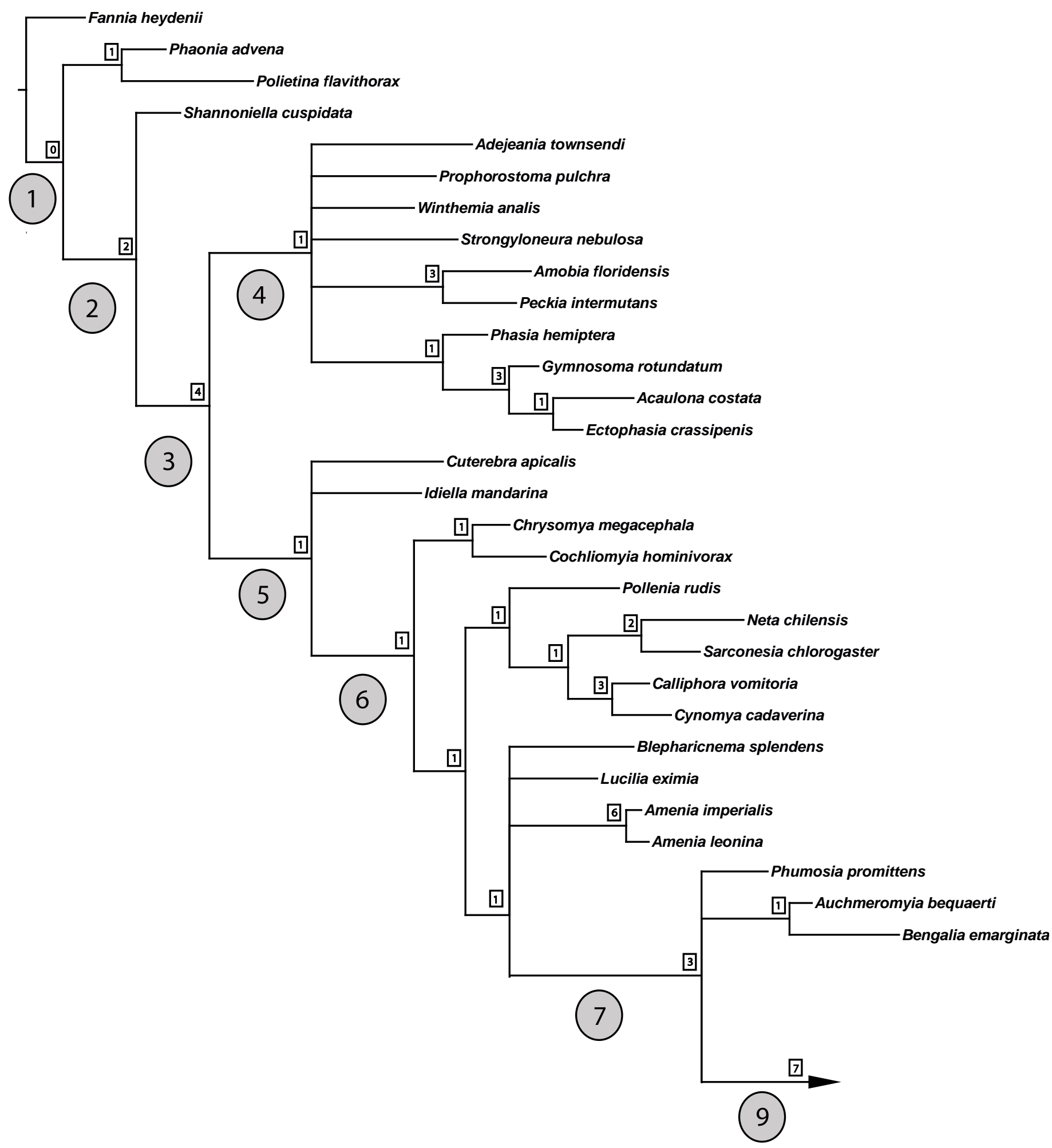

Figura 117. Parte 1 da árvore de consenso estrito dos 392 cladogramas igualmente parcimoniosos ( $\mathrm{L}=671$; $\mathrm{IC}=21 ; \mathrm{RI}=67$ ) encontrados na análise de parcimônia sob pesagem igual dos caracteres. Os números acima dos nós, dentro de retângulos, indicam os valores do Índice de decaimento de Bremer (1994). Os números abaixo dos nós, dentro de círculos, são uma codificação arbitrária dos nós, utilizada para referência ao longo do texto. 


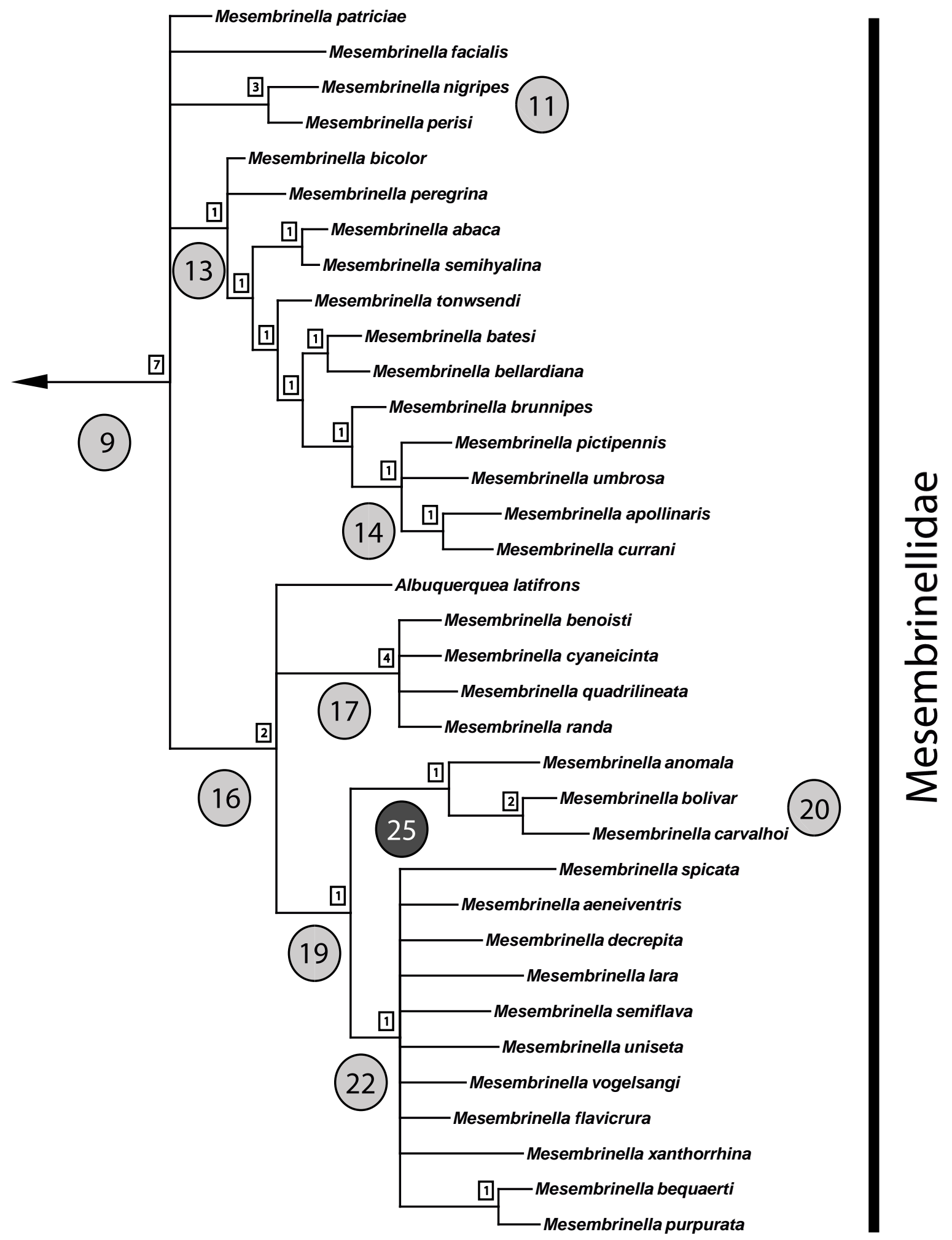

Figura 118. Parte 2 da árvore de consenso estrito dos 392 cladogramas igualmente parcimoniosos $(\mathrm{L}=671$; $\mathrm{CI}=21 ; \mathrm{RI}=67$ ) encontrados na análise de parcimônia sob pesagem igual dos caracteres. Os números acima dos nós, dentro de retângulos, indicam os valores do Índice de decaimento de Bremer (1994). Os números abaixo dos nós, dentro de círculos, são uma codificação arbitrária dos nós, utilizada para referência ao longo do texto. 


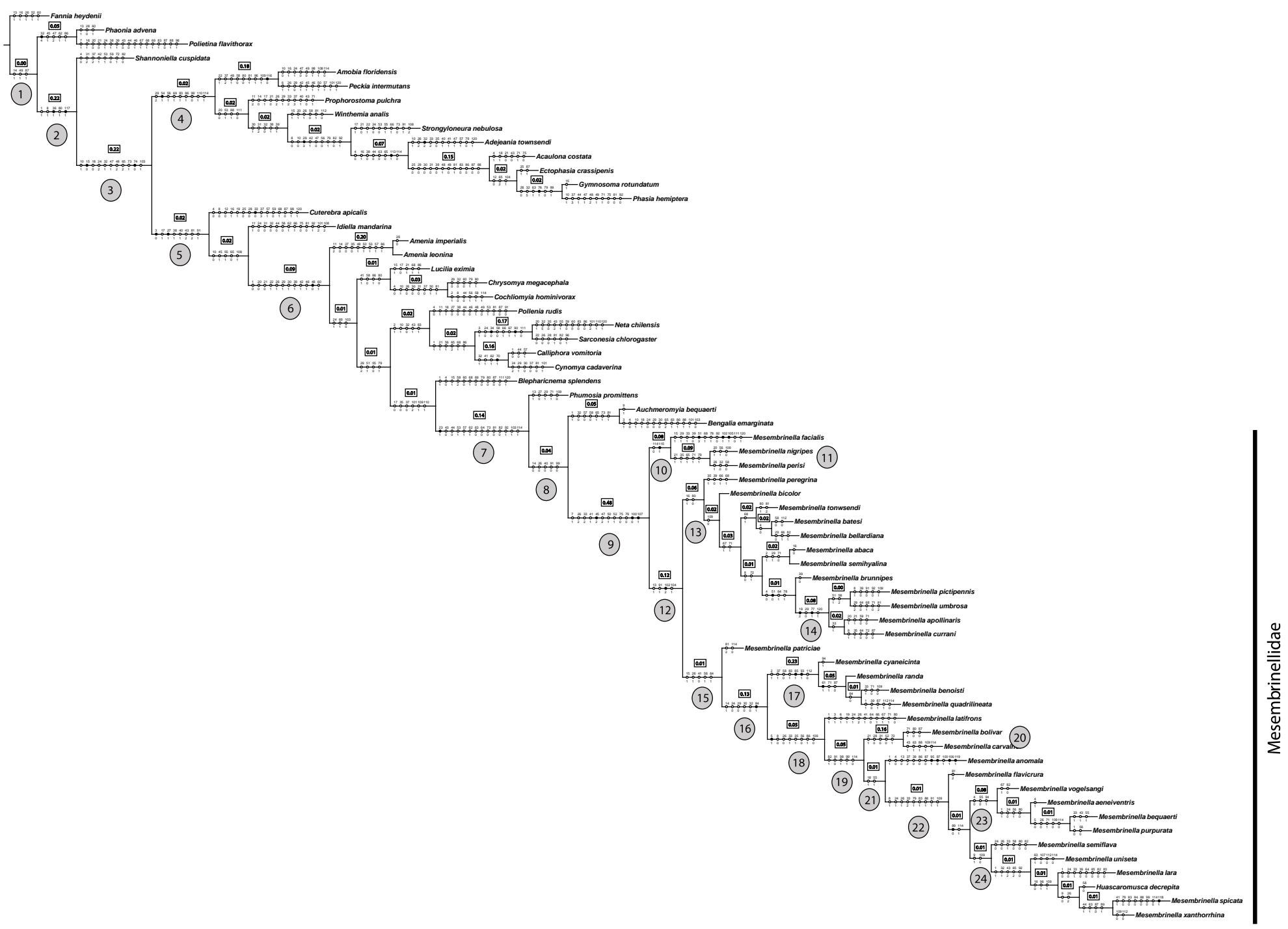

Figura 119. Cladograma obtido na análise sob pesagem implícita dos caracteres ( $\mathrm{L}=679 ; \mathrm{CI}=21$; RI=67; $k=9$,6875). Os números acima dos nós, dentro de retângulos, indicam os valores do Índice de decaimento de Bremer (1994). Os números abaixo dos nós, dentro de círculos, são uma codificação arbitrária dos nós, utilizada para referência ao longo do texto. Nos ramos, os círculos pretos representam sinapomorfias e os brancos, homoplasias. Otimização ACCTRAN. 

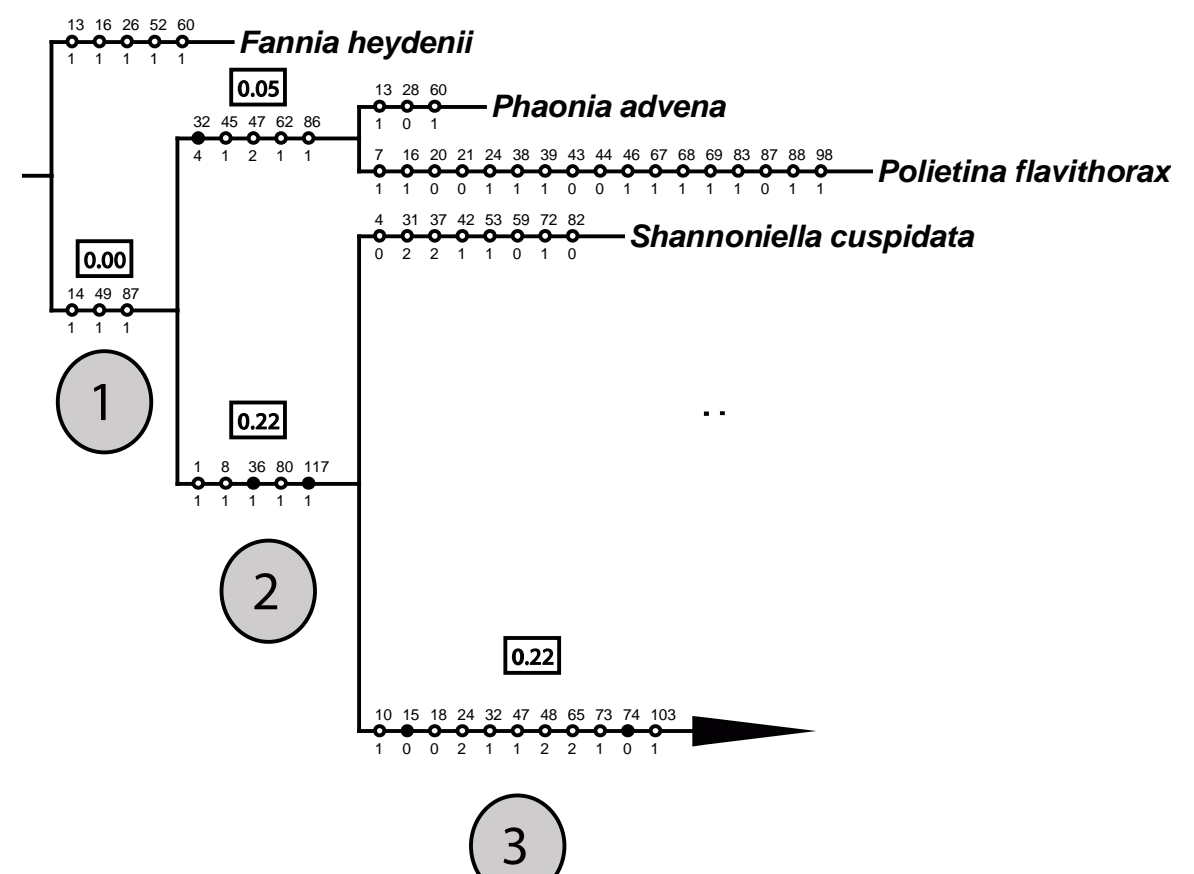

Figura 120. Parte 1 do cladograma obtido na análise sob pesagem implícita dos caracteres ( $\mathrm{L}=679 ; \mathrm{CI}=21 ; \mathrm{RI}=67 ; k=9,6875)$. Os números acima dos nós, dentro de retângulos, indicam os valores do Índice de decaimento de Bremer (1994). Os números abaixo dos nós, dentro de círculos, são uma codificação arbitrária dos nós, utilizada para referência ao longo do texto. Nos ramos, os círculos pretos representam sinapomorfias e os brancos, homoplasias. Otimização ACCTRAN. 

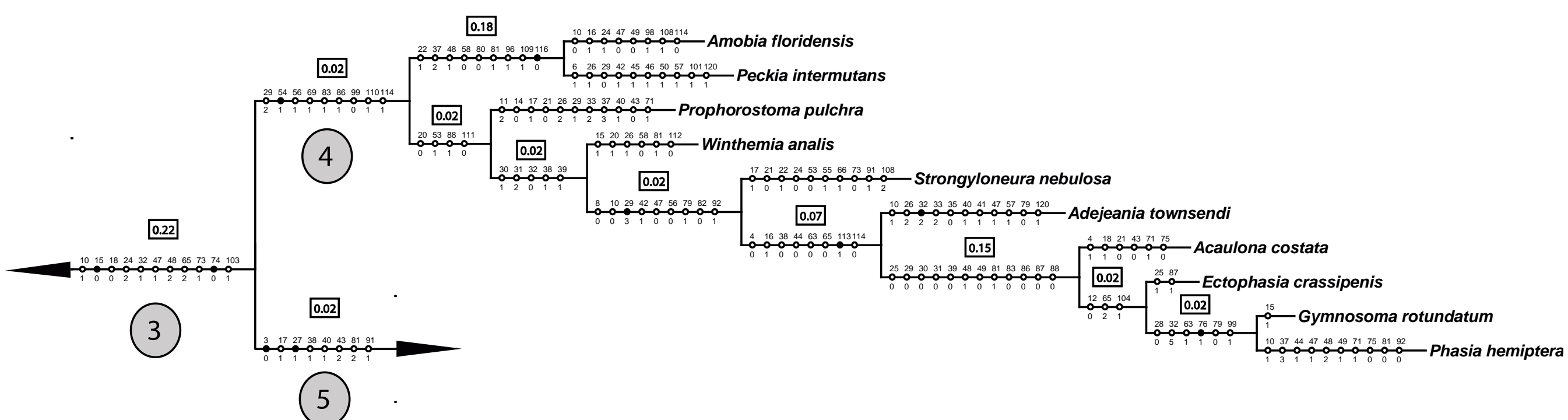

Figura 121. Parte 2 do cladograma obtido na análise sob pesagem implícita dos caracteres ( $\mathrm{L}=679 ; \mathrm{CI}=21 ; \mathrm{RI}=67 ; k=9,6875)$. Os números acima dos nós, dentro de retângulos, indicam os valores do Índice de decaimento de Bremer (1994). Os números abaixo dos nós, dentro de círculos, são uma codificação arbitrária dos nós, utilizada para referência ao longo do texto. Nos ramos, os círculos pretos representam sinapomorfias e os brancos, homoplasias. Otimização ACCTRAN. 


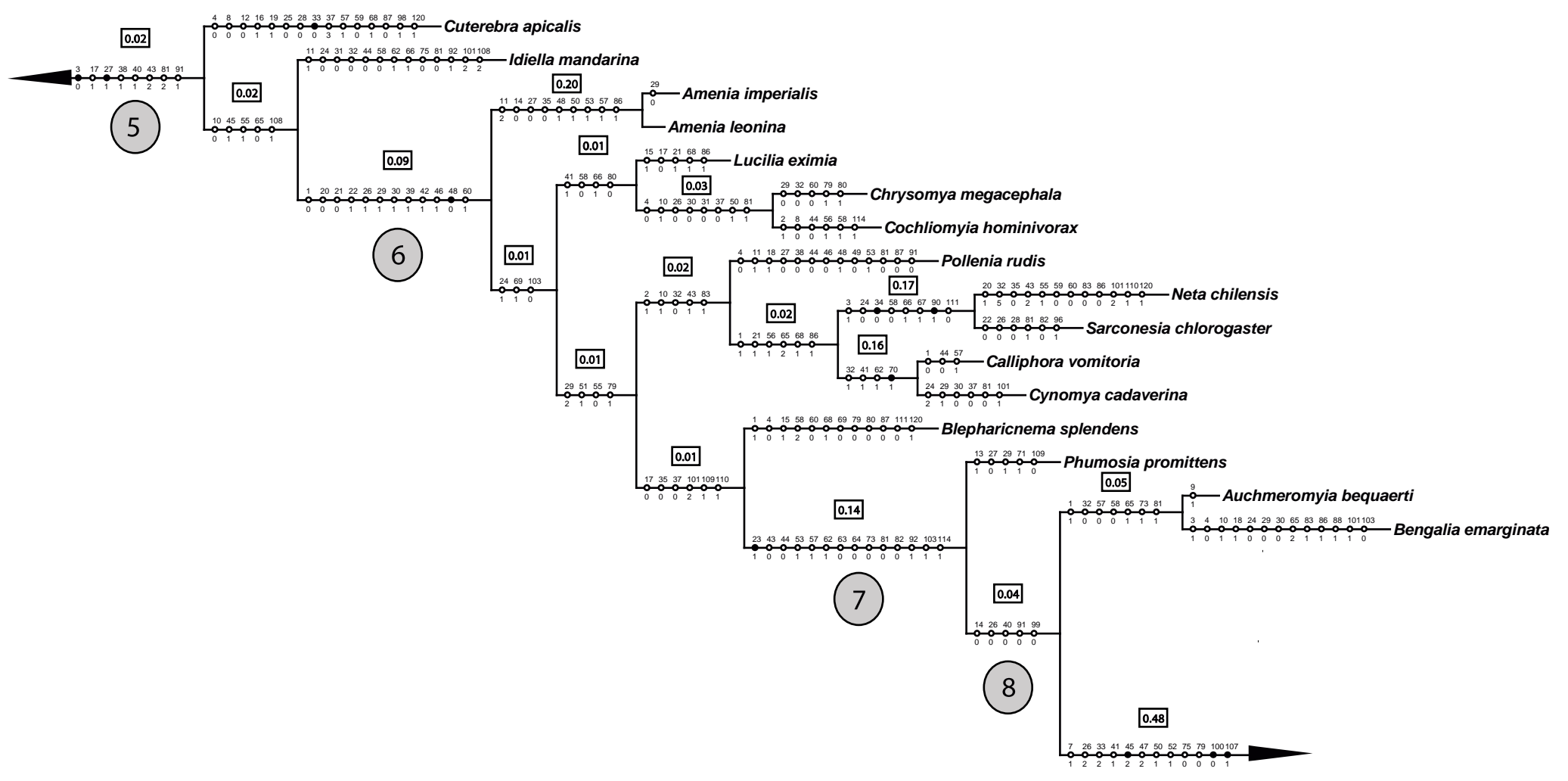

(9)

Figura 122. Parte 3 do cladograma obtido na análise sob pesagem implícita dos caracteres (L=679; CI=21; RI=67; $k=9$,6875). Os números acima dos nós, dentro de retângulos, indicam os valores do Índice de decaimento de Bremer (1994). Os números abaixo dos nós, dentro de círculos, são uma codificação arbitrária dos nós, utilizada para referência ao longo do texto. Nos ramos, os círculos pretos representam sinapomorfias e os brancos, homoplasias. Otimização ACCTRAN. 


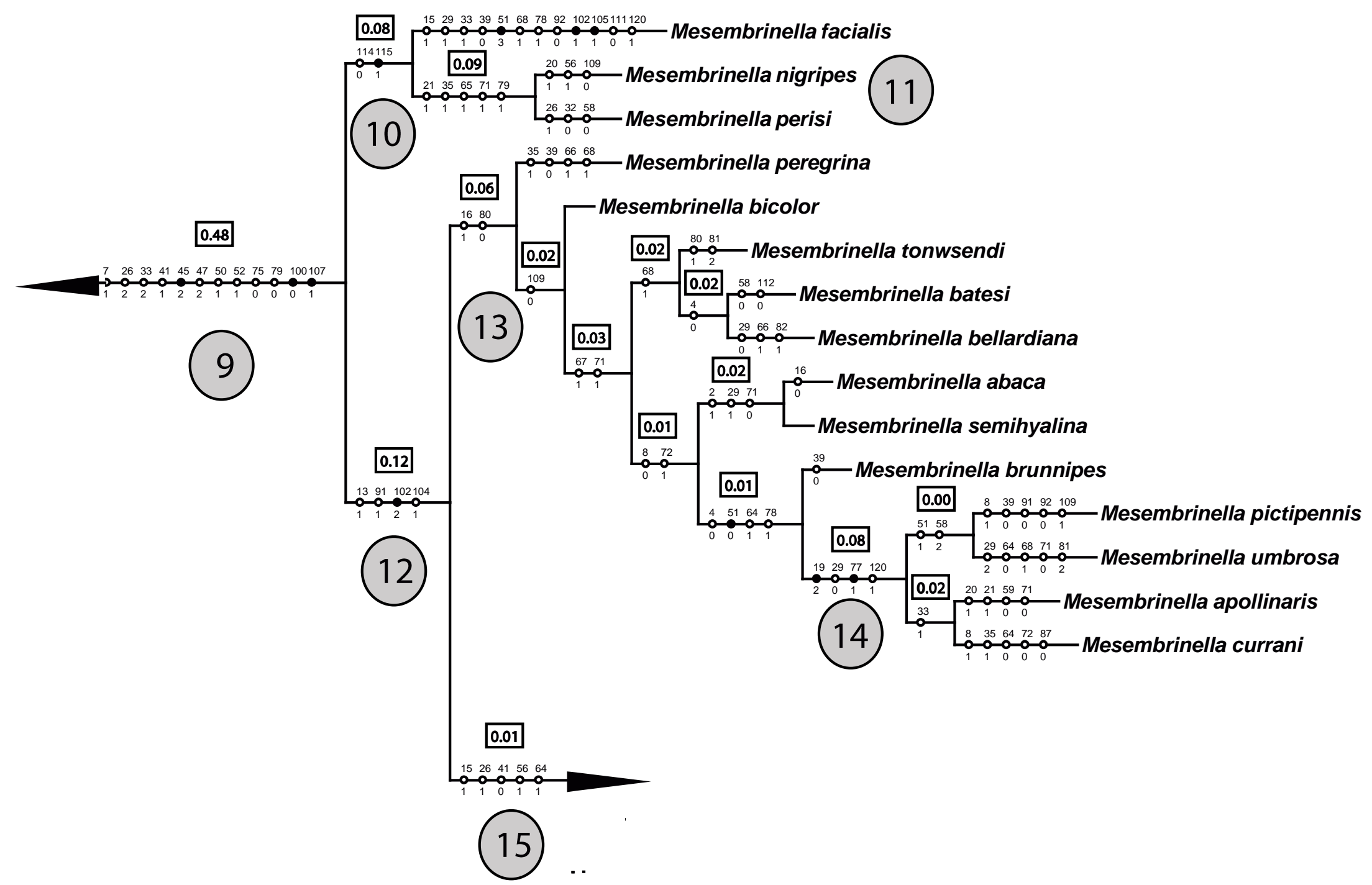

Figura 123. Parte 4 do cladograma obtido na análise sob pesagem implícita dos caracteres ( $\mathrm{L}=679 ; \mathrm{CI}=21 ; \mathrm{RI}=67 ; k=9,6875)$. Os números acima dos nós, dentro de retângulos, indicam os valores do Índice de decaimento de Bremer (1994). Os números abaixo dos nós, dentro de círculos, são uma codificação arbitrária dos nós, utilizada para referência ao longo do texto. Nos ramos, os círculos pretos representam sinapomorfias e os brancos, homoplasias. Otimização ACCTRAN. 


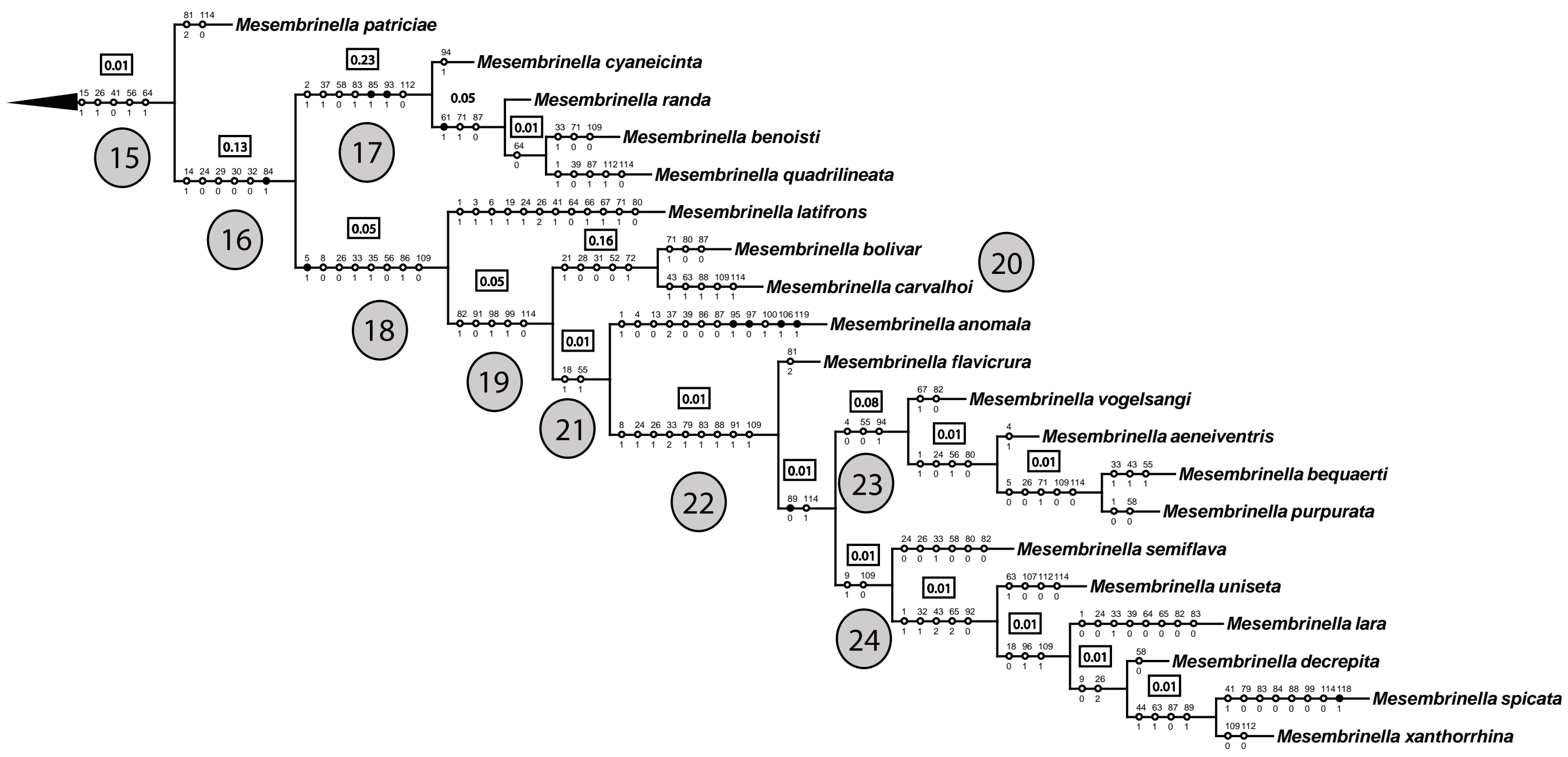

Figura 124. Parte 5 do cladograma obtido na análise sob pesagem implícita dos caracteres ( $\mathrm{L}=679 ; \mathrm{CI}=21 ; \mathrm{RI}=67 ; k=9,6875)$. Os números acima dos nós, dentro de retângulos, indicam os valores do Índice de decaimento de Bremer (1994). Os números abaixo dos nós, dentro de círculos, são uma codificação arbitrária dos nós, utilizada para referência ao longo do texto. Nos ramos, os círculos pretos representam sinapomorfias e os brancos, homoplasias. Otimização ACCTRAN. 
Além do valor de $k$ obtido por meio do uso do script, foram utilizados diversos outros valores, listado na Tabela 2, correspondentes a um intervalo de teste de estabilidade da topologia. Os valores de CI e RI obtidos foram os mesmos para $k=5,6$ e 13, em comparação com os valores para o $k=9,6875$, utilizado nesse trabalho como principal resultado para a discussão. Somente para $k=3$ foram encontradas duas topologias, sendo que para os demais $k$ somente uma árvore mais parcimoniosa foi obtida como resultado.

Tabela 3. Valores de $k$ utilizados na análise de parcimônia com pesagem implícita, com seu respectivo número de passos, valor do fit e número de árvores encontradas.

\begin{tabular}{|c|c|c|c|c|c|}
\hline Valor do $k$ & $\mathbf{N}^{0}$ de passos & CI & $\mathbf{R I}$ & Valor do fit & $\mathbf{N}^{0}$ de árvores \\
\hline 1 (Fig. 125) & 708 & 20 & 65 & 74.44906 & 1 \\
\hline 3 (Fig. 126) & 695 & 20 & 66 & 55.64964 & 2 \\
\hline 5 (Fig. 127) & 686 & 21 & 67 & 45.11869 & 1 \\
\hline 7 (Fig. 128) & 684 & 21 & 67 & 38.13987 & 1 \\
\hline $\begin{array}{c}9,6875 \text { (Figs. } \\
119-124)\end{array}$ & 679 & 21 & 67 & 31.68566 & 1 \\
\hline 11 (Fig. 129) & 679 & 20 & 67 & 29.29312 & 1 \\
\hline 13 (Fig. 130) & 674 & 21 & 67 & 26.27324 & 1 \\
\hline 15 (Fig. 131) & 674 & 20 & 67 & 23.83035 & 1 \\
\hline 30 (Fig. 132) & 671 & 21 & 68 & 14.11038 & 1 \\
\hline 40 (Fig. 133) & 671 & 21 & 68 & 11.10795 & 1 \\
\hline
\end{tabular}


Em todas as topologias dos diferentes valores de $k$ (Figs. 125-133), Mesembrinellidae é monofilético e tem o clado Auchmeromyia bequaerti e Bengalia emarginata como grupo irmão. O que varia nas diferentes topologias são as relações do grupo externo, que não serão comentadas, e as relações internas em Mesembrinellidae. Em todos os valores de $k$ estudados, é possível observar algumas estruturas na topologia que se mantêm constantes, tais como: o grupo composto por Mesembrinella facialis, $M$. nigripes comb. n. e $M$. perisi, clado irmão de todas as demais espécies; o clado 13 (Fig. 118) com somente com algumas variações internas de relacionamento; o clado 16; os clados 11, 17 e 20 (Fig. 118), que representam os antigos gêneros Laneella, Giovanella e Eumesembrinella, respectivamente, são sempre monofiléticos, enquanto os antigos Mesembrinella senso stricto e Huascaromusca são sempre polifiléticos e os antigos gêneros monotípicos Souzalopesiella, Thompsoniella e Albuquerquea nunca aparecem aninhados a nenhum outro gênero. Com relação as diferenças entre as topologias, elas se devem principalmente: ao posicionamento de Mesembrinella anomala comb. n., que ora está relacionada ao clado 20 (Figs. 125-128, 130-133), ora aparece como uma linhagem independente, grupo irmão de algum clado maior (Fig. 129); ao posicionamento de Mesembrinella spicata, que pode estar aninhada ao clado 22 (Figs. 129-133) ou posicionar-se como uma linhagem independente, grupo irmão de um clado maior (Figs. 125-128); ao posicionamento do clado 17, que às vezes encontra-se isolado como grupo irmão do clado 19 (Figs. 126-133), e às vezes está inserido no clado 22 (Fig. 125), como um ramo interno desse clado. 


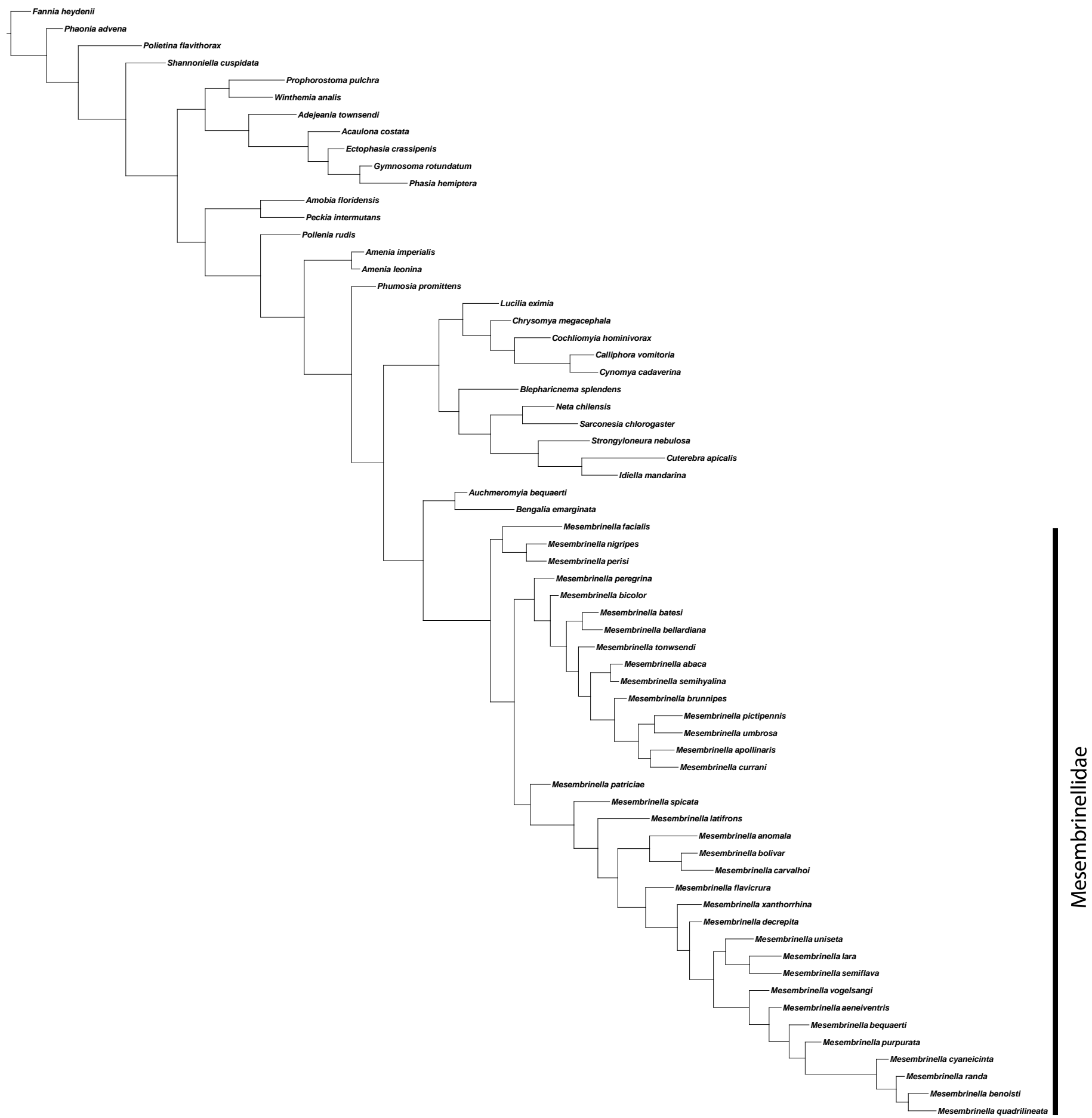

Figura 125. Cladograma mais parcimonioso resultante da análise sob pesagem implícita dos caracteres $(\mathrm{L}=708 ; \mathrm{CI}=20 ; \mathrm{RI}=65 ; k=1)$. 


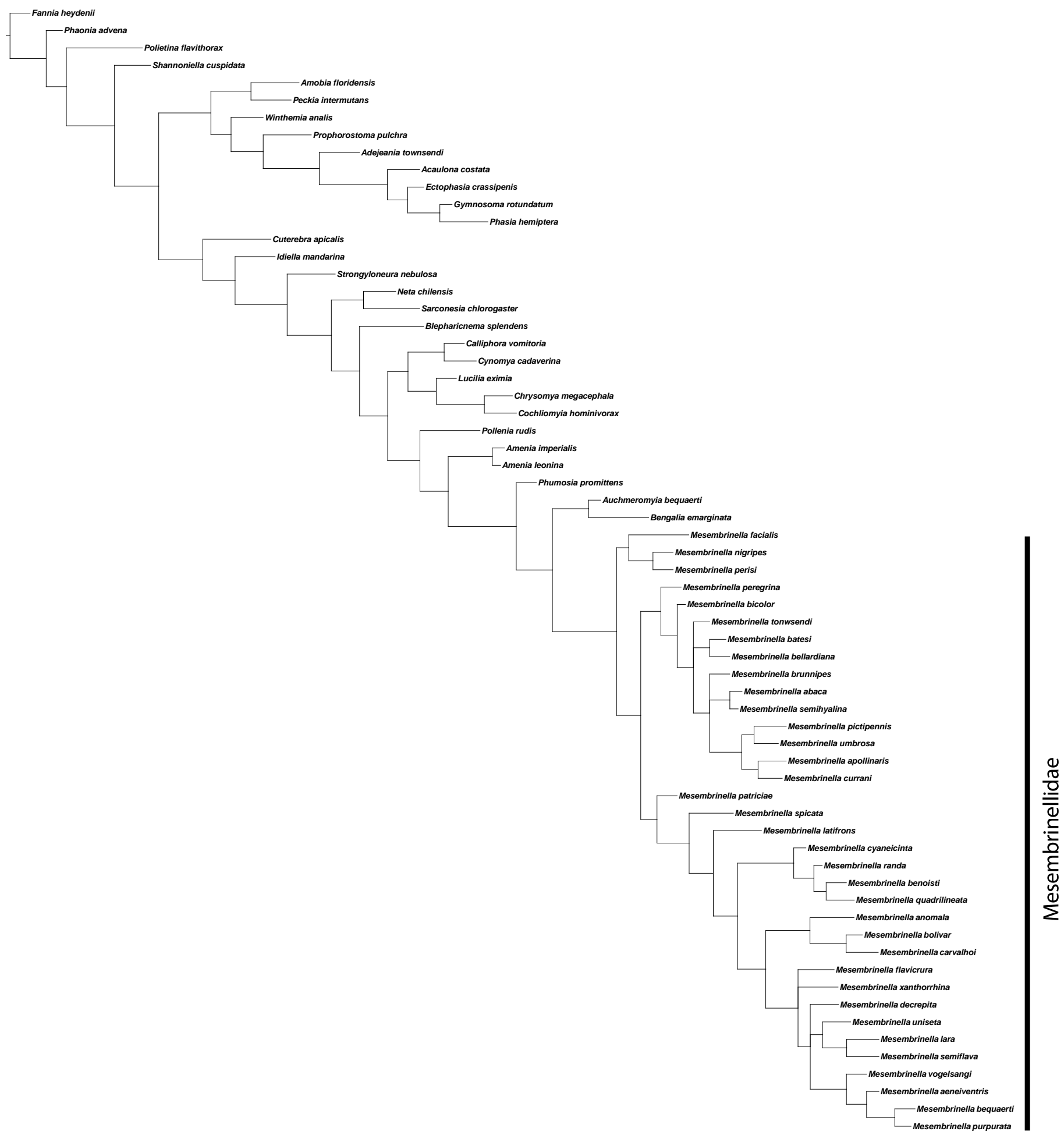

Figura 126. Cladograma de consenso estrito resultante das duas árvores igualmente parcimoniosas encontradas na análise sob pesagem implícita dos caracteres ( $\mathrm{L}=695 ; \mathrm{CI}=20 ; \mathrm{RI}=66 ; k=3)$. 


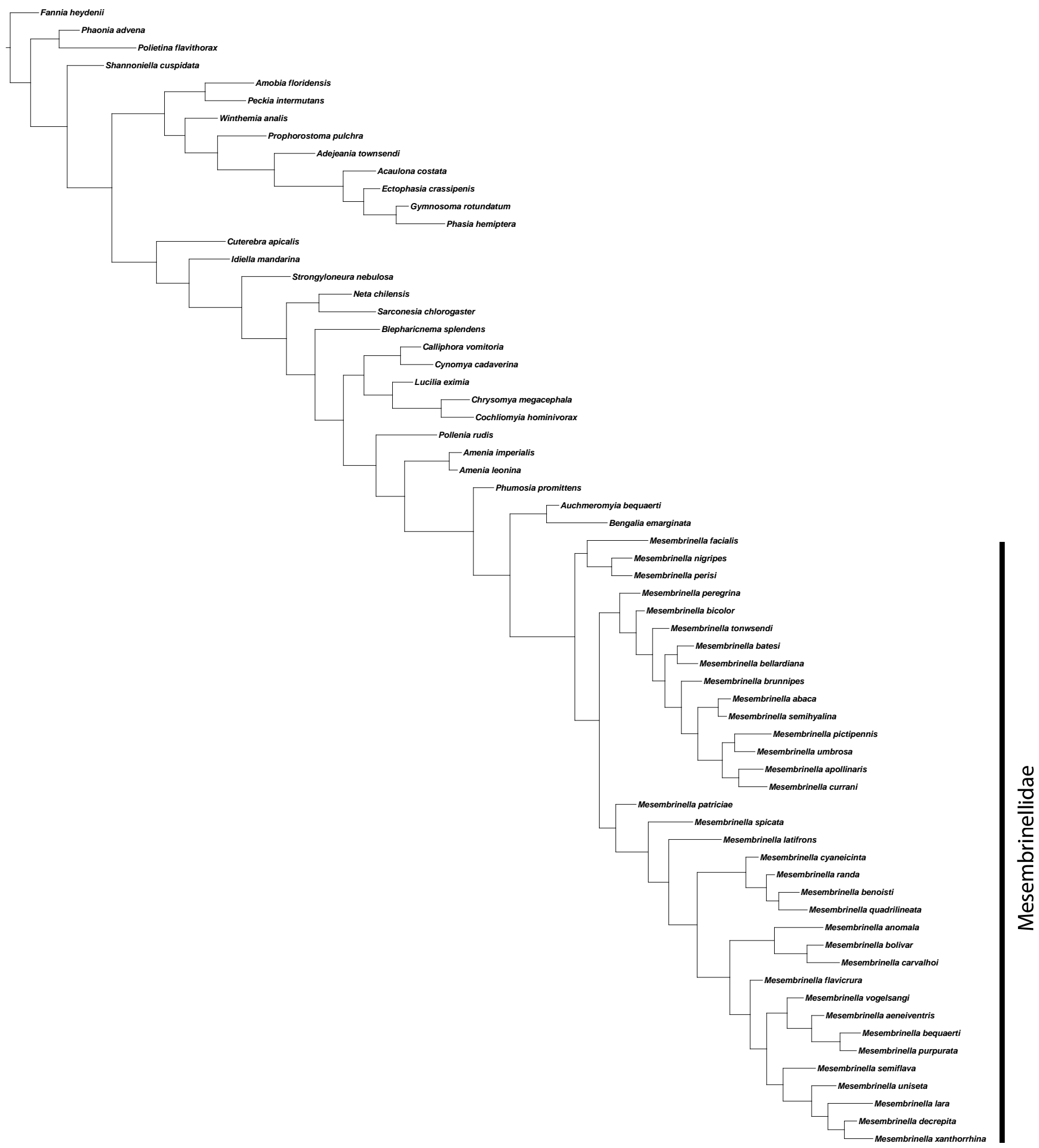

Figura 127. Cladograma mais parcimonioso resultante da análise sob pesagem implícita dos caracteres $(\mathrm{L}=686 ; \mathrm{CI}=21 ; \mathrm{RI}=67 ; k=5)$. 


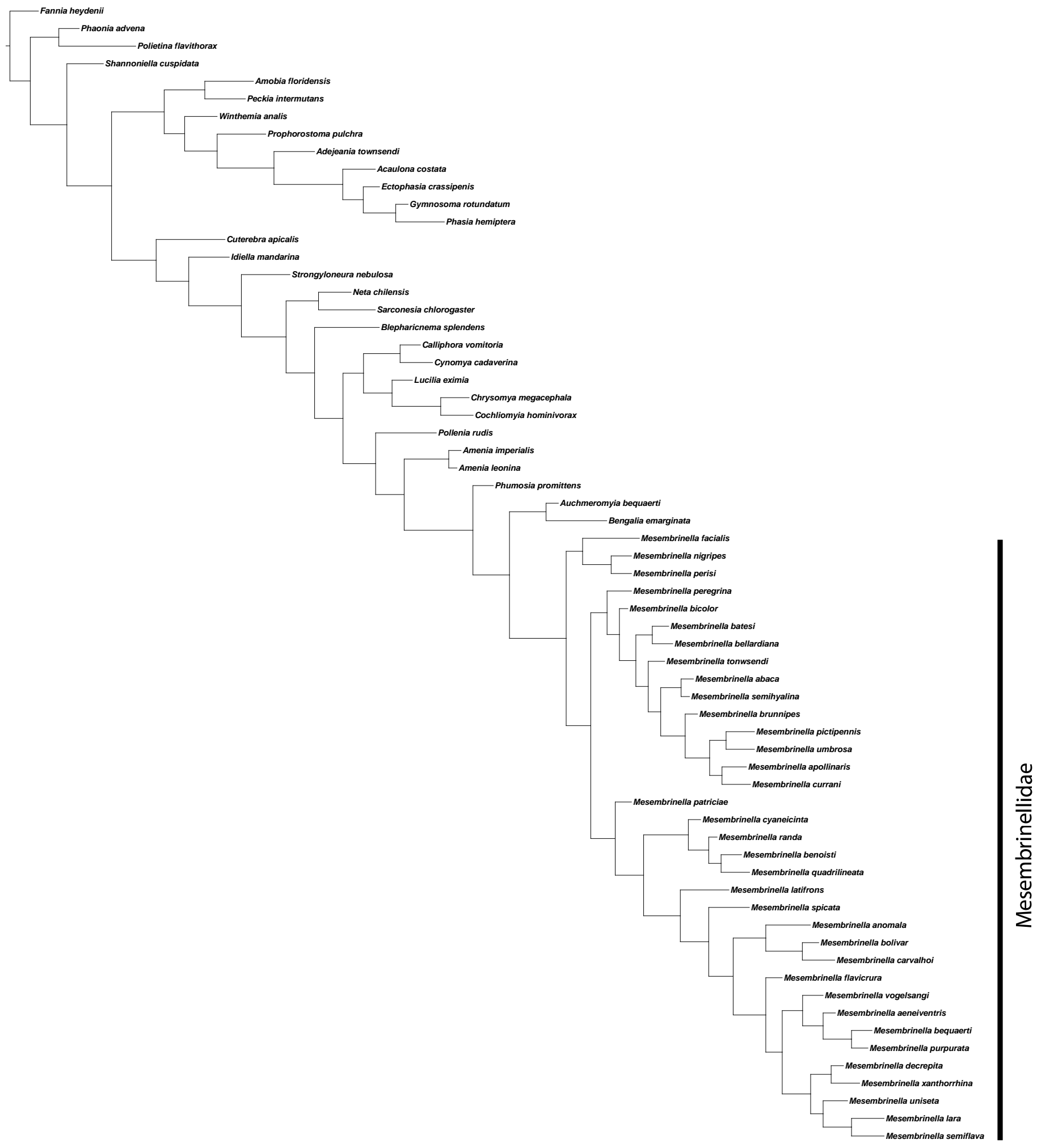

Figura 128. Cladograma mais parcimonioso resultante da análise sob pesagem implícita dos caracteres ( $\mathrm{L}=684 ; \mathrm{CI}=21 ; \mathrm{RI}=67 ; k=7)$. 


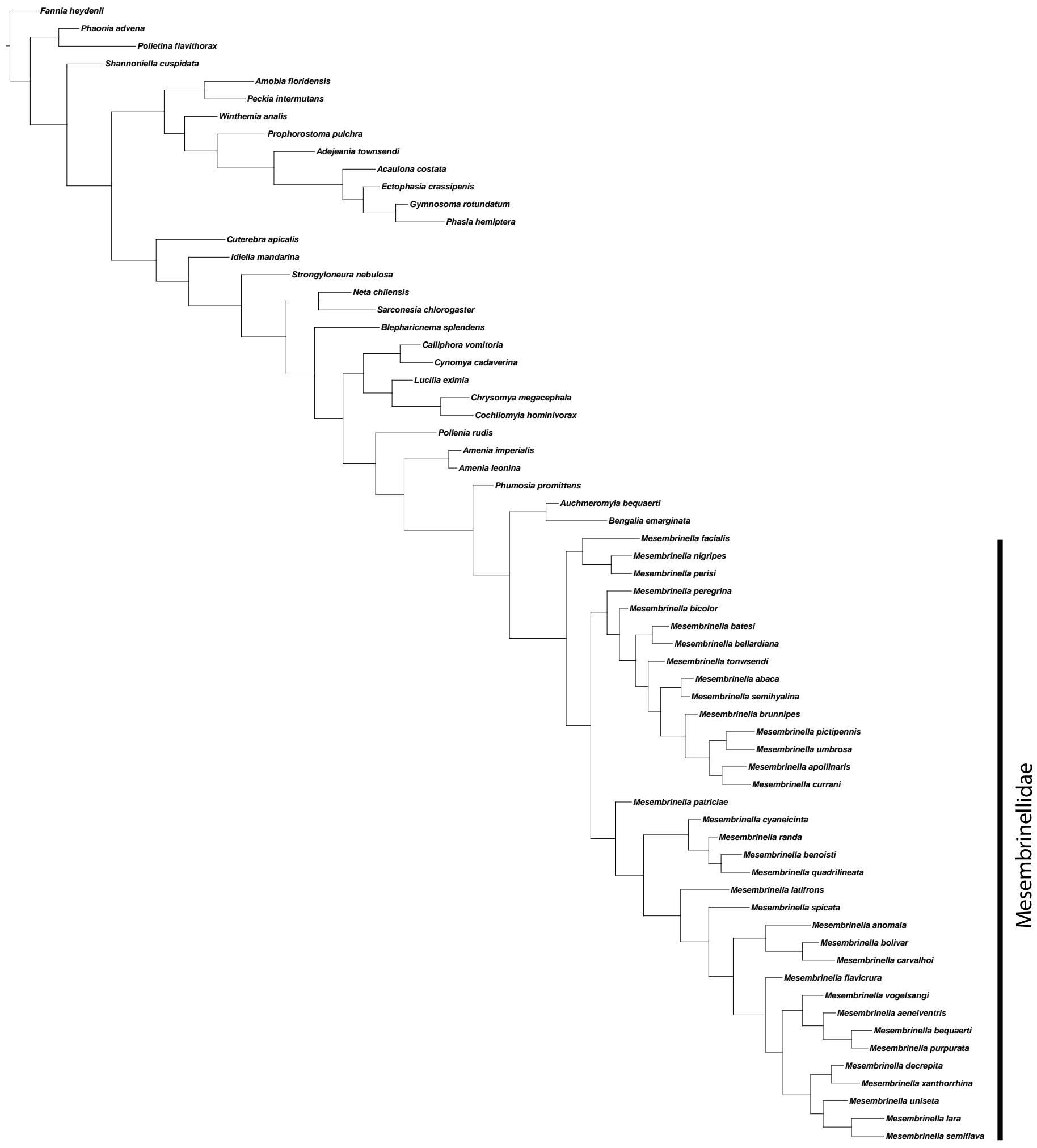

Figura 129. Cladograma mais parcimonioso resultante da análise sob pesagem implícita dos caracteres $(\mathrm{L}=679 ; \mathrm{CI}=20 ; \mathrm{RI}=67 ; k=11)$. 


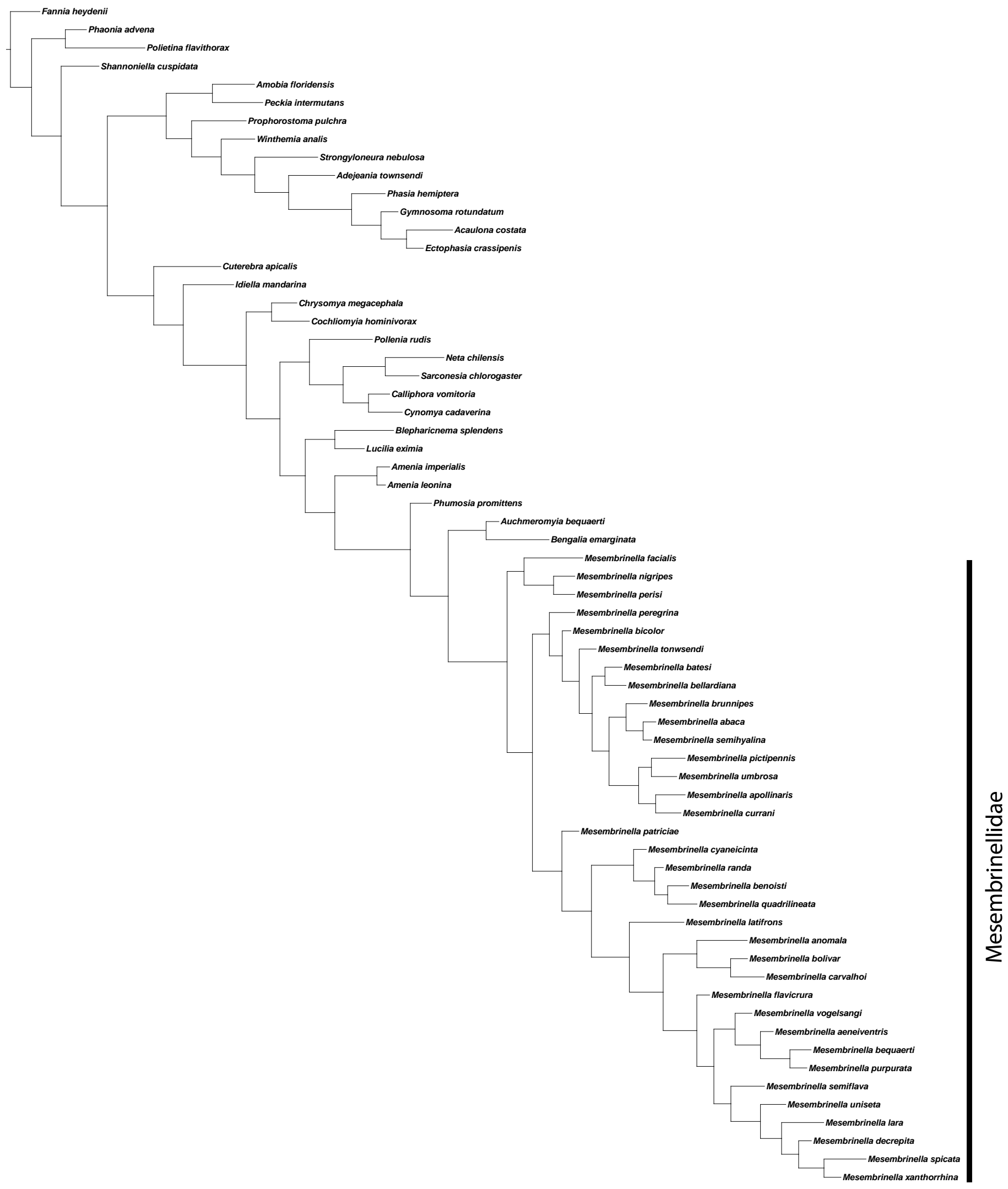

Figura 130. Cladograma mais parcimonioso resultante da análise sob pesagem implícita dos caracteres (L=674; $\mathrm{CI}=21 ; \mathrm{RI}=67 ; k=13)$. 


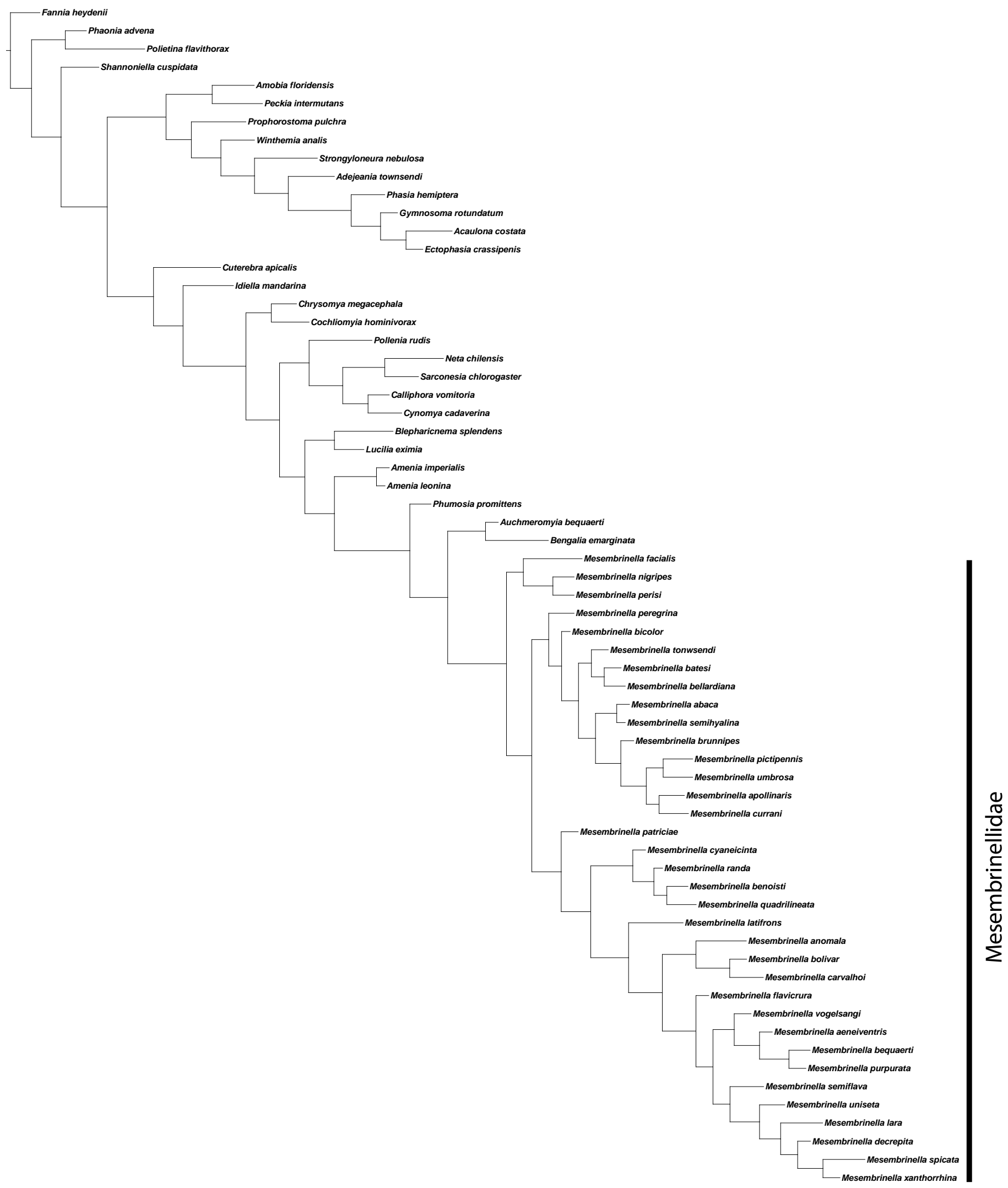

Figura 131. Cladograma mais parcimonioso resultante da análise sob pesagem implícita dos caracteres $(\mathrm{L}=674 ; \mathrm{CI}=20 ; \mathrm{RI}=67 ; k=15)$. 


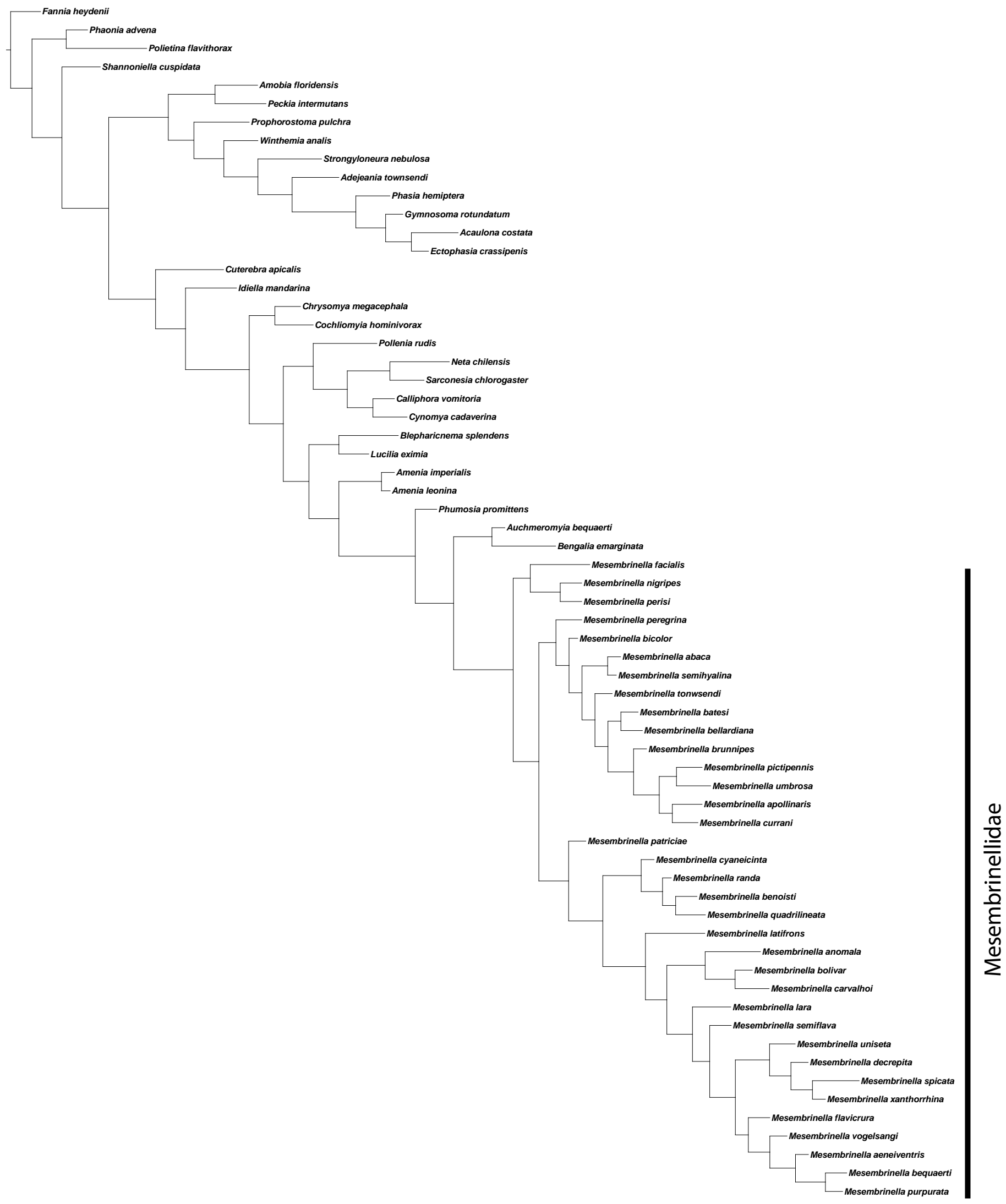

Figura 132. Cladograma mais parcimonioso resultante da análise sob pesagem implícita dos caracteres $(\mathrm{L}=671 ; \mathrm{CI}=21 ; \mathrm{RI}=68 ; k=30)$. 


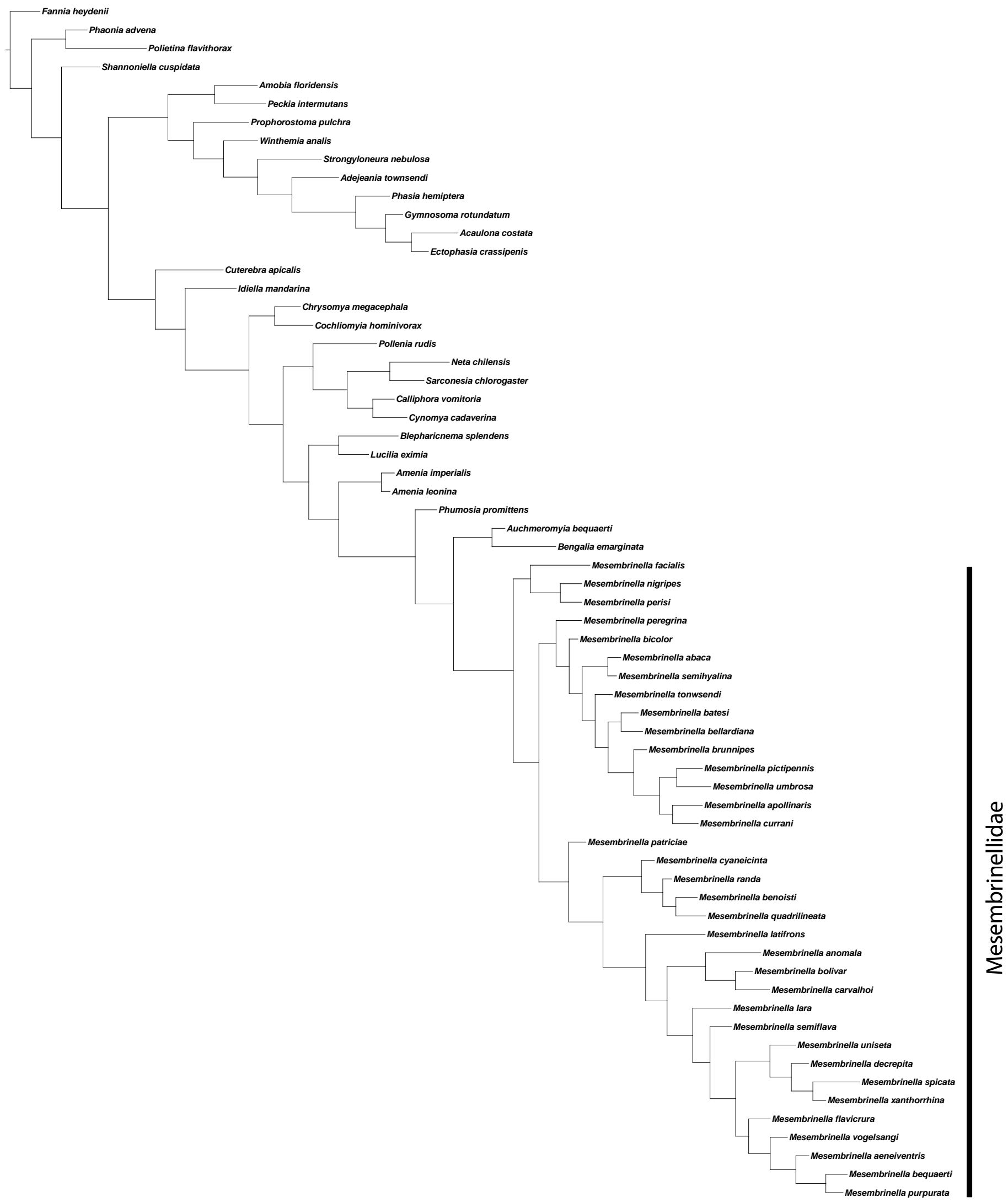

Figura 133. Cladograma mais parcimonioso resultante da análise sob pesagem implícita dos caracteres $(\mathrm{L}=671 ; \mathrm{CI}=21 ; \mathrm{RI}=68 ; k=40)$. 


\subsection{Biogeografia de Mesembrinellidae}

\subsubsection{Distribuição geográfica das espécies}
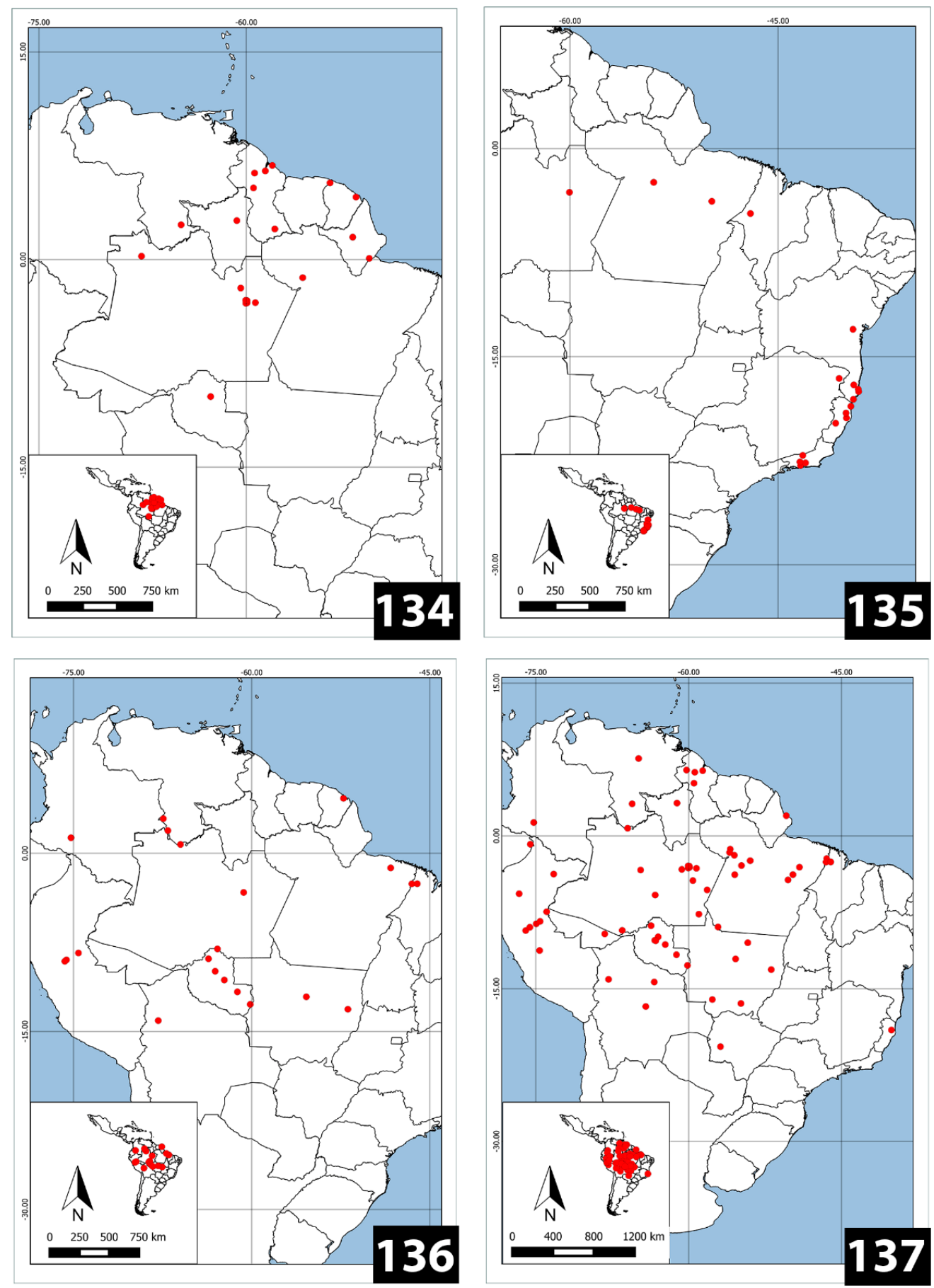

Figuras 134-137. Distribuição geográfica das espécies de Mesembrinellidae. 134. Mesembrinella benoisti comb. n. (Séguy, 1925). 135. Mesembrinella cyaneicincta (Surcouf, 1919). 136. Mesembrinella randa (Walker, 1849). 137. Mesembrinella quadrilineata (Fabricius, 1805). 

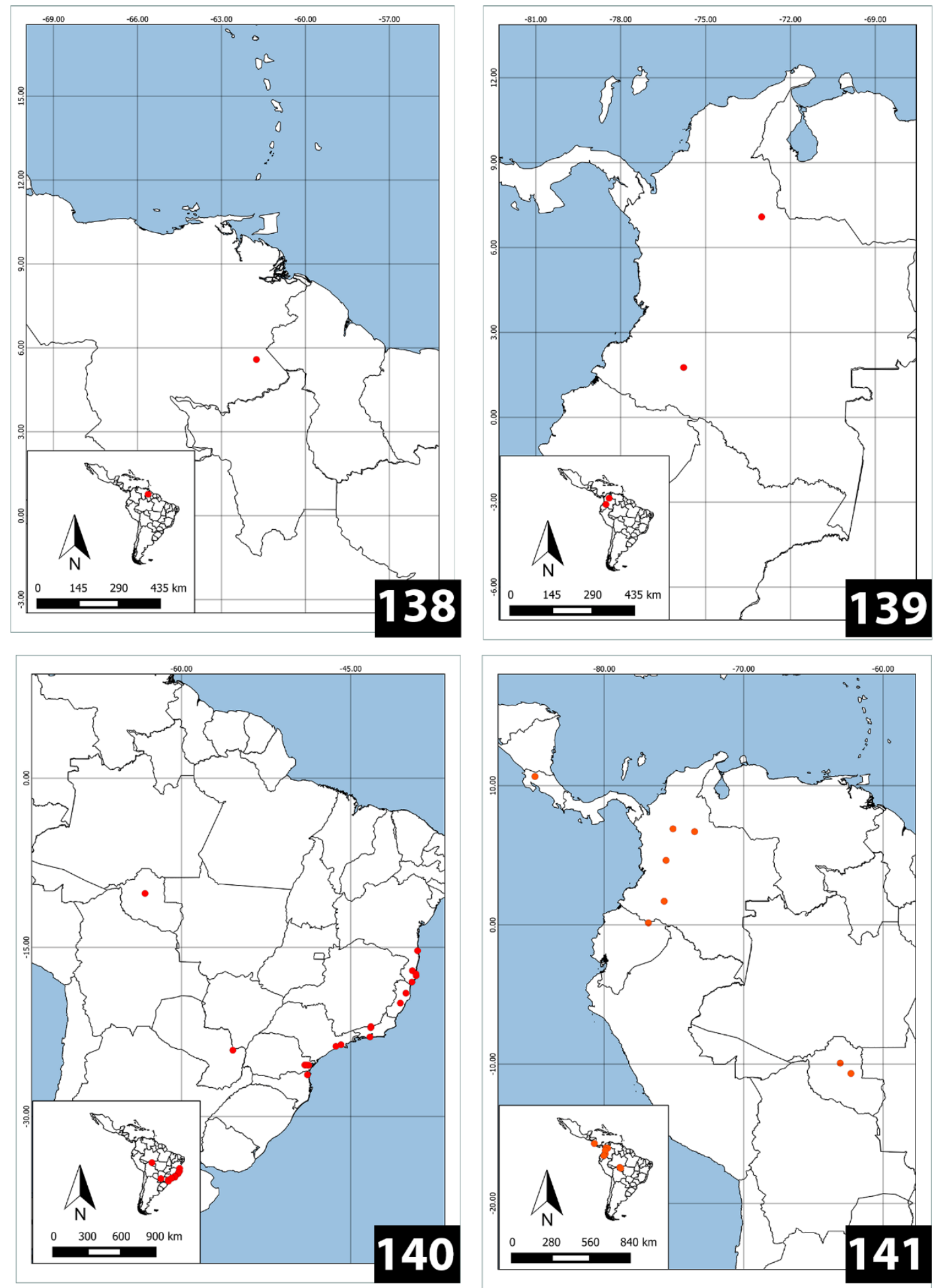

Figuras 138-141. Distribuição geográfica das espécies de Mesembrinellidae. 138. Mesembrinella bolivar Bonatto \& Marinoni, 2005. 139. Mesembrinella carvalhoi comb.

n. (Wolff, 2013). 140. Mesembrinella nigripes comb. n. (Guimarães, 1977). 141. Mesembrinella perisi (Mariluis, 1987). 

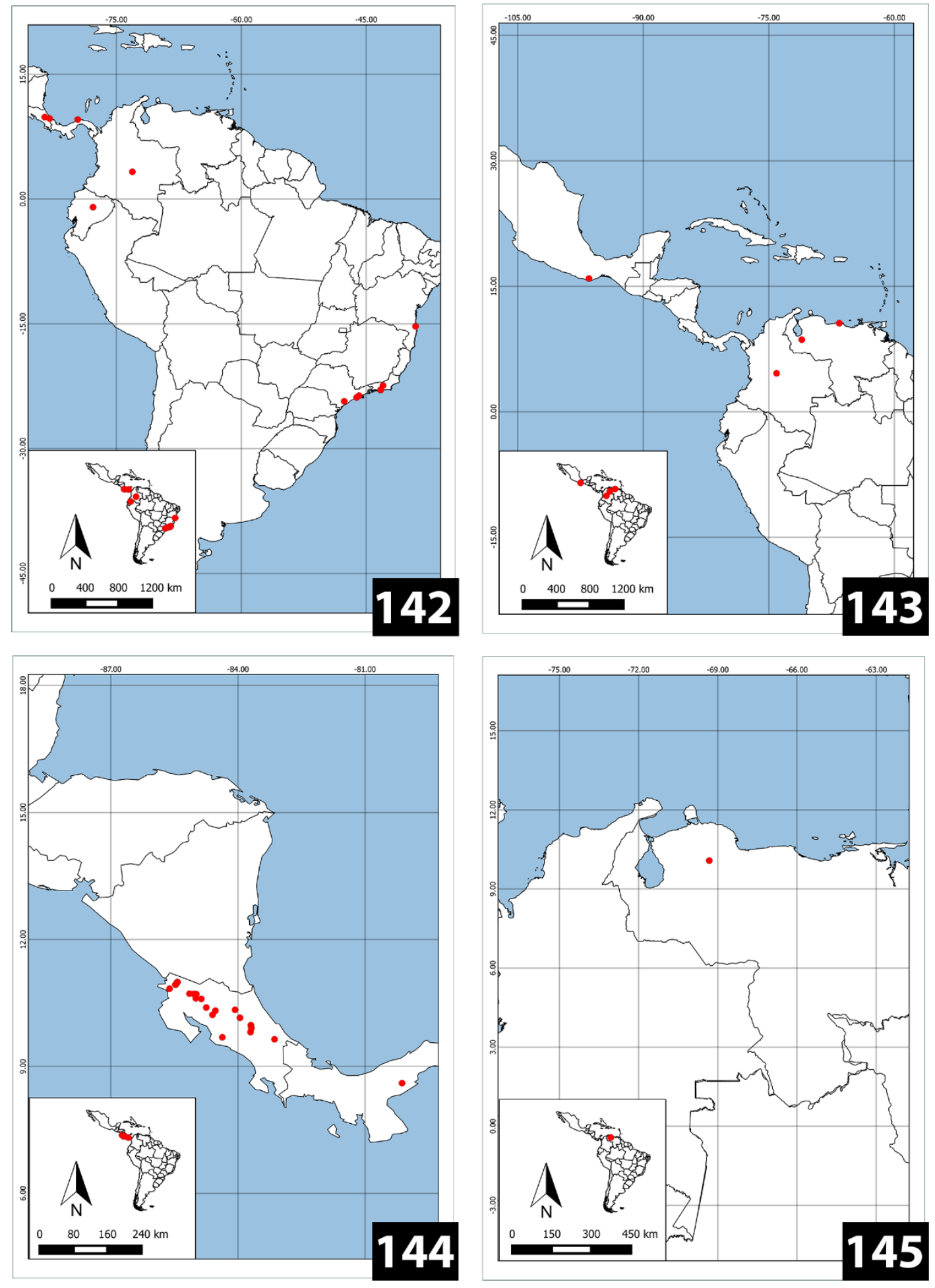

Figuras 142-145. Distribuição geográfica das espécies de Mesembrinellidae. 142. Mesembrinella aeneiventris (Wiedemann, 1830). 143. Mesembrinella decrepita (Séguy, 1925). 144. Mesembrinella flavicrura Aldrich, 1925. 145. Mesembrinella lara comb. $\mathbf{n}$. (Bonatto \& Marinoni, 2005). 

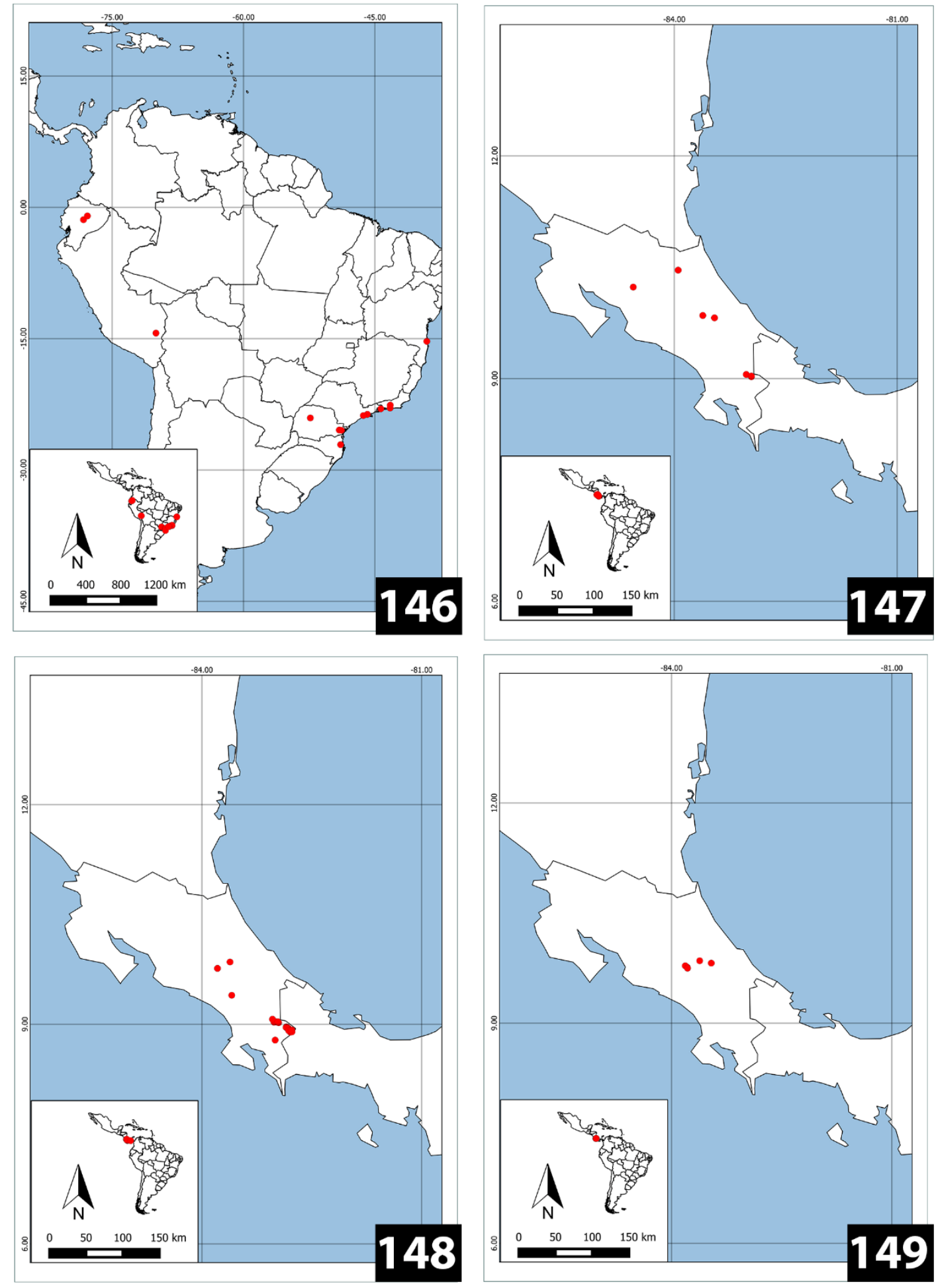

Figuras 146-149. Distribuição geográfica das espécies de Mesembrinellidae. 146. Mesembrinella purpurata (Aldrich, 1922). 147. Mesembrinella semiflava (Aldrich, 1925). 148. Mesembrinella spicata (Aldrich, 1922). 149. Mesembrinella uniseta (Aldrich, 1925). 

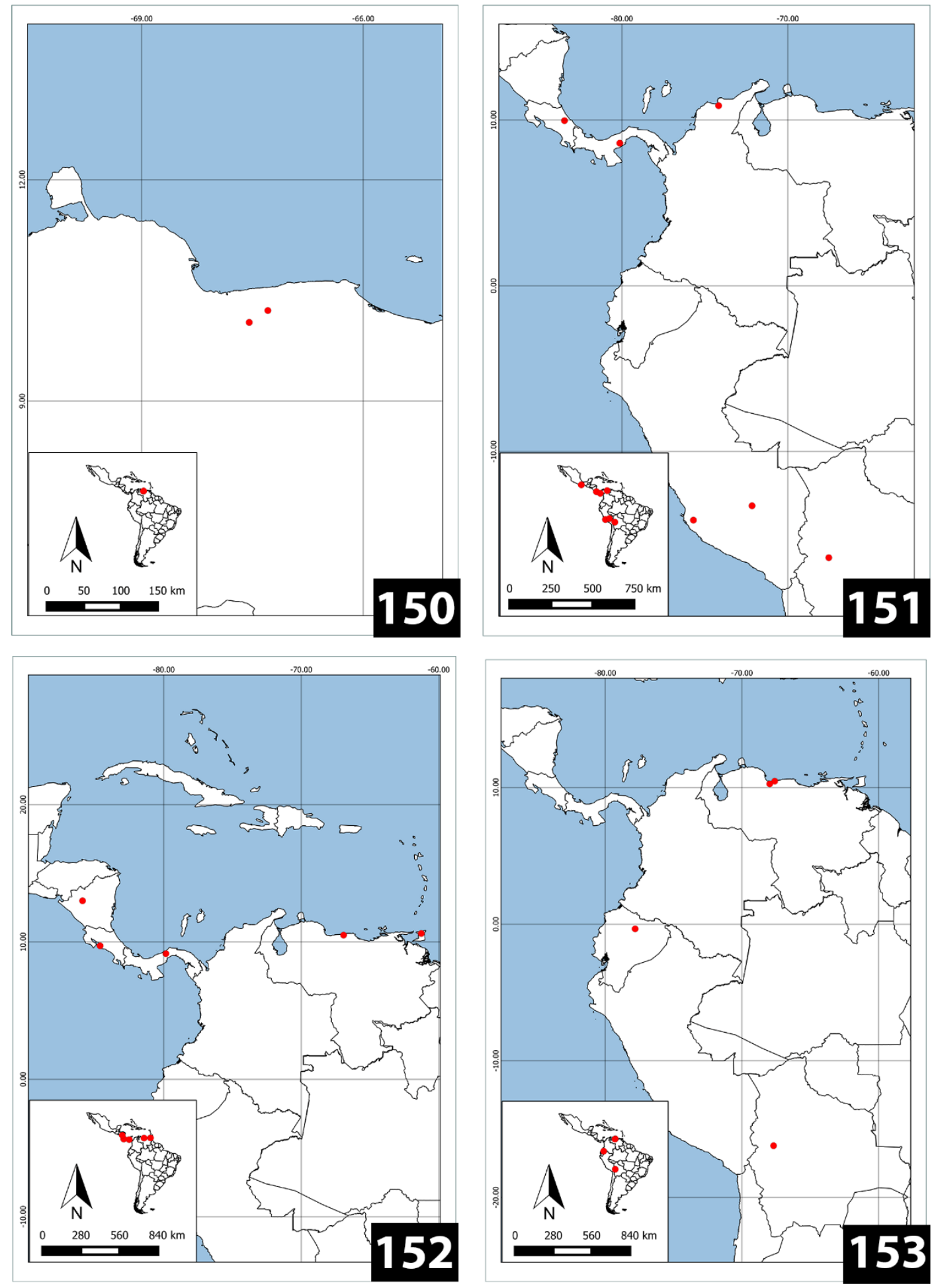

Figuras 150-153. Distribuição geográfica das espécies de Mesembrinellidae. 150. Mesembrinella vogelsangi comb. n. (Mello, 1967). 151. Mesembrinella xanthorrhina (Bigot, 1887). 152. Mesembrinella facialis (Aldrich, 1922). 153. Mesembrinella anomala comb. n. (Guimarães, 1977). 

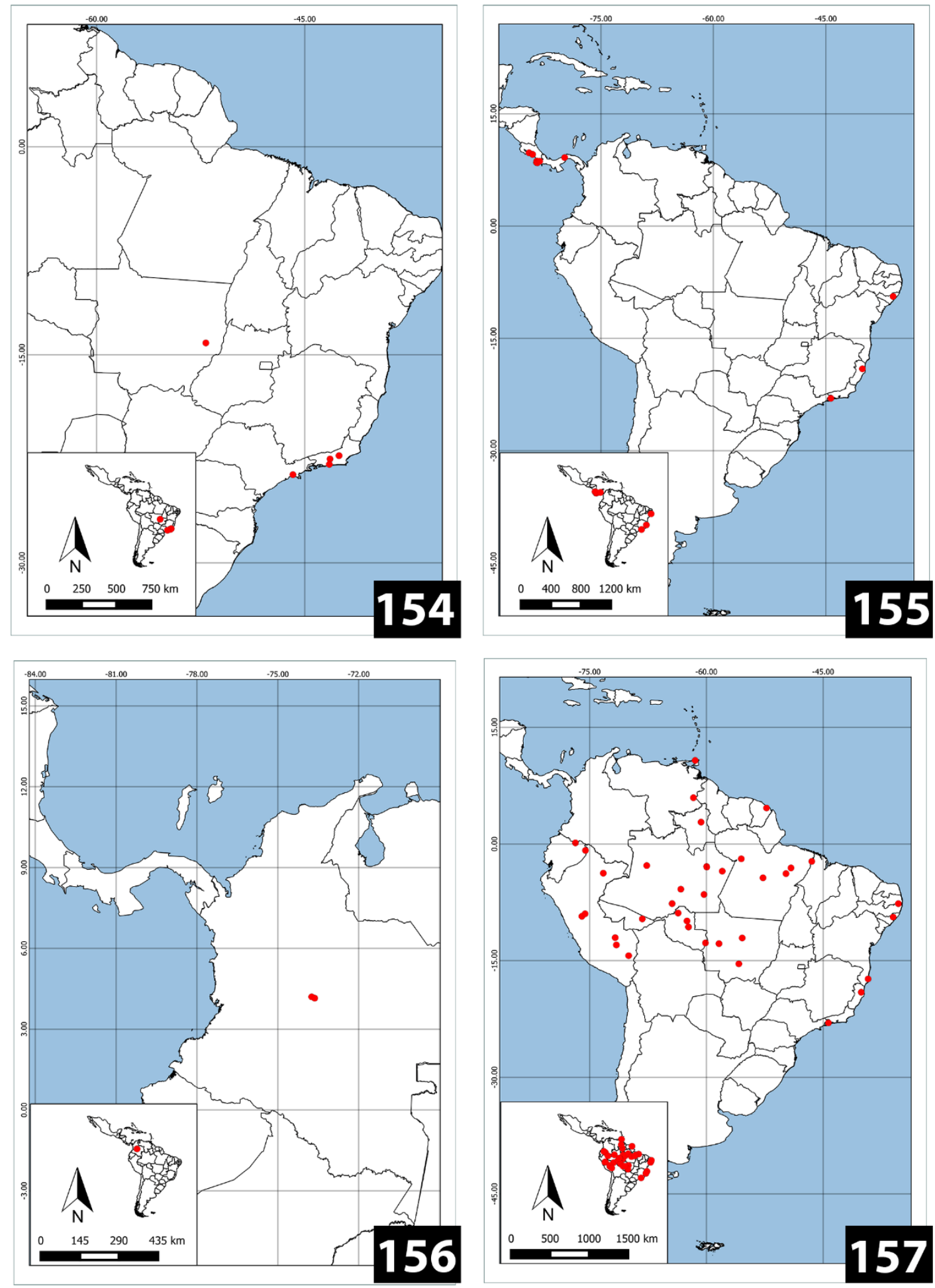

Figuras 154-157. Distribuição geográfica das espécies de Mesembrinellidae. 154. Mesembrinella latifrons comb. n. (Mello, 1967). 155. Mesembrinella abaca (Hall, 1948). 156. Mesembrinella apollinaris Séguy, 1925. 157. Mesembrinella batesi Aldrich, 1922. 

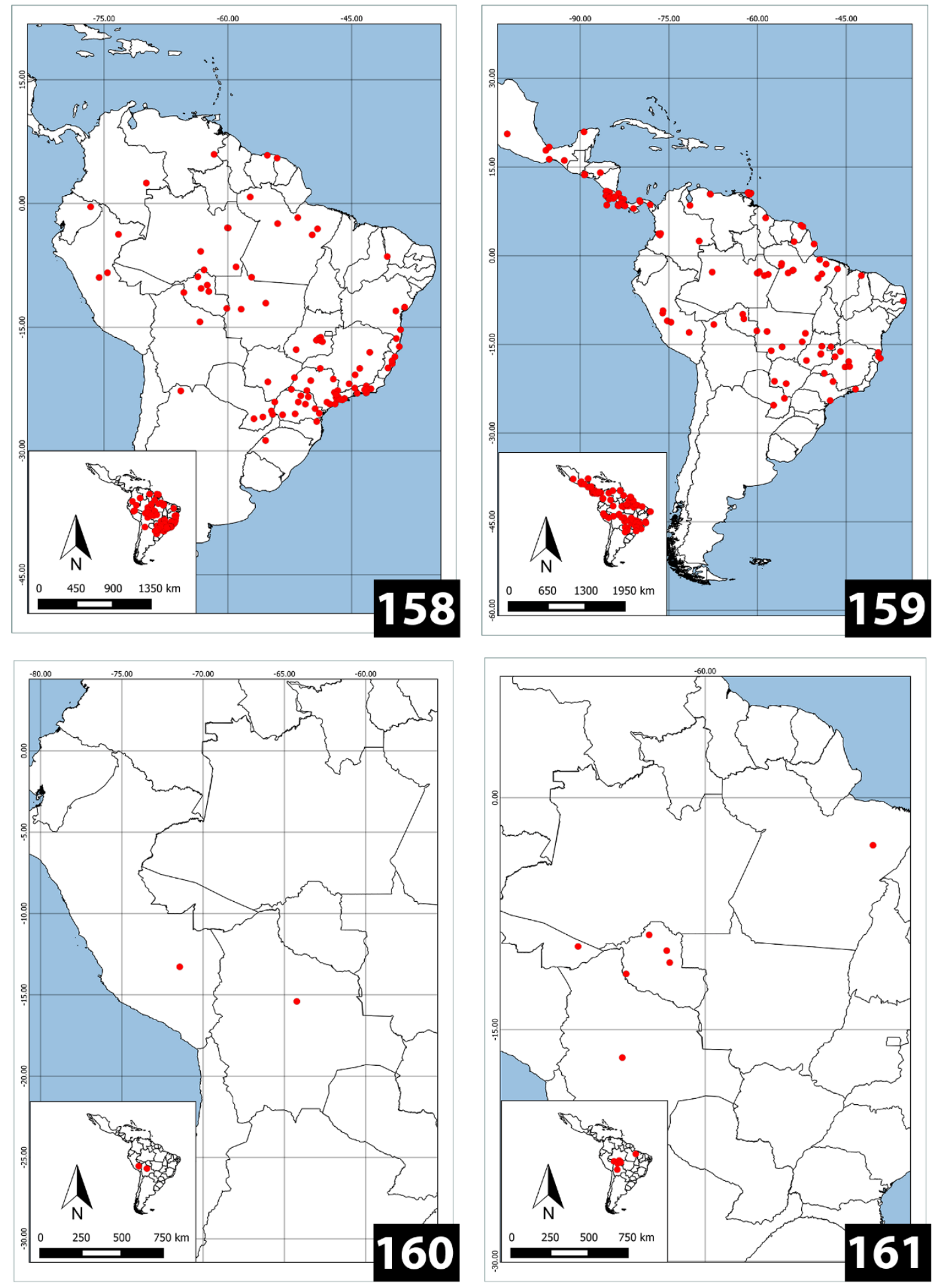

Figuras 158-161. Distribuição geográfica das espécies de Mesembrinellidae. 158. Mesembrinella bellardiana Aldrich, 1922. 159. Mesembrinella bicolor (Fabricius, 1805). 160. Mesembrinella brunnipes Surcouf, 1919. 161. Mesembrinella currani Guimarães, 1977. 

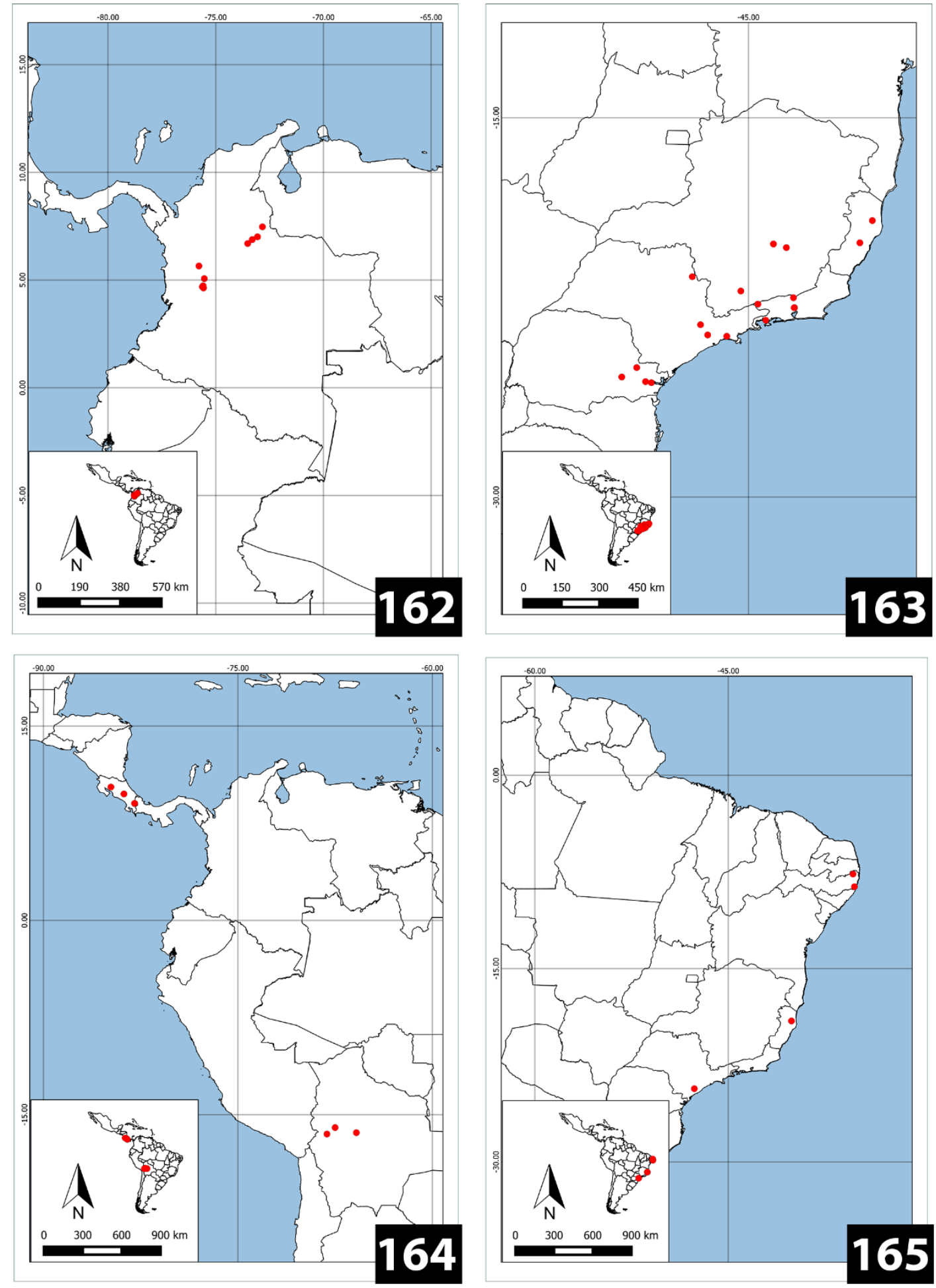

Figuras 162-165. Distribuição geográfica das espécies de Mesembrinellidae. 162. Mesembrinella patriciae Wolff, 2013. 163. Mesembrinella peregrina Aldrich, 1922. 164. Mesembrinella pictipennis Aldrich, 1922. 165. Mesembrinella semyhialina Mello, 1867. 

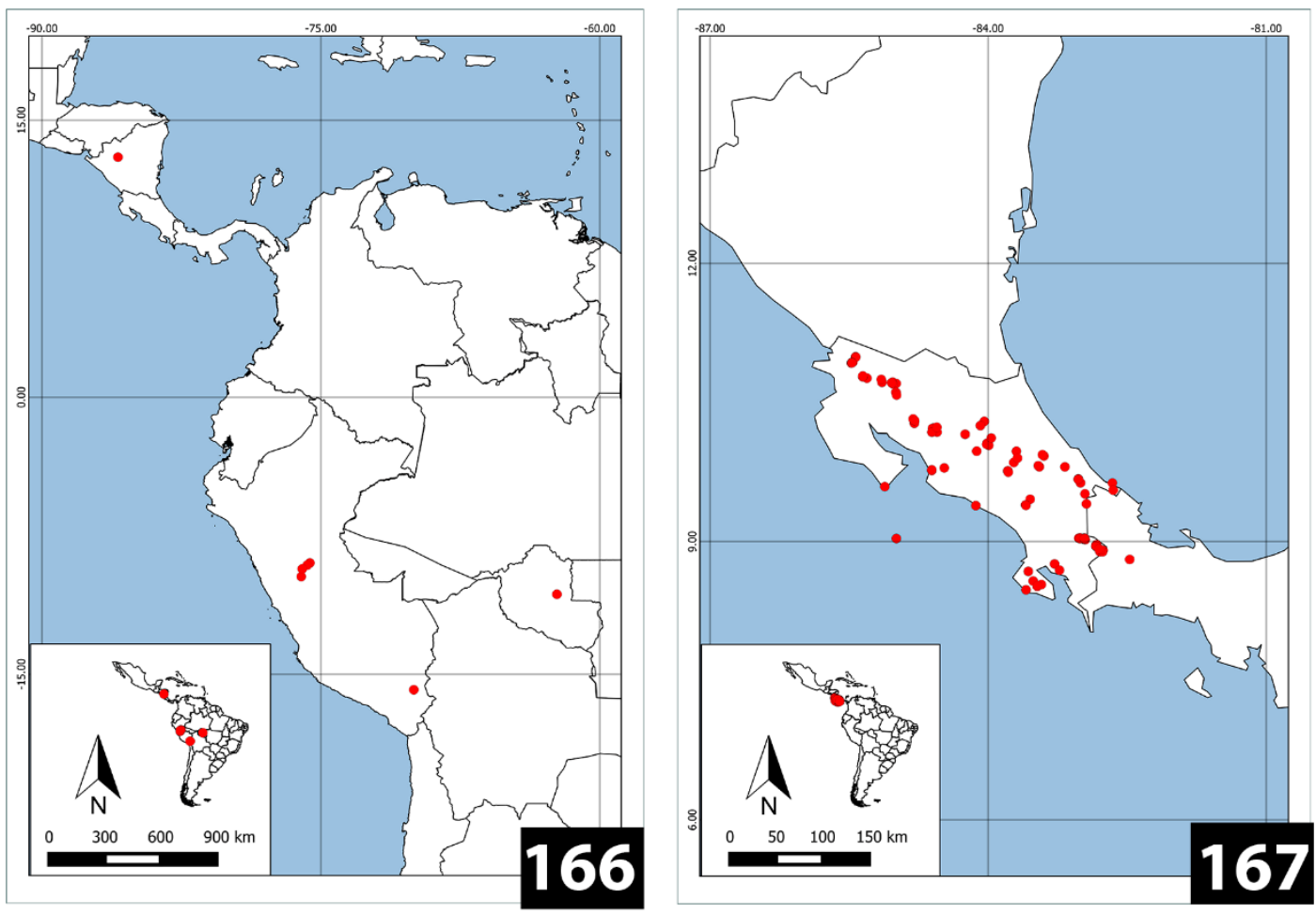

Figuras 166-167. Distribuição geográfica das espécies de Mesembrinellidae. 166. Mesembrinella townsendi Guimarães, 1977. 167. Mesembrinella umbrosa Aldrich, 1922. 


\subsubsection{Análises biogeográficas}

Após a confecção dos mapas de distribuição e feitas as análises cladísticas dos táxons, foi escolhida a árvore obtida sob pesagem implícita dos caracteres (Figs. 119124) para o estudo biogeográfico de Mesembrinellidae. As áreas utilizadas para as análises biogeográficas encontram-se na Fig. 168. Para facilitar a citação das áreas em diversos momentos ao longo do texto e/ou em figuras, foram atribuídas letras para cada uma delas, conforme legenda.

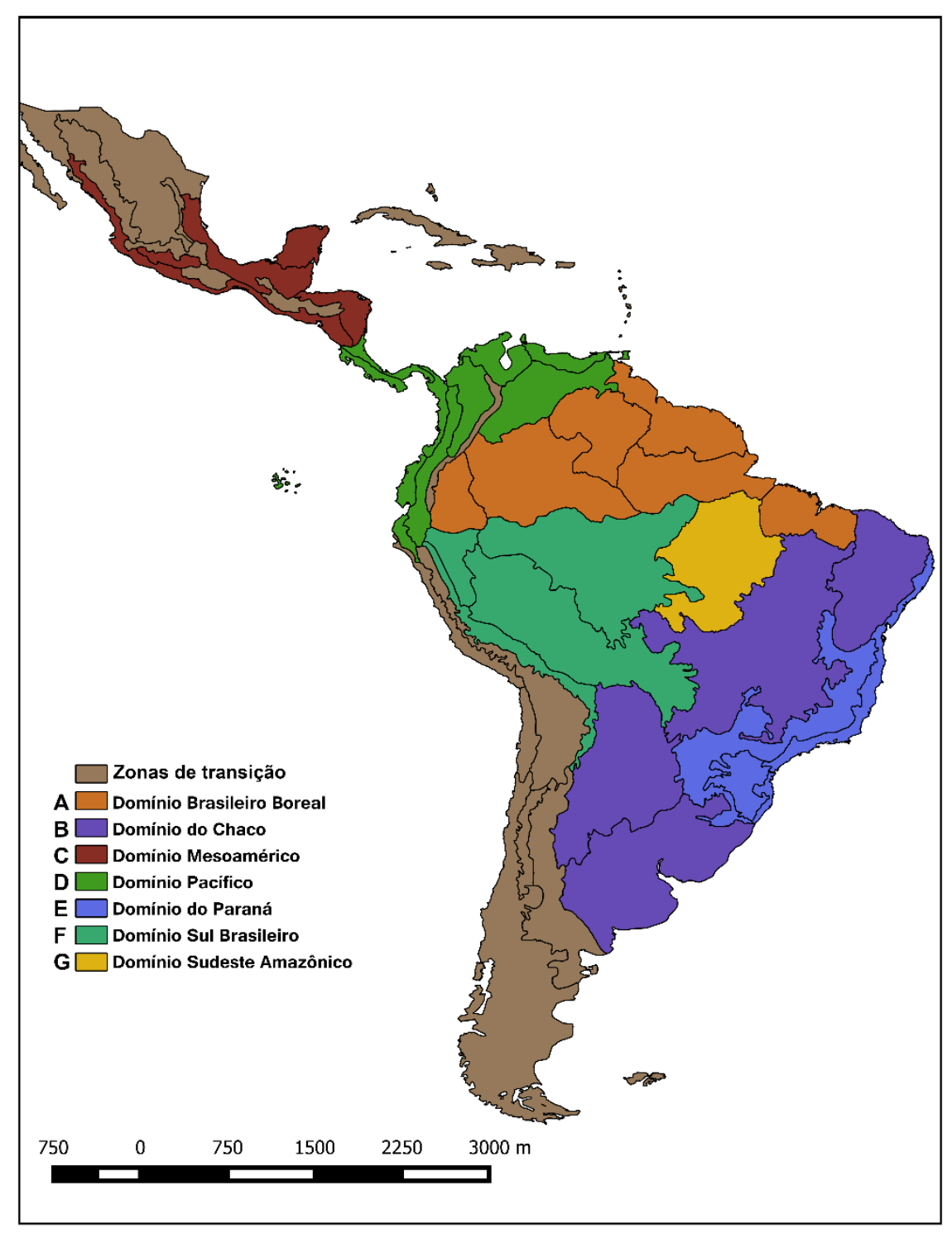

Figura. 168. Domínios delimitados para a Região Neotropical por Morrone (2014), utilizados para as análises biogeográficas do presente estudo. 
A Análise de Dispersão Vicariância resultou em 34 dispersões requeridas para o cenário biogeográfico de Mesembrinellidae. Na Figura 169 é possível observar todas as possibilidades de áreas ancestrais obtidas pela análise. A origem de Mesembrinellidae resultou de uma área ancestral formada pelos Domínios Brasileiro Boreal, Chaco, Pacífico, Paraná e Sul Brasileiro, com exceção somente do Domínio Mesoamérico. Então, na primeira cladogênese, o clado 1, formado pelas espécies Mesembrinella facialis, $M$. nigripes comb. n. e M. perisi se diversificaram primeiramente para ocupar o Domínio do Pacífico, com dispersões posteriores para os Domínios do Paraná, por M. nigripes comb. n., com desaparecimento no Domínio do Pacífico, e para o Sul Brasileiro, por M. perisi. Posteriormente, o outro clado restante se diversificou sofrendo um evento de vicariância, separando as áreas ABDEF em ABEF e D, clado 2 e 3, respectivamente. Dentro desses dois clados, houve diversas dispersões e vicariâncias, que serão discutidas posteriormente.

Já na Análise de Parcimônia de Brooks, os terminais e os nós do cladograma foram numerados para a construção da matriz binária Táxon X Área, conforme Apêndice 3. A Análise resultou em somente uma árvore mais parcimoniosa: ((Domínio do Chaco, Domínio Brasileiro Boreal) (Domínio do Paraná (Domínio Mesoamérico (Domínio Sul Brasileiro, Domínio Pacífico)))) (L=99, CI=69, RI=55, Fig. 170). È possível observar uma grande dicotomia entre os domínios do Chaco e Boreal Brasileiro, que estão mais proximamente relacionados entre si, e os domínios do Paraná, Mesoamérico, Sul Brasileiro e Pacífico, formando o outro grupo da dicotomia. Dentro desse último grupo, os domínios Mesoaméricos, Sul Brasileiro e Pacífico, que estão mais próximos geograficamente, também são mais relacionados entre si, e o Domínio do Paraná é grupo irmão desse clado. 

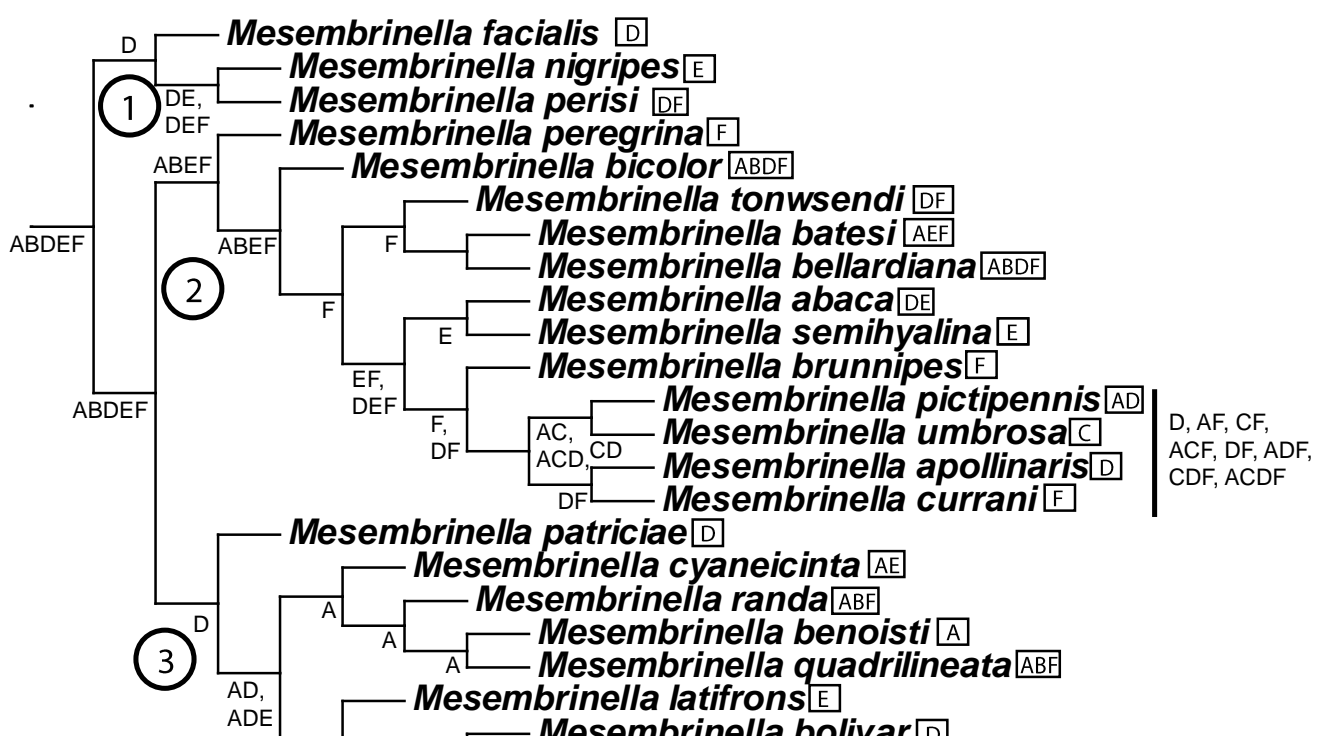

Mesembrinella patriciae D

Mesembrinella cyaneicinta $\mathrm{AE}$

Mesembrinella randa $\triangle \mathrm{ABF}$

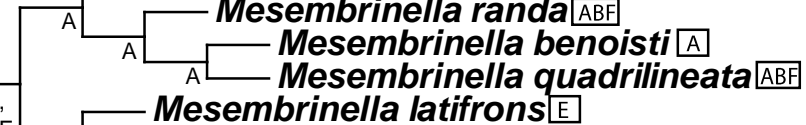

ADE - Mesembrinella latifrons $\mathrm{E}$

$\mathrm{DE} \quad \mathrm{D}$ Mesembrinella carvalhoi $\mathrm{D}$

Mesembrinella anomala $D$
M

D, Mesembrinella vogelsangi $\square$

$\begin{array}{lll}\mathrm{CDF} & \mathrm{C}, \\ & \mathrm{CD} & \mathrm{D}\end{array}$

$\mathrm{D} D \mathrm{DEF}$ Mesembrinella semiflava $\mathrm{C}$

C, Mesembrinella uniseta $\square$

Mesembrinella decrepita $\square$

${ }_{\mathrm{CD}}, \mathrm{Z}$ Mesembrinella spicata $\mathrm{C}$

Figura 169. Cladograma resultante da análise implícita dos caracteres com todas as possibilidades de áreas ancestrais encontrada com a Análise de Dispersão Vicariância. Para a codificação das áreas, ver Fig. 168. Letras dentro de retângulos representam as áreas de ocorrência dos terminais. Números dentro de círculos são uma codificação arbitrária dos nós, utilizada ao longo do texto.

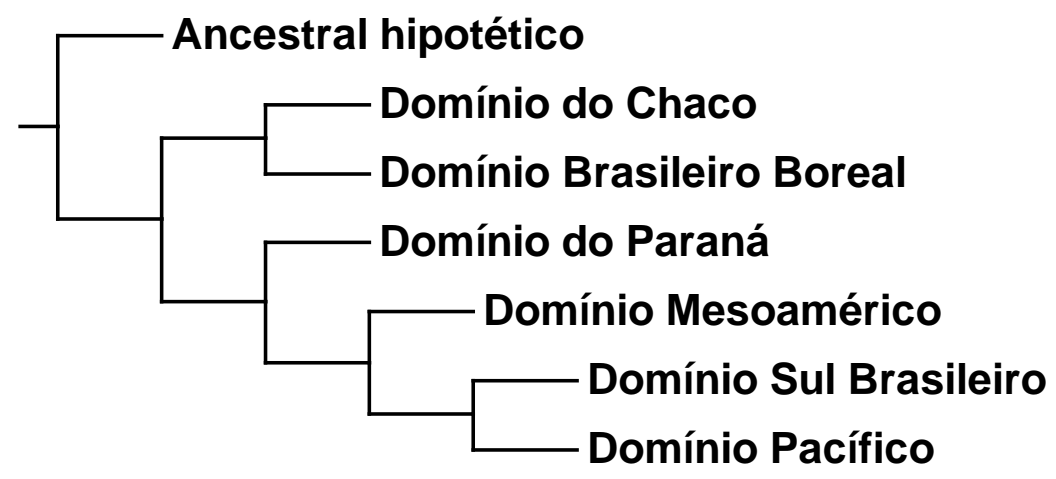

Figura 170. Cladograma obtido pela Análise de Parcimônia de Brooks (L=99, CI=69,

$$
\mathrm{RI}=55) \text {. }
$$




\section{Discussão}

Toda a discussão será baseada na análise de pesagem implícita (Figs. 119124), sendo a análise de pesos iguais (Figs. 116-118), utilizada para eventuais comparações.

\subsection{Breves considerações sobre posicionamento de Mesembrinellidae e relacionamentos no grupo externo}

A elucidação das relações do grupo externo, bem como o posicionamento de Mesembrinellidae dentro de Oestroidea não são objetivos deste trabalho, por conta da pequena amostragem de representantes dessa superfamília, cuja diversidade ultrapassa as 15.000 espécies (Brown et al., 2009). Porém, os resultados pertinentes a essas duas questões serão brevemente apresentados nessa seção, pois podem vir a ser úteis como caráter comparativo, em análises futuras e mais abrangentes. A família Calliphoridae (clado 6) se mostrou monofilética, com a exclusão de Rhiniinae (Idiella mandarina e Strongyloneura nebulosa), tendo como grupo irmão uma das duas espécies que se encontram em politomia, Cuterebra apicalis ou Idiella mandarina (Clado 5). Não há, entretanto, nenhuma sinapomorfia para a família Calliphoridae, como já era esperado, de acordo com a literatura (e.g. Rognes, 1997).

Dentro de Calliphoridae s.l., os seguintes grupos foram recuperadas como clados monofileticos: Mesembrinellidae, grupo interno do presente trabalho; Chrysomyinae, representada pelas espécies Chrysomya megacephala e Cochliomyia hominivorax; Toxotarsinae, representada pelas espécies Neta chilensis e Sarconesia chlorogaster, a subfamília Calliphorinae, representada pelas espécies Calliphora vomitoria e Cynomya cadaverina e a subfamília Ameniinae, representada pelas espécies Amenia leonina e A. imperialis. A única subfamília não monofilética foi Luciliinae, representada pelas espéies Lucilia eximia e Blepharicnema splendens.

O posicionamento de Mesembrinellidae dentro ou fora da família Calliphoridae vem gerando frequentes discussões na literatura (e.g. Guimarães, 1977; Rognes, 1997; Kutty et al., 2010; Marinho et al., 2012). Guimarães propôs que o grupo 
fosse elevados ao status de família, pela presença de diversas características aberrantes aos califorídeos típicos (Guimarães, 1977, p.7). De fato, todas as características mencionadas por esse autor são bastante diferenes dos demais Calliphoridae, porém isso não basta para elevar Mesembrinellidae ao status de família. Outros grupos de Calliphoridae, como Phumosiinae (Rognes, comm pess), também apresentam características muito aberrantes, como por exemplo o hábito parasitóide de anfíbios anuros, sendo chamados popularmente de "frog flies" e, no entanto, nunca foi duvidado que pertencessem a essa família. Portanto, a simples presença de determinadas características diferentes do padrão geral observado em um táxon mais inclusivo não é suficiente para justificar a sua remoção deste. Com este objetivo, a melhor maneira de testar a hipótese de segregação, é realizar uma análise cladística em busca de evidências filogenéticas para tal ato. Contudo, trabalhos filogenéticos posteriores corroboraram a hipótese de que Mesembrinellidae não é um grupo de Calliphoridae e pode estar relacionado à Tachinidae (Kutty et al. 2010; Marinho et al., 2012) ou aparecer como um clado independente dentro de Oestroidea, o que justificaria seus status como família (Singh \& Wells, 2013). Devido à rápida radiação dos Schizophora (Wiegemann et al., 2011), torna-se muito mais complicada uma inferência filogenética molecular dentro desse grupo, pois os marcadores moleculares podem apresentar sinais fracos ou conflitantes (Marinho et al., 2012). Apesar disso, as evidências atuais mostram que o grupo se trata de uma família, Mesembrinellidae. Como já postulado por Rognes (1997), certamente Calliphoridae não é um grupo monofilético e faz-se necessário o desmembramento dessa família em clados menores, monofiléticos. Como o grupo externo da presente análise é pouco representativo da superfamília Oestroidea, uma vez que o posicionamento do grupo interno não era objetivo da presente análise, acredita-se que a monofilia de Calliphoridae, suportada em nosso resultado, seja, provavelmente, artificial e tenha ocorrido em função da incompleta amostragem de terminais.

As famílias Tachinidae e Sarcophagidae formaram um grupo monofilético (Clado 4), mas com a inclusão da espécie Strongyloneura nebulosa dentro do clado e sem sinapomorfias, como no caso dos califorídeos. Dentro do clado 4, é possível observar que Sarcophagidae é uma família monofilética e, Tachinidae, parafilética, pela politomia formada por suas espécies juntamente com Strongyloneura nebulosa. Uma exceção, entretanto, é a subfamília Phasiinae, que se mostrou monofilética. Por último, a superfamília Oestroidea é monofilética por duas sinapomorfias: presença de cerdas no 
méron (36) e presença do apódema basal do gonóstilo (117). Em todas as análises, a espécie Shannoniella cuspitada (Rhinophoridae) aparece como espécie irmã de todos os demais Oestroidea.

Esses resultados são, em parte, semelhantes a Pape (1992) e Rognes (1997), pois em suas análises Rhinophoridae também é o grupo mais primitivo de Oestroidea e Tachinidae é grupo irmão de Sarcophagidae. Em Rognes (1997) as subfamílias Ameniinae e Phumosiinae também estão próximas à Mesembrinellidae. No entanto, a presença de Oestridae dentro de Calliphoridae não é corroborada na presente análise e o clado Auchmeromyinae e Bengaliinae, embora esteja presente nas análises desse autor, não está proximamente relacionado à Mesembrinellidae, como foi encontrado no presente trabalho e discutido brevemente abaixo.

\subsection{O relacionamento de Mesembrinellidae com as subfamílias}

\section{Phumosiinae, Auchmeromyinae e Bengaliinae}

Em Rognes (1997; Fig 3), Mesembrinellidae é grupo irmão de um clado maior formado por Phumosiinae, Euphumosia, Ameniini, Parameniini e Catapicephala, sustentado pelos seguintes caracteres: parafaciália nua, metakatepisterno setoso, ovopositor muito curto e reduzido, e pelo tipo de reprodução macrolarvíparo. Dentre esses caractereres, dois estão presentes na análise apresentada aqui, a condição de setosidade da parafaciália e a forma do ovpositor. Diferentemente de Rognes (1997), a parafaciália nua não é condição exclusiva desse clado, estando presente também em algumas espécies de Sarcophagidae, Tachinidae e outros Calliphoridae sendo, portanto um caráter bastante homoplástico. Já a forma do ovopositor, muito curto e reduzido, merece bastante destaque, como já havia sido mencionado anteriormente por Guimarães (1977) como uma característica importante de Mesembrinellidae. O clado formado por Auchmeromyiinae e Bengaliinae aparece mais distante, sendo o grupo irmão de um clado maior, formado pela maioria das subfamílias de Calliphoridae. Porém, na presente análise, esse clado é grupo irmão de Mesembrinellidae, agrupamento sustentado por caracteres homoplásticos, tendo Phumosia promittens como espécie irmã desse grupo maior. A conformação do ovopositor, curto e reduzido, está presente também em Auchmeromyia e Phumosiinae, um dos caracteres que sustentam essa relação Phumosiinae + 
(Auchmeromyinae+Bengaliinae) + Mesembrinellidae, mas ausente em Bengaliinae, que apresenta o ovopositor longo e telescopado (Rognes, 2011; 2012). Os demais caracteres são bastante homoplásticos.

\subsection{Monofilia de Mesembrinellidae}

Guimarães (1977), em seu estudo taxonômico de Mesembrinellidae, listou algumas características importantes desse grupo que eram muito diferentes dos Calliphoridae típicos: espiráculo metatórácico com uma única, grande e reniforme aba, e com abertura dorsal; espermateca em forma de tubo longo e esclerosado; pós-abdômen feminino não formando um ovopositor telescópico; espécies macrolarvíparas e veia $\mathrm{M}$ com uma curva suave em sentido anterior. Essas características foram utilizadas para justificar a hipótese do status de família, proposto por esse autor, alegando que essas características eram muito aberrantes em comparação com os califorídeos típicos e que, portanto, os mesembrinelideos não pertenciam a essa família. No primeiro estudo filogenético do grupo (Toma \& Carvalho, 1995), a monofilia de Mesembrinellidae era suportada pelos seguintes caracteres: espiráculo metatorácico único, reniforme com abertura dorsal; espermateca em forma de tubo longo e esclerosado; asa com mácula na porção médio-apical, próximo as veias $\mathrm{R}_{1}$ e $\mathrm{R}_{2+3}$; esternito 8 ausente na fêmea. Mais adiante, Bonatto (2001) encontrou cinco sinapomorfias para Mesembrinellidae: forma e estrutura do espiráculo posterior, espermateca alongada, redução à ausência do esternito 8 da fêmea, fusão dos surstilos ao epândrio e estrutura do espiráculo anterior. A fusão dos surstilos ao epândrio é de fato uma sinapomorfia do grupo, assim como a redução do esternito 8 da fêmea, ambas sinapomorfias corroboradas no presente trabalho. De fato, todas essas características são extremamente importantes para sustentar Mesembrinellidae e são praticamente iguais aos postulados por Guimarães (1977), porém nem todas foram corroboradas no presente trabalho.

A forma do espiráculo metatórácico é única dentre os Oestroidea, por possuir formato reniforme, com somente uma aba e abertura dorsal (e.g. Fig.37). Como comentado previamente por Pape (1992), a forma do espiráculo em Mesembrinellidae é muito diferente dos demais Oestroidea e se assemelha a alguns Muscidae. Na presente análise, foram utilizadas duas espécies de Muscidae na composição do grupo externo (Phaonia advena e Polietina flavithorax) e de fato a forma do espiráculo metatorácico é 
semelhante à Mesembrinellidae, com a presença de uma abertura dorsal e uma única aba, porém não apresenta o formato reniforme. Portanto, esse caráter foi corroborado como sinapomorfia de Mesembrinellidae.

Além disso, a redução do esternito 8 na fêmea (Fig. 85) também é corroborada como característica exclusiva de Mesembrinellidae dentro de Oestroidea. No grupo externo o esternito 8 estava presente em todas as espécies estudadas aqui. A única exceção a essa regra, dentro de Mesembrinella, como mencionado por Toma \& Carvalho (1995) é a espécie Mesembrinella anomala comb. n., em que o esternito 8 está presente e o tergito 8 está ausente, o que foi considerada uma reversão do estado presente desse esternito.

Entretanto, os outros dois caracteres mencionados por Toma \& Carvalho (1995) e Bonatto (2001) como sinapomórficos para Mesembrinellidae, não foram considerados sinapomorfias na presente análise. A forma da espermateca alongada e esclerosada (Figs. 89-91) é bastante marcante em Mesembrinellidae e foi considerado caráter exclusivo na literatura até agora. No entanto, ao examinar as espécies do grupo externo, foi constatado que algumas delas também apresentam uma espermateca bastante alongada e semelhante a algumas Mesembrinellidae Portanto, esse caráter não foi corroborado aqui como sinapomorfia de Mesembrinellidae. Dentro de Mesembrinellidae, contudo, existem variações do formato da espermateca (formatos tuberiforme, bulbosa e filiforme), e as condições bulbosa e filiforme são exclusivas de espécies desse grupo. A espermateca bulbosa (Fig. 90) é uma autapomorfia da espécie Mesembrinella facialis e a condição filiforme (Fig. 91) está presente na maioria das espécies, sendo caráter sinapomórfico do clado 12 (Caráter 102). A condição tuberiforme (Fig. 89) foi assinalada a todas as espécies do grupo externo que apresentam espermateca alongada assim como às espécies Mesembrinella nigripes comb. n. e Mesembrinella perisi. Além disso, Toma \& Carvalho (1995) citam a mácula na porção médio-apical, próximo as veias $\mathrm{R}_{1}$ e $\mathrm{R}_{2+3}$. Esse caráter é bastante homoplástico, estando presente em diversas espécies de Mesembrinellidae, sem formar nenhum agrupamento. Por último, a forma do espiráculo anterior com uma abertura dorsal (Bonatto, 2001) é homoplástico em Mesembrinella porque as espécies Mesembrinella bolívar comb. n. e Mesembrinella carvalhoi comb. $\mathbf{n}$. apresentam o estado 0 , em forma de fenda, sendo uma reversão do estado encontrado no grupo externo. 
Portanto, as sinapomorfias de Mesembrinellidae, de acordo com a presente análise, são: espiráculo metatorácico reniforme (45), surstilo fundido ao epândrio (107) e esternito 8 ausente na fêmea (100).

\subsection{Relações internas de Mesembrinellidae}

Dentro de Mesembrinellidae, o clado 10 é o primeiro grupo a divergir como uma linhagem independente, tendo como grupo irmão clado maior (clado 12), composto por todas as demais espécies do grupo. Esse clado 12, por sua vez, é composto por dois grandes clados, detalhados a seguir. O clado 10 é suportado por uma sinapomorfia: cercos do macho fortemente arqueados em vista lateral (115) (Fig. 108). Embora a terminália masculina das espécies do clado 10 possua algumas diferenças significativas, a presença desse forte arqueamento dos cercos em vista lateral é visivelmente comum entre elas, resultanto, na presente análise, em uma sinapomorfia desse clado. Além disso, a ausência de gancho na extremidade dos cercos (114) aparece suportanto esse clado, porém é um estado de caráter bastante homoplástico, sendo compartilhados por diversas outras espécies. Esse agrupamento não foi encontrado por Bonatto (2001), em que o então gênero Laneella (Mesembrinella nigripes comb. n. e Mesembrinella perisi) é grupo irmão de Souzalopesiella ${ }^{+}$, grupo suportado pela espermateca do tipo bulbosa. A morfologia da espermateca em Mesembrinella nigripes comb. n. e Mesembrinella perisi é, de fato, muito semelhante às espécies do grupo externo que possuem espermateca alongada, o que indica que esse gênero esteja mais próximo à raíz de Mesembrinellidae, como corroborado aqui, porém juntamente com Mesembrinella facialis.

O clado 11 é, tradicionalmente, suportado pela coloração branca na metade basal das garras tarsais (65) (Toma \& Carvalho, 1995; Bonatto, 2001) (Fig. 58), estado de caráter exclusivo dentro de Mesembrinellidae. Entretanto, esse estado de caráter também foi encontrado em Auchmeromyia bequaerti, ocasionando essa homoplasia. Laneella foi descrita originalmente por Mello (1967) para alocar Mesembrinella brunnipes, que, posteriormente foi considerada erro de identificação por Guimarães (1977) ao descrever a espécie Laneella nigripes (Mesembrinella brunnipes sensu Mello, 1967). Esse gênero foi proposto por Mello (1967) após a a observação principalmente da forma da espermateca, em forma de tubo engrossada uniformemente, bastante esclerosada 
e curta, em comparção com os demais mesembrinelídeos, em que a espermateca é afilada em direção ao ápice, bastante frágil, pouco esclerosada e mais alongada. Entretanto, somente Guimarãs (1977) notou a coloração bastante característica da metade basal das garras tarsais nesse gênero, até então composto apenas por Mesembrinella nigripes comb. n. Posteriormente, Bonatto (2001) observou que a então espécie Mesembrinella perisi pertencia ao gênero Laneella, que foi publicado posteriormente por Wolff et al., 2013. Essa espécie também possui as garras tarsais brancas na base e espermateca típica de Laneella. Portanto, o clado 11, embora não apresente sinapomorfias, possui esses dois estados de caráter bastante característicos e exclusivos dentro de Mesembrinellidae, o que indica sua forte existência como um clado, além do bom suporte do ramo (Índice de Bremer=0.09). O clado 12 possui bom suporte (Índice de Bremer=0.12) e uma sinapomorfia: espermateca do tipo filiforme (102), exemplificada anteriormente. Dentro do clado 12, pode-se observar a presença de dois clados maiores (13 e 15).

O antigo gênero Mesembrinella senso stricto (clado 13) vem sendo o mais problemático e citado como muito provavelmente polifilético por todos os autores que estudaram esse grupo (e.g. Guimarães, 1977; Toma \& Carvalho, 1992; Bonatto, 2001). Todos os autores comentam que não existe nenhum estado de caráter exclusivo desse gênero, que garanta sua monofilia, fato corroborado no presente trabalho. O clado 13 é suportado por duas homoplasias: primeiro flagelômero mais da metade do comprimento do pedicelo (16) (Fig. 13) e veia transversal dm-cu reta ou quase reta (80) (Fig. 65). No entanto, ambos são altamente homoplásticos. Dentro do clado 13 existem alguns agrupamentos que merecem ser destacados. O clado 14, composto pelas espécies Mesembrinella pictipennis, M. umbrosa, M. apollinaris e M. currani é bastante bem suportado, por um índice de Bremer $=0.08$ e duas sinapomorfias: cerdas na crista facial avermelhadas (19) e distância entre a $R_{2+3}$ e $R_{4+5}$ igual à distância entre a $R_{4+5}$ e $M$, no ápice da asa (77). Esse último caráter foi, primeiramente utilizado por Guimarães (1977) em seu estudo taxonômico do grupo e, posteriormente, por Bonatto (2001) como um caráter filogenético também sinapomórfico para o agrupamento citado.

O clado 15, por sua vez, é um grupo bastante grande, composto de 20 espécies, porém sustentado apenas por homoplasias. O clado 16 é suportado por uma sinapomorfia: presença de linha de cerdas dorsolaterais no $\mathrm{T}_{1+2}$ (84) (Fig. 77), além de quatro homoplasias. Esse estado de caráter foi também proposto por Bonatto (2001) como sinapomorfia desse clado, porém, na análise desse autor, a espécie Mesembrinella spicata 
não estava posicionada dentro desse grupo, por não ter essa fileira de cerdas. De fato, essa espécie não possui esse estado de caráter, mas está dentro desse agrupamento por estar proximamente relacionada ao clado 22.

Dentro do clado 16, os antigos gêneros Eumesembrinella (clado 17) e Giovanella (Clado 20) são monofiléticos. O clado 17 possui um bom suporte de ramos (Índice de Bremer=0,23) e é suportado por duas sinapomorfias: linha de cerdas dorsolaterais no $T_{1+2}$ em uma composição oblíqua à margem do tergito (85) (Fig. 78) e coloração amarela em pelo menos metade do $T_{3}$, exclusivamente nos machos (93) (Fig. 80). Esse grupo foi estudado com bastante detalhe em Toma \& Carvalho (1995) e sua monofilia era suportada pelos seguintes estados de caráter: fileira de cerdas vertical no méron curvando-se levemente na porção posterior e dimorfismo sexual no padrão de coloração do abdômen. De acordo com esses autores, a fileira de cerdas no méron apresenta-se em duas conformações básicas, na forma de um L invertido ou com uma curva suave, presente somente em Eumesembrinella. Já em Bonatto (2001), Eumesembrinella é suportado por esses mesmos dois caracteres de Toma \& Carvalho (1995) e um terceiro, linhas de cerdas discais laterais no $T_{1+2}$ oblíquas à margem do tergito. Somente a conformação das cerdas merais não foi corroborada como sinapomorfia desse gênero nesse estudo, estando presente em diversas espécies do grupo externo. No entanto, foi confirmado que, no grupo interno, O clado 17 é o único grupo que possui esse estado de caráter.

O clado 18 é suportado por uma única sinapomorfia: cerdas ocelares do macho mais que o triplo do tamanho do triângulo ocelar (5) (Fig. 17). Dentro desse clado, Mesembrinella latifrons comb. n. e Mesembrinella anomala comb. n., considerados até então gêneros monotípicos, encontram-se posicionadas isoladamente, o que corroboraria a origem independente da linhagem dentro de Mesembrinellidae. Mesembrinella anomala comb. n. é grupo irmão do clado 22, que foi considerado Huascaromusca sensu lato, com a inclusão de Mesembrinella flavicrura, M. xanthorrhina e Mesembrinella spicata. Esse posicionamento de Mesembrinella anomala comb. n. é diferente daquele obtido por Bonatto (2001), em que essa espécie é espécie irmã do que seria o clado 20 + clado 22 . Esse último agrupamento é suportado pela presença do tergito 8 projetado dorsalmente (98) (Fig. 85), estado de caráter ausente em Mesembrinella anomala comb. n. Entretanto, o posicionamento de Mesembrinella anomala comb. n. varia entre espécie irmã do clado 22 ou irmã do clado 20, de acordo com as diversas análises feitas aqui, Já Mesembrinella 
latifrons comb. n., embora esteja posicionada em locais diferentes dentro do clado 18 sempre aparece como uma linhagem independente. Em Bonatto (2001), essa espécie encontrava-se em uma politomia com diversas espécies do então gênero Mesembrinella senso stricto, o que indicaria sua relação com esse gênero e possível sinonímia. Já em Toma \& Carvalho (1995), ora esse gênero monotípico estava relacionado também à Mesembrinella, ora com Huascaromusca e Eumesembrinella, como foi encontrado no presente trabalho. Além da sinapomorfia citada anteriormente (5), Mesembrinella latifrons comb. n. apresenta alguns estados de caráter que, embora homoplásticos, são compartilhados com os clados 17 e 22, o que faz com que essa espécie esteja posicionada dentro do clado 18 e não no clado 13 junto com Mesembrinella senso stricto, como sugerido por Bonatto (2001).

O clado 20 é um grupo monofilético com Índice de Bremer=0.16, suportado somente por homoplasias. Entretanto, duas dessas homoplasias são exclusivas dentro de Mesembrinellidae: cerdas acrosticais pós-suturais ausentes (28) e espiráculo anterior em forma de fenda (52) (e.g. Fig. 44), sendo este último uma reversão do estado encontrado em todo o grupo externo. As demais espécies de Mesembrinellidae apresentam o espiráculo anterior com uma abertura dorsal em forma de gota (Fig. 45), caráter bastante característico desse grupo. A forma do espiráculo também foi apontado por Toma \& Carvalho (1995) e Bonatto (2001) como característica exclusiva do clado 20 dentro do grupo.

O antigo gênero Huascaromusca se mostrou polifilético pela inclusão das espécies Mesembrinella flavicrura, M. xanthorrhina e Mesembrinella spicata dentro do clado. O clado 22, não apresenta nenhuma sinapomorfia, suportado por 9 homoplasias. Tradicionalmente, Huascaromusca é suportado pela presença de cerdas discais no $\mathrm{T}_{5}$ (Mello, 1969; Guimarães, 1977; Bonatto, 2001) (Fig. 79). Dentro de Mesembrinellidae, esse é um estado de caráter exclusivo e foi corroborado na presente análise, por uma homoplasia (88). Entretanto, a distribuição dessas cerdas é diferente em algumas espécies, ora apresentando-se como uma fileira muito forte, central e bem organizada, ora como a presença de algumas cerdas desorganizadas e mais fracas (89), esse último estado presente em Mesembrinella flavicrura e M. xanthorrhina. A presença das cerdas no tergito 5 foi uma das características que aproximou essas duas espécies de Huascaromusca, como havia proposto por Bonatto (2001). Entretanto, a organização dessas cerdas, sendo fracas e aleatórias nessas duas espécies, causou o posicionamento 
mais afastado de M. flavicrura, que apareceu como espécie irmã das demais espécies do clado. Além disso, apesar da ausência de cerdas no $\mathrm{T}_{5}$ em Mesembrinella spicata, essa espécie está intimamente relacionada com esse grupo, na maioria das análises. Em algumas análises com diferentes valores de k, entretanto, Mesembrinella spicata é uma linhagem independente, fora do agrupamento 22. Dentro do clado 22 é possível observar a presença de Mesembrinella flavicura como grupo irmão de dois grupos (clados 23 e 24). O clado 23 , embora não tenha sinapomorfia, apresenta uma homoplasia que merece destaque, que é a presença de bandas de coloração violeta nos tergitos abdominais (94). Esse caráter é compartilhado exclusivamente com Mesembrinella cyaneicincta, não estando presente em mais nenhuma espécie, do grupo interno ou externo da presente análise. Já o clado 24 é suportado por duas características: uma cerda orbital proclinada na fêmea (9) e ausência de dentículos na extremidade do parafalo (109), ambas bastante homoplásticas.

Para sumarizar brevemente o que foi discutido até agora e para apresentar os argumentos que justifiquem as mudanças taxonômicas a serem feitas, somente os antigos gêneros Laneella (clado 11), Eumesembrinella (clado 19) e Giovanella (clado 20) são monofiléticos, com suporte dos ramos ao menos regular (Índice de decaimento de Bremer acima de 2, para análise de pesagem igual e 0.02, pesagem implícita). Desses gêneros, contudo, somente Eumesembrinella apresenta dois caracteres sinapomórficos, enquanto Laneella e Giovanella são suportados somente por homoplasias. O antigo gênero Mesembrinella, embora polifilético com relação a algumas espécies, possui um clado que contém a maioria de suas espécies (clado 13). No entanto, o suporte do ramo é baixo (Índice de decaimento $=1$ para pesagem igual e 0.06 , pesagem implícita) e não possui nenhum caráter sinapomórfico, sendo sustentado somente por dois caracteres homoplásticos. Da mesma maneira, o gênero Huascaromusca aparece polifilético pela presença das espécies Mesembrinella flavicrura, M. xathorrhina e M. spicata dentro do clado 22. Também possui suporte de ramos extremamente baixo (Índice de Bremer=0.01). Com relação aos antigos gêneros monotípicos, somente Henriquella (M. spicata) está inserida dentro de um clado maior (clado 22), os demais são recuperados como linhagens independentes.

Dessa maneira, o que se observa em todas essas análises é que existem grupamentos importantes dentro de Mesembrinellidae. Porém, esses agrupamentos não são bem suportados e não refletem os gêneros existentes até o momento. A maioria dos 
gêneros, quando representado por um clado monofilético, têm índices de decaimento de Bremer muito baixos e poucas sinapomorfias que sustentem os clados. Dessa maneira, a validade dos gêneros é discutida no item 5.6.

\subsection{Cenários biogeogáficos em Mesembrinellidae}

De acordo com Wiegemann et al. (2011), Schizophora, grupo ao qual Mesembrinellidae pertence, é um clado em que ocorreu uma radiação de espécies extremamente rápida e cuja filogenia é incerta. A origem desse grupo, de acordo com os autores, está em torno de 65Ma. A origem e diversificação de Mesembrinellidae, portanto, é muito mais recente que isso, mas não existe uma estimativa até esse momento. De acordo com o presente estudo, Mesembrinellidae, grupo exclusivamente Neotropical, é grupo irmão de Bengaliinae + Auchmeromyinae, ambos africanos, o que poderia sugerir uma origem gonduânica para esse agrupamento, com posterior cladogênese durante a separação dos continentes. Entretanto, essa hipótese está descartada devido à origem recente dos Mesembrinellidae, uma vez que a separação da América do Sul e da África ocorreu por volta de 110Ma (e.g. Sanmartín \& Ronquist, 2004).

A região Neotropical está compreendida desde o sul do México até aproximadamente metade da Argentina, excluindo do continente Sul Americano, somente a porção andina (Morrone, 2006). É uma área que fazia parte da porção tropical do Gondwana, de temperaturas com médias altas e grande biodiversidade. É muito interessante observar que a distribuição de Mesembrinellidae (Figs. 134-167) é praticamente coincidente com a região Neotropical (Morrone, 2006, 2014), indicando que essas espécies estão intimamente conectadas à história dessa região e adaptados às condições que ela oferece. Os limites da região Neotropical são, ao Norte, a Zona de Transição Mexicana, uma importante área, conhecida por ser barreira geográfica de diversos grupos, onde a fauna das regiões Neártica e Neotropical se encontram de uma maneira muito complexa (e.g. Morrone, 2006). Já so sul, a região Neotropical é limitada ao norte da Argentina, onde o clima e vegetação começam a mudar drasticamente e a fauna parece estar mais relacionada à região Andina (Morrone, 2006). As análises biogeográficas realizadas aqui tiveram dois principais objetivos: hipotetizar um cenário biogeográfico histórico para as espécies de Mesembrinellidae, utilizando a análise DIVA 
como ferramenta, e estudar o relacionamento entre as áreas de ocorrência desse grupo, a fim de contribuir para a biogeografia da Região Neotropical.

De acordo com os resultados encontrados pela análise DIVA, os Mesembrinellidae têm sua origem na América do Sul e parte sul da América Central, tendo sua distribuição aumentada em sentido norte da América Central posteriormente, para o Domínio Mesoamérico. Entretanto, afirmações com relação à origem de clados nas análises DIVA não podem ser feitas com veemência, uma vez que essa análise trabalha com otimização de áreas ancestrais no cladograma dos táxons e, quanto mais se aproxima da raíz, maior é o erro embutido (Ronquist, 1996). Dentro de Mesembrinellidae, uma primeira cladogênese separarou o clado 1 (Fig. 170) do agrupamento formado pelos clados 2 e 3, em um evento de especiação simpátrica, pois ambos clados, clado 1 e clados $2+3$, permaneceram em parte na área $\mathrm{D}$. A área ancestral otimizada para o clado 1 é a área D, Domínio Pacífico. A espécie Mesembrinella nigripes teria, secondariamente, se dispersado para a área E, Domínio do Paraná, e sido extinta na área D. Já a espécie $M$. perisi se dispersou para a área E. Então, ocorreu um evento de vicariância que separou as áreas $\mathrm{D}$ de $\mathrm{ABEF}$, formando os clados 2 e 3 . A origem do clado 2, portanto, ocorreu em uma área mais ao sul da América do Sul, majoritariamente dentro do Brasil, tendo sua distribuição aumentada por dispersão para a América Central. Dentro do clado 2, existem algumas possibilidades de cenários diferentes para os clados menores, e diversas dispersões ocorreram. O clado formado pelas espécies Mesembirnella townsendi, $M$. batesi e M. bellardiana tem como área ancestral o Domínio Sul Brasileiro, com posterior dispersão para as áreas D, A e E. Os demais clados dentro do clado 2 possuem diversas possibilidades de áreas ancestrais. $\mathrm{O}$ clado 3 , em contrapartida, tem como área ancestral o Domínio Pacífico (D), com posterior dispersão em sentido sul para as áreas A, B e F e em sentido norte para a área C. Assim como no clado 2, há diversas possibilidades de áreas ancestral para os clados menores dentro do clado 3. De uma forma geral, pode-se observar que o Domínio Pacífico parece ter papel fundamental na origem de clados dentro de Mesembrinellidae, tendo sido otimizado como área ancestral em dois momentos diferentes no tempo filogenético do grupo, nos clados 1 e 3 . O clado 2, por sua vez, parece ter uma origem mais ao Sul do Continente, tendo tido sua distribuição aumentada posteriormente por dispersão.

O objetivo da análise BPA, em contrapartida, era estudar os relacionamentos entre as áreas de distribuição de Mesembrinellidae, na região 
Neotropical. A análise resultou em uma árvore em que os Domínios Boreal Brasileiro e do Chaco são áreas irmãs, separadas dos demais Domínios. Esse resultado é bastante interessante. Os mesembrinelídeos são moscas exclusivas de Florestas Ombrófilas, ou seja, bastante úmidas. Por esse motivo, seria esperado que não ocorressem no Domínio do Chaco, predominantemente seco. Entretanto, algumas espécies ocorrem nesse Domínio, em matas ciliares ou pequenos fragmentos de floresta. Dessa maneira, pode-se levantar algumas hipóteses: 1. Os mesembrinelídeos chegaram ao Domínio do Chaco por dispersão, tendo utilizado a conexão dos Domínios Boreal Brasileiro e do Chaco para como ponte para dispersarem; 2. Os Domínios Boreal Brasileiro e do Chaco foram uma área ancestral cuja vicariância resultou na ocupação das duas áreas por espécies de Mesembrinellidae. Comparando a análise BPA com DIVA pode-se supor que a hipótese 1 seja mais plausível, pois, de acordo com a análise DIVA, não há evidências de que esses dois domínios tenham sido uma área ancestral no passado. O relacionamento entre áreas secas e florestadas, em um primeiro momento, não é esperado, de acordo com a hipótese da diagonal aberta (Vanzolini, 1974), em que as áreas secas formariam uma região isolada na América do Sul, amplamente discutida na literatura (e.g. Werneck, 2011; 2012; Quijadas-Mascareñas, 2007). Entretanto, resultados divergentes a essas teorias, assim como os encontrados no presente trabalho, foram recuperados em outros estudos (e.g. Costa, 2003) em que a região do Chaco se mostrava mais proximamente relacionada ora à Amazônia ora à Floresta Atlântica. $\mathrm{O}$ outro agrupamento é composto pelos Domínios do Paraná, Mesoamérico, Sul Brasileiro e Pacífico. Nesse agrupamento, é possível observar que uma primeira vicariância teria separado o Domínio do Paraná dos demais. Posteriormente, um segundo evento de vicariância separou o Domínio Mesoamérico e, por último, os Domínios Sul Brasileiro e Pacífico. Essas áreas contêm Florestas Densas, habitat dos mesembrinelídeos e que, portanto, são mais proximamente relacionadas entre si, compartilhando faunas semelhantes.

\subsection{O que é um gênero e como estabelecer sua validade? Implicações na taxonomia de Mesembrinellidae}

O conceito de gênero, embora menos discutido na literatura que o conceito de espécie, também apresenta variações, de acordo com os pensamentos e crenças do autor que o propõe. Winston (1999), em seu livro sobre prática taxonômica, faz uma 
importante reflexão sobre a definição de gênero, brevemente sumarizado a seguir. De acordo com esse autor, o primeiro a tratar especificamente do conceito de gênero foi Alain Dubois, por volta de 1988 e, para ele, um gênero tem a capacidade de produzir híbridos de espécies que sejam viáveis na forma de adultos. Já Mayr \& Ashlock (1991) apud Winston (1999), após o advento da Sistemática Filogenética, afirmam que "um gênero é um grupo monofilético composto de diversas espécies que podem ser separados de outros táxons genéricos de maneira clara”. Willey (1981) apud Winston (1999), por sua vez, afirma que um gênero é uma "categoria a que pertencem todas as espécies e que contém uma ou mais espécies em um grupo monofilético".

O que se pode observar nesse breve resumo sobre a literatura reflexiva do conceito de gênero, de acordo com Winston (1999), é que não há um consenso sobre esse tema, como já esperado. O que fica claro é que um gênero precisa ser um grupo monofilético, pelo simples princípio da Sistemática Filogenética, óbvia nos dias de hoje, de que qualquer grupo deve ter um ancestral comum e exclusivo (Wiley \& Lieberman, 2011). Portanto, em se tratando de um grupo monofilético, depende do autor, sendo um lamper ou um splitter, definir quais desses clados são grupos de espécies e quais são gêneros e, mais ainda, quais são categorias taxonômicas mais abrangentes. Um critério bastante adotado no meio taxonômico é de caráter bastante prático, validando um gênero de acordo com sua facilidade em identificá-lo, mesmo por uma pessoa não especialista em determinado grupo (Thomas Pape, comm. pess.). Esse critério estaria mais relacionado com o conceito lumper, ou seja, aquela pessoa que está mais inclinada a utilizar nomes mais abrangentes, preferindo grandes gêneros a gêneros pequenos ou monotípicos (splitter). Por outro lado, gêneros monotípicos podem significar apenas falta de conhecimento daquele grupo e, com o advento de mais estudos, outras espécies podem ser descritas (Winston, 1999).

Na prática taxonômica, um novo gênero é descrito quando aquela espécie nova descoberta apresenta um conjunto de características bem diferentes ao gênero vigente ao qual se encaixaria, o que vai de encontro com o conceito de Mayr \& Ashlock (1991) apud Winston (1999) que afirmam que gêneros devem possuir características claras que o diferenciam. No entanto, como já mencionado anteriormente, "características claras que o diferenciam“ é uma expressão muito ampla, pois isso vai depender do que é claro ou não para o taxonomista daquele grupo e novamente vai de encontro à dicotomia 
dos lumpers e splitters. Algumas características vão parecer pequenas e merecedoras de variações interespecíficas e outras, intergenéricas.

Em Mesembrinellidae, tradicionalmente, tem se observado que o comportamento splitter é predominante, pois os gêneros são pequenos, com no máximo 15 espécies (somente Mesembrinella senso stricto), sendo que vários deles eram monotípicos (Souzalopesiella, Albuquerquea, Thompsoniella e Henriquella). Na análise filogenética apresentada aqui, alguns gêneros foram recuperados como monofiléticos e os que não são poderiam vir a ser com apenas algumas sinonímias, por somente algumas espécies ocasionaram problemas de monofilia. Entretanto, os suportes dos ramos genéricos são extremamente baixos e quase não há sinapomorfias nos clados.

Considerando o conceito prático, em que gêneros devem possuir características claras que o definem, esse é um grupo muito complexo, por apresentar alguns desses antigos gêneros facilmente identificáveis e outros, muito difíceis, com caracteres muito variáveis ou comuns a outros gêneros. O exemplo mais óbvio nesse sentido é o antigo gênero Mesembrinella senso stricto (Clado 13), que não possui nenhum caráter exclusivo ou de fácil identificação, sendo frequentemente confundido com Eumesembrinella (Clado 17) e Huascaromusca (Clado 22).

Os caracteres usualmente utilizados para definir os gêneros em Mesembrinellidae, costumam ser extremamente variáveis e comuns a espécies de gêneros diferentes, com poucas exceções. Alguns exemplos interessantes que pode ser citado nesse aspecto são os seguintes caracteres: número de cerdas humerais, presença ou ausência de cerdas no esclerito subcostal e na veia tronco. Esses três caracteres já foram utilizados para separar gêneros dentro do grupo, por diversos autores e de diversas maneiras (e.g. Aldrich, 1922; Guimarães, 1977). No entanto, como demonstrado na presente análise, os três caracteres são muito homplásticos, estando presentes em diversas espécies dentro de Mesembrinellidae, não formando nenhum agrupamento. Já os poucos caracteres autapomórficos dos gêneros (e.g. garras tarsais brancas em Laneella; cerdas discais no $\mathrm{T}_{5}$ em Huascaromusca, $\mathrm{T}_{5}$ duas vezes maior que $\mathrm{o} \mathrm{T}_{4} \mathrm{em}$ Thompsoniella, forma da genitália masculina com diversas modificações em Henriquella, olhos dicópticos nos machos de Albuquerquea etc) podem ser interpretados somente como variações morfológicas de um mesmo gênero, em agrupamentos de espécies. 
Na literatura de Diptera, a terminália masculina exerce papel fundamental na taxonomia e filogenia de grupos (e.g. Buenaventura \& Pape, 2013; Nihei \& Carvalho, 2007; Tschornig, 1985) por ser uma estrutura altamente vulnerável à rápida evolução morfológica. Essa evolução acelerada se deve ao fato da terminália sofrer muita pressão para modificar sua forma, por conta dos mecanismos de seleção sexual (Ebenhard, 2010). Por isso, o que se observa geralmente é uma grande variação das estruturas que compõem a terminália masculina entre espécies diferentes e uma variação ainda maior, entre gêneros distintos. Entretanto, isso não acontece em Mesembrinellidae, de um modo geral, pois a terminália é extremamente semelhante, com variações pequenas e espalhadas de forma bastante aleatória entre as espécies, não formando agrupamentos. Essa semelhança da terminália masculina pode ser um argumento de que se está lidando com um gênero somente, com pequenas variações entre suas espécies, mas nenhuma modificação significativa para merecer status genérico.

Outro fato interessante vem da análise biogeográfica de Mesembrinellidae feita no presente estudo. Os cenários biogeográficos, embora extremamente interessantes, apontam para os grandes clados dentro de Mesembrinellidae, não refletindo nenhum comportamento que mereça destaque para os clados considerados gêneros previamente a este estudo. Os padrões bioeográficos em Mesembrinellidae estão muito mais relacionados aos grandes clados formados (Clados 1, 2, e 3, Fig. 169) do que aos gêneros propriamente ditos. Como discutido anteriormente, o grupo ao qual pertence Mesembrinellidae, os Schizophora, tiveram uma radiação muito rápida nos últimos 65Ma, o que dificulta qualquer estudo filogenético e/ou biogeográfico, pois os eventos vicariantes se tornam muito mais difíceis de serem hipotetizados. Mais ainda, é bastante possível que esses agrupamentos de espécies (ora considerados gêneros) ainda estejam em processo de separação morfológica e especiação geográfica, que pode evoluir para gêneros mais consistentes no futuro. Por ora, porém, as evidências apontam para um único gênero, como proposto aqui.

Como se pode observar, existem diversos argumentos a favor e contra o mantenimento dos gêneros de Mesembrinellidae ou sua completa fusão em somente um gênero (decisão tomada no presente trabalho). Todos os argumentos têm sua importância e relevância, porém uma posição deve ser tomada. Optou-se, portanto, em sinonimizar todos as espécies de Mesembrinellidae no gênero Mesembrinella, sob os argumentos de que: 1. Embora haja gêneros clados monofiléticos, não há sinapomorfias para a maioria 
dos gêneros; 2. Muitos dos gêneros não são facilmente identificáveis e sua separação não é tão clara; 3. A terminália masculina é bastante semelhante, com pequenas variações que podem ser consideradas específicas; 4. Os suportes dos clados pelo índice de Bremer são muito baixos. 4. As análises biogeográficas demonstraram que os gêneros estão distribuídos aleatoriamente na Região Neotropical, não formando nenhum padrão de especiação. 


\section{Conclusões}

- A monofilia da família Mesembrinellidae é confirmada pela presença de três sinapomorfias: espiráculo metatorácico reniforme (45), surstilo fundido ao epândrio (107) e esternito 8 ausente na fêmea (100). Esses resultados diferem, em parte, de autores que estudaram esse grupo previamente (Bonatto, 2011; Guimarães, 1977; Toma \& Carvalho, 1995), principalmente devido à forma das espermatecas. Optou-se por considerar Mesembrinellidae uma família dentro de Oestroidea, como sugere todos os trabalhos filogenéticos mais recentes (e.g. Kutty et al., 2010, Marinho et al., 2012, Singh \& Wells, 2013).

- Os gêneros até então considerados válidos para o grupo, embora recuperados como clados monofiléticos, possuem suporte muito baixo, tanto de caracteres, com ausência de sinapomorfias, quanto de suporte de ramos. Acredita-se que, possivelmente, esses clados sejam somente agrupamentos de espécies dentro de Mesembrinellidae, mas que não mereçam status de gênero. Optou-se, portanto, pela sinonímia de todos os gêneros a Mesembrinella. Dessa maneira, diversas espécies foram revalidadas a Mesembrinella, uma vez que já foram realocadas nesse gênero previamente e, para as demais, foram feitas novas combinações.

- A família Mesembrinellidae parece estar mais relacionada as seguintes subfamílias de Calliphoridae: Auchmeromyinae, Bengaliinae e Phumosiinae. Esse resultado, em parte, corrobora o que foi proposto por Rognes (1997), de que Mesembrinellidae seria grupo irmão de Phumosiinae.

- Na presente análise, o clado dos mesembrinelideos foi recuperado dentro de Calliphoridae s.l., que se mostrou monofilético. Entretanto, o objetivo desse trabalho não era fazer afirmações sobre posicionamento de Mesembrinellidae dentro de Oestroidea nem verificar a monofilia de Calliphoridae, pois acredita-se que, para esse propósito, a amostragem utilizada deva ser mais representativa.

- A origem biogeográfica de Mesembrinellidae parece ter ocorrido na América do Sul e parte da América Central, tendo sua distribuição aumentada posteriormente por dispersões, em sentido norte. 
- O Domínio do pacífico (Área D) parece ter um papel essencial na evolução biogeográfica de Mesembrinellidae, sendo área ancestral de dois dos 3 grandes clados da família, em momentos diferentes no tempo.

- Embora o grupo seja exclusivamente de áreas florestadas na região Neotropical, parte da Amazônia norte parece estar mais relacionada à diagonal seca da América do Sul do que às demais regiões florestadas do continente, o que indica uma importante troca de faunas entre essas duas regiões, contrariando as teorias de que a diagonal seca seja uma área com história isolada nessa região. 


\section{Referências bibliográficas}

ALDRICH, J. M. 1922. The Neotropical Muscoid Genus Mesembrinella Giglio-Tos and Other Testaceous Muscoid Flies. Proc. V.S. Nat. Mus. 62: 1-36.

ALMEIDA, E. A. B. \& SANTOS, C. M. D. 2011. Lógica da Biogeografia de Vicariância. In: de CARVALHO, C. J. B. \& ALMEIDA, E. A. B. (Eds.). Biogeografia da América do Sul: Padrões e Processos. São Paulo, Brasil. Editora Roca. p. 52-62.

AMORIM, D. S. \& PIRES, M. R. S. 1996. Neotropical Biogeography and a Method for Maximum Biodiversity Estimation. In: BICUDO, C. E. M. \& MENEZES, N. A. (Eds). Biodiversity in Brazil, a First Approach. São Paulo, Brasil. CNPq. p. 183219.

AMORIM, D. S.; SILVA, V. C. \& BALBI, M. I. P. A. 2002. Estado do Conhecimento de Diptera Neotropicais. In: COSTA, C.; VANIN, S. A.; LOBO, J. M. \& MELIC, A. (Eds.). Proyecto Red Iberoamerica de Biogeografía y Entomología Sistemática (PRIBES). Zaragoza. Sociedad Entomológica Aragonesa - SEA. v.2. p. 29-36.

BARRIEL, V. \& TASSY, P. 1998. Rooting with Multiple Outgroups: Consensus Versus Parsimony. Cladistics 14: 193-200

BONATTO, S. R. 2001. Revisão e Análise Cladística ee Mesembrinellidae stat. rev. (Diptera, Oestroidea). Tese de Doutorado, Curso de Pós-graduação em Ciências Biológicas (Entomologia), Universidade Federal do Paraná, Curitiba, PR.

BONATTO, S. R. \& MARINONI, L. 2005. Gêneros e Espécies Novos de Mesembrinellinae (Diptera, Calliphoridae) da Costa Rica e Venezuela. Revista Brasileira de Zoologia 22: 883-890.

BRAUER, F. 1895. Bemerkugen zu Einigen Neuen Gattungen der Muscarien und Deutung Einiger Original-Exemplare. Sitz. K. Akad. Wiss. Wien, Math, Naturw. 104: 582-604.

BRAUER, F \& J. E. von BERGENSTAMM. 1893. Die Zweiflüger des Kaiserlichen Museums zu Wien. VI. Vorarbeiten zu Einer Monographie des Muscaria 
Schizometopa (Exclusive Anthomyiidae). Pars III. Denksch. K. Akad. Wiss., Wien 6: 89-240.

BREMER, K. 1994. Branch Support dnd Tree Stability. Cladistics 10: 295-304.

BROOKS, D. R. 1981. Hennig's Parasitology Method: A Proposed Solution. Systematic Zoology 30: 229-249.

; VAN VELlER, M. G. P. \& McLENNAN, D. A. 2001. How To Do BPA, Really. Journal of Biogeography 28: 345-358.

BROWN, B. V. et al. (Eds). Manual of Central American Diptera. Ottawa: National Research Council of Canada Monograph Publishing Program, 2009. v. 1. 714 p.

BUENAVENTURA, E. \& PAPE, T. 2013. Revision of the New World Genus Peckia Robineau-Desvoidy (Diptera, Sarcophagidae). Zootaxa 3622: 1-87.

COSTA, L. P. 2003. The Historical Bridge Between the Amazon and the Atlantic Forest of Brazil: A Study of Molecular Phylogeography with Small Mammals. Journal of Biogeography 30: 71-86.

CRISCI, J. V.; KATINAS, L. \& POSADAS, P. 2003. Historical Biogeography. Cambridge. Harvard University Press. 250p.

CROSSKEY, R.W. 1965. A Systematic Revision of the Ameniinae (Diptera, Calliphoridae). Bull. Brit. Mus. (Nat. Hist.) Entom. 16 (2): 35-140.

DIRECTORY OF CITIES AND TOWNS IN THE WORLD. Disponível em: http://www.fallingrain.com/world/.

EBENHARD, W. G. Rapid Divergent Evolution in Genitalia. In: J. LEONARD \& A. CORDOBA (Eds.), The Evolution of Primary Sexual Characters in Animals. Oxford University Press, Oxford, 40-78.

FARRIS, J. S. 1969. A Successive Approximations Approach to Character Weighting. Systematic Zoology 18: 374-385.

1989. The Retention Index and the Rescaled Consistency Index. Cladistics 5: 417-419. 
FERREIRA, M. J. de M. 1978. Sinantropia de Dípteros Muscóideos de Curitiba, Paraná. I. Calliphoridae. Revista Brasileira de Biologia 38: 445-454.

FOREY, P. L \& KITCHING, I. J. 2000. Experiments in Coding Multistate Characters. In: SCOTLAND, R. \& PENNINGTON, R. T. (Eds.). Homology and Systematics: Coding characters for phylogenetic analysis. Taylor \& Francis, London. 54-80 pp.

GADELHA, B. DE Q.; FERRAZ, A. C. P. \& COELHO, V. M. A. 2009. A Importância dos Mesembrinelíneos (Diptera: Calliphoridae) e seu Potencial como Indicadores de Preservação Ambiental. Oecologia Brasiliensis 13: 661-665.

GOLOBOFF, P. 1993. Estimating Character Weights During Tree Search. Cladistics 9: 83-91.

; CARPENTER, J. M.; ARIAS, J. S. \& ESQUIVEL, D. R. M. Weighting Against Homoplasy Improves Phylogenetic Analysis of Morphological Data Sets. Cladistics 24: 758-773.

; FARRIS, J. \&, NIXON, K.C. 2003. T.N.T.: Tree Analysis Using New Technology. Programa e documentação, disponível em: http://www.zmuc.dk/public/phylogeny/tnt.

GETTY THESAURUS OF GEOGRAPHICAL NAMES. Disponível em: http://www.getty.edu/research/conducting_research/vocabularies/tgn/.

GIGLIO-TOS, D. E. 1893. Diagnosi di Nuovi Generi e di Nuove Specie di Ditteri. Boll. Mus. Zool. Anat. Comp. 8: 1-11.

GRIFFITHS, G. C. D. 1972. The Phylogenetic Classification of Diptera Cyclorrhapha, with Special Reference to the Structure of the Male Postabdome. The Hague: W. Junk Publishers 340 p. (Series entomologica, 8).

GUIMARÃES, J. H. 1977. A Systematic Revision of The Mesembrinellidae stat. nov. (Diptera, Cyclorrhapha). Arquivos de Zoologia 29: 1-109.

GUimARÃES, J. H. PAPAVERO, N \& do PRADO, A. P. 1983. As Miíases da Região Neotropical (Identificação, Biologia, Bibliografia). Revista Brasileira de Zoologia 1: 239-416. 
HALL, D. G. 1948. The Blowflies of North America. Washington, DC. Thomas Say Foundation. Entomological Society of America. v.4. 477 p.

HAWKINS, J. A.; HUGHES, C. E. \& SCOTLAND, R. W. 1997. Primary Homology Assessment, Characters and Character States. Cladistics 13: 275-283.

HENNIG, W. 1973. Diptera (Zweiflüger). Handbuch der Zoologie 4: 1-337.

INSTITUTO BRASILEIRO DE GEOGRAFIA E ESTATÍSTICA (IBGE). Disponível em: http://www.ibge.gov.br/.

JAMES, M. T. 1970. Family Calliphoridae. In Museu de Zoologia, Universidade de São Paulo, A Catalogue of the Diptera of the Americas South of the United States 102. São Paulo, Brasil. p. 1-28.

KITCHING, I. J.; FOREY, P. L.; HUMPHRIES, C. J. \& WILLIAMS, D. M. 1998. Cladistics: the Theory and Practice of Parsimony Analysis. 2nd ed. Oxford University Press, Oxford. 228 pp.

KLUGE, A. G., FARRIS, J.S., 1969. Quantitative Phyletics and the Evolution of Anurans. Systematic Zoology 18: 1-32.

KUTTY, S. N.; PAPE, T. WIEGMAN, B. M. \& MEIER, R. 2010. Molecular Phylogeny of the Calyptratae (Diptera: Cyclorrhapha) with an Emphasis on the Superfamily Oestroidea and the Position of the Mystacinobiidae and Mcalpine'S Fly. Systematic Entomology 35: 614-635.

PONT, A. WIEGMAN, B. M. \& MEIER, R. 2008. The Muscoidea (Diptera: Calyptratae) are Paraphyletic: Evidence from Four Mitochondrial Genes. Molecular Phylogenetics and Evolution 49: 639-652.

LÖWENBERG-NETO. 2014. Neotropical Region: A Shapefile of Morrone's (2014) Biogeographical Regionalisation. Zootaxa 3802: 300.

MADISON, W. P. \& MADISON, D. R. 2011. Mesquite: A Modular System for Evolutionary Analysis. Version 2.75 http://mesquiteproject.org.

MARILUIS, J. C. 1987. Una Nueva Especie de Mesembrinellinae. Eos 63: 107-113. 
MARINHO, M. A. T.; Junqueira, A. C. M.; Paulo, D. F.; Esposito, M. C.; Villet, M. H. \& Azeredo-Spin, A. M. L. 2012. Molecular Phylogenetics of Oestroidea (Diptera: Calyptratae) with Emphasis on Calliphoridae: Insights Into the Inter-Familial Relationships and Additional Evidence for Paraphyly Among Blowflies. Molecular Phylogenetics and Evolution 65: 840-854.

MCALPINE, J. F. 1981. Morphology and Terminology - Adults. In: MCALPINE, J.F.; PETERSON, B.V.; SHEWELL, G.H.; TGESKEY, H.J.; VOCHEROTH, J.R.; WOOD, D.M. (Eds.). Manual of Neartic Diptera. Ottawa, Canadá: Editora Agriculture Canada. v 1. p. 9-64.

MELLO, R. P. 1967. Contribuição aos Mesembrinelinae Sul-Americanos (Diptera, Calliphoridae). Studia Entomologica 10: 1-80.

.2003. Chave para a identificação das formas adultas das espécies da família Calliphoridae (Diptera, Brachycera, Cyclorrhapha) encontradas no Brasil. Entomologia y Vectores 10: 255-269.

MORRONE, J. J. 2006. Biogeographic Areas and Transition Zones of Latin America and the Caribbean Islands Based on Panbiogeographic and Cladistic Analyses of The Entomofauna. Annual Review of Entomology 51: 467-494.

J. J. 2014. Biogeographic Regionalization of the Neotropical Region. Zootaxa 3782: 001-100.

NASCIMENTO, E. M. F.; OLIVEIRA, J. B.; PAES, M. J.; LOBO, A. P.; SILVA, A. L. A.; JÚNIOR, E. R. S.; LEAL, J. L. F. \& MOYA-BORJA, G. E. 2005. Miíases Humanas por Cochliomyia Hominivorax (Coquerel, 1858) (Diptera, Calliphoridae) em Hospitais Públicos na Cidade do Recife, Pernambuco, Brasil. Entomología y Vectores 12: 37-51.

NIHEI, S. S. 2011. Biogeografia cladística. In: de CARVALHO, C. J. B. \& ALMEIDA, E. A. B. (Eds.). Biogeografia da América do Sul: Padrões e Processos. São Paulo, Brasil. Editora Roca. p. 99-122.

NIHEI, S. S. \& de CARVALHO, C. J. B. 2007. Systematics and Biogeography of Polietina Schnabl \& Dziedzicki (Diptera, Muscidae): Neotropical Area 
Relationships and Amazonia as a Composite Area. Systematic Entomology 32: 477-501.

NIXON, K \& CARPENTER, J. M. 1993. On Outgroups. Cladistics 9: 413-426.

PAPE, T. 1992. Phylogeny of the Tachinidae Family-Group (Diptera: Calyptratae). Tijdschrift Voor Entomologie 135:43-86.

PAPE, T. \& THOMPSON, F. C. (Eds.). 2010. Systema Dipterorum v. 1.0. Disponível em: http://www.diptera.org.

PERIS, S. V. \& MARILUIS, J. C. 1984. Notas Sobre Mesembrinellidae. EOS- Revista Brasileira de Entomología 60: 251-265.

PLEIJEL, F. 1995. On Character Coding for Phylogeny Reconstruction. Cladistics 11: 309-315.

POHJOISMÄKI, J. L. O.; KARHUNEN, P. J.; GOEBELER, S.; SAUKKO, P. \& SÄÄKSJÄRVI, I. E. 2010. Indoors Forensic Entomology: Colonization of Human Remains in Closed Environments by Specific Species of Sarcosaprophagous flies. Forensic Science International 199: 38-42.

QUIJADA-MASCAREÑAS, A.; FERGUSON, J. E.; POOK, C. E.; SALOMÃO, M. D. G.; THORPE, R. S. \& WUSTER, W. 2007. Phylogeographic Patterns of TransAmazonian Vicariants and Amazonian Biogeography: The Neotropical Rattlesnake (Crotalus Durissus Complex) as an Example. Journal of Biogeography 34: 12961312 .

ROBACK, S. S. 1951. A Classification of the Muscoid Calyptratae Diptera. Annals of the Entomological Society of America 44: 327-361.

ROBINEAU-DESVOIDY, A. J. B. 1830. Essair sur les Myodaires. Mem. Prés. Div. Sav. Acad. Sei. Inst. Fr. 2: 1-813.

ROGNES, K. 1986. The Systematic Position of the Genus Helicobosca Bezzi with a Discussion of the Monophyly of the Calyptratae Families Calliphoridae, Rhinophoridae, Sarcophagidae and Tachinidae (Diptera). Entomologica Scandinavica 17: 75-92. 
1991. Blowflies (Diptera, Calliphoridae) of Fennoscandia and Denmark.

Fauna Entomologica Scandinavica 24. 271 p.

1997. The Calliphoridae (Blowflies) (Diptera: Oestroidea) are Not a Monophyletic Group. Cladistics 13: 27-66.

2011. A Review of the Monophyly and Composition of Bengaliinae with the Description of New Genus and Species, and New Evidence for the Presence of Melanomyinae in The Afrotropical Region (Diptera, Calliphoridae). Zootaxa 2964: $1-60$.

2012. Revision of the Afrotropical Species of the Bengalia peuhi SpeciesGroup, Including a Species Reassigned to the B. spinifemorata Species-Group (Diptera, Calliphoridae), with Notes on the Identity of Ochromyia Petersiana Loew, 1852 (Diptera, Rhiniidae). Zootaxa 3553: 1-79.

RONQUIST, F. 1996. DIVA 1.1. Computer Program and Manual Available by Anonymous FTP from Uppsala University. Disponível em http://www.ebc.uu.se/systzoo/research/diva/diva.html.

- 1997. Dispersal-Vicariance Analysis: A New Approach to the Quantification of Historical Biogegraphy. Systematic Biology 46: 195-203.

\& SANMARTÍN, I. 2011. Phylogenetic Methods in Biogeography. Annu. Rev. Ecol. Evol. Syst. 42:441-64.

SANMARTÍN, I. \& RONQUIST, F. Southern Hemisphere Biogeography Inferred by Event-Based Models: Plant Versus Animal Patterns. Systematic Biology 53: 216243.

SERENO, P. C. 2007. Logical Basis for Morphological Characters in Phylogenetics. Cladistics 23: 1-23.

SÈGUY, E. 1925. Espèces Nouvelles du Genre Mesembrinella G-T. Encycl. Entomol. Diptera, Ser B2 2: 195-196.

SHANNON. R. C. 1923. Genera of Neartic Calliphoridae (blowflies) with Revision of the Calliphorini (Diptera). Insecutor Inscitiae Menstruus 11: 101-118. 
SHEWELL, G. B. 1987. Calliphoridae. In: MCALPINE, J.F. (Ed); PETERSON, B.V.; SHEWELL, G.H.; TGESKEY, H.J.; VOCHEROTH, J.R.; WOOD, D.M. (Eds.). Manual of Neartic Diptera. Ottawa, Canadá: Editora Agriculture Canada. v 2. p. 1133-1145.

SINGH, B. \& WELLS, J. D. 2013. Molecular Systematics of the Calliphoridae (Diptera: Oestroidea): Evidence from One Mitochondrial and Three Nuclear Genes. Journal of Medical Entomology 50: 15-23.

SHUEY, J. A. 1997. An Optimizing Portable Bait Trap for Quantitative Sampling of Butterflies. Tropical Lepidoptera 8: 1-4.

STEVENS, W; OTRANTO, W. \& PAPE, T. 2006. The Evolution of Myiasis in Humans and Other Animals in the Old and New Worlds (Part II): Biological and LifeHistory Studies. Trends in Parasitology 22: 181-188.

SURCOUF, J. M. R. 1919. Revision des Muscidae Testaceae. Nouv. Arch. Mus. Hist. Nat., Paris 5: 27-124.

TOMA, R. \& CARVALHO, C. J. B. de. 1995. Estudo Filogenético de Mesembrinellinae com Ênfase no Gênero Eumesembrinella Townsend (Diptera, Calliphoridae). Revista Brasileira de Zoologia 12: 127-144.

TOWNSEND, C. H. T. 1918, New Muscoid Genera, Species and Synonymy. Insecutor Inscitiae Menstruus 6:151-156. 1931. Notes on American Oestromuscoid Types. Rev. Ent. I: 65$104,157-183$. 1935. Manual of Myiology. 2. São Paulo, Brasil. p. 143-146.

TSCHORSNIG, V. H-P. 1985. Taxonomie Forstlich Wichtiger Parasiten: Untersuchungen zur Struktur des Männlichen Postabdomens der Raupenfliegen (Diptera, Tachinidae). Stuttgarter Beiträge zur Naturkunde 383: 1-137.

WILEY, E. O. 1988. Parsimony Analysis and Vicariance Biogeography. Systematic Zoology 37: 271-290. 
\& LIEBERMAN, B. S. 2011. Phylogenetics, Theory and Practice of Phylogenetics Systematics. Hoboke, New Kersey. Wiley-Blackwell. 414 p.

WIEGMANN, B. M. et al. 2011. Episodic Radiations in the fly Tree of Life. PNAS 108: $5690-5695$.

WIENS, J. J. 1998. Polymorphism in Systematics and Comparative Biology. Annu. Rev. Ecol. Syst. 30: 327-62.

WINSTON, J. E. 1999. Describing Species: Practical Taxonomic Procedure for Biologists. New York. Columbia University Press. 528 p.

WERNECK, F. P. 2011. The Diversification of Eastern South American Open Vegetation Biomes: Historical Biogeography and Perspectives. Quaternary Science Reviews 30: $1630-1648$.

; NOGUEIRA, C.; COLLI, G. R.; SITES JR, J. W. \& COSTA, G. S. 2012. Climatic Stability in the Brazilian Cerrado: Implications for Biogeographical Connections of South American Savannas, Species Richness and Conservation in a Biodiversity Hotspot. Journal of Biogeography.

WHITWORTH, T. 2010. Keys to the Genera and Species of Blowflies (Diptera: Calliphoridae) of the West Indies and Description of a New Species of Lucilia Robineau-Desvoidy. Zootaxa 2663: 1-35.

WOLFF, M. 2013. A New Species of Mesembrinella (Diptera: Calliphoridae: Mesembrinellinae) from Colombia. Revista Colombiana de Entomología 39: $120-124$.

WOLFF, M. RAMOS-PASTRANA, Y. \& PUJOL-LUZ, J. R. 2013a. Description of the Male of Laneella perisi (Mariluis) (Diptera: Calliphoridae) n. comb. Neotropical Entomology 42: 58-62.

WOLFF, M. RAMOS-PASTRANA, Y. \& PUJOL-LUZ, J. R. 2013b. A New Species of Giovanella Bonatto (Diptera, Calliphoridae, Mesembrinellinae) from Colombia. Revista Brasileira de Entomologia 57: 129-132. 
VANZOLINI, P. E. 1974. Ecological and Geographical Distribution of Lizards in Pernambuco, Northeastern Brazil (Sauria). Pap Avulsos Zool 28: 61-90.

VARGAS \& WOOD. Calliphoridae (Blowflies). In: BROWN, B. V.; BORKENT, C.; CUMMING, J. M. WOOD, D. M. WOODLEY, N. E. \& ZUMBADO, M. A. 2009. Manual of Central American Diptera. National Research Council or Canada. 12971304.

VILLENEUVE, J. 1920. A propos de revision des Muscidae Testaceae de J. Surcouf. Bull. Soc. Ent., France 14: 223-226.

YEATES, D. K.; WIEGMANN, B. M. 1999. Congruence and Controversy: Toward a Higher-Level Phylogeny of Diptera. Annual Review of Entomology: 397-428. COURTNEY, G. W. MEIER, R. LAMBKIN, C. \& PAPE, T. 2007. Phylogeny and Systematics of Diptera: Two Decades of Progress and Prospects. Zootaxa 1668: 565-590. 


\section{APENDICES}

APÊNDICE 1. Matriz de caracteres morfológicos.

\begin{tabular}{|c|c|c|c|c|c|c|c|c|c|c|c|c|c|c|c|c|c|c|c|c|c|c|c|c|c|c|c|c|c|c|c|c|}
\hline & - & N & $m$ & $\nabla$ & in & b & $r$ & $\infty$ & $a$ & $\Theta$ & $=$ & $\simeq$ & 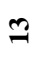 & $\Xi$ & 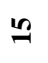 & $\stackrel{\bullet}{\bullet}$ & 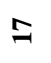 & $\stackrel{\infty}{\sim}$ & 2 & తి & $\bar{\lambda}$ & $\widetilde{\Im}$ & $\approx$ & 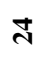 & $\stackrel{2}{4}$ & $\stackrel{\sim}{\sim}$ & $\curvearrowright$ & $\stackrel{\infty}{\sim}$ & ते & ले & $\bar{n}$ & లె \\
\hline Fannia heydenii & $?$ & $?$ & $?$ & $?$ & $?$ & 0 & 0 & 0 & - & 0 & 0 & 1 & 1 & 0 & 1 & 1 & 0 & 1 & 0 & 1 & 1 & 0 & - & 0 & 1 & 1 & 0 & 1 & 0 & 0 & 1 & 0 \\
\hline Phaonia advena & 0 & 0 & - & 1 & 0 & 0 & 0 & 0 & - & 0 & 0 & 1 & 1 & 1 & 1 & 0 & 0 & 1 & 0 & 1 & 1 & 0 & - & 0 & 1 & 0 & - & 0 & - & 0 & 1 & 4 \\
\hline Polietina flavithorax & 0 & 0 & - & 1 & 0 & 0 & 1 & 0 & - & 0 & 0 & 1 & 0 & 1 & 1 & 1 & 0 & 1 & 0 & 0 & 0 & 0 & - & 1 & 1 & 0 & - & 1 & 0 & 0 & 1 & 4 \\
\hline Acaulona costata & 1 & - & 1 & 1 & 0 & 0 & 0 & 0 & - & 0 & 0 & 1 & 0 & 1 & 0 & 1 & 0 & 1 & 0 & 0 & 0 & 0 & - & 2 & 0 & - & - & 1 & 0 & 0 & 0 & 0 \\
\hline Adejeania townsendi & 1 & - & 1 & 0 & - & 0 & 0 & 0 & - & 1 & 0 & 1 & 0 & 1 & 0 & 1 & 0 & 0 & 0 & 0 & 1 & 0 & - & 2 & 1 & 2 & 0 & 1 & 3 & 1 & 2 & 2 \\
\hline Ectophasia crassipenis & 1 & - & 1 & 0 & - & 0 & 0 & 0 & - & 0 & 0 & 0 & $?$ & 1 & 0 & 1 & 0 & 0 & 0 & 0 & 1 & 0 & - & 2 & 1 & 0 & - & 1 & 0 & 0 & 0 & 0 \\
\hline Gymnosoma rotundatum & 1 & - & $?$ & 0 & - & 0 & $?$ & ? & $?$ & 0 & 0 & 0 & ? & 1 & 1 & 1 & 0 & 0 & 0 & 0 & 1 & 0 & - & - & 0 & - & - & 0 & - & 0 & 0 & 5 \\
\hline Phasia hemiptera & 1 & - & 1 & 0 & - & 0 & 0 & 0 & - & 1 & 0 & 0 & $?$ & 1 & 0 & 1 & 0 & 0 & 0 & 0 & 1 & 0 & - & - & 0 & - & - & 0 & - & 0 & $?$ & $?$ \\
\hline Prophorostoma pulchra & 1 & - & 1 & 1 & 0 & 0 & 0 & 1 & 0 & 1 & 2 & 1 & 0 & 0 & 0 & 0 & 1 & 0 & 0 & 0 & 0 & 0 & - & 2 & 1 & 2 & 0 & 1 & 1 & 0 & 1 & 1 \\
\hline Winthemia analis & 1 & - & 1 & 1 & 0 & 0 & 0 & 1 & 0 & 1 & 0 & 1 & 0 & 1 & 1 & 0 & 0 & 0 & 0 & 1 & 1 & 0 & - & 2 & 1 & 1 & 0 & 1 & 2 & 1 & 2 & 0 \\
\hline Amobia floridensis & 1 & - & 1 & 1 & 0 & 0 & 0 & 1 & $?$ & 0 & 0 & 1 & 0 & 1 & 0 & 1 & 0 & 0 & 0 & 1 & 1 & 1 & 0 & 1 & 1 & 0 & - & 1 & 2 & 0 & 1 & 1 \\
\hline Peckia intermutans & 1 & - & 1 & 1 & 0 & 1 & 0 & 1 & $?$ & 1 & 0 & 1 & 0 & 1 & 0 & 0 & 0 & 0 & 0 & 1 & 1 & 1 & 0 & 2 & 1 & 1 & 0 & 1 & 0 & 0 & 1 & 1 \\
\hline Cuterebra apicalis & 1 & - & 0 & 0 & - & 0 & 0 & 0 & - & 1 & 0 & 0 & - & - & 0 & 1 & 1 & 0 & 1 & - & 1 & 0 & - & - & 0 & - & - & 0 & - & 0 & $?$ & $?$ \\
\hline Shannoniella cuspidata & 1 & - & 1 & 0 & - & 0 & 0 & 1 & $?$ & 0 & 0 & 1 & 0 & 1 & 1 & 0 & 0 & 1 & 0 & - & 1 & 0 & - & 0 & 1 & 0 & - & 1 & 0 & 0 & 2 & 0 \\
\hline Amenia imperialis & 0 & 0 & - & 1 & 0 & 0 & 0 & 1 & 0 & 0 & 2 & 1 & 0 & 0 & 0 & 0 & 1 & 0 & 0 & 0 & 0 & 1 & 0 & 2 & 1 & 1 & 0 & 1 & 0 & 1 & 1 & 1 \\
\hline Amenia leonina & 0 & 0 & - & 1 & 0 & 0 & 0 & 1 & 0 & 0 & 2 & 1 & 0 & 0 & 0 & 0 & 1 & 0 & 0 & 0 & 0 & 1 & 0 & 2 & 1 & 1 & 0 & 1 & 1 & 1 & 1 & 1 \\
\hline Auchmeromyia bequaerti & 1 & - & 0 & 1 & 0 & 0 & 0 & 1 & 1 & 0 & 0 & 1 & 0 & 0 & 0 & 0 & 0 & 0 & 0 & 0 & 0 & $?$ & $?$ & 1 & 1 & 0 & - & 1 & 2 & 1 & 1 & 0 \\
\hline Bengalia emarginata & 1 & - & 1 & 0 & - & 0 & 0 & 1 & 0 & 1 & 0 & 1 & 0 & 0 & 0 & 0 & 0 & 1 & 0 & 0 & 0 & $?$ & $?$ & 0 & 1 & 0 & - & 1 & 0 & 0 & 1 & 0 \\
\hline Blepharicnema splendens & 1 & - & 0 & 0 & - & 0 & 0 & 1 & 0 & 0 & 0 & 1 & 0 & 1 & 1 & 0 & 0 & 0 & 0 & 0 & 0 & 1 & 0 & 1 & 1 & 1 & 1 & 1 & 2 & 1 & 1 & 1 \\
\hline Calliphora vomitoria & 0 & 1 & - & 1 & 0 & 0 & 0 & 1 & 0 & 1 & 0 & 1 & 0 & 1 & 0 & 0 & 1 & 0 & 0 & 0 & 1 & 1 & 0 & 1 & 1 & 1 & 1 & 1 & 2 & 1 & 1 & 1 \\
\hline Chrysomya megacephala & 0 & 0 & - & $?$ & $?$ & 0 & 0 & 1 & 0 & 1 & 0 & 1 & 0 & 1 & 0 & 0 & 1 & 0 & 0 & 0 & 0 & 1 & 0 & 1 & 1 & 0 & - & 1 & 0 & 0 & 0 & 0 \\
\hline Cynomya cadaverina & 1 & - & 0 & 1 & 0 & 0 & 0 & 1 & 0 & 1 & 0 & 1 & 0 & 1 & 0 & 0 & 1 & 0 & 0 & 0 & 1 & 1 & 0 & 2 & 1 & 1 & 1 & 1 & 1 & 0 & 1 & 1 \\
\hline Cochliomyia hominivorax & 0 & 1 & - & 0 & - & 0 & 0 & 0 & - & 1 & 0 & 1 & 0 & 1 & 0 & 0 & 1 & 0 & 0 & 0 & 0 & 1 & 0 & 1 & 1 & 0 & - & 1 & 1 & 0 & 0 & 1 \\
\hline Idiella mandarina & 1 & - & 0 & $?$ & $?$ & 0 & 0 & 1 & 0 & 0 & 1 & 1 & 0 & 1 & 0 & 0 & 1 & 0 & 0 & 1 & 1 & 0 & - & 0 & 1 & 0 & 1 & 1 & 0 & 0 & 0 & 0 \\
\hline Lucilia eximia & 0 & 0 & - & 1 & 0 & 0 & 0 & 1 & 0 & 0 & 0 & 1 & 0 & 1 & 1 & 0 & 0 & 0 & 0 & 0 & 1 & 1 & 0 & 1 & 1 & 1 & 1 & 1 & 1 & 1 & 1 & 1 \\
\hline
\end{tabular}




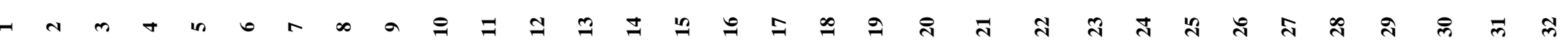

Neta chilensis

Phumosia promittens

Pollenia rudis

Sarconesia chlorogaster

Strongyloneura nebulosa

Mesembrinella latifrons comb. $n$.

Mesembrinella benoisti comb. $\boldsymbol{n}$.

Mesembrinella cyaneicinta

Mesembrinella quadrilineata

Mesembrinella randa

Mesembrinella bolivar comb. $\boldsymbol{n}$.

Mesembrinella carvalhoi comb. $\boldsymbol{n}$.

Mesembrinella spicata

Mesembrinella aeneiventris

Mesembrinella bequaerti comb. $\boldsymbol{n}$.

Mesembrinella decrepita

Mesembrinella lara comb. $\boldsymbol{n}$.

Mesembrinella purpurata

Mesembrinella semiflava

Mesembrinella uniseta

Mesembrinella vogelsangi

Mesembrinella nigripes comb. $\boldsymbol{n}$.

Mesembrinella perisi

Mesembrinella abaca

Mesembrinella apollinaris

Mesembrinella batesi

Mesembrinella bellardiana

Mesembrinella bicolor

Mesembrinella brunnipes

Mesembrinella currani

Mesembrinella flavicrura

$\begin{array}{lllllllllllllllllllllllllllllllllllllllllll}1 & - & 1 & ? & ? & 0 & 0 & 1 & ? & 1 & 0 & 1 & 0 & 1 & 0 & 0 & 1 & 0 & 0 & 1 & 1 & 1 & 0 & 0 & 1 & 1 & 1 & 1 & 1 \& 2 & 1 & 1 & 5\end{array}$

$\begin{array}{lllllllllllllllllllllllllllllllllllllllll}0 & 0 & - & 1 & 0 & 0 & 0 & 1 & 0 & 0 & 0 & 1 & 1 & 1 & 0 & 0 & 0 & 0 & 0 & 0 & 0 & ? & ? & 1 & 1 & 1 & 0 & 1 & 1 & 1 & 1 & 1\end{array}$

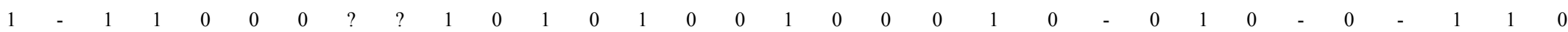

$1-? \begin{array}{lllllllllllllllllllllllllllllllllllllllllllll}1 & - & 0 & 0 & 0 & ? & ? & 0 & 0 & 1 & 0 & 1 & 0 & 0 & 1 & 0 & 0 & 0 & 0 & 1 & 0 & 0 & 1 & 0 & - & 1 & 3 & 1 & 2 & 0\end{array}$

$\begin{array}{llllllllllllllllllllllllllllllllllllllllllllll} & & 1 & 1 & 1 & 1 & 1 & 0 & - & 0 & 0 & 1 & 1 & 1 & 1 & 0 & 0 & 0 & 1 & 0 & 0 & 1 & 1 & 1 & 1 & 2 & 1 & 1 & 0 & 0 & 1 & 0\end{array}$

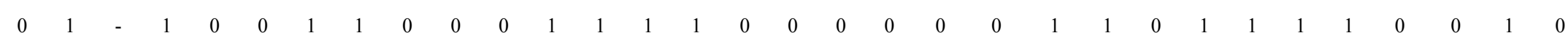

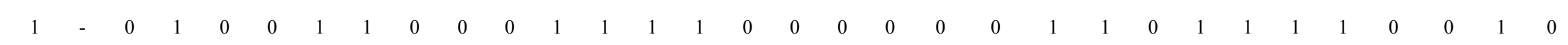

$\begin{array}{llllllllllllllllllllllllllllllllll}? & ? & 0 & 1 & 0 & - & 0 & 0 & 1 & 1 & 1 & 1 & 0 & 0 & 0 & 0 & 0 & 1 & 1 & 1 & 0 & 1 & 0 & 1 & 0 & - & 0 & 0 & 0\end{array}$

$\begin{array}{lllllllllllllllllllllllllllllllllllllll}- & 0 & 1 & 1 & 0 & 1 & ? & ? & 0 & 0 & 1 & 1 & 1 & 1 & 0 & 0 & 0 & 0 & 0 & 0 & 1 & 1 & 1 & 1 & 2 & 1 & 1 & 0 & 0 & 1 & 1\end{array}$

$\begin{array}{ccccccccccccccccccccccccccccccccccc}1 & - & 0 & 1 & 1 & 0 & 1 & 1 & 0 & 0 & 0 & 1 & 1 & 1 & 1 & 0 & 0 & 1 & 0 & 0 & 0 & 1 & 1 & 0 & 1 & 1 & 1 & 1 & 0 & 0 & 1 & 0 \\ 1 & 0 & ? & 0 & - & 0 & 1 & 1 & 0 & 0 & 0 & 1 & 1 & 1 & 1 & 0 & 0 & 1 & 0 & 0 & 0 & 1 & 1 & 0 & 1 & 0 & - & 1 & 0 & 0 & 1 & 0\end{array}$

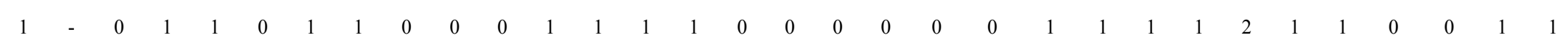

$\begin{array}{llllllllllllllllllllllllllllllllllllllllll}0 & ? & - & 1 & 1 & 0 & 1 & 1 & 1 & 0 & 0 & 1 & 1 & 1 & 1 & 0 & 0 & 0 & 0 & 0 & 0 & 1 & 1 & 0 & 1 & 1 & 1 & 1 & 0 & 0 & 1 & 1\end{array}$

$\begin{array}{llllllllllllllllllllllllllllllllllllllllll}0 & - & 0 & 0 & 0 & 1 & 1 & 0 & 0 & 0 & 1 & 1 & 1 & 1 & 0 & 0 & 1 & 0 & 0 & 0 & 1 & 1 & 0 & 1 & 0 & 1 & 1 & 0 & 0 & 1 & 0\end{array}$

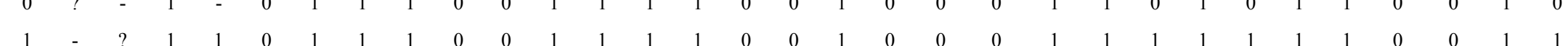

$\begin{array}{lllllllllllllllllllllllllllllllllllllllllllllll}0 & 0 & - & 0 & - & 0 & 1 & 1 & 0 & 0 & 0 & 1 & 1 & 1 & 1 & 0 & 0 & 1 & 0 & 0 & 0 & 1 & 1 & 1 & 1 & 1 & 1 & 1 & 0 & 0 & 1 & 0\end{array}$

$\begin{array}{llllllllllllllllllllllllllllllllllllllllllllllll}0 & 0 & - & 1 & 0 & 0 & 1 & 1 & 0 & 0 & 0 & 1 & 0 & 0 & 0 & 0 & 0 & 0 & 0 & 1 & 1 & 1 & 1 & 1 & 1 & 2 & 1 & 1 & 2 & 1 & 1 & 1\end{array}$

$\begin{array}{llllllllllllllllllllllllllllllllllllllllllll}0 & 0 & - & 1 & 0 & 0 & 1 & 1 & 0 & 0 & 0 & 1 & 0 & 0 & 0 & 0 & 0 & 0 & 0 & 0 & 1 & 1 & 1 & 1 & 1 & 1 & 1 & 1 & 2 & 1 & 1 & 0\end{array}$

$\begin{array}{lllllllllllllllllllllllllllllllllllllllllll}0 & 1 & - & 1 & 0 & 0 & 1 & 0 & - & 0 & 0 & 1 & 1 & 0 & 0 & 0 & 0 & 0 & 0 & 0 & 0 & 1 & 1 & 1 & 1 & 2 & 1 & 1 & 1 & 1 & 1 & 1\end{array}$

$\begin{array}{lllllllllllllllllllllllllllllllllllllllllll}0 & ? & - & ? & ? & 0 & 1 & 0 & - & 0 & 0 & 1 & 1 & 0 & 0 & 1 & 0 & 0 & 2 & 1 & 1 & 1 & 1 & 1 & 1 & 2 & 1 & 1 & 0 & 1 & 1 & 1\end{array}$

$\begin{array}{lllllllllllllllllllllllllllllllllllllllllllllllll}0 & 0 & - & 0 & - & 0 & 1 & 1 & 0 & 0 & 0 & 1 & 1 & 0 & 0 & 1 & 0 & 0 & 0 & 0 & 0 & 1 & 1 & 1 & 1 & 2 & 1 & 1 & 2 & 1 & 1 & 1\end{array}$

$\begin{array}{llllllllllllllllllllllllllllllllllllllllllllllll}0 & 0 & - & 0 & - & 0 & 1 & 1 & 0 & 0 & 0 & 1 & 1 & 0 & 0 & 1 & 0 & 0 & 0 & 0 & 0 & 1 & 1 & 1 & 1 & 2 & 1 & 1 & 0 & 1 & 1 & 1\end{array}$

$\begin{array}{lllllllllllllllllllllllllllllllllllllllllllll}0 & 0 & - & 1 & 0 & 0 & 1 & 1 & 0 & 0 & 0 & 1 & 1 & 0 & 0 & 1 & 0 & 0 & 0 & 0 & 0 & 1 & 1 & 1 & 1 & 2 & 1 & 1 & 2 & 1 & 1 & 0 \& 1\end{array}$

$\begin{array}{llllllllllllllllllllllllllllllllllllllllll}? & ? & ? & ? & ? & 0 & 1 & ? & ? & 0 & 0 & 1 & 1 & 0 & 0 & 1 & 0 & ? & 0 & 0 & 0 & 1 & 1 & 1 & 1 & 2 & 1 & 1 & 2 & 1 & 1 & 1\end{array}$

$\begin{array}{lllllllllllllllllllllllllllllllllllllllllll}0 & - & - & ? & ? & 0 & 1 & 1 & 0 & 0 & 0 & 1 & 1 & 0 & 0 & 1 & 0 & 0 & 2 & 0 & 0 & 1 & 1 & 1 & 1 & 2 & 1 & 1 & 0 & 1 & 1 & 1\end{array}$ 


\begin{tabular}{|c|c|c|c|c|c|c|c|c|c|c|c|c|c|c|c|c|c|c|c|c|c|c|c|c|c|c|c|c|c|c|c|c|}
\hline & - & N & $m$ & $\theta$ & in & 0 & $n$ & $\infty$ & $a$ & $\varrho$ & $=$ & 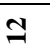 & 2 & $\Xi$ & 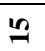 & $\mathscr{c}$ & 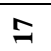 & $\mathscr{\infty}$ & 2 & $\overline{\text { d }}$ & $\bar{\lambda}$ & $\pi$ & $\pi$ & $\bar{d}$ & 2 & iั & $\hat{\sim}$ & $\infty$ & ते & లి & $\bar{m}$ & लै \\
\hline Mesembrinella patriciae & 0 & $?$ & - & 1 & 0 & 0 & 1 & 1 & 0 & 0 & 0 & 1 & 1 & 0 & $?$ & 0 & 0 & $?$ & 0 & 0 & 0 & 1 & 1 & 1 & 1 & 1 & 1 & 1 & 2 & 1 & 1 & 1 \\
\hline Mesembrinella peregrina & 0 & 0 & - & 1 & 0 & 0 & 1 & 1 & 0 & 0 & 0 & 1 & 1 & 0 & 0 & 1 & 0 & 0 & 0 & 0 & 0 & 1 & 1 & 1 & 1 & 2 & 1 & 1 & 2 & 1 & 1 & 1 \\
\hline Mesembrinella pictipenis & 0 & ? & - & ? & $?$ & 0 & 1 & 1 & 0 & 0 & 0 & 1 & 1 & 0 & 0 & 1 & 0 & 0 & 2 & 0 & 0 & 1 & 1 & 1 & 1 & 2 & 1 & 1 & 0 & 1 & 1 & 1 \\
\hline Mesembrinella semihyalina & 0 & 1 & - & 1 & 0 & 0 & 1 & 0 & - & 0 & 0 & 1 & 1 & 0 & 0 & 1 & 0 & 0 & 0 & 0 & 0 & 1 & 1 & 1 & 1 & 2 & 1 & 1 & 1 & 1 & 1 & 1 \\
\hline Mesembrinella towsendi & 0 & 0 & - & 1 & 0 & 0 & 1 & - & $?$ & 0 & 0 & 1 & 1 & 0 & 0 & 1 & 0 & 0 & 0 & 0 & 0 & 1 & 1 & 1 & 1 & 2 & 1 & 1 & $0 \& 2$ & $?$ & 1 & 1 \\
\hline Mesembrinella umbrosa & 0 & 0 & - & 0 & - & 0 & 1 & 0 & - & 0 & 0 & 1 & 1 & 0 & 0 & 1 & 0 & 0 & 2 & 0 & 0 & 1 & 1 & 1 & 1 & 2 & 1 & 1 & 2 & 1 & 1 & 1 \\
\hline Mesembrinella xantorrhina & 1 & - & 0 & $?$ & $?$ & 0 & 1 & 1 & 0 & 0 & 0 & 1 & 1 & 1 & 1 & 0 & 0 & 0 & 0 & 0 & 0 & 1 & 1 & 1 & 1 & 2 & 1 & 1 & 0 & 0 & 1 & 1 \\
\hline Mesembrinella facialis & 0 & 0 & - & 1 & 0 & 0 & 1 & 1 & 0 & 0 & 0 & 1 & 0 & 0 & 1 & 0 & 0 & 0 & 0 & 0 & 0 & 1 & 1 & 1 & 1 & 2 & 1 & 1 & 1 & 1 & 1 & 1 \\
\hline Mesembrinella anomala comb. $\boldsymbol{n}$. & 1 & - & 0 & 0 & $?$ & 0 & 1 & 0 & - & 0 & 0 & 1 & 0 & 1 & 1 & 0 & 0 & 1 & 0 & 0 & $0 \& 1$ & 1 & 1 & 0 & 1 & 0 & - & 1 & 0 & 0 & 1 & 0 \\
\hline
\end{tabular}

Continuação da matriz de caracteres morfológicos.

\begin{tabular}{|c|c|c|c|c|c|c|c|c|c|c|c|c|c|c|c|c|c|c|c|c|c|c|c|c|c|c|c|c|c|c|c|c|c|c|}
\hline & $\ddot{m}$ & ले & $\Leftrightarrow$ & en & $\hat{m}$ & $\stackrel{\infty}{\infty}$ & ले & \& & $F$ & F & 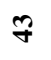 & $\exists$ & $\stackrel{f}{7}$ & $\stackrel{+}{+}$ & F & $\stackrel{\infty}{+}$ & $\hat{q}$ & in & $\bar{n}$ & in & in & in & in & in & in & $i$ & in & 8 & 6 & ชี & 8 & $\vec{b}$ & 6 & : \\
\hline Fannia heydenii & 1 & 1 & 1 & 0 & $?$ & 0 & 0 & 0 & 0 & 0 & 1 & 1 & 0 & 0 & 0 & 1 & 0 & 0 & - & 1 & 0 & - & 0 & 0 & 0 & 1 & 1 & 1 & $?$ & 0 & 1 & 1 & 0 & 0 \\
\hline Phaonia advena & 1 & 1 & 1 & 0 & $?$ & 0 & 0 & 0 & 0 & 0 & 1 & 1 & 1 & 0 & 2 & - & $?$ & 0 & - & 0 & 0 & - & 0 & 0 & 0 & 1 & 1 & 1 & 0 & 1 & 1 & 1 & 0 & 0 \\
\hline Polietina flavithorax & 1 & 1 & 1 & 0 & $?$ & 1 & 1 & 0 & 0 & 0 & 0 & 0 & 1 & 1 & 2 & - & $?$ & 0 & - & 0 & 0 & - & 0 & 0 & 0 & 1 & $?$ & 0 & $?$ & $?$ & 1 & 1 & 0 & 0 \\
\hline Acaulona costata & 1 & 1 & 1 & 1 & 1 & 0 & 0 & 0 & 0 & 1 & 0 & 0 & 0 & 0 & 0 & 1 & 0 & 0 & - & 0 & 1 & 1 & 0 & 0 & 0 & $?$ & 1 & 0 & 0 & 0 & 0 & 1 & 0 & 0 \\
\hline Adejeania townsendi & 2 & 1 & 0 & 1 & 1 & 0 & 1 & 1 & 1 & 1 & 1 & 0 & 0 & $?$ & 1 & 2 & 1 & 0 & - & 0 & 1 & 1 & 0 & 0 & 1 & 1 & 1 & 0 & 0 & 0 & $0 \& 1$ & 1 & 0 & 0 \\
\hline Ectophasia crassipenis & 1 & 1 & 1 & 1 & 1 & 0 & 0 & 0 & 0 & 1 & 1 & 0 & 0 & 0 & 0 & 1 & 0 & 0 & - & 0 & 1 & 1 & 0 & 0 & 0 & 1 & 1 & 0 & 0 & 0 & 0 & 1 & 2 & 0 \\
\hline Gymnosoma rotundatum & 1 & 1 & $?$ & 1 & 1 & 0 & 0 & 0 & 0 & 1 & 1 & 0 & 0 & 0 & 0 & 1 & 0 & 0 & - & 0 & 1 & 1 & 0 & 0 & 0 & $?$ & 1 & 0 & 0 & 0 & 1 & 1 & 2 & 0 \\
\hline Phasia hemiptera & 1 & 1 & 1 & 1 & 3 & 0 & 0 & 0 & 0 & 1 & 1 & 1 & 0 & 0 & 1 & 2 & 1 & 0 & - & 0 & 1 & 1 & 0 & 0 & 0 & 1 & 1 & 0 & 0 & 0 & 1 & 1 & 2 & 0 \\
\hline Prophorostoma pulchra & 2 & 1 & 1 & 1 & 3 & 0 & 0 & 1 & 0 & 0 & 0 & 1 & 0 & 0 & 1 & 2 & 1 & 0 & - & 0 & 1 & 1 & 0 & 1 & 0 & 1 & 1 & 0 & 0 & 0 & 1 & 1 & 2 & 0 \\
\hline Winthemia analis & 1 & 1 & 1 & 1 & 1 & 1 & 1 & 0 & 0 & 0 & 1 & 1 & 0 & 0 & 1 & 2 & 1 & 0 & - & 0 & 1 & 1 & 0 & 1 & 0 & 0 & 1 & 0 & 0 & 0 & 1 & 1 & 2 & 0 \\
\hline Amobia floridensis & 1 & 1 & 1 & 1 & 2 & 0 & 0 & 0 & 0 & 0 & 1 & 1 & 0 & 0 & 0 & 1 & 0 & 0 & - & 0 & 0 & - & 0 & 1 & 0 & 0 & 1 & 0 & 0 & 0 & 1 & 1 & 2 & 0 \\
\hline Peckia intermutans & 1 & 1 & 1 & 1 & 2 & 0 & 0 & 0 & 0 & 1 & 1 & 1 & 1 & 1 & 1 & 1 & 1 & 1 & 2 & 0 & 0 & - & 0 & 1 & 1 & 0 & 1 & 0 & 0 & 0 & 1 & 1 & 2 & 0 \\
\hline Cuterebra apicalis & 0 & $?$ & $?$ & 1 & 3 & 1 & 0 & 1 & 0 & 0 & 2 & 1 & 0 & 0 & 1 & 2 & 1 & 0 & - & 0 & 0 & - & 0 & 0 & 1 & $?$ & 0 & 0 & 0 & 0 & 1 & 1 & 2 & 0 \\
\hline Shannoniella cuspidata & 1 & 1 & $?$ & 1 & 2 & 0 & 0 & 0 & 0 & 1 & 1 & 1 & 0 & 0 & 0 & 1 & - & 0 & - & 0 & 1 & 0 & 0 & 0 & 0 & $?$ & 0 & 0 & 0 & 0 & 1 & 1 & 0 & 0 \\
\hline Amenia imperialis & 1 & 1 & $0 \& 1$ & 1 & 1 & 1 & 1 & 1 & 0 & 1 & 2 & 1 & 1 & 1 & 1 & 1 & 1 & 1 & 2 & 0 & 1 & 0 & 1 & 0 & 1 & 1 & 1 & 1 & 0 & 0 & 1 & 1 & 0 & 0 \\
\hline Amenia leonina & 1 & 1 & 0 & 1 & 1 & 1 & 1 & 1 & 0 & 1 & 2 & 1 & 1 & 1 & 1 & 1 & 1 & 1 & 2 & 0 & 1 & 0 & 1 & 0 & 1 & 1 & 1 & 1 & 0 & 0 & 1 & 1 & ${ }^{0}$ & 0 \\
\hline
\end{tabular}




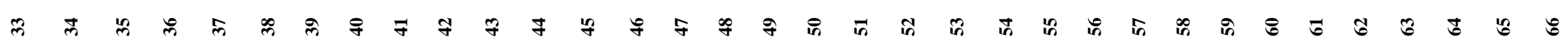

\begin{tabular}{|c|c|c|c|c|c|c|c|c|c|c|c|c|c|c|c|c|c|c|c|c|c|c|c|c|c|c|c|c|c|c|c|c|c|c|c|}
\hline Auchmeromyia bequaerti & 1 & 1 & 0 & 1 & 0 & 1 & 1 & 0 & 0 & 1 & 0 & 0 & 1 & 1 & 1 & 0 & 1 & 0 & - & 0 & 1 & 0 & 0 & 0 & $?$ & 0 & $?$ & $?$ & $?$ & $?$ & 0 & 0 & & 1 & 0 \\
\hline Bengalia emarginata & 1 & 1 & 0 & 1 & 0 & 1 & 1 & 0 & 0 & 1 & 0 & 0 & 1 & 1 & 1 & 0 & 1 & 0 & - & 0 & 1 & 0 & 0 & 0 & 0 & $?$ & $?$ & $?$ & $?$ & $?$ & 0 & 0 & & 2 & 0 \\
\hline Blepharicnema splendens & 1 & 1 & 0 & 1 & 0 & 1 & 1 & 1 & 0 & 1 & 2 & 1 & 1 & 1 & 1 & 0 & 1 & 0 & - & 0 & 0 & - & 0 & 0 & 0 & 2 & 1 & 0 & 0 & 0 & 1 & 1 & & 0 & 0 \\
\hline Calliphora vomitoria & 1 & 1 & 1 & 1 & 1 & 1 & 1 & 1 & 1 & 1 & 1 & 0 & 1 & 1 & 1 & 0 & 1 & 0 & - & 0 & 0 & - & 0 & 1 & 1 & 1 & 1 & 1 & 0 & 1 & 1 & 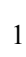 & & 2 & 0 \\
\hline Chrysomya megacephala & 1 & 1 & 1 & 1 & 0 & 1 & 1 & 1 & 1 & 1 & 2 & 1 & 1 & 1 & 1 & 0 & 1 & 1 & 2 & 0 & 0 & - & 1 & 0 & 0 & 0 & 1 & 0 & 0 & 0 & 1 & 1 & & 0 & 1 \\
\hline Cynomya cadaverina & 1 & 1 & 1 & 1 & 0 & 1 & 1 & 1 & 1 & 1 & 1 & 1 & 1 & 1 & 1 & 0 & 1 & 0 & - & 0 & 0 & - & 0 & 1 & 0 & 1 & 1 & 1 & 0 & 1 & 1 & 1 & & 2 & 0 \\
\hline Cochliomyia hominivorax & 1 & 1 & $?$ & 1 & 0 & 1 & 1 & 1 & 1 & 1 & 2 & 0 & 1 & 1 & 1 & 0 & 1 & 1 & 2 & 0 & 0 & - & 1 & 1 & 0 & 1 & 1 & 1 & 0 & 0 & 1 & 1 & & 0 & 1 \\
\hline Idiella mandarina & 1 & 1 & 1 & 1 & 1 & 1 & 0 & 1 & 0 & 0 & $0 \& 2$ & 0 & 1 & 0 & 1 & 2 & 1 & 0 & - & 0 & 0 & - & 1 & 0 & 0 & 0 & 1 & 0 & 0 & 1 & 1 & 1 & & 0 & 1 \\
\hline Lucilia eximia & 1 & 1 & $?$ & 1 & 1 & 1 & 1 & 1 & 1 & 1 & 2 & 1 & 1 & 1 & 1 & 0 & 1 & 0 & - & 0 & 0 & - & 1 & 0 & 0 & 0 & 1 & 1 & 0 & 0 & 1 & 1 & & 0 & 1 \\
\hline Neta chilensis & 1 & 0 & 0 & 1 & 1 & 1 & 1 & 1 & 0 & 1 & 2 & 1 & 1 & 1 & 1 & 0 & 1 & 0 & - & 0 & 0 & - & 1 & 1 & 0 & $?$ & 0 & 0 & 0 & 0 & 1 & 1 & & 2 & 1 \\
\hline Phumosia promittens & 1 & 1 & 0 & 1 & 0 & 1 & 1 & 1 & 0 & 1 & 0 & 0 & 1 & 1 & 1 & 0 & 1 & 0 & - & 0 & 1 & 0 & 0 & 0 & 1 & 1 & $?$ & $?$ & $?$ & $?$ & 0 & 0 & & 0 & 0 \\
\hline Pollenia rudis & 1 & 1 & 1 & 1 & 1 & 0 & 1 & 1 & 0 & 1 & 1 & 0 & 1 & 0 & 1 & 1 & 0 & 0 & - & 0 & 1 & 0 & 0 & 0 & 0 & 1 & 1 & 1 & 0 & 0 & 1 & 1 & & 0 & 0 \\
\hline Sarconesia chlorogaster & 1 & 0 & 1 & 1 & 1 & 1 & 1 & 1 & 0 & 1 & 1 & 1 & 1 & 1 & 1 & 0 & 1 & 0 & - & 0 & 0 & - & 0 & 1 & 0 & 0 & 1 & 1 & 0 & 0 & 1 & 1 & & 2 & 1 \\
\hline Strongyloneura nebulosa & 1 & 1 & 1 & 1 & 1 & 1 & $?$ & 0 & 0 & 1 & 1 & 1 & 0 & 0 & 0 & 2 & 1 & 0 & - & 0 & 0 & - & 1 & 0 & 0 & $?$ & $?$ & $?$ & $?$ & $?$ & 1 & 1 & & 2 & 1 \\
\hline Mesembrinella latifrons comb. $\boldsymbol{n}$. & 1 & 1 & $0 \& 1$ & 1 & 0 & 1 & 1 & 0 & 1 & 1 & 0 & 0 & 2 & 1 & 2 & - & - & 1 & 1 & 1 & 1 & 0 & 0 & 0 & 1 & 1 & 1 & 1 & 0 & 1 & 0 & 0 & & 0 & 1 \\
\hline Mesembrinella benoisti comb. $\boldsymbol{n}$. & 1 & 1 & 0 & 1 & 1 & 1 & 1 & 0 & 0 & 1 & 0 & 0 & 2 & 1 & 2 & - & - & 1 & 1 & 1 & 1 & 0 & 0 & 1 & 1 & 0 & 1 & 1 & 1 & 1 & 0 & 0 & & 0 & 0 \\
\hline Mesembrinella cyaneicinta & 2 & 1 & 0 & 1 & 1 & 1 & 1 & 0 & 0 & 1 & 0 & 0 & 2 & 1 & 2 & - & - & 1 & 1 & 1 & 1 & 0 & 0 & 1 & 1 & 0 & 1 & 1 & 0 & 1 & 0 & 1 & & 0 & 0 \\
\hline Mesembrinella quadrilineata & 2 & 1 & $0 \& 1$ & 1 & 1 & 1 & 0 & 0 & 0 & 1 & 0 & 0 & 2 & 1 & 2 & - & - & 1 & 1 & 1 & 1 & 0 & 0 & 1 & 1 & 0 & 1 & 1 & 1 & 1 & 0 & 0 & & 0 & 0 \\
\hline Mesembrinella randa & 2 & 1 & $0 \& 1$ & 1 & 1 & 1 & 1 & 0 & 0 & 1 & 0 & 0 & 2 & 1 & 2 & - & - & 1 & 1 & 1 & 1 & 0 & 0 & 1 & 1 & 0 & 1 & 1 & 1 & 1 & 0 & 1 & & 0 & 0 \\
\hline Mesembrinella bolivar comb. $\boldsymbol{n}$. & 1 & 1 & 1 & 1 & 0 & 1 & 1 & 0 & 0 & 1 & 0 & 0 & 2 & 1 & 2 & - & - & 1 & 1 & 0 & 1 & 0 & 0 & 0 & 1 & 1 & 1 & 1 & $?$ & 1 & 0 & 1 & & 0 & 0 \\
\hline Mesembrinella carvalhoi comb. $\boldsymbol{n}$. & 1 & 1 & 1 & 1 & 0 & $?$ & 1 & 0 & 0 & $?$ & 1 & 0 & 2 & 1 & 2 & - & - & 1 & 1 & 0 & 1 & 0 & 0 & 0 & $?$ & 1 & $?$ & $?$ & $?$ & $?$ & 1 & 1 & & 0 & 0 \\
\hline Mesembrinella spicata & 2 & 1 & 1 & 1 & 0 & 1 & 1 & 0 & 1 & 1 & 2 & 1 & 2 & 1 & 2 & - & - & 1 & 1 & 1 & 1 & 0 & 1 & 0 & 1 & 1 & 1 & 1 & 0 & 1 & 1 & 1 & & 2 & 0 \\
\hline Mesembrinella aeneiventris & 2 & 1 & 1 & 1 & 0 & 1 & 1 & 0 & 0 & 1 & 0 & 0 & 2 & 1 & 2 & - & - & 1 & 1 & 1 & 1 & 0 & 0 & 1 & 1 & 1 & 1 & 1 & 0 & 1 & 0 & 1 & & 0 & 0 \\
\hline Mesembrinella bequaerti comb. $\boldsymbol{n}$. & 1 & 1 & 1 & 1 & 0 & 1 & 1 & 0 & 0 & 1 & 1 & 0 & 2 & 1 & 2 & - & - & 1 & 1 & 1 & 1 & 0 & 1 & 1 & 1 & 1 & 1 & 1 & 0 & 1 & $0 \& 1$ & 1 & & ? & 0 \\
\hline Mesembrinella decrepita & 2 & 1 & 1 & 1 & 0 & 1 & 1 & 0 & 0 & 1 & 2 & 0 & 2 & 1 & 2 & - & - & 1 & 1 & 1 & 1 & 0 & 1 & 0 & 1 & 0 & 1 & 1 & 0 & 1 & 0 & 1 & & 2 & 0 \\
\hline Mesembrinella lara comb. $\boldsymbol{n}$. & 1 & 1 & 1 & 1 & 0 & 1 & 0 & 0 & 0 & 1 & 2 & 0 & 2 & 1 & 2 & - & - & 1 & 1 & 1 & 1 & 0 & 1 & 0 & 1 & 1 & 1 & 1 & $?$ & 1 & 0 & 0 & & 0 & 0 \\
\hline Mesembrinella purpurata & 2 & 1 & 1 & 1 & 0 & 1 & 1 & 0 & 0 & 1 & 0 & 0 & 2 & 1 & 2 & - & - & 1 & 1 & 1 & 1 & 0 & 0 & 1 & 1 & 0 & 1 & 1 & 0 & 1 & 0 & 1 & & 0 & 0 \\
\hline Mesembrinella semiflava & 1 & 1 & 1 & 1 & 0 & 1 & 1 & 0 & 0 & 1 & 0 & 0 & 2 & 1 & 2 & - & - & 1 & 1 & 1 & 1 & 0 & 1 & 0 & 1 & 0 & 1 & 1 & $?$ & 1 & 0 & 1 & & 0 & 0 \\
\hline Mesembrinella uniseta & 2 & 1 & 1 & 1 & 0 & 1 & 1 & 0 & 0 & 1 & 2 & 0 & 2 & 1 & 2 & - & - & 1 & 1 & 1 & 1 & 0 & 1 & 0 & 1 & 1 & 1 & 1 & 0 & 1 & 1 & 1 & & & 0 \\
\hline Mesembrinella vogelsangi & 2 & 1 & 1 & 1 & 0 & 1 & 1 & 0 & 0 & 1 & 0 & 0 & 2 & 1 & 2 & - & - & 1 & 1 & 1 & 1 & 0 & 0 & 0 & 1 & $?$ & 1 & 1 & $?$ & 1 & 0 & 1 & & 0 & 0 \\
\hline Mesembrinella nigripes comb. $\boldsymbol{n}$. & 2 & 1 & 1 & 1 & 0 & 1 & 1 & 0 & 1 & 1 & 0 & 0 & 2 & 1 & 2 & - & - & 1 & 1 & 1 & 1 & 0 & 0 & 1 & 1 & 1 & 1 & 1 & 0 & 1 & 0 & 0 & & 1 & 0 \\
\hline
\end{tabular}




\begin{tabular}{|c|c|c|c|c|c|c|c|c|c|c|c|c|c|c|c|c|c|c|c|c|c|c|c|c|c|c|c|c|c|c|c|c|c|c|}
\hline & $m$ & $\vec{m}$ & $\ddot{n}$ & e & n & $\infty$ & ले & \& & $F$ & Y & 9 & $\exists$ & 8 & tr & F & $\stackrel{\infty}{+}$ & $\hat{q}$ & in & $\bar{n}$ & กิ & $\tilde{n}$ & in & in & in & in & in & in & 8 & 5 & ช్ & 3 & $\vec{b}$ & 8 & : \\
\hline Mesembrinella perisi. & 2 & 1 & 1 & 1 & 0 & 1 & 1 & 0 & 1 & 1 & 0 & 0 & 2 & 1 & 2 & - & - & 1 & 1 & 1 & 1 & 0 & 0 & 0 & 1 & 0 & 1 & 1 & 0 & 1 & 0 & 0 & 1 & 0 \\
\hline Mesembrinella abaca & 2 & 1 & $0 \& 1$ & 1 & 0 & 1 & 1 & 0 & 1 & 1 & 0 & 0 & 2 & 1 & 2 & - & - & 1 & 1 & 1 & 1 & 0 & 0 & 0 & 1 & 1 & 1 & 1 & 0 & 1 & 0 & 0 & 0 & 0 \\
\hline Mesembrinella apollinaris & 1 & 1 & 0 & 1 & 0 & 1 & 1 & 0 & 1 & 1 & 0 & 0 & 2 & 1 & 2 & - & - & 1 & 0 & 1 & 1 & 0 & 0 & 0 & 1 & 1 & 0 & $?$ & $?$ & 1 & 0 & 1 & 0 & 0 \\
\hline Mesembrinella batesi & 2 & 1 & $0 \& 1$ & 1 & 0 & 1 & 1 & 0 & 1 & 1 & 0 & 0 & 2 & 1 & 2 & - & - & 1 & 1 & 1 & 1 & 0 & 0 & 0 & 1 & 0 & 1 & 1 & 0 & 1 & 0 & 0 & 0 & 0 \\
\hline Mesembrinella bellardiana & $1 \& 2$ & 1 & $0 \& 1$ & 1 & 0 & 1 & 1 & 0 & 1 & 1 & 0 & 0 & 2 & 1 & 2 & - & - & 1 & 1 & 1 & 1 & 0 & 0 & 0 & 1 & 1 & 1 & 1 & 0 & 1 & 0 & 0 & 0 & 1 \\
\hline Mesembrinella bicolor & 2 & 1 & $0 \& 1$ & 1 & 0 & 1 & 1 & 0 & 1 & 1 & 0 & 0 & 2 & 1 & 2 & - & - & 1 & $1 \& 2$ & 1 & 1 & 0 & 0 & 0 & 1 & 1 & 1 & 1 & 0 & 1 & 0 & 0 & 0 & 0 \\
\hline Mesembrinella brunnipes & 2 & 1 & $?$ & 1 & 0 & 1 & 0 & 0 & 1 & 1 & 0 & 0 & 2 & 1 & 2 & - & - & 1 & 0 & 1 & 1 & 0 & 0 & 0 & 1 & $?$ & $?$ & $?$ & $?$ & $?$ & $0 \& 1$ & 1 & 0 & 0 \\
\hline Mesembrinella currani & 1 & 1 & 1 & 1 & 0 & 1 & 1 & 0 & 1 & 1 & 0 & 0 & 2 & 1 & 2 & - & - & 1 & 0 & 1 & 1 & 0 & 0 & 0 & 1 & 1 & 1 & 1 & $?$ & 1 & 0 & 0 & 0 & 0 \\
\hline Mesembrinella flavicrura & 2 & 1 & 1 & 1 & 0 & 1 & 1 & 0 & 0 & 1 & 0 & 0 & 2 & 1 & 2 & - & - & 1 & 1 & 1 & 1 & 0 & 1 & 0 & 1 & 1 & 1 & 1 & 0 & 1 & 0 & 1 & 0 & 0 \\
\hline Mesembrinella patriciae & 2 & 1 & $?$ & 1 & 0 & 1 & 1 & 0 & $?$ & 1 & 0 & 0 & 2 & 1 & 2 & - & - & 1 & 1 & 1 & 1 & 0 & 0 & 1 & $?$ & $?$ & $?$ & $?$ & $?$ & $?$ & 0 & 1 & 0 & 0 \\
\hline Mesembrinella peregrina & 2 & 1 & 1 & 1 & 0 & 1 & 0 & 0 & 1 & 1 & 0 & 0 & 2 & 1 & 2 & - & - & 1 & 1 & 1 & 1 & 0 & 0 & 0 & 1 & 1 & 1 & 1 & 0 & 1 & 0 & 0 & 0 & 1 \\
\hline Mesembrinella pictipenis & 2 & 1 & $?$ & 1 & 0 & 1 & 0 & 0 & 1 & 1 & 0 & 0 & 2 & 1 & 2 & - & - & 1 & 1 & 1 & 1 & 0 & 0 & 0 & 1 & 2 & 1 & $?$ & $?$ & 1 & 0 & 1 & 0 & 0 \\
\hline Mesembrinella semihyalina & 2 & 1 & $0 \& 1$ & 1 & 0 & 1 & 1 & 0 & 1 & 1 & 0 & 0 & 2 & 1 & 2 & - & - & 1 & 1 & 1 & 1 & 0 & 0 & 0 & 1 & 1 & 1 & 1 & 0 & 1 & 0 & 0 & 0 & 0 \\
\hline Mesembrinella towsendi & 2 & 1 & 0 & 1 & 0 & 1 & 1 & 0 & 1 & 1 & 0 & 0 & 2 & 1 & 2 & - & - & 1 & 1 & 1 & 1 & 0 & 0 & 0 & 1 & 1 & 1 & 1 & 0 & 1 & 0 & 0 & 0 & 0 \\
\hline Mesembrinella umbrosa & 2 & 1 & 0 & 1 & 0 & 1 & 1 & 0 & 1 & 1 & 0 & 0 & 2 & 1 & 2 & - & - & 1 & 1 & 1 & 1 & 0 & 0 & 0 & 1 & 2 & 1 & $?$ & 0 & 1 & 0 & 0 & 0 & 0 \\
\hline Mesembrinella xantorrhina & 2 & 1 & 1 & 1 & 0 & 1 & 1 & 0 & 0 & 1 & 2 & 1 & 2 & 1 & 2 & - & - & 1 & 1 & 1 & 1 & 0 & 1 & 0 & 1 & 1 & 1 & 1 & $?$ & 1 & 1 & 1 & 2 & 0 \\
\hline Mesembrinella facialis. & 1 & 1 & 0 & 1 & 0 & 1 & 0 & 0 & 1 & 1 & 0 & 0 & 2 & 1 & 2 & - & - & 1 & 3 & 1 & 1 & 0 & 0 & 0 & 1 & 1 & 1 & $?$ & 0 & 1 & 0 & 0 & 0 & 0 \\
\hline Mesembrinella anomala comb. $\boldsymbol{n}$. & 1 & 1 & $?$ & 1 & 2 & 1 & 0 & 0 & 0 & 1 & $0 \& 2$ & 0 & 2 & 1 & 2 & - & - & 1 & 1 & 1 & 1 & 0 & 1 & 0 & 1 & 1 & 1 & 1 & 0 & 1 & 0 & 1 & 0 & 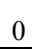 \\
\hline
\end{tabular}

\section{Continuação da matriz de caracteres morfológicos.}

\begin{tabular}{|c|c|c|c|c|c|c|c|c|c|c|c|c|c|c|c|c|c|c|c|c|c|c|c|c|c|c|c|c|c|c|c|c|c|c|c|}
\hline & 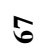 & $\overline{6}$ & $\widetilde{\sigma}$ & 3 & t & 8 & 8 & $\widehat{6}$ & $\infty$ & 8 & $R$ & F & $\frac{1}{4}$ & $m$ & i & 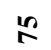 & 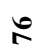 & $乏$ & $\stackrel{2}{R}$ & 2 & 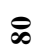 & $\bar{\infty}$ & $\infty$ & $\infty$ & 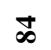 & $\infty$ & $\varnothing$ & $\infty$ & $\infty$ & $\infty$ & ฉ & $\approx$ & I & $\approx$ & ฉ \\
\hline Fannia heydenii & 0 & 0 & 0 & 0 & 0 & 0 & 0 & 1 & - & 0 & - & - & - & 0 & 0 & 1 & 0 & 0 & $?$ & 0 & 0 & 0 & - & 0 & 0 & 0 & 0 & 0 & 0 & 0 & 0 & 0 & 0 & 0 & 0 \\
\hline Phaonia advena & 0 & 0 & 0 & 0 & 0 & 0 & 0 & 1 & - & 0 & - & - & - & 0 & 0 & 1 & 0 & 0 & - & 1 & 1 & 0 & - & 0 & 0 & 0 & 0 & 0 & 0 & 0 & 0 & 0 & 0 & 0 & 0 \\
\hline Polietina flavithorax & 1 & 1 & 1 & 0 & 0 & 0 & 0 & 1 & - & ? & - & - & - & - & 0 & 1 & 1 & 0 & - & 1 & 0 & 1 & 1 & 0 & 0 & 0 & 0 & 0 & 0 & 0 & 1 & 1 & 1 & 0 & 0 \\
\hline Acaulona costata & 0 & $?$ & 1 & 0 & 1 & 0 & 1 & 0 & 0 & 0 & 0 & 0 & 1 & 1 & 1 & 0 & 0 & 0 & - & 0 & 0 & 0 & - & 0 & 0 & 1 & 0 & 0 & 0 & 0 & 0 & $?$ & 1 & 0 & 1 \\
\hline Adejeania townsendi & 0 & 0 & 1 & 0 & 0 & 0 & 1 & 0 & 1 & 0 & 0 & 0 & 0 & 1 & 0 & 0 & 1 & 0 & - & 1 & 1 & 1 & 1 & 0 & 0 & 1 & 0 & 0 & 0 & 0 & 0 & 0 & 1 & 0 & 0 \\
\hline Ectophasia crassipenis & 0 & 0 & 1 & 0 & 0 & 0 & 1 & 0 & 1 & 0 & 0 & 0 & 1 & 1 & 1 & 0 & 0 & 0 & - & 0 & 1 & 0 & - & 0 & 0 & 1 & 0 & 0 & 0 & 0 & 0 & 0 & 1 & 0 & 0 \\
\hline
\end{tabular}




\begin{tabular}{|c|c|c|c|c|c|c|c|c|c|c|c|c|c|c|c|c|c|c|c|c|c|c|c|c|c|c|c|c|c|c|c|c|c|c|c|}
\hline & 5 & 5 & $\widetilde{\sigma}$ & 8 & t & 8 & : & $\hat{6}$ & $\stackrel{8}{\infty}$ & bे & $R$ & F & $\frac{5}{4}$ & $\Re$ & A & 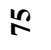 & 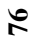 & N & $\stackrel{2}{\sim}$ & 2 & $\varnothing$ & $\infty$ & $\tilde{\infty}$ & $\infty$ & $\Phi$ & $\infty$ & $\infty$ & $\infty$ & $\infty$ & $a$ & & 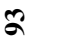 & $\Xi$ & 22 & $\stackrel{2}{\circ}$ \\
\hline Gymnosoma rotundatum & 0 & 0 & 1 & 0 & 0 & 0 & 1 & 0 & 1 & 1 & - & - & 0 & 1 & 1 & 0 & 0 & 0 & - & 0 & 0 & 0 & - & 0 & 0 & 1 & 0 & 0 & 0 & $?$ & & 0 & 1 & 0 & 0 \\
\hline Phasia hemiptera & 0 & 0 & 1 & 0 & 1 & 0 & 1 & 0 & 0 & 1 & - & - & 0 & 1 & 0 & 0 & 0 & 0 & - & 0 & 0 & 0 & - & 0 & 0 & 0 & 0 & 0 & 0 & 0 & & 0 & 1 & 0 & 1 \\
\hline Prophorostoma pulchra & 0 & 0 & 1 & 0 & 1 & 0 & 1 & 0 & 1 & 0 & 0 & 0 & 0 & 1 & 0 & 1 & 1 & 0 & - & 1 & 1 & 1 & 1 & 0 & 0 & 0 & 0 & 0 & 0 & 0 & & 0 & 1 & 0 & 1 \\
\hline Winthemia analis & 0 & 0 & 1 & 0 & 0 & 0 & 1 & 0 & 1 & 0 & 0 & 0 & 0 & 1 & 1 & 1 & 1 & 0 & - & 1 & 1 & 1 & 1 & 0 & 0 & 0 & 0 & 0 & 0 & ? & & 0 & 1 & 0 & 0 \\
\hline Amobia floridensis & 0 & 0 & 1 & 0 & 0 & 0 & 1 & 0 & 1 & 0 & 0 & 0 & 0 & 0 & 1 & 1 & 1 & 0 & - & 1 & 1 & 0 & - & 0 & 0 & 0 & 0 & 0 & 0 & 1 & & 0 & 1 & 0 & 0 \\
\hline Peckia intermutans & 0 & 0 & 1 & 0 & 0 & 0 & 1 & 0 & 1 & 0 & 0 & 0 & 0 & 0 & 1 & 1 & 1 & 0 & - & 1 & 1 & 0 & - & 0 & 0 & 0 & 0 & 0 & 0 & 1 & & 0 & 1 & 0 & 0 \\
\hline Cuterebra apicalis & 0 & 1 & 0 & 0 & 0 & 0 & 1 & 0 & 1 & 0 & 0 & 0 & 0 & 1 & 2 & 1 & 0 & 0 & - & 0 & 0 & 0 & - & 0 & 1 & 0 & 0 & 0 & 0 & 0 & & 1 & 0 & 0 & 0 \\
\hline Shannoniella cuspidata & 0 & 0 & 0 & 0 & 0 & 1 & 0 & 1 & - & 0 & 0 & $?$ & $?$ & $?$ & 0 & 0 & 0 & 0 & - & 0 & 1 & 0 & - & 0 & 0 & 0 & 0 & 0 & 0 & 0 & & 0 & 0 & 0 & 0 \\
\hline Amenia imperialis & 0 & 0 & 0 & 0 & 0 & 0 & 1 & 0 & 1 & 0 & 0 & 0 & 0 & 1 & $1 \& 2$ & 1 & 0 & 0 & - & 1 & 1 & 0 & - & 0 & 1 & 0 & 0 & 0 & 0 & 0 & & 0 & 0 & 0 & 0 \\
\hline Amenia leonina & 0 & 0 & 0 & 0 & 0 & 0 & 1 & 0 & 1 & 0 & 0 & 0 & 0 & 1 & $1 \& 2$ & 1 & 0 & 0 & - & 1 & 1 & 0 & - & 0 & 1 & 0 & 0 & 0 & 0 & 0 & & 0 & 0 & 0 & 0 \\
\hline Auchmeromyia bequaerti & 0 & 0 & 1 & 0 & 0 & 0 & 1 & 0 & 1 & 0 & 0 & 0 & 1 & 1 & 1 & 0 & 0 & 0 & - & 0 & 1 & 0 & - & 0 & 0 & 1 & $?$ & 0 & 0 & 0 & & 0 & 1 & 0 & 0 \\
\hline Bengalia emarginata & 0 & 0 & 1 & 0 & 0 & 0 & 1 & 0 & 1 & 0 & 0 & 0 & 1 & 1 & 1 & 0 & 1 & 0 & - & 1 & 1 & 1 & 1 & 0 & 0 & $?$ & 0 & 0 & 0 & 0 & & 0 & 1 & 0 & 0 \\
\hline Blepharicnema splendens & 0 & 1 & 0 & 0 & 0 & 0 & 1 & 0 & 1 & 0 & 0 & 0 & 0 & 0 & 2 & 1 & 0 & 0 & - & 0 & 0 & 0 & - & 0 & 1 & 0 & 0 & 0 & 0 & 0 & & 1 & 0 & 0 & 0 \\
\hline Calliphora vomitoria & 0 & 1 & 1 & 1 & 0 & 0 & 1 & 0 & 1 & 0 & 0 & 0 & 1 & 1 & 2 & 1 & 1 & 0 & - & 1 & 1 & 0 & - & 0 & 1 & 0 & 0 & 0 & 0 & 0 & & 1 & 1 & 1 & 0 \\
\hline Chrysomya megacephala & 0 & $?$ & 1 & 0 & 0 & 0 & 1 & 0 & 1 & 0 & 0 & 0 & 1 & 1 & $1 \& 2$ & 1 & 0 & 0 & - & 0 & 1 & 0 & - & 0 & 1 & 0 & 0 & 0 & 0 & 0 & & $?$ & 1 & 0 & 0 \\
\hline Cynomya cadaverina & 0 & 1 & 1 & 1 & 0 & 0 & 1 & 0 & 1 & 0 & 0 & 0 & 1 & 1 & 0 & 1 & 1 & 0 & - & 1 & 1 & 0 & - & 0 & 1 & 0 & 0 & 0 & 0 & 0 & & 1 & 1 & 1 & 0 \\
\hline Cochliomyia hominivorax & 0 & 0 & 1 & 0 & 0 & 0 & 1 & 0 & 1 & 0 & 0 & 0 & 0 & 0 & 1 & 1 & 0 & 0 & - & 0 & 1 & 0 & - & 0 & 1 & 0 & 0 & 0 & 0 & 0 & & 0 & 1 & 0 & 0 \\
\hline Idiella mandarina & 0 & 0 & 0 & 0 & 0 & 0 & 1 & 0 & 0 & 0 & 0 & 0 & 0 & 1 & 0 & 1 & 0 & 0 & - & 0 & 1 & 0 & - & 0 & 1 & 1 & $?$ & 0 & 0 & ? & & 0 & 0 & 0 & 0 \\
\hline Lucilia eximia & 0 & 1 & 1 & 0 & 0 & 0 & 1 & 0 & 1 & 0 & 0 & 0 & 0 & 0 & 2 & 1 & 0 & 0 & - & 1 & 1 & 0 & - & 0 & 1 & 0 & 0 & 0 & 0 & 0 & & 1 & 1 & 0 & 0 \\
\hline Neta chilensis & 1 & 1 & 1 & 0 & 0 & 0 & 1 & 0 & 1 & 0 & 0 & 0 & 1 & 1 & 2 & 1 & 0 & 0 & - & 0 & 1 & 0 & - & 1 & 1 & 0 & 0 & 0 & 0 & 0 & & 1 & 1 & 0 & 0 \\
\hline Phumosia promittens & 0 & 0 & 1 & 0 & 1 & 0 & 0 & 0 & 1 & 0 & 0 & 0 & 1 & 1 & 0 & 0 & 0 & 0 & - & $?$ & 1 & 0 & - & 0 & 1 & 1 & 0 & 0 & 0 & 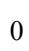 & & 0 & 1 & 0 & 1 \\
\hline Pollenia rudis & 0 & 0 & 1 & 0 & 0 & 0 & 1 & 0 & 1 & 0 & 0 & 0 & 1 & 1 & 0 & 1 & 1 & 0 & - & 0 & 0 & 0 & - & 0 & 0 & 0 & 0 & 0 & 0 & 0 & & 0 & 1 & 0 & 0 \\
\hline Sarconesia chlorogaster & 1 & 1 & 1 & 0 & 0 & 0 & 1 & 0 & 1 & 0 & 0 & 0 & 1 & 1 & 1 & 0 & 1 & 0 & - & 1 & 1 & 0 & - & 1 & 1 & 0 & 0 & 0 & 0 & 1 & & 1 & 1 & 0 & 0 \\
\hline Strongyloneura nebulosa & 0 & $?$ & 1 & 0 & 0 & 0 & 0 & 0 & 1 & 0 & 0 & 0 & 1 & 1 & 0 & 0 & 1 & 0 & - & 1 & $?$ & $?$ & - & 0 & 1 & 1 & $?$ & 0 & 0 & ? & & $?$ & 1 & 0 & 0 \\
\hline Mesembrinella latifrons comb. $\boldsymbol{n}$. & 1 & 0 & 1 & 0 & 1 & 0 & 0 & 0 & 0 & 0 & 0 & 0 & 0 & 0 & 0 & 0 & 0 & 1 & 0 & 1 & 1 & 0 & - & 0 & 1 & 1 & 0 & 0 & 0 & 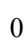 & & 0 & 1 & 0 & 1 \\
\hline Mesembrinella benoisti comb. $\boldsymbol{n}$. & 0 & 0 & 1 & 0 & 0 & 0 & 0 & 0 & 0 & 0 & 0 & 0 & 0 & 1 & 0 & 0 & 1 & 1 & 1 & 0 & 0 & 0 & - & 0 & 1 & 1 & 1 & 0 & 0 & 0 & & 0 & 1 & 0 & 0 \\
\hline Mesembrinella cyaneicinta & 0 & 0 & 1 & 0 & 0 & 0 & 0 & 0 & 0 & 0 & 0 & 0 & 0 & 1 & 0 & 0 & 1 & 1 & 1 & 0 & 1 & 0 & - & 0 & 1 & 1 & 1 & 1 & 0 & 0 & & 0 & 1 & 0 & 0 \\
\hline Mesembrinella quadrilineata & 0 & 0 & 1 & 0 & 1 & 0 & 0 & 0 & 0 & 0 & 0 & 0 & 0 & 1 & 0 & 0 & 1 & 1 & 1 & 0 & 1 & 0 & - & 0 & 1 & 1 & 1 & 0 & 0 & 0 & & 0 & 1 & 0 & 1 \\
\hline Mesembrinella randa & 0 & 0 & 1 & 0 & 1 & 0 & 0 & 0 & 0 & 0 & 0 & 0 & 0 & 1 & 0 & 0 & 1 & 1 & 1 & 0 & 0 & 0 & - & 0 & 1 & 1 & 1 & 0 & 0 & 0 & & 0 & 1 & 0 & 1 \\
\hline Mesembrinella bolivar comb. $\boldsymbol{n}$. & 0 & 0 & 1 & 0 & 1 & 1 & 0 & 0 & 0 & 0 & 0 & 0 & 0 & 0 & 0 & 1 & 0 & 1 & 0 & 1 & 0 & 0 & - & 0 & 0 & 1 & 0 & 0 & 0 & 0 & & 0 & 1 & 0 & 1 \\
\hline Mesembrinella carvalhoi comb. $\boldsymbol{n}$. & 0 & 0 & $?$ & 0 & 0 & 1 & 0 & 0 & 0 & 0 & 0 & 0 & 0 & 1 & 0 & 1 & 0 & 1 & 0 & 1 & 1 & 1 & 1 & 0 & 0 & 1 & 0 & 0 & 0 & 0 & & 0 & $?$ & 0 & 0 \\
\hline
\end{tabular}




\begin{tabular}{|c|c|c|c|c|c|c|c|c|c|c|c|c|c|c|c|c|c|c|c|c|c|c|c|c|c|c|c|c|c|c|c|c|c|c|c|}
\hline & 5 & 5 & $\widetilde{\sigma}$ & 8 & t & $\because 8$ & 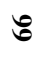 & 5 & $\infty$ & 8 & $R$ & F & $\mathrm{n}$ & $\approx$ & $\pi$ & 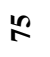 & た & 尺 & $\stackrel{2}{\infty}$ & $\hat{\imath}$ & $\varnothing$ & $\infty$ & $\tilde{\infty}$ & $\infty$ & $\Phi$ & $\infty$ & $\infty$ & $\infty$ & $\infty$ & के & 8 & $\approx$ & a & $\dddot{\circ}$ & 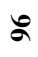 \\
\hline Mesembrinella spicata & 0 & 0 & 1 & 0 & 0 & 0 & 0 & 0 & 0 & 0 & 0 & 0 & 0 & 1 & $0 \& 2$ & 1 & 0 & 0 & - & 1 & 0 & 0 & - & 0 & 1 & 0 & 0 & 0 & 0 & $?$ & 0 & 0 & 1 & 0 & 0 \\
\hline Mesembrinella aeneiventris & 0 & 0 & 1 & 0 & 0 & 0 & 0 & 0 & 0 & 0 & 0 & 0 & 1 & 0 & 0 & 1 & 1 & 1 & 0 & 1 & 1 & 1 & 0 & 0 & 1 & 1 & 0 & 1 & 0 & 0 & 0 & 0 & 1 & 0 & 0 \\
\hline Mesembrinella bequaerti comb. $n$. & 0 & 0 & 1 & 0 & 1 & 0 & 0 & 0 & 0 & 0 & 0 & 0 & 1 & 0 & 0 & 1 & 1 & 1 & 0 & 1 & 1 & 1 & 0 & 0 & 1 & 1 & 0 & 1 & 0 & $?$ & 0 & 0 & 1 & 0 & 1 \\
\hline Mesembrinella decrepita & 0 & 0 & 1 & 0 & 0 & 0 & 0 & 0 & 0 & 0 & 0 & 0 & 1 & 1 & 0 & 1 & 1 & 1 & 0 & 1 & 1 & 1 & 0 & 0 & 1 & 0 & 0 & 0 & 0 & 1 & 0 & 0 & 1 & 0 & 0 \\
\hline Mesembrinella lara comb. $\boldsymbol{n}$. & 0 & 0 & 1 & 0 & 0 & 0 & 0 & 0 & 0 & 0 & 0 & 0 & 1 & 1 & 0 & 0 & 0 & 1 & 0 & 1 & 1 & 1 & 0 & 0 & 1 & 0 & 0 & 0 & 0 & 1 & 0 & 0 & 1 & 0 & 0 \\
\hline Mesembrinella purpurata & 0 & 0 & 1 & 0 & 1 & 0 & 0 & 0 & 0 & 0 & 0 & 0 & 1 & 0 & 0 & 1 & 1 & 1 & 0 & 1 & 1 & 1 & 0 & 0 & 1 & 1 & 0 & 1 & 0 & 0 & 0 & 0 & 1 & 0 & 1 \\
\hline Mesembrinella semiflava & 0 & 0 & 1 & 0 & 0 & 0 & 0 & 0 & 0 & 0 & 0 & 0 & 1 & 0 & 0 & 0 & 1 & 1 & 0 & 1 & 1 & 1 & 0 & 0 & 1 & 1 & 0 & 0 & 0 & 0 & 0 & 0 & 1 & 0 & 0 \\
\hline Mesembrinella uniseta & 0 & 0 & 1 & 0 & 0 & 0 & 0 & 0 & 0 & 0 & 0 & 0 & 1 & 1 & 0 & 1 & 1 & 1 & 0 & 1 & 1 & 1 & 0 & 0 & 1 & 0 & 0 & 0 & 0 & 0 & 0 & 0 & 1 & 0 & 0 \\
\hline Mesembrinella vogelsangi & 1 & 0 & 1 & 0 & 0 & 0 & 0 & 0 & 0 & 0 & 0 & 0 & 1 & 1 & 0 & 0 & 1 & 1 & 0 & 1 & 1 & 1 & 0 & 0 & 1 & 1 & 0 & 1 & 0 & 0 & 1 & 0 & 1 & 0 & 0 \\
\hline Mesembrinella nigripes comb. $\boldsymbol{n}$. & 0 & 0 & 1 & 0 & 1 & 0 & 0 & 0 & 0 & 0 & 0 & 0 & 1 & 1 & 0 & 0 & 0 & 0 & - & 0 & 1 & 0 & - & 0 & 0 & 1 & 0 & 0 & 0 & 0 & 0 & 0 & 1 & 0 & 1 \\
\hline Mesembrinella perisi & 0 & 0 & 1 & 0 & 1 & 0 & 0 & 0 & 0 & 0 & 0 & 0 & 1 & 1 & 0 & 0 & 0 & 0 & - & 0 & 1 & 0 & - & 0 & 0 & 1 & 0 & 0 & 0 & 0 & 0 & 0 & 1 & 0 & 1 \\
\hline Mesembrinella abaca & 1 & 0 & 1 & 0 & 0 & 1 & 0 & 0 & 0 & 0 & 0 & 0 & 0 & 0 & 0 & 0 & 0 & 0 & - & 0 & 1 & 0 & - & 0 & 1 & 1 & 0 & 0 & 0 & 0 & 1 & 0 & 1 & 0 & 0 \\
\hline Mesembrinella apollinaris & 1 & 0 & 1 & 0 & 0 & 1 & 0 & 0 & 0 & 0 & 1 & 1 & 0 & 0 & 0 & 0 & 0 & 0 & - & 0 & 1 & $?$ & - & 0 & 1 & 1 & 0 & 0 & 0 & 0 & 1 & 0 & 1 & 0 & 0 \\
\hline Mesembrinella batesi & 1 & 1 & 1 & 0 & 1 & 0 & 0 & 0 & 0 & 0 & 0 & 0 & 0 & 0 & 0 & 0 & 0 & 0 & - & 0 & 1 & 0 & - & 0 & 1 & 1 & 0 & 0 & 0 & 0 & 1 & 1 & 1 & 0 & 1 \\
\hline Mesembrinella bellardiana & 1 & 1 & 1 & 0 & 1 & 0 & 0 & 0 & 0 & 0 & 0 & 0 & 0 & 0 & 0 & 1 & 0 & 0 & - & 0 & 1 & 0 & - & 0 & 1 & 1 & 0 & 0 & 0 & 0 & 1 & 1 & 1 & 0 & 1 \\
\hline Mesembrinella bicolor & 0 & 0 & 1 & 0 & 0 & 0 & 0 & 0 & 0 & 0 & 0 & 0 & 0 & 0 & 0 & 0 & 0 & 0 & - & 0 & 1 & 0 & - & 0 & 1 & 1 & 0 & 0 & 0 & 0 & 0 & 0 & 1 & 0 & 0 \\
\hline Mesembrinella brunnipes & 1 & 0 & 1 & 0 & 1 & 1 & 0 & 0 & 0 & 0 & 0 & $?$ & $?$ & $?$ & 0 & 0 & 0 & 0 & - & 0 & 1 & 0 & - & 0 & 1 & 1 & 0 & 0 & 0 & $?$ & 1 & 0 & 1 & 0 & 1 \\
\hline Mesembrinella currani & 1 & 0 & 1 & 0 & 1 & 0 & 0 & 0 & 0 & 0 & 1 & 1 & 0 & 0 & 0 & 0 & 0 & 0 & - & 0 & 0 & 0 & - & 0 & 1 & 1 & 0 & 0 & 0 & 0 & 1 & 0 & 1 & 0 & 1 \\
\hline Mesembrinella flavicrura & 0 & 0 & 1 & 0 & 0 & 0 & 0 & 0 & 0 & 0 & 0 & 0 & 1 & 1 & 2 & 1 & 1 & 1 & 0 & 1 & 1 & 1 & 1 & 0 & 1 & 1 & 0 & 0 & 0 & 0 & 0 & 0 & 1 & 0 & 0 \\
\hline Mesembrinella patriciae & 0 & 0 & 1 & 0 & 0 & 0 & 0 & 0 & 0 & 0 & 0 & 0 & 0 & 1 & 2 & 0 & 0 & 0 & - & 0 & 1 & 0 & - & 0 & 1 & 1 & 0 & 0 & 0 & $?$ & 0 & 0 & 1 & 0 & 0 \\
\hline Mesembrinella peregrina & 0 & 1 & 1 & 0 & 0 & 0 & 0 & 0 & 0 & 0 & 0 & 0 & 0 & 0 & 0 & 0 & 0 & 0 & - & 0 & 1 & 0 & - & 0 & 1 & 1 & 0 & 0 & 0 & 0 & 0 & 1 & 1 & 0 & 0 \\
\hline Mesembrinella pictipenis & 1 & 0 & 1 & 0 & 1 & 1 & 0 & 0 & 0 & 0 & 1 & 1 & 0 & 0 & 0 & 0 & 0 & 0 & - & 0 & 1 & 0 & - & 0 & 0 & 0 & 0 & 0 & 0 & 0 & 1 & 0 & 1 & 0 & 1 \\
\hline Mesembrinella semihyalina & 1 & 0 & 1 & 0 & 0 & 1 & 0 & 0 & 0 & 0 & 0 & 0 & 0 & 0 & 0 & 0 & 0 & 0 & - & 0 & 1 & 0 & - & 0 & 1 & 1 & 0 & 0 & 0 & 0 & 1 & 0 & 1 & 0 & 0 \\
\hline Mesembrinella towsendi & 1 & $?$ & 1 & 0 & 1 & 0 & 0 & 0 & 0 & 0 & 0 & 0 & 0 & 1 & 2 & 0 & $?$ & $?$ & $?$ & 0 & 1 & 0 & - & 0 & 1 & $?$ & 0 & 0 & 0 & 0 & 1 & $?$ & 1 & 0 & 1 \\
\hline Mesembrinella umbrosa & 1 & 1 & 1 & 0 & 0 & 1 & 0 & 0 & 0 & 0 & 1 & 1 & 0 & 0 & 2 & 0 & 0 & 0 & - & 0 & 1 & 0 & - & 0 & 1 & 1 & 0 & 0 & 0 & 0 & 1 & 1 & 1 & 0 & 0 \\
\hline Mesembrinella xantorrhina & 0 & $?$ & 1 & 0 & 0 & 0 & 0 & 0 & 0 & 0 & 0 & 0 & 1 & 1 & 0 & 1 & 1 & 1 & 0 & 1 & 0 & 1 & 1 & 0 & 1 & 0 & 0 & 0 & 0 & 1 & 0 & $?$ & 1 & 0 & 0 \\
\hline Mesembrinella facialis & 0 & 1 & 1 & 0 & 0 & 0 & 0 & 0 & 0 & 0 & 0 & 1 & 0 & 1 & 0 & 0 & 0 & 0 & - & 0 & 1 & 0 & - & 0 & 0 & 0 & 0 & 0 & 0 & 0 & 0 & 1 & 1 & 0 & 0 \\
\hline Mesembrinella anomala comb. $\boldsymbol{n}$. & 0 & 0 & 1 & 0 & 0 & 0 & 0 & 0 & 0 & 0 & 0 & 0 & 0 & 1 & 0 & 1 & 0 & 1 & 0 & 0 & 0 & 0 & - & 0 & 0 & 1 & 0 & 0 & 1 & 0 & 0 & 0 & 1 & 0 & 0 \\
\hline
\end{tabular}


Continuação da matriz de caracteres morfológicos.

ち。

\begin{tabular}{|c|c|c|c|c|c|c|c|c|c|c|c|c|c|c|c|c|c|c|c|c|c|c|c|c|}
\hline Fannia heydenii & 1 & 0 & 1 & 1 & 0 & - & 0 & 0 & 0 & - & 0 & 0 & - & - & $?$ & 1 & 0 & 0 & 0 & $?$ & 0 & 0 & 0 & 0 \\
\hline Phaonia advena & 1 & 0 & 1 & 1 & 0 & - & 0 & 0 & 0 & - & 0 & 0 & - & - & $?$ & 1 & 0 & 0 & 0 & $?$ & 0 & 0 & 0 & 0 \\
\hline Polietina flavithorax & 1 & 1 & 1 & 1 & 0 & - & 0 & 0 & 0 & - & 0 & 0 & - & - & $?$ & 1 & 0 & 0 & 0 & $?$ & 0 & 0 & 0 & 0 \\
\hline Acaulona costata & 1 & 0 & 0 & 1 & 0 & - & 1 & 0 & 0 & - & 0 & 0 & - & - & $?$ & 1 & 1 & 0 & 0 & 1 & $?$ & 0 & 0 & 0 \\
\hline Adejeania townsendi & 1 & 0 & 0 & 1 & 0 & - & 1 & 0 & 0 & - & 0 & 0 & - & - & 0 & 1 & 1 & 0 & 0 & 1 & 1 & 0 & 0 & 1 \\
\hline Ectophasia crassipenis & 1 & 0 & 0 & 1 & 0 & - & 1 & 1 & - & $?$ & 0 & 0 & - & - & $?$ & 1 & 1 & 0 & 0 & 1 & $?$ & 0 & 0 & 0 \\
\hline Gymnosoma rotundatum & $?$ & $?$ & $?$ & $?$ & $?$ & $?$ & $?$ & 1 & - & $?$ & 0 & 0 & - & - & $?$ & 1 & 1 & 0 & 0 & 1 & 1 & 0 & 0 & 0 \\
\hline Phasia hemiptera & 1 & 0 & 1 & 1 & 0 & - & 1 & 1 & - & $?$ & 0 & 0 & - & - & $?$ & 1 & 1 & 0 & 0 & 1 & 1 & 0 & 0 & 0 \\
\hline Prophorostoma pulchra & 1 & 0 & 0 & 1 & 0 & - & 1 & 0 & 0 & - & 0 & 0 & - & - & 0 & 1 & 0 & 1 & 0 & 1 & 1 & 0 & 0 & 0 \\
\hline Winthemia analis & $?$ & $?$ & $?$ & $?$ & $?$ & $?$ & $?$ & 0 & 0 & - & 0 & 0 & - & - & 0 & 0 & - & 1 & 0 & 1 & 1 & 0 & 0 & 0 \\
\hline Amobia floridensis & 1 & 1 & 0 & 1 & 0 & - & 1 & 0 & 0 & - & 0 & 1 & 1 & 1 & 1 & 1 & 0 & 0 & 0 & 0 & 1 & 0 & 0 & 0 \\
\hline Peckia intermutans & 1 & 0 & 0 & 1 & 1 & - & 1 & 0 & 0 & - & 0 & 0 & - & - & 1 & 1 & 0 & 1 & 0 & 0 & 1 & 0 & 0 & 1 \\
\hline Cuterebra apicalis & 1 & 1 & $?$ & 1 & $?$ & $?$ & 1 & 0 & 0 & - & 0 & 0 & - & - & 1 & 1 & 0 & 0 & 0 & 1 & 1 & 0 & 0 & 1 \\
\hline Shannoniella cuspidata & 1 & 0 & 1 & 1 & 0 & - & 0 & 0 & 0 & - & 0 & 0 & - & - & 1 & 1 & 0 & 0 & 0 & 1 & 1 & 0 & 0 & 0 \\
\hline Amenia imperialis & 1 & 0 & 1 & 1 & 0 & - & 1 & 0 & 0 & - & 0 & 1 & 0 & 0 & 1 & 1 & 0 & 0 & 0 & 1 & 1 & 0 & 0 & 0 \\
\hline Amenia leonina & 1 & 0 & 1 & 1 & 0 & - & 1 & 0 & 0 & - & 0 & 1 & 0 & 0 & 1 & 1 & 0 & 0 & 0 & 1 & 1 & 0 & 0 & 0 \\
\hline Auchmeromyia bequaerti & 1 & 0 & 0 & 1 & 2 & 0 & 1 & 0 & 0 & - & 0 & 1 & 1 & 1 & 1 & 1 & 0 & 1 & 0 & 1 & 1 & 0 & 0 & 0 \\
\hline Bengalia emarginata & 1 & 0 & 0 & 1 & 1 & - & 0 & 0 & 0 & - & 0 & $?$ & $?$ & 1 & 1 & 1 & 0 & 1 & 0 & 1 & 1 & 0 & 0 & 0 \\
\hline Blepharicnema splendens & 1 & 0 & 1 & 1 & 2 & 0 & 0 & 0 & 0 & - & 0 & 1 & 1 & 1 & 0 & 1 & 0 & 0 & 0 & 1 & 1 & 0 & 0 & 1 \\
\hline Calliphora vomitoria & 1 & 0 & 1 & 1 & 0 & - & 0 & 0 & 0 & - & 0 & 1 & 0 & 0 & 1 & 1 & 0 & 0 & 0 & 1 & 1 & 0 & 0 & 0 \\
\hline Chrysomya megacephala & 1 & 0 & 1 & 1 & 0 & - & 0 & 0 & 0 & - & 0 & 1 & 0 & 0 & 1 & 1 & 0 & 0 & 0 & 1 & 1 & 0 & 0 & 0 \\
\hline Cynomya cadaverina & 1 & 0 & 1 & 1 & 1 & - & 0 & 0 & 0 & - & 0 & 1 & 0 & 0 & 1 & 1 & 0 & 0 & 0 & 1 & 1 & 0 & 0 & 0 \\
\hline Cochliomyia hominivorax & 1 & 0 & 1 & 1 & $?$ & $?$ & 0 & 0 & 0 & - & 0 & 1 & 0 & 0 & 1 & 1 & 0 & 1 & 0 & 1 & 1 & 0 & 0 & 0 \\
\hline Idiella mandarina & 1 & 0 & 1 & 1 & 2 & 0 & 1 & 0 & 0 & - & 0 & 2 & 0 & 0 & 1 & 1 & 0 & 0 & 0 & 1 & 1 & 0 & 0 & 0 \\
\hline Lucilia eximia & 1 & 0 & 1 & 1 & 0 & - & 0 & 0 & 0 & - & 0 & 1 & 0 & 0 & $?$ & 1 & 0 & 0 & 0 & 1 & 1 & 0 & 0 & 0 \\
\hline Neta chilensis & 1 & 0 & 1 & 1 & 2 & 0 & 0 & 0 & 0 & - & 0 & 1 & 0 & 1 & $?$ & 1 & 0 & 0 & 0 & 1 & 1 & 0 & 0 & 1 \\
\hline Phumosia promittens & 1 & 0 & 1 & 1 & 2 & 0 & 1 & 0 & 0 & - & 0 & 1 & 0 & 1 & 1 & 1 & 0 & 1 & 0 & 1 & 1 & 0 & 0 & 0 \\
\hline Pollenia rudis & 1 & 0 & 1 & 1 & 0 & - & 0 & 0 & 0 & - & 0 & 1 & 0 & 0 & 1 & 1 & 0 & 0 & 0 & 1 & 1 & 0 & 0 & 0 \\
\hline
\end{tabular}




\begin{tabular}{|c|c|c|c|c|c|c|c|c|c|c|c|c|c|c|c|c|c|c|c|c|c|c|c|c|}
\hline & $\hat{a}$ & $\approx$ & ลे & $\S$ & $\bar{\theta}$ & $\cong$ & 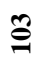 & $\stackrel{ \pm}{\Xi}$ & 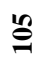 & 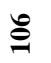 & $\hat{气}$ & $\stackrel{\infty}{\varrho}$ & $\hat{\varrho}$ & 을 & $\Xi$ & $\cong$ & $\stackrel{\varrho}{\exists}$ & $\Xi$ & $\cong$ & $\varrho$ & $\Xi$ & $\stackrel{\infty}{=}$ & 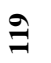 & తิ \\
\hline Sarconesia chlorogaster & 1 & 0 & 1 & 1 & 0 & - & 0 & 0 & 0 & - & 0 & 1 & 0 & 0 & 0 & 1 & 0 & 0 & 0 & 1 & 1 & 0 & 0 & 0 \\
\hline Strongyloneura nebulosa & $?$ & $?$ & $?$ & $?$ & $?$ & $?$ & $?$ & $?$ & $?$ & $?$ & 0 & 2 & 0 & 1 & 0 & 1 & 0 & 1 & 0 & 1 & 1 & 0 & 0 & 0 \\
\hline Mesembrinella latifrons comb. $\boldsymbol{n}$. & 1 & 0 & 0 & 0 & 2 & 2 & 1 & 1 & - & 0 & 1 & 1 & 0 & 1 & 1 & 1 & 0 & 1 & 0 & 1 & 1 & 0 & 0 & 0 \\
\hline Mesembrinella benoisti comb. $\boldsymbol{n}$. & 1 & 0 & 0 & 0 & 2 & 2 & 1 & 1 & - & 0 & 1 & 1 & 0 & 1 & 1 & 0 & - & 1 & 0 & 1 & 1 & 0 & 0 & 0 \\
\hline Mesembrinella cyaneicinta & 1 & 0 & 0 & 0 & 2 & 2 & 1 & 1 & - & 0 & 1 & 1 & 1 & 1 & 1 & 0 & - & 1 & 0 & 1 & 1 & 0 & 0 & 0 \\
\hline Mesembrinella quadrilineata & 1 & 0 & 0 & 0 & 2 & 2 & 1 & 1 & - & 0 & 1 & 1 & 1 & 1 & 1 & 1 & 0 & 0 & 0 & 1 & 1 & 0 & 0 & 0 \\
\hline Mesembrinella randa & 1 & 0 & 0 & 0 & 2 & 2 & 1 & 1 & - & 0 & 1 & 1 & 1 & 1 & 1 & 0 & - & 1 & 0 & 1 & 1 & 0 & 0 & 0 \\
\hline Mesembrinella bolivar comb. $\boldsymbol{n}$. & 1 & 1 & 1 & 0 & 2 & 2 & 1 & 1 & - & 0 & 1 & 1 & 0 & 1 & 1 & 1 & 0 & 0 & 0 & 1 & 1 & 0 & 0 & 0 \\
\hline Mesembrinella carvalhoi comb. $\boldsymbol{n}$. & 1 & 1 & $?$ & 0 & $?$ & $?$ & 1 & 1 & - & 0 & 1 & 1 & 1 & 1 & 1 & 1 & 0 & 1 & 0 & 1 & 1 & 0 & 0 & 0 \\
\hline Mesembrinella spicata & $?$ & $?$ & 0 & $?$ & $?$ & $?$ & 1 & 1 & - & 0 & 1 & 1 & 1 & 1 & 1 & 1 & 0 & 0 & 0 & 1 & 1 & 1 & 0 & 0 \\
\hline Mesembrinella aeneiventris & 1 & 1 & 1 & 0 & 2 & 2 & 1 & 1 & - & 0 & 1 & 1 & 1 & 1 & 1 & 1 & 0 & 1 & 0 & 1 & 1 & 0 & 0 & 0 \\
\hline Mesembrinella bequaerti comb. $\boldsymbol{n}$. & $?$ & $?$ & $?$ & $?$ & 2 & 2 & 1 & 1 & - & 0 & 1 & $?$ & $?$ & $?$ & $?$ & 1 & 0 & $?$ & $?$ & $?$ & $?$ & 0 & 0 & 0 \\
\hline Mesembrinella decrepita & 1 & 1 & 1 & 0 & 2 & 2 & 1 & 1 & - & 0 & 1 & 1 & $?$ & 1 & 1 & 1 & 0 & 1 & 0 & 1 & 1 & 0 & 0 & 0 \\
\hline Mesembrinella lara comb. $\boldsymbol{n}$. & 1 & 1 & 1 & 0 & 2 & 2 & 1 & 1 & - & 0 & 1 & 1 & 1 & 1 & 1 & 1 & 0 & 1 & 0 & 1 & 1 & 0 & 0 & 0 \\
\hline Mesembrinella purpurata & 1 & 1 & 1 & 0 & 2 & 2 & 1 & 1 & - & 0 & 1 & 1 & 0 & 1 & 1 & 1 & 0 & 0 & 0 & 1 & 1 & 0 & 0 & 0 \\
\hline Mesembrinella semiflava & 1 & 1 & 1 & 0 & 2 & 2 & 1 & 1 & - & 0 & 1 & 1 & 0 & 1 & 1 & 1 & 0 & 1 & 0 & 1 & 1 & 0 & 0 & 0 \\
\hline Mesembrinella uniseta & 1 & 1 & 1 & 0 & 2 & 2 & 1 & 1 & - & 0 & 0 & 1 & 0 & 1 & 1 & 0 & - & 0 & 0 & 1 & 1 & 0 & 0 & 0 \\
\hline Mesembrinella vogelsangi & 1 & 1 & 1 & 0 & 2 & 2 & 1 & 1 & - & 0 & 1 & 1 & 1 & 1 & 1 & 1 & 0 & 1 & 0 & 1 & 1 & 0 & 0 & 0 \\
\hline Mesembrinella nigripes comb. $\boldsymbol{n}$. & 1 & 0 & 0 & 0 & 2 & 0 & 1 & 0 & 0 & - & 1 & 1 & 0 & 1 & 1 & 1 & 0 & 0 & 1 & 1 & 1 & 0 & 0 & 0 \\
\hline Mesembrinella perisi & 1 & 0 & 0 & 0 & 2 & 0 & 1 & 0 & 0 & - & 1 & 1 & 1 & 1 & 1 & 1 & 0 & 0 & 1 & 1 & 1 & 0 & 0 & 0 \\
\hline Mesembrinella abaca & 1 & 0 & 0 & 0 & 2 & 2 & 1 & 1 & - & 0 & 1 & 1 & 0 & 1 & 1 & 1 & 0 & 1 & 0 & 1 & 1 & 0 & 0 & 0 \\
\hline Mesembrinella apollinaris & 1 & 0 & 0 & 0 & 2 & 2 & 1 & 1 & - & 0 & 1 & 1 & 0 & 1 & $?$ & 1 & 0 & 1 & 0 & 1 & 1 & 0 & 0 & 1 \\
\hline Mesembrinella batesi & 1 & 0 & 0 & 0 & 2 & 2 & 1 & 1 & - & 0 & 1 & 1 & 0 & 1 & 1 & 0 & - & 1 & 0 & 1 & 1 & 0 & 0 & 0 \\
\hline Mesembrinella bellardiana & 1 & 0 & 0 & 0 & 2 & 2 & 1 & 1 & - & 0 & 1 & 1 & 0 & 1 & 1 & 1 & 0 & 1 & 0 & 1 & 1 & 0 & 0 & 0 \\
\hline Mesembrinella bicolor & 1 & 0 & 0 & 0 & 2 & 2 & 1 & 1 & - & 0 & 1 & 1 & 0 & 1 & 1 & 1 & 0 & 1 & 0 & 1 & 1 & 0 & 0 & 0 \\
\hline Mesembrinella brunnipes & 1 & 0 & 0 & 0 & 2 & 2 & 1 & $?$ & $?$ & 0 & $?$ & $?$ & $?$ & 1 & $?$ & $?$ & $?$ & $?$ & 0 & 1 & 1 & 0 & 0 & 0 \\
\hline Mesembrinella currani & 1 & 0 & 0 & 0 & 2 & 2 & 1 & 1 & - & 0 & 1 & 1 & 0 & 1 & $?$ & 1 & - & 1 & 0 & 1 & 1 & 0 & 0 & 1 \\
\hline Mesembrinella flavicrura & 1 & 1 & 1 & 0 & 2 & 2 & 1 & 1 & - & 0 & 1 & 1 & 1 & 1 & 1 & 1 & 0 & 0 & 0 & 1 & 1 & 0 & 0 & 0 \\
\hline Mesembrinella patriciae & $?$ & $?$ & $?$ & $?$ & 2 & 2 & 1 & 1 & - & 0 & 1 & 1 & 1 & 1 & 1 & 1 & 0 & 0 & 0 & $?$ & 1 & 0 & 0 & 0 \\
\hline Mesembrinella peregrina & 1 & 0 & 0 & 0 & 2 & 2 & 1 & 1 & - & 0 & 1 & 1 & 1 & 1 & 1 & 1 & 0 & 1 & 0 & 1 & 1 & 0 & 0 & 0 \\
\hline Mesembrinella pictipenis & 1 & 0 & 0 & 0 & 2 & 2 & 1 & 1 & - & 0 & 1 & 1 & 1 & 1 & $?$ & 1 & 0 & 1 & 0 & 1 & 1 & 0 & 0 & 1 \\
\hline
\end{tabular}


ち。

$\begin{array}{llllllllllllllllllllllllllllll}\text { Mesembrinella semihyalina } & 1 & 0 & 0 & 0 & 2 & 2 & 1 & 1 & - & 0 & 1 & 1 & 0 & 1 & 1 & 1 & 0 & 1 & 0 & 1 & 1 & 0 & 0 & 0\end{array}$

Mesembrinella towsendi

Mesembrinella umbrosa

Mesembrinella xantorrhina

Mesembrinella facialis

$\begin{array}{llllllllllllllllllllllll}1 & 0 & 0 & 0 & 2 & 2 & 1 & 1 & - & 0 & 1 & 1 & 0 & 1 & ? & 1 & 0 & 1 & 0 & 1 & 1 & 0 & 0 & 0\end{array}$

$\begin{array}{lllllllllllllllllllllllll}1 & 0 & 0 & 0 & 2 & 2 & 1 & 1 & - & 0 & 1 & 1 & 0 & 1 & 1 & 1 & 0 & 1 & 0 & 1 & 1 & 0 & 0 & 1\end{array}$

Mesembrinella facialis 
APÊNDICE 2. Espécimenes utilizados durante o presente estudo. A tabela apresenta os dados dos exemplares do material examinado no estudo morfológico, bem como provenientes de banco de dados de coleções científicas e da literatura, conforme especificado na coluna "Fonte da informação". nt=não-tipo; HT=holótipo; PT=parátipo; LT=lectótipo; PLT=paralectótipo.

Por conta da utilização de bases de dados de coleções científicas online, além da extensa lista de material examinado, essa tabela ficou muito extensa, o que inviabilizou sua inserção no corpo da dissertação. Então, a tabela encontra-se anexa à essa dissertação, em um CD acoplado à última página. 
APÊNDICE 3. Script construído para a Análise de Dispersão e Vicariância (DIVA).

tree Mesembrinellinae

$((1,(2,3)),((4,(5,((6,(7,8)),((9,10),(11,((12,13),(14,15))))))),(16,((17,(18,(19,20))),(21,((22,23),(24,(25,((26,(27,(28,29))),(30,(31,(32,(33,(34$, $35))))))))()))))$;

distribution D E DF E ABEF DF AEF ABEF DE E F AD C D F D AE ABF A ABF E D D DF C D DE F DEF C C D D C DF; optimize;

return;

1 facialis D

2 nigripes $\mathrm{E}$

3 perisi DF

4 peregrina $\mathrm{E}$

5 bicolor $\mathrm{ABEF}$

6 townsendi DF

7 batesi AEF

8 bellardiana ABEF

9 abaca DE

10 semyhialina $\mathrm{E}$ 
11 brunnipes $F$

12 pictipennis $A D$

13 umbrosa $\mathrm{C}$

14 apollinaris D

15 currani $F$

16 patriciae $\mathrm{D}$

17 cyaneicincta $\mathrm{AE}$

18 randa $\mathrm{ABF}$

19 benoisti $A$

20 quadrilineata $\mathrm{ABF}$

21 latifrons E

22 bolivar $\mathrm{D}$

23 carvalhoi D

24 anomala DF

25 flavicrura $\mathrm{C}$

26 vogelsangi $\mathrm{D}$

27 aeneiventris DE

28 bequaerti $\mathrm{F}$

29 purpurata DEF

30 semiflava $\mathrm{C}$ 
31 uniseta $C$

32 lara D

33 decrepita D

34 spicata C

35 xanthorrhina DF

$\mathrm{A}=$ Dominio Brasileiro Boreal

$\mathrm{B}=$ Dominio do Chaco

$\mathrm{C}=$ Dominio Mesoamerico

$\mathrm{D}=$ Dominio Pacifico

$\mathrm{E}=\mathrm{DOminio}$ do Parana

$\mathrm{F}=$ Dominio Sul Brasileiro 


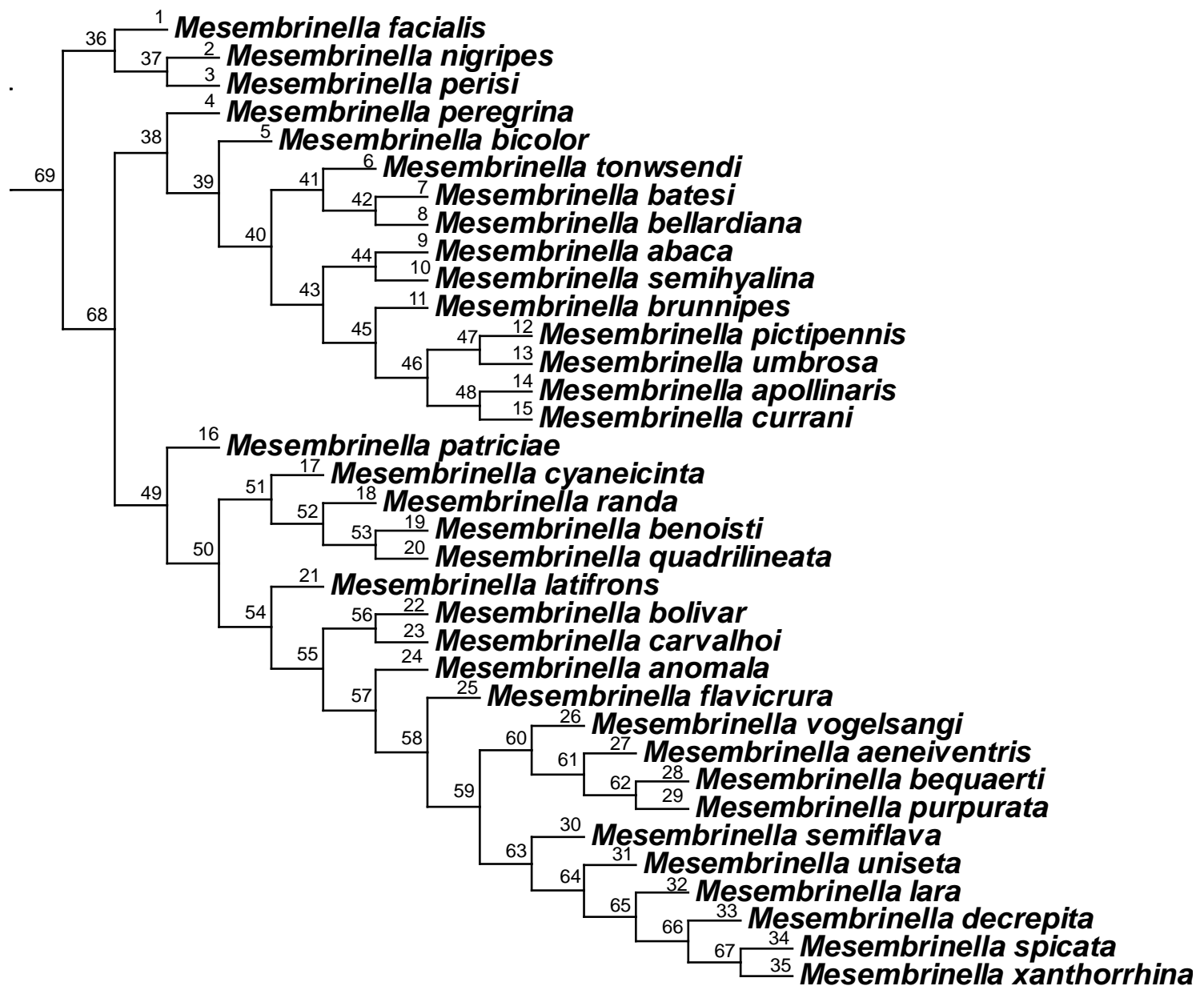

APÊNDICE 4. Cladograma mais parcimonioso obtido por análise com pesagem implícita com os terminais e nós numerados para a construção da matriz binária da Análise de Parcimônia de Brooks. 
APÊNDICE 5. Matriz binária Táxon x Área utilizada para a Análise de Parcimônia de Brooks (BPA).

\begin{tabular}{|c|c|c|c|c|c|c|c|c|c|c|c|c|c|c|c|c|c|c|c|c|c|c|c|c|c|c|c|c|c|c|c|c|c|c|}
\hline & 1 & 2 & 3 & 4 & 5 & 6 & 7 & 8 & 9 & 10 & 11 & 12 & 13 & 14 & 15 & 16 & 17 & 18 & 19 & 20 & 21 & 22 & 23 & 24 & 25 & 26 & 27 & 28 & 29 & 30 & 31 & 32 & 33 & 34 \\
\hline Ancestral Hipotético & 0 & 0 & 0 & 0 & 0 & 0 & 0 & 0 & 0 & 0 & 0 & 0 & 0 & 0 & 0 & 0 & 0 & 0 & 0 & 0 & 0 & 0 & 0 & 0 & 0 & 0 & 0 & 0 & 0 & 0 & 0 & 0 & 0 & 0 \\
\hline Domínio Brasileiro Boreal & 0 & 0 & 0 & 0 & 1 & 0 & 1 & 1 & 0 & 0 & 0 & 1 & 0 & 0 & 0 & 0 & 1 & 1 & 1 & 1 & 0 & 0 & 0 & 0 & 0 & 0 & 0 & 0 & 0 & 0 & 0 & 0 & 0 & 0 \\
\hline Domínio Chaco & 0 & 0 & 0 & 0 & 1 & 0 & 0 & 1 & 0 & 0 & 0 & 0 & 0 & 0 & 0 & 0 & 0 & 1 & 0 & 1 & 0 & 0 & 0 & 0 & 0 & 0 & 0 & 0 & 0 & 0 & 0 & 0 & 0 & 0 \\
\hline Domínio Mesoamérico & 0 & 0 & 0 & 0 & 0 & 0 & 0 & 0 & 0 & 0 & 0 & 0 & 1 & 0 & 0 & 0 & 0 & 0 & 0 & 0 & 0 & 0 & 0 & 0 & 1 & 0 & 0 & 0 & 0 & 1 & 1 & 0 & 0 & 1 \\
\hline Domínio Pacífico & 1 & 0 & 1 & 0 & 0 & 1 & 0 & 0 & 1 & 0 & 0 & 1 & 0 & 1 & 0 & 1 & 0 & 0 & 0 & 0 & 0 & 1 & 1 & 1 & 0 & 1 & 1 & 0 & 1 & 0 & 0 & 1 & 1 & 0 \\
\hline Domínio Paraná & 0 & 1 & 0 & 1 & 1 & 0 & 1 & 1 & 1 & 1 & 0 & 0 & 0 & 0 & 0 & 0 & 1 & 0 & 0 & 0 & 1 & 0 & 0 & 0 & 0 & 0 & 1 & 0 & 1 & 0 & 0 & 0 & 0 & 0 \\
\hline Domínio Sul Brasileiro & 0 & 0 & 1 & 0 & 1 & 1 & 1 & 1 & 0 & 0 & 1 & 0 & 0 & 0 & 1 & 0 & 0 & 1 & 0 & 1 & 0 & 0 & 0 & 1 & 0 & 0 & 0 & 1 & 1 & 0 & 0 & 0 & 0 & 0 \\
\hline
\end{tabular}

$\begin{array}{llllllllllllllllllllllllllllllllllllllll}35 & 36 & 37 & 38 & 39 & 40 & 41 & 42 & 43 & 44 & 45 & 46 & 47 & 48 & 49 & 50 & 51 & 52 & 53 & 54 & 55 & 56 & 57 & 58 & 59 & 60 & 61 & 62 & 63 & 64 & 65 & 66 & 67 & 68 & 69\end{array}$

Ancestral Hipotético

$\begin{array}{llllllllllllllllllllllllllllllllllllllllllllll}0 & 0 & 0 & 0 & 0 & 0 & 0 & 0 & 0 & 0 & 0 & 0 & 0 & 0 & 0 & 0 & 0 & 0 & 0 & 0 & 0 & 0 & 0 & 0 & 0 & 0 & 0 & 0 & 0 & 0 & 0 & 0 & 0 & 0 & 0\end{array}$

Domínio Brasileiro Boreal

Domínio Chaco

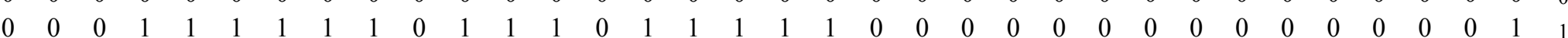

Domínio Mesoamérico

Domínio Pacífico

$\begin{array}{lllllllllllllllllllllllllllllllllllllllllllllll}0 & 0 & 0 & 1 & 1 & 1 & 1 & 1 & 0 & 0 & 0 & 0 & 0 & 0 & 1 & 1 & 1 & 1 & 1 & 0 & 0 & 0 & 0 & 0 & 0 & 0 & 0 & 0 & 0 & 0 & 0 & 0 & 0 & 1 & 1\end{array}$

Domínio Paraná

Domínio Sul Brasileiro

$\begin{array}{lllllllllllllllllllllllllllllllllllllllllllllllllll}0 & 0 & 0 & 1 & 1 & 1 & 0 & 0 & 1 & 0 & 1 & 1 & 1 & 0 & 1 & 1 & 0 & 0 & 0 & 1 & 1 & 1 & 0 & 1 & 1 & 0 & 0 & 0 & 1 & 1 & 1 & 1 & 1 & 1 & 1\end{array}$

$\begin{array}{lllllllllllllllllllllllllllllllllllllllllllllllllllll}1 & 1 & 1 & 1 & 1 & 1 & 1 & 0 & 1 & 1 & 1 & 1 & 1 & 1 & 1 & 1 & 0 & 0 & 0 & 1 & 1 & 1 & 1 & 1 & 1 & 1 & 1 & 1 & 1 & 1 & 1 & 1 & 1 & 1 & 1\end{array}$

$\begin{array}{lllllllllllllllllllllllllllllllllllllllllllllllllll}0 & 1 & 1 & 1 & 1 & 1 & 1 & 1 & 1 & 1 & 0 & 0 & 0 & 0 & 1 & 1 & 1 & 0 & 0 & 1 & 1 & 1 & 0 & 1 & 1 & 1 & 1 & 1 & 0 & 0 & 0 & 0 & 0 & 1 & 1\end{array}$ 


\begin{abstract}
ANEXOS
ANEXO 1. Script utilizado para busca de valor de k, na análise de parcimônia com pesagem implícita dos caracteres.

macro $=$;
\end{abstract}

var :

actK

$\operatorname{minK}$

$\operatorname{maxK}$

$\operatorname{maxH}$

actH

nVal

maxIts

factor

a

;

if $($ ntax $<0)$

quote NO HAY DATOS! ;

$\operatorname{proc} /$;

end

set $\operatorname{maxH} 1$;

/* Busca el valor de maxima homoplasia, 
la idea se basa un poco en la idea de Marcos, de buscar como se comportan los caracteres en un arbol particular

$* /$

keep 0 ;

rseed 0 ;

mult $=$ wagner replic 1 ;

loop =actc 0 nchar

if (! isinfo [\#1]) continue ; end

if $(!$ isact $[\# 1])$ continue ; end

set actH homo [0 \#actc] ;

if ('actH' > 'maxH')

set maxH 'actH' ;

end

stop

quote Maxima homoplasia en un arbol de Wagner = 'maxH' ;

set $\max \mathrm{H}^{*}=2$;

/* Busca el valor de K, segun la idea de Goloboff et al. */

set $\operatorname{actK} 10$;

set $\operatorname{minK} 0$;

set $\operatorname{maxK} 500$; /* Asume 500 como el maximo posible valor de $\mathrm{K} *$ /

set maxIts 0 ;

loop 01 
quote Valor actual de $\mathrm{K}=$ 'actK' ;

set factor 1 - ( 'actK' / ('actK' + 1));

set a ( 'actK' / ( 'actK' + 'maxH' - 1)) - ( 'actK' / ('actK' + 'maxH')) ;

set nVal 'factor' / 'a' ;

quote Proporcion maxima homoplasia no homoplasia = 'nVal' ;

if $((' n V a l '>14.8) \& \&(' n V a l '<15.2))$ endloop ; end /* $\mathrm{N}$ esta en el rango */

if ('nVal' > 15.2)

set $\min K$ 'actK';

else

set maxK 'actK';

end

set a ( 'maxK' - 'minK') / 2;

set actK 'minK' + 'a';

set maxIts ++ ;

if ( 'maxIts' == 100) endloop; end $/ *$ salida de emergencia */

setloop 0;

stop

/* Si salio de emergencia */

if $($ 'maxIts'==100)

quote NO SE TERMINARON LAS ITERACIONES;

quote mejor K encontrado: 'actK';

$\operatorname{proc} /$;

end

quote Valor de K: 'actK' (Diferencia = 'nVal'); 
if $($ 'actK' $<3)$

quote Valor de $\mathrm{K}$ muy pequenio, usando $\mathrm{K}=3$;

set $\operatorname{actK} 6$;

end

piwe $=$ 'actK';

quote Se puso a mult en los valores por omision ; keep 0;

mult : tbr hold 10 replic 10 ;

proc/; 
ANEXO 2. Script utilizado para cálculo do índice de Bremer, utilizado como suporte de ramos nas análises de parcimônias.

macro- ;

macro [ 500 ;

if $((100+(5 *(\operatorname{ntax}+1)))>1000)$

macro*10 $(100+(5 *(n t a x+1)))$;

else macro *10 1000 ;

macro $=$;

/**** CHECK WHETHER WE HAVE TREES *******/

if $($ ntrees $<0)$ quote $*$

This macro calculates Bremer supports, by

reference to groups in some tree(s). To

run this macro, you need to have some

tree(s) in memory. Find them and re-run.; proc/; end

$$
\begin{aligned}
& \text { /**** DECLARE VARIABLES } * * * * * * * * * / \\
& \operatorname{var}=10 \\
& \text { schalgs[30] + tmpstring[30] + danumreps + fillonly + maxsave + maxsub } \\
& + \text { savesub }+ \text { hold }+ \text { tmpbrem }[(2 *(\text { ntax }+1))]+\text { swaptype }+ \text { piweisoff } \\
& + \text { scorinc }+ \text { useconst }+ \text { numsearches }+ \text { avermin }+ \text { alltrees }+ \text { whichtree } \\
& + \text { allnods }+ \text { whichnod }+ \text { inclist }[(n \operatorname{tax}+1)]+\text { overimpose }+ \text { ratreps } \\
& + \text { driftreps }+ \text { dofuse }+ \text { secsearch }+ \text { dorat }+ \text { dodrift }+ \text { domonosch } \\
& + \text { timedsch }+ \text { schtime }+ \text { saveemf }+ \text { emfname[30] }+ \text { usersch }+ \text { maxsupis } \\
& + \text { beswith }+ \text { beswithout }+ \text { numincs }+ \text { nowatsub }+ \text { referscore }+ \text { supis } \\
& + \text { olrseed }+ \text { whichtreewas }+ \text { thereftree }
\end{aligned}
$$


set piweisoff $($ length $[0]==\operatorname{score}[0])$;

set 0 ntrees ;

set $1(\operatorname{ntax}+2)$;

set $2(2 * \operatorname{ntax})$;

set olrseed rseed ;

/*********** SET DEFAULTS $\quad * * * * * * * * * * * /$

/* in non-Windows versions, set variables */

/* below to your preferred values! */

set savesub $1 ; \quad \quad / *$ search suboptimal trees $* /$

set useconst $1 ; \quad / *$ do constrained searches $* /$

set allnods $1 ; \quad \quad / *$ do all nodes, or single node $\quad * /$

set whichnod $($ ntax +2$) ; / *$ single node to do if allnods $==0 * /$

set alltrees $1 ; \quad / *$ calculate support using all trees $* /$

set whichtree $0 ; \quad I^{*}$ if alltrees $==0$, use groups from this tree $* /$

set maxsave $1000 ; \quad / *$ max. number of trees to save in each round */

set maxsub $1 ; \quad \quad / *$ save trees up to $\mathrm{N}$ steps longer $* /$

set scorinc 1; $\quad / *$ increase score gradually, in $\mathrm{N}$ steps each time $* /$

set avermin $1 ; \quad / *$ if 0 , use average difference of neg/pos constrained searches */

set numsearches $3 ; \quad$ * repeat constrained searches 3 times (to use either best/avg. score) */

set danumreps $1 ; \quad \quad \quad / *$ use 1 repls. for each constrained search */

set domonosch $0 ; \quad I^{*}$ do a search constraining for monophyly (instead of comparing score

of negatively constrained search with score of reference tree) */

loop 0 ntax $\quad / *$ by default, include all taxa $* /$

set inclist[\#1] 1; stop

set saveemf $0 ; \quad \quad \quad \quad *$ don't save tree-diagrama to a metafile (Windows only) $* /$ 
set emfname \$Bremer.emf ; /* metafile default name */

set usersch $0 ; \quad / *$ for constrained searches, use commands given by user $* /$

set schalgs $\$ ; \quad / *$ default user-commands (i.e. none) $* /$

set dorat $0 ; \quad / *$ do not use ratchet in constrained searches $* /$

set ratreps $10 ; \quad / *$ number of ratchet reps. in constrained searches */

set dodrift $1 ; \quad \quad \quad$ * use drift in constrained searches $* /$

set driftreps $10 ; \quad / *$ number of drift cycles in constrained searches */

set secsearch $1 ; \quad / *$ use sectorial search in constrained searches */

set dofuse $1 ; \quad \quad \quad I^{*}$ fuse results of the 'danumreps' replications */

set timedsch $0 ; \quad \quad \quad{ }^{*}$ use timeout for constrained searches */

set schtime $0 ; \quad I^{*}$ number of minutes to give up a constrained search $(0=$ don't give up) $* /$

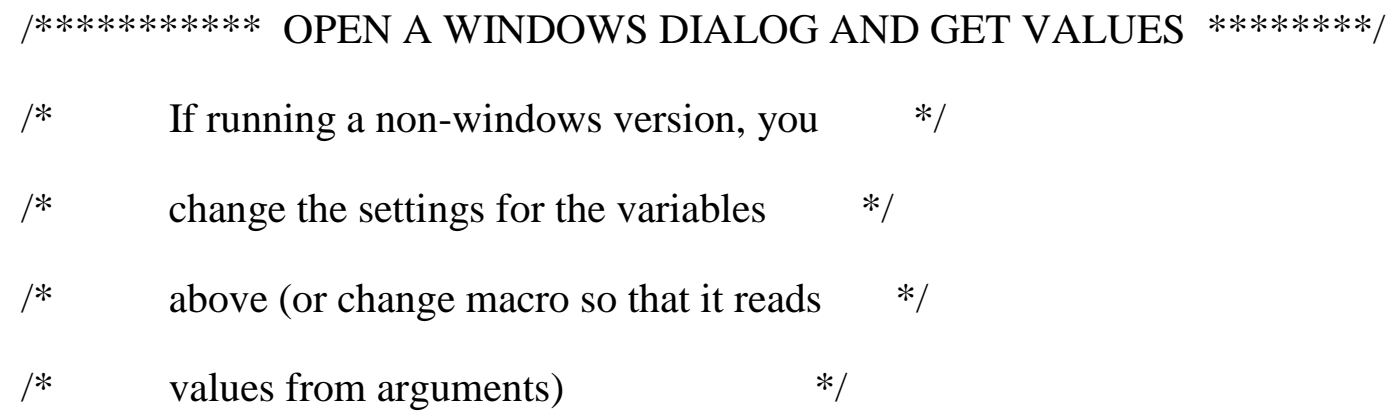

if ( windows )

opendlg 3030555280 Get trees and calculate supports...;

frame 5525060 ;

check savesub 101516018 Search suboptimal trees...;

+ subdlg 180306520 Settings ;

5050300160 Swap existing trees...

showtxt 30109018 ...saving up to ;

spin 132767 maxsave 125108018 trees ; 
showtxt 70355518 ...up to ;

spin 132767 maxsub 125358018 longer ;

showtxt 106011018 ...increasing score ;

spin 132767 scorinc 125608018 every time ;

closedlg ; =

frame 2605275130 ;

showtxt 2853523018 search with constraints...;

check useconst 2701524018 For groups not lost in suboptimal trees, ;

+ showtxt $300605518 \ldots$...search ;

spin 132767 numsearches 360607518 times, and... ;

choose avermin

3258513018 use average score

32511013018 use minimum score ;

subdlg 460356520 Settings ;

24550300310 Constrained searches... ;

frame 5528535 ;

frame 540285130 ;

gettxt schalgs 1101516018 ;

check usersch 10159018 User search: ;

- showtxt 105010518 for each one, use ;

spin 11000 danumreps 1205012018 replications ;

check secsearch 107014018 do sectorial searches ;

check dorat 10953518 do ;

+ spin 01000 ratreps 509513018 ratchet iterations ; =

check dodrift 101203518 do ;

+ spin 01000 driftreps 5012013018 tree-drift cycles ; =

check dofuse 1014517018 fuse results from all repls. ; = 
check domonosch 1017524016 do a monophyly search as well (instead ;

showtxt 2519124016 of using length of reference tree(s) );

check timedsch 1021211518 use no more than ;

+ spin 11000 schtime 13021216018 mins./search ; =

closedlg ; =

frame 565250170 ;

choose alltrees

158012018 For groups of tree

+ spin 0 '0' whichtree 140803018 ;

choose allnods

601057018 for node

+ spin '1' '2' whichnod 1301053018 ; =

601309018 for all nodes ; =

[ ( ntrees $>=0)] 1515512018$ For all trees ;

showtxt 1519015018 exclude some taxa ;

showtxt 1520815018 from the consensus...;

taxsel inclist 1502058020 ;

frame 26013527565 ;

check overimpose 27015022018 Add labels to an existing target tree ;

check saveemf 27017011218 Save metafile as ;

+ gettxt emfname 38717013018 ; =

subdlg 3112186025 HELP;

8560460240 How this macro works... ;

showtxt 101043015 This macro instructs TNT to search trees in stages. First, it searches ;

showtxt 102543015 saving suboptimal trees (possibly saving more suboptimal trees gradually, ;

showtxt 104043015 to avoid filling the tree buffer with superfluous trees), which it uses to ; 
showtxt 105543015 identify the groups of low support. Then, it searches using positive and ;

showtxt 107043015 negative constraints for each of the remaining groups. It compares the score;

showtxt 108543015 length of the best trees with and without each group. For this, it can use ;

showtxt 1010043015 the best score found (useful when you do very exhaustive searches) or the ;

showtxt 1011543015 average (less prone to errors when you use more superficial searches or have ;

showtxt 1013043015 very difficult data sets). The macro considers only currently active chars.,;

showtxt 1014543015 so that overimposed labels can be used for Bremer supports of each partition.;

closedlg ;

closedlg ;

if ( !exstatus ) proc/; end

end

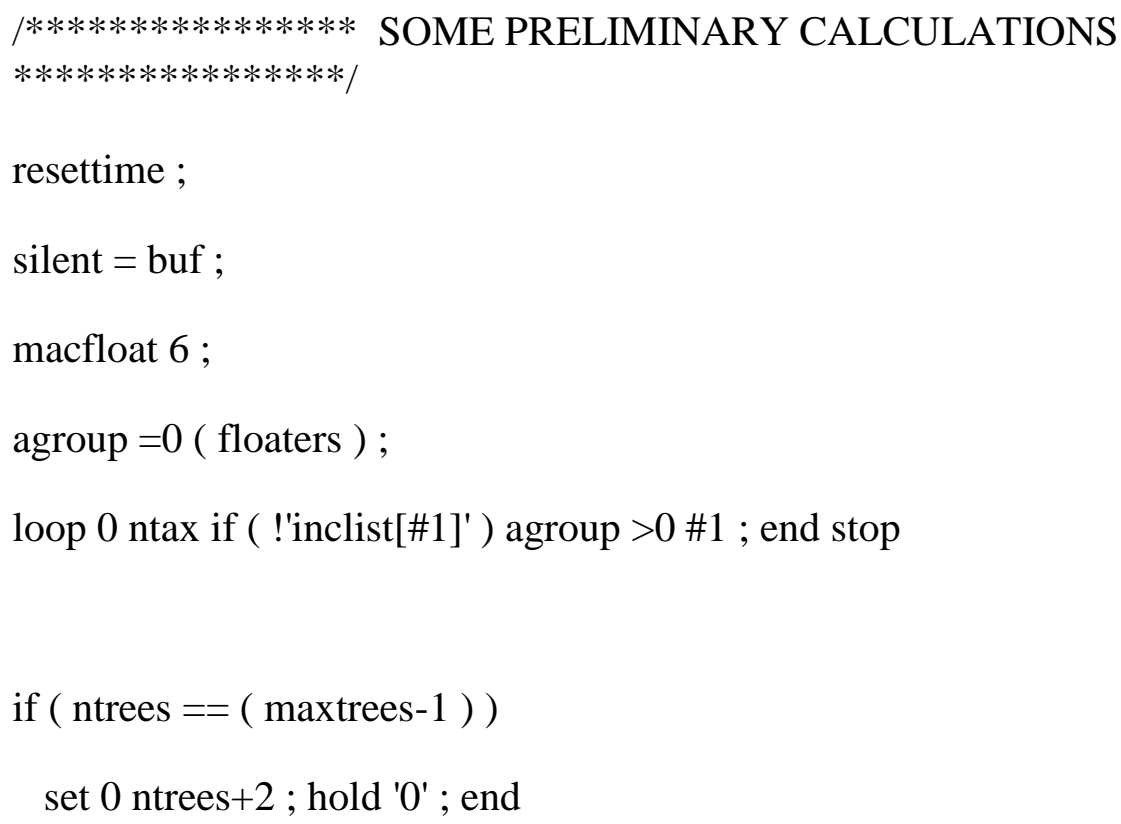


set whichtreewas 'whichtree' ;

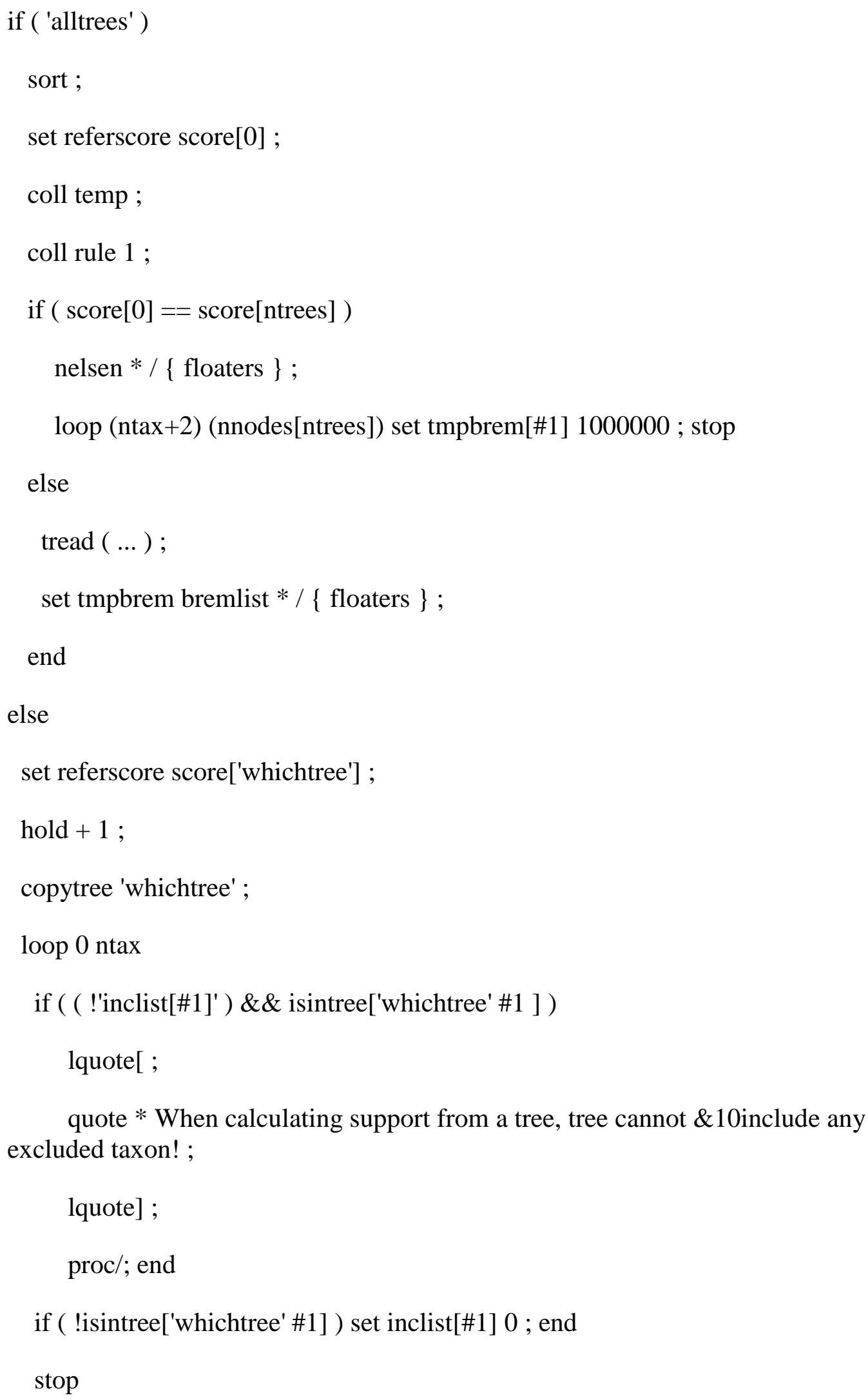


loop $($ ntax+2) (nnodes[ntrees]) set tmpbrem[\#1] 1000000 ; stop

end

set 50 ;

loop 0 ntax if ( 'inclist[\#1]' ) set $5++$; end stop

if $\left(5^{\prime}<4\right)$

lquote[ ;

quote * Sorry, cannot calculate support $\& 10$ for only ' 5 ' taxa;

lquote ] ;

proc/; end

set whichtree ntrees ;

tsave/ ;

tsave $*$ refbrem.tre ;

save 'whichtree' ;

tsave/;

tsave $*$ tempbrem.tre

save 'whichtree' ;

loop (ntax+2) nnodes['whichtree'] set tmpbrem[\#1] 1000000 ; stop

if ( ''overimpose' )

ttag - ;

nak $=$;

ttag * 'whichtree' ;

end

set 0 ntrees ;

set maxsupis score['whichtree'] ; 


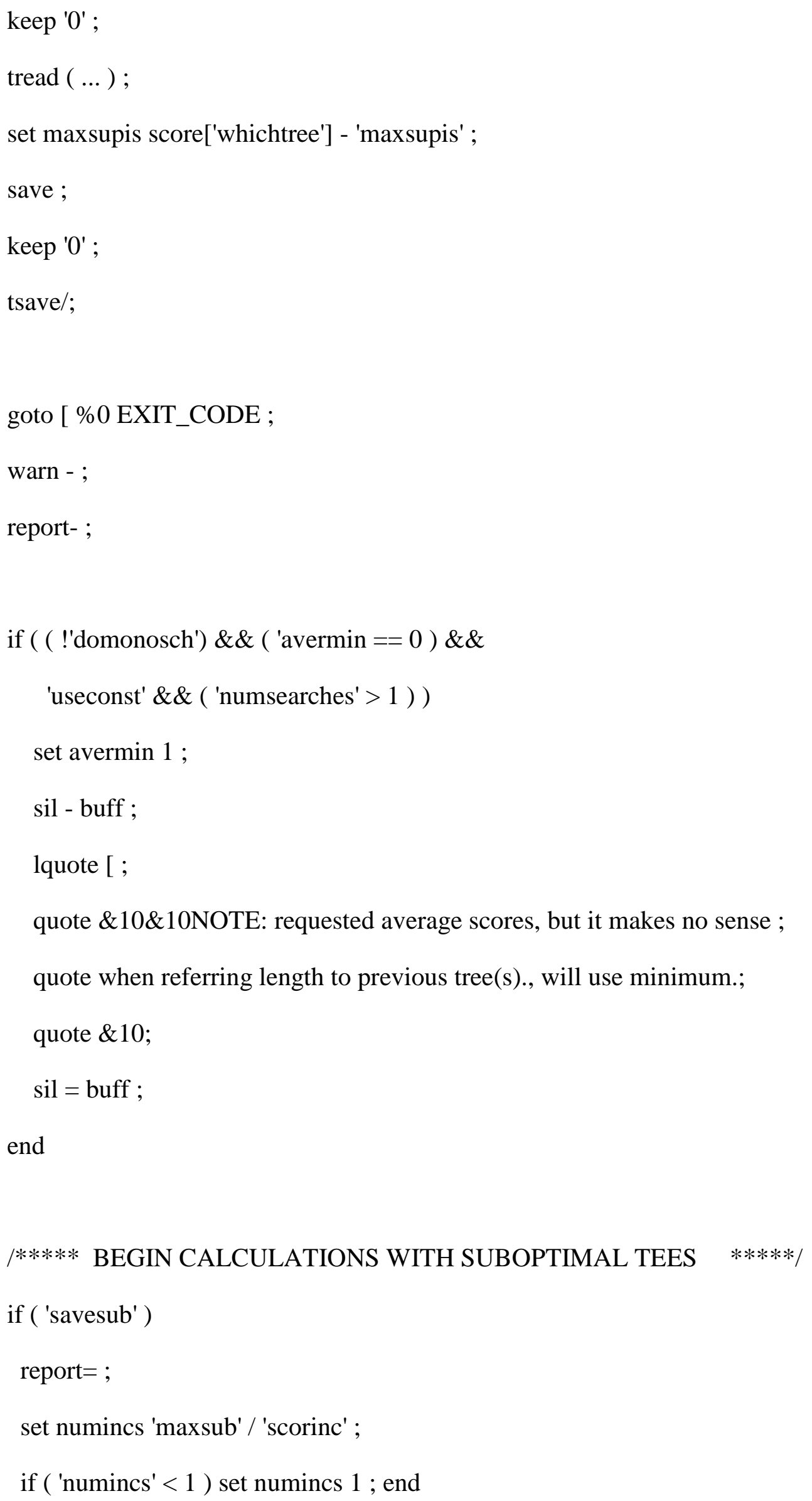


set nowatsub 'scorinc';

loop 1 'numincs'

sub 'nowatsub' ;

hold + 'maxsave' ;

$\mathrm{bb}=$ fillonly tbr

set nowatsub $+=$ 'scorinc' ;

if ( ( nowatsub' + 'scorinc' $)>$ 'maxsub' $)$

set nowatsub 'maxsave' ;

end

stop

if ( 'alltrees' )

p tempbrem.tre ;

uniq ;

coll temp ;

set tmpbrem bremlist / \{ floaters \};

else

set thereftree (ntrees+1) ;

$\mathrm{p}$ refbrem.tre ;

report- ;

set 20 ;

set 3 nnodes['thereftree'] - $($ ntax +2$)$;

loop ( ntax+2) nnodes['thereftree']

progress '2' '3' Checking suboptimal groups ('2' of '3');

chkbreak 1 ;

set $2++$;

keep 'thereftree' ;

p refbrem.tre ; 


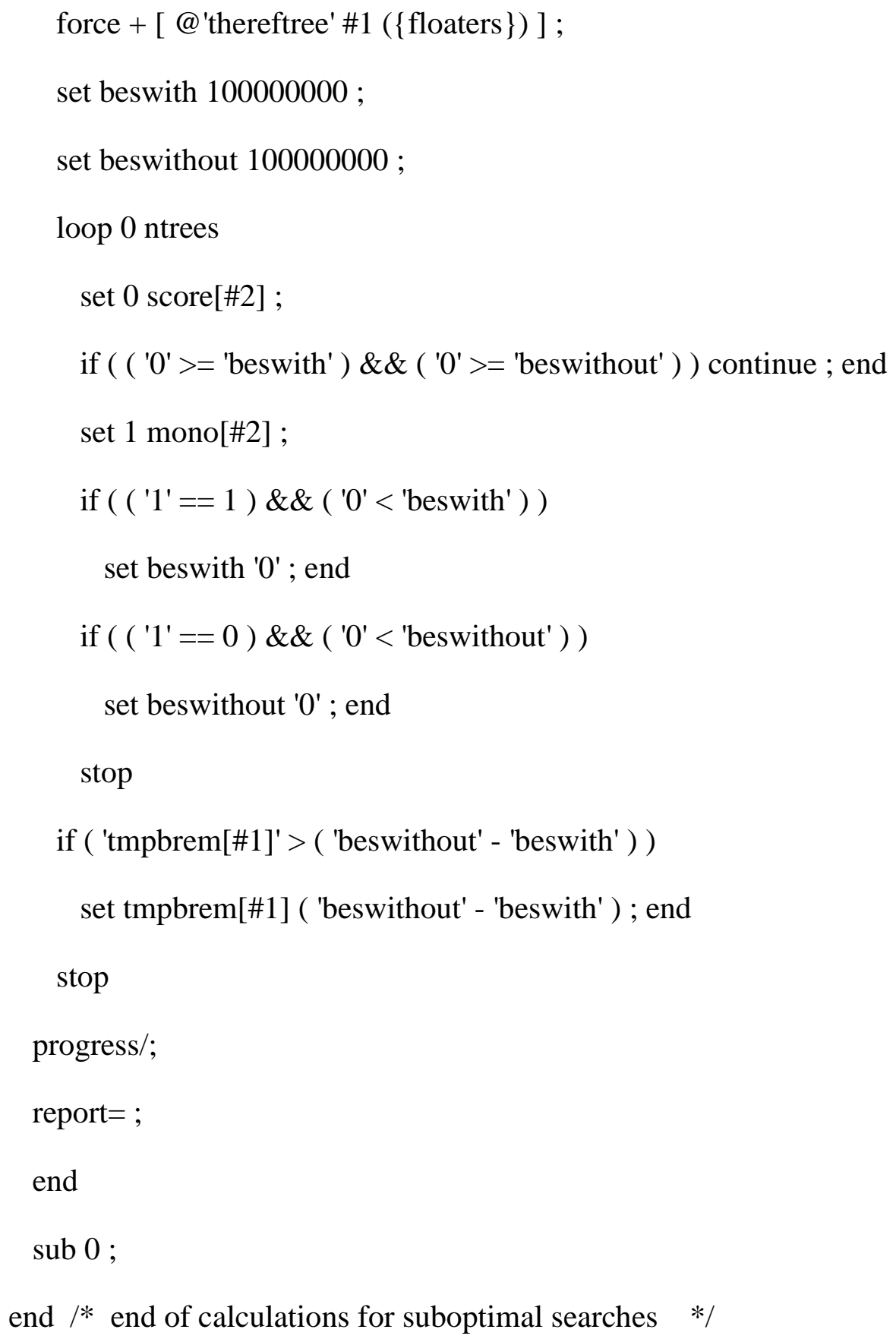


macfloat 0 ;

timeout 0:'schtime':0 ;

macfloat 6 ;

end

silent $=$ all

if ( !'usersch' )

set schalgs \$xmu = noke rep'danumreps';

if ( 'secsearch' ) set tmpstring \$ \$schalgs css rss autoc1 ;

else set tmpstring \$ \$schalgs nocss norss noaut; end

set schalgs \$ \$tmpstring;

if ( 'dorat' ) set tmpstring \$ \$schalgs rat'ratreps';

else set tmpstring \$ \$schalgs norat; end

set schalgs \$ \$tmpstring;

if ( 'dodrift' ) set tmpstring \$ \$schalgs drif'driftreps';

else set tmpstring \$ \$schalgs nodri; end

set schalgs \$ \$tmpstring;

if ( 'dofuse' ) set tmpstring \$ \$schalgs fuse5;

else set tmpstring \$ \$schalgs nofu ; end

set schalgs \$ \$tmpstring;

end

keep 0 ;

p refbrem.tre ;

set 0 nnodes $[0]$;

set 10

set 20 ;

if ( 'alltrees' || 'allnods' )

loop $(n \operatorname{ntax}+2)$ '0' 


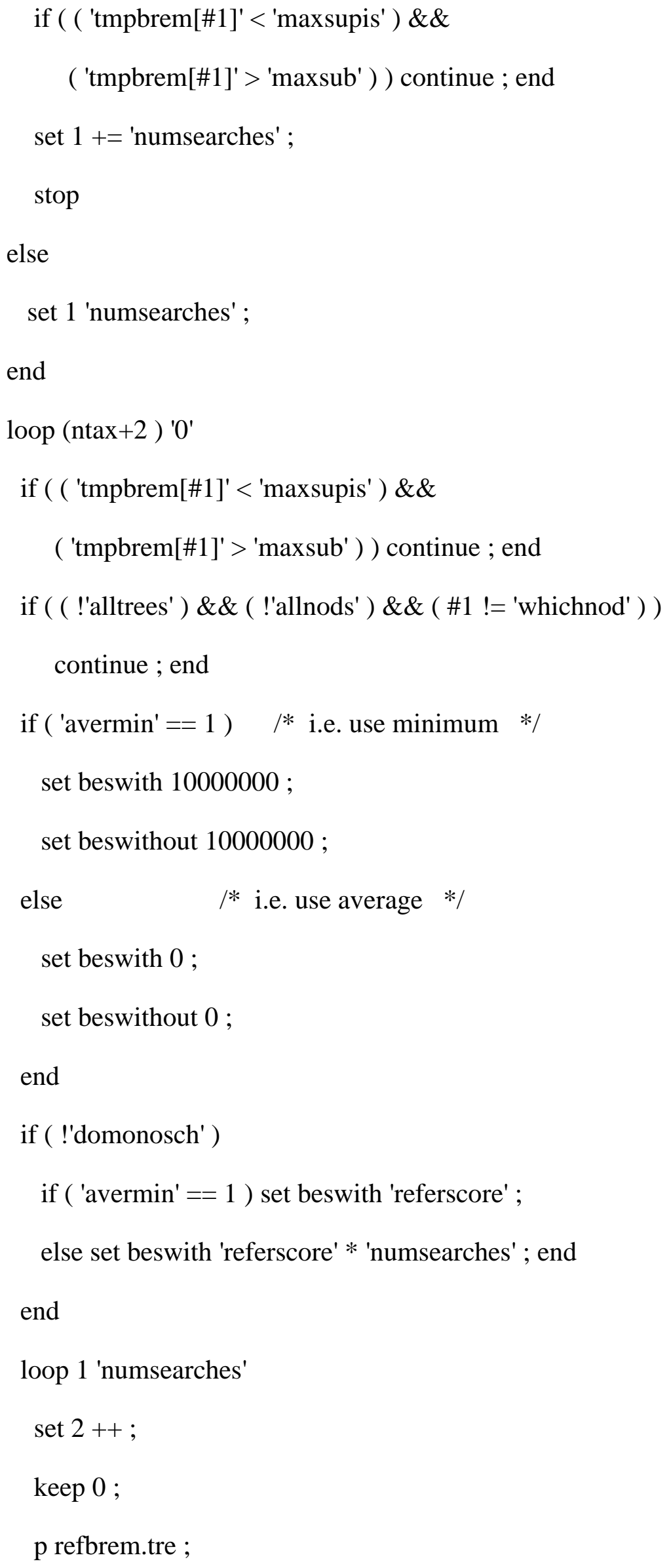




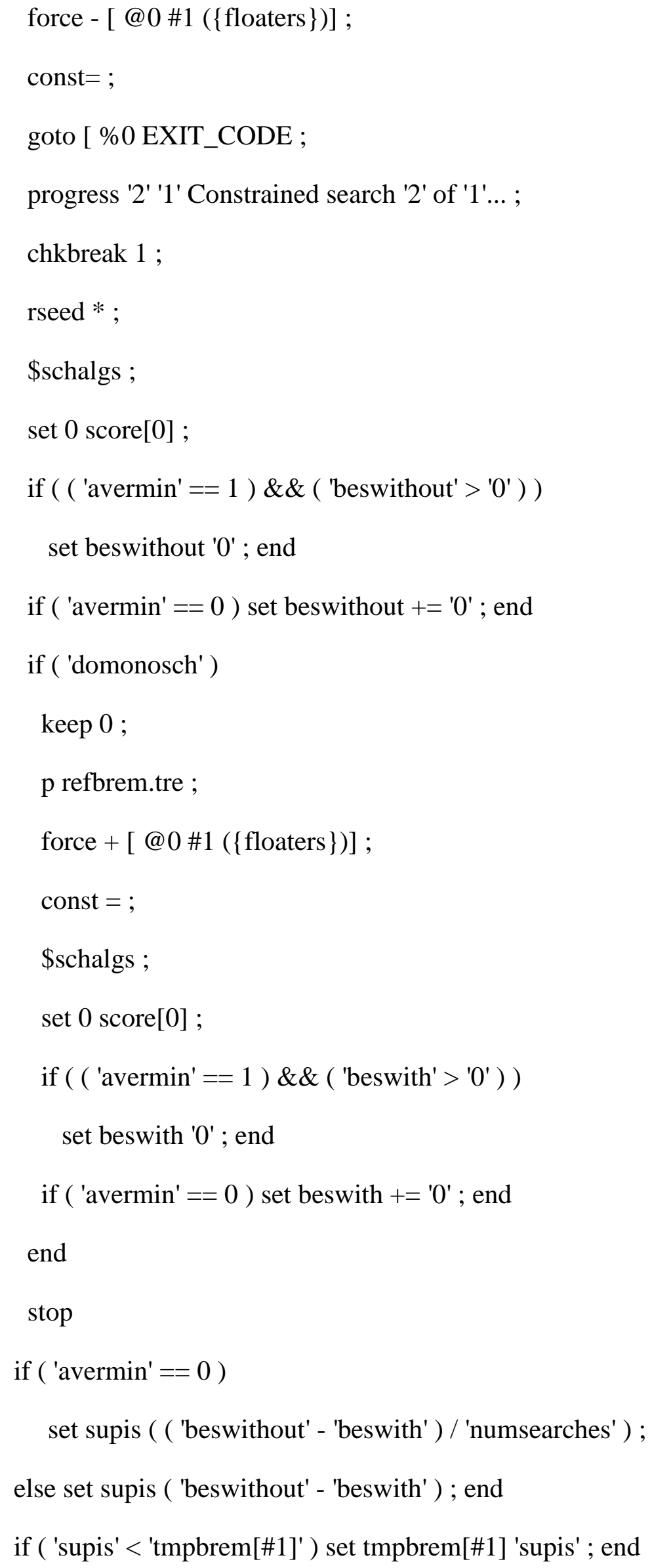


stop

progress/;

const $=$;

end $\quad / *$ end of calculations for constrained searches */

/******** WRITE LABELS TO TARGET TREE $* * * * * * * * * * * * * * /$

keep 0 ;

p tempbrem.tre ;

if ( 'piweisoff' \&\& 'avermin' ) macfloat 0 ;

else macfloat 2 ; end

loop $(\mathrm{ntax}+2)$ nnodes[0]

if ( ( !'alltrees' ) \&\& (!'allnods' ) \&\& ( \#1 != 'whichnod' ) )

continue ; end

if ( 'overimpose' ) ttag +\#1/; end

if ( 'tmpbrem[\#1]' >= 'maxsupis' )

ttag +\#1 ???; continue ; end

if ( 'tmpbrem[\#1]' < 0 )

ttag +\#1 ['tmpbrem[\#1]'];

else ttag +\#1 'tmpbrem[\#1]'; end

stop

const - ;

force - ;

macfloat 6 ;

rseed 'olrseed' ; 
keep 0 ;

$\mathrm{p}$ tempbrem.tre ;

set $0($ ntrees - 1$)$;

tc $1 .{ }^{\prime} 0^{\prime}$;

/********** SHOW SETTINGS AND TREE (SAVING IT, IF SO REQUESTED) $* * * * * * * /$

macfloat 0 ;

sil - all ;

lquote $[$;

quote \&10\&10SETTINGS FOR CALCULATION OF BREMER SUPPORTS: ;

if ( 'savesub' )

sil $=$ all ;

if ( !'piweisoff' ) macfloat 3 ; end

sil - all ;

quote $\& 32$ Searching suboptimal trees, with score up to 'maxsub' worse than ;

sil $=$ all ; macfloat 0 ; sil - all ;

quote $\& 32$ best (in 'numincs' searches, each 'scorinc' worse than previous);

end

if ( 'useconst' )

quote $\& 32$ Searching with constraints, 'numsearches' times (each with ;

if ( ''usersch')

lquote $=$;

quote \&32 'danumreps' replications;

if ( 'secsearch' ) quote, sectorial search; else quote , no sectorial search; end 
if ( 'dorat' ) quote , 'ratreps' ratchet iterations; else quote , no ratchet; end

lquote - ; quote,$\& 10 ;$ lquote $=$;

if ( 'dodrift' ) quote \&32 'driftreps' drifting cycles; else quote \&32 no drifting; end

if ( 'dofuse' )

quote, fusing results from the 'danumreps' replications) ;

else

quote, no fusing);

end

lquote - ;

else

quote $\& 32$ user-defined search (\$schalgs);

end

lquote - ;

quote $\& 10$;

if ( 'numsearches' > 1 )

if $($ 'avermin' $==0$ )

quote $\& 32$ Calculating average scores (with and without constraints) ;

else

quote $\& 32$ Using the best scores (with and without constraints);

end

end

if ( 'useconst' )

if ( 'domonosch' )

quote $\& 32$ Best score with a group calculated constraining group for monophyly ;

else quote $\& 32$ Best score with a group taken from reference tree(s) ;

end 
end

if ( 'alltrees' )

quote \&32 Calculating supports on consensus of shortest trees in memory ;

else

if ( 'allnods' )

quote $\& 32$ Calculating supports for groups of tree 'whichtreewas';

else

quote \&32 Calculating support only for node 'whichnod' of tree 'whichtreewas' ;

end

end

end

lquote - ; lquote [ ;

set 0 time ;

quote TOTAL TIME USED: '0' secs.;

quote $\& 10$

lquote ] ;

warn $=$;

report= ;

if ( 'saveemf' ) $\log \&$ \$emfname ; end

$\operatorname{ttag}$;

if ( 'saveemf' ) $\log / \&$; end

proc/ ;

/**** This is used if routine is interrupted... ****/ 
label EXIT_CODE ;

keep 0 ;

p tempbrem.tre ;

set $0($ ntrees -1$)$;

tc $1.0^{\prime}$;

warn $=$;

report= ;

silent - all ;

sub 0 ;

const - ;

lquote $[$;

if ( !windows )

quote EXECUTION OF SCRIPT INTERRUPTED... RESETTING PROGRAM STATUS $\ldots$;

else

quote *SCRIPT INTERRUPTED... ;

end

proc/; 